\title{
Conceptual Model for the Transport of Energetic Residues from Surface Soil to Groundwater by Range Activities
}

Jay L. Clausen, Nic Korte, Mary Dodson,

Joe Robb, and Shirley Rieven

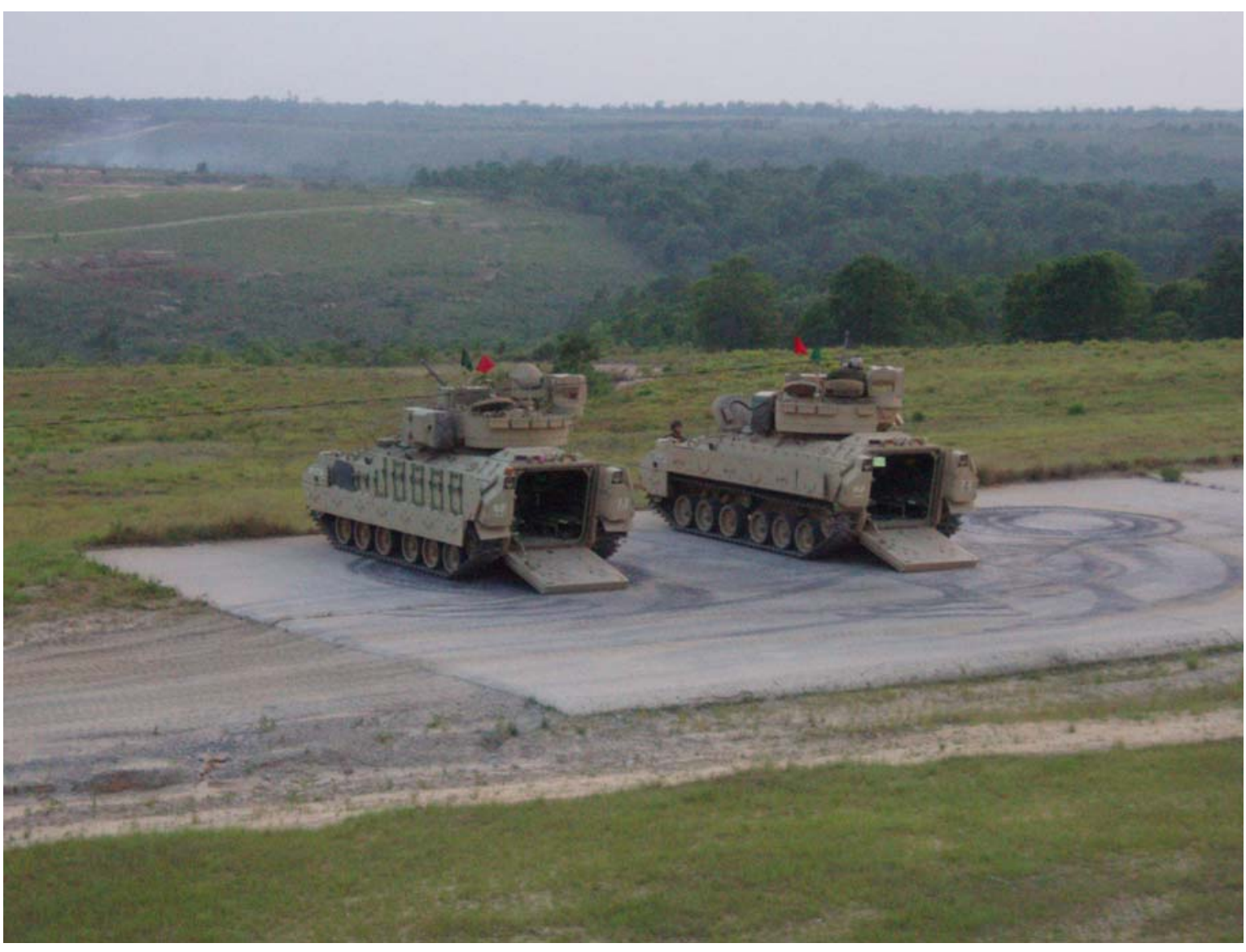


COVER: Live-fire training with Stryker vehicles at Fort Bragg, Georgia. 


\section{Conceptual Model for the Transport of Energetic Residues from Surface Soil to Groundwater by Range Activities}

Jay L. Clausen

Cold Regions Research and Engineering Laboratory

US Army Engineer Research and Development Center

72 Lyme Road

Hanover, NH 03755-1290

Nic Norte

1946 Clover Court

Grand Junction Colorado 81506

Mary Dodson, Joe Robb, and Shirley Rieven

AMEC Earth and Environmental, Inc.

239 Littleton Road, Suite $1 B$

Westford, MA 01886

Final report

Approved for public release; distribution is unlimited. 


\begin{abstract}
This report integrates and summarizes research on the fateand-transport properties of munition energetic compounds potentially migrating to groundwater. The goals of the report are to 1) review and summarize previous work; 2) identify data gaps; 3) provide research recommendations; and integrate conclusions from peer-reviewed research, results from investigations at military ranges, and consultations with explosives experts in the United States and Canada (Waterways Experiment Station, Army Environmental Center, Defence Research EstablishmentValcartier, and various universities) into a conceptual model for the transport of energetic compounds from the land surface to groundwater.
\end{abstract}

DISCLAIMER: The contents of this report are not to be used for advertising, publication, or promotional purposes. Citation of trade names does not constitute an official endorsement or approval of the use of such commercial products. All product names and trademarks cited are the property of their respective owners. The findings of this report are not to be construed as an official Department of the Army position unless so designated by other authorized documents. 


\section{Contents}

Figures and Tables....................................................................................................................

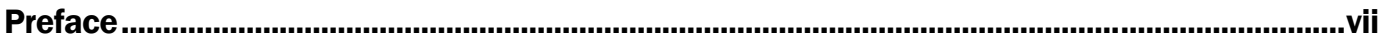

Nomenclature ...............................................................................................................................................vifi

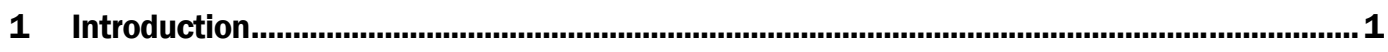

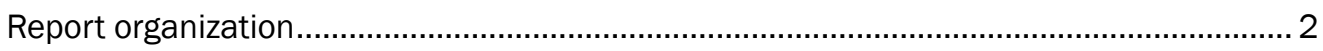

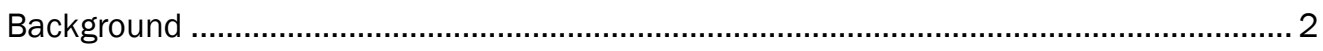

Overview of supporting investigations ........................................................................ 3

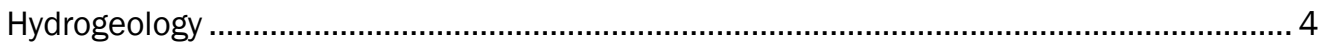

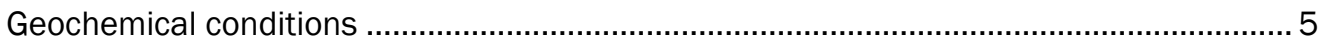

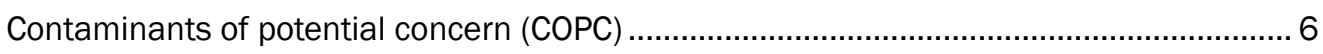

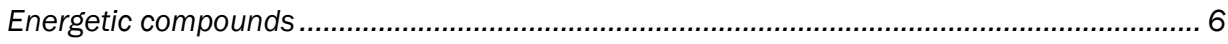

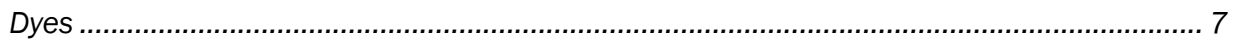

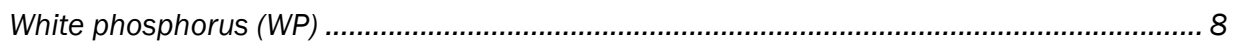

Pesticides/herbicides/polychlorinated biphenyls (PCBs)................................................ 9

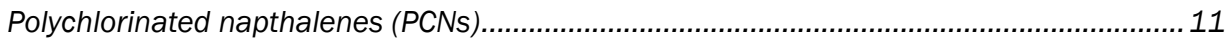

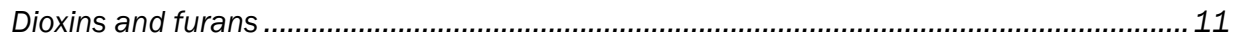

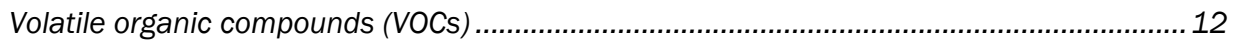

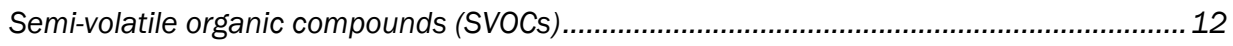

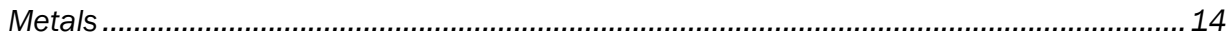

2 UXO Corrosion.......................................................................................................................16

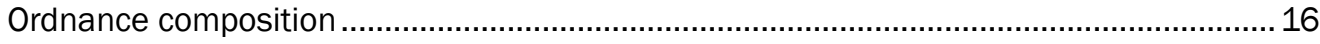

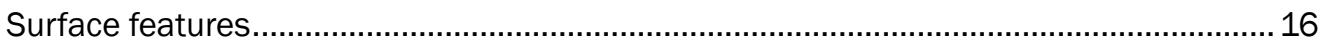

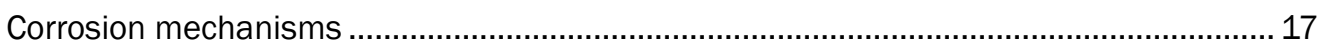

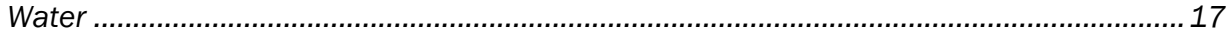

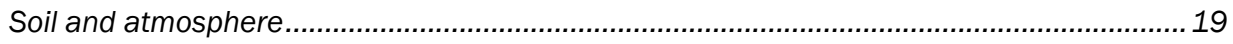

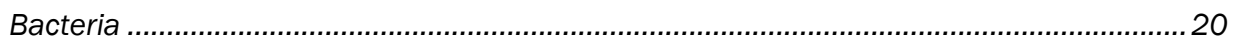

UXO corrosion studies ......................................................................................... 21

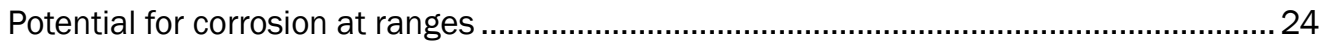

3 Conceptual Models of Fate and Transport for Energetic Compounds................................27

Mechanisms of contaminant deposition for non-impact range areas ................................ 27

Open burn/open detonation $(O B / O D)$ sites....................................................................... 28

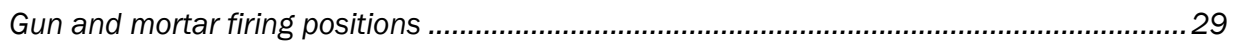

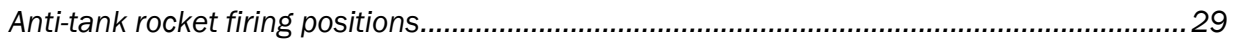

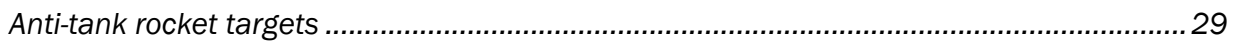

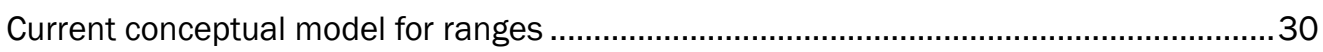

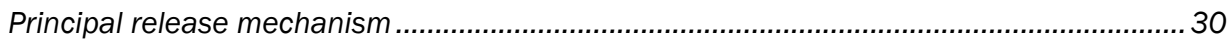

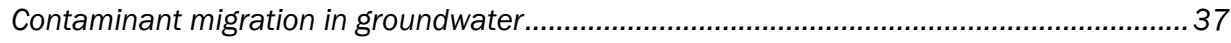




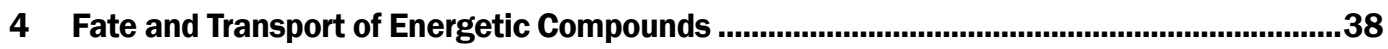

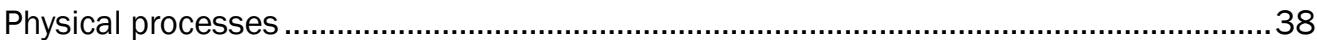

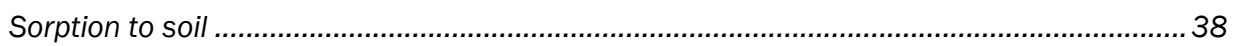

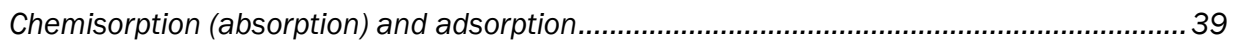

Organic carbon-based water partition coefficient................................................................. 40

Octanol-water partitioning coefficient ............................................................................... 40

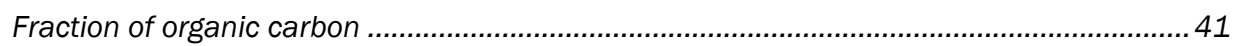

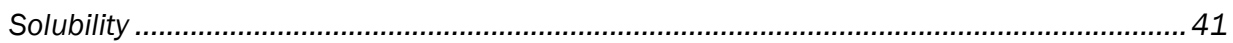

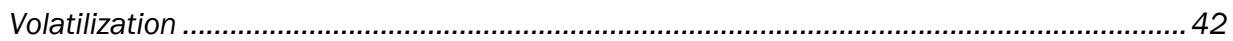

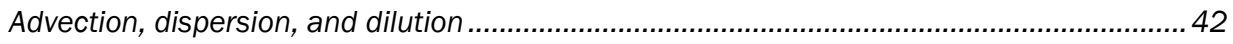

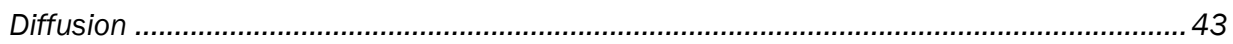

Chemical and biological transformations ............................................................... 43

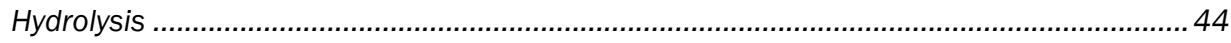

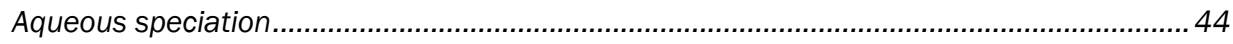

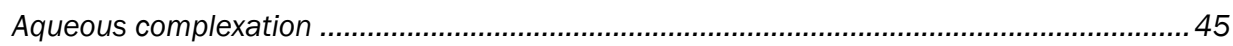

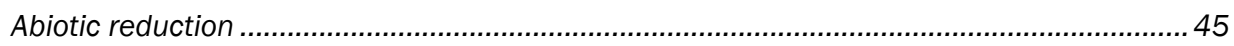

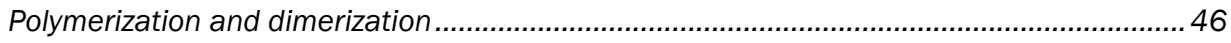

Energetic compound fate-and-transport properties....................................................46

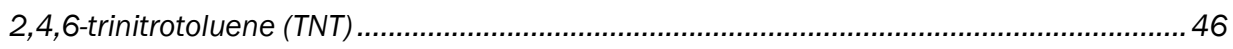

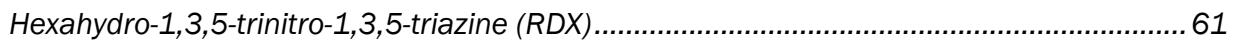

Octahydro-1,3,5, 7-tetranitro-1,3,5, 7-tetrazocine (HMX)................................................. 70

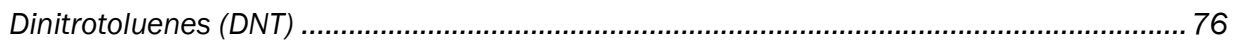

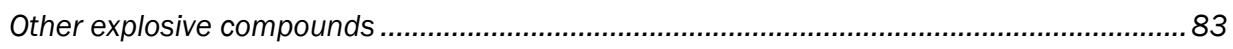

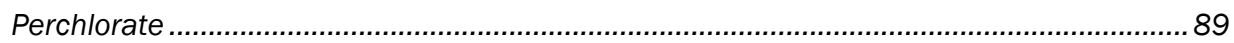

5 Case History: Application of Conceptual Model and Fate-and-Transport Concepts

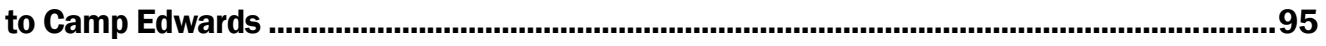

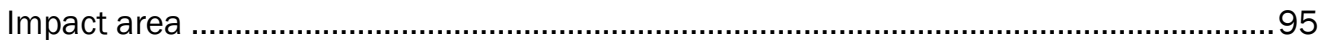

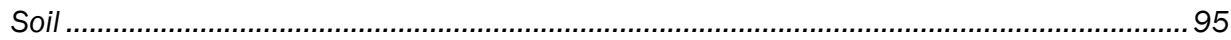

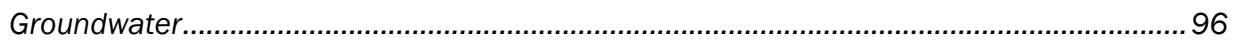

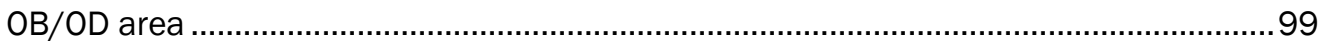

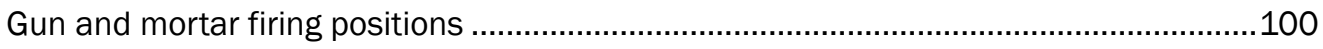

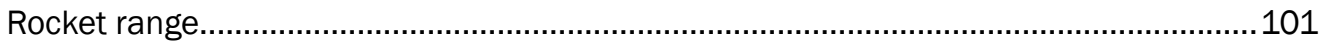

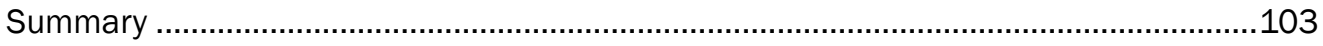

6 Training, Surface Soil, and Groundwater Relationship ............................................... 104

Surface soil sample result uncertainty ..................................................................106

Impact and source-term estimates for specific military activities .................................107

High-order detonations ................................................................................................... 107

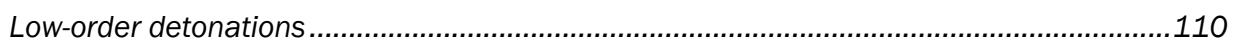

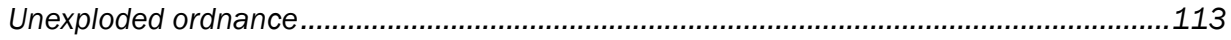

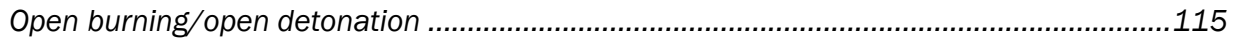

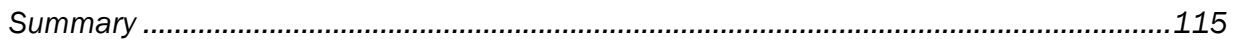

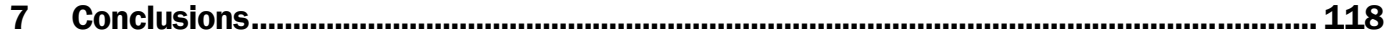

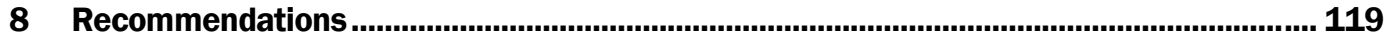


Nature and particle size of high-explosive residues...................................................119

Laboratory dissolution rate evaluations..................................................................120

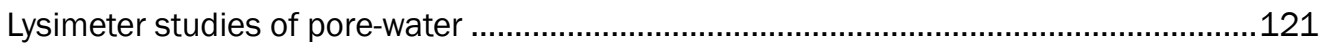

Improved soil sampling methodologies.......................................................................122

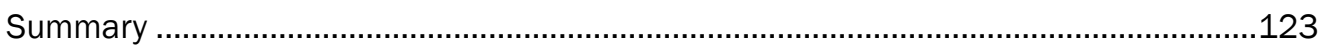

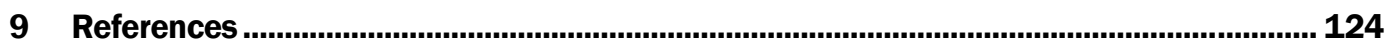

Appendix A. Physical and chemical properties of explosives and other compounds............... 153

Report Documentation Page ..................................................................................................157 


\section{Figures and Tables}

\section{Figures}

Figure 1. Typical layout of an artillery training range showing firing points, range safety fan, and impact areas

Figure 2. Corrosion rates for Camp Edwards intact UXO using various corrosion models................23

Figure 3. Unexploded ordnance (UXO) pit density versus pit depth for ordnance from

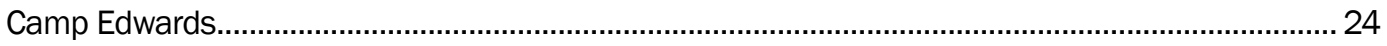

Figure 4. Propellants, explosives, and pyrotechnics fate-and-transport conceptual model ............. 31

Figure 5. Distribution of explosives residue after open detonation on snow ...................................32

Figure 6. Chemical structures of trinitrotoluene (TNT), hexahydro-1,3,5-trinitro-1,3,5triazine (RDX), octahydro-1,3,5,7-tetranitro-1,3,5,7-TET (HMX), and 2,4-dinitrotoluene (2,4-DNT)

Figure 7. Relative percentage of detections of munition explosive constituents in groundwater at Camp Edwards impact area...

Figure 8. Example of a low-order detonation.

\section{Tables}

Table 1. Evaluation of potential contaminants of concern. 8

Table 2. Corrosion rates calculated by Army Environmental Center...................................................26

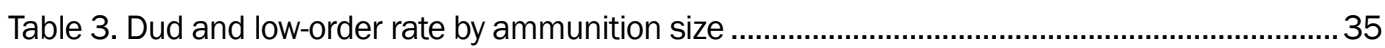

Table 4. Biotransformation products of 2,4,6-trinitrotoluene (TNT) ….............................................. 50

Table 5. 2,4-dinitrotoluene (DNT) distribution coefficients ............................................................. 77

Table 6. Perchlorate solubility .................................................................................................93

Table 7. Summary table showing link between training and environmental impacts ......................105

Table 8. Munitions fired at Camp Edwards in 1989 and estimate of cumulative RDX contamination during the 44-year period 1945 to 1989 


\section{Preface}

This report was prepared by Jay L. Clausen, Research Physical Scientist, Biogeochemical Sciences Branch (BSB), US Army Engineer Research and Development Center (ERDC), Cold Regions Research and Engineering Laboratory (CRREL), Hanover, New Hampshire, in partnership with Nic Korte, Consultant, Grand Junction, Colorado, and with Mary Dodson, Joe Robb, and Shirley Rieven, AMEC Earth and Environmental, Inc., Westford, Massachusetts.

The US Army Corps of Engineers, New England District, funded this work.

Alan D. Hewitt and Dr. Thomas F. Jenkins, BSB, CRREL, provided technical reviews.

This report was prepared under the general supervision of Terrence M. Sobecki, Branch Chief, BSB, CRREL; Dr. Lance D. Hansen, Deputy Director, CRREL; and Dr. Robert E. Davis, Director, CRREL.

At the time this work was performed, Colonel Richard B. Jenkins was Commander and Executive Director of ERDC. Dr. James R. Houston was Director. 


\section{Nomenclature}

\begin{tabular}{|c|c|}
\hline 2,2AZOX & $2,2,6,6^{\prime}$-tetranitro- $4,4^{\prime}$ azoxytoluene \\
\hline 4,4AZOX & 4,4,'6,6-tetranitro-2,2' azoxytoluene \\
\hline 2,4-DANT & 2,4-diamino-6-nitrotoluene \\
\hline 2,6-DANT & 2,6-diamino-4-nitrotoluene \\
\hline $3,5-\mathrm{DNA}$ & 3,5-dinitroaniline \\
\hline $2,4-\mathrm{DNT}$ & 2,4-dinitrotoluene \\
\hline 2,6-DNT & 2,6-dinitrotoluene \\
\hline 2a-DNT & 2-amino-4,6-dinitrotoluene \\
\hline 4a-DNT & 4-amino-2,6-dinitrotoluene \\
\hline $2 \mathrm{a}-4-\mathrm{NT}$ & 2-amino-4-nitrotoluene \\
\hline 2a-6-NT & 2-amino-6-nitrotoluene \\
\hline $4 \mathrm{a}-2-\mathrm{NT}$ & 4-amino-2-nitrotoluene \\
\hline $4 a-6-N T$ & 4-amino-6-nitrotoluene \\
\hline 2-NT & 2-nitrotoluene \\
\hline $4-\mathrm{NT}$ & 4-nitrotoluene \\
\hline AAP & Army Ammunition Plant \\
\hline aDNT & aminodinitrotoluene \\
\hline AIRMAG & Aerial magnetometry \\
\hline aNT & Amino nitrotoluene \\
\hline AP & $\begin{array}{l}\text { Ammonium-2,4,6-trinitrophenoxide or Ammonium } \\
\text { picrate }\end{array}$ \\
\hline BEHP & Bis (2-ethylhexyl) phthalate \\
\hline bgs & Below ground surface \\
\hline BIC & Bacterially induced corrosion \\
\hline BIP & Blow-in-place \\
\hline but & Below water table \\
\hline BZA & Benzanthrone (yellow dye) \\
\hline${ }^{\circ} \mathrm{C}$ & Degrees centigrade \\
\hline $\mathrm{C}_{4}$ & Composition $\mathrm{C}_{4}$ \\
\hline $\mathrm{CaCO}_{3}$ & Calcium carbonate \\
\hline CEC & Cation exchange capacity \\
\hline CENAE & US Army Corps of Engineers, New England District \\
\hline CERL & $\begin{array}{l}\text { US Army Corps of Engineers Construction Engineering } \\
\text { Research Laboratory }\end{array}$ \\
\hline $\mathrm{CFB}$ & Canadian Forces Base \\
\hline Comp B & Composition B \\
\hline
\end{tabular}




$\begin{array}{ll}\text { COPC } & \text { Contaminant of potential concern } \\ \text { Cr }^{+3} & \text { Chromate } \\ \text { Cr }^{+6} & \text { Hexavalent chromium } \\ \text { CRREL } & \text { US Army Corps of Engineers Cold Regions Research and } \\ & \text { Engineering Laboratory } \\ \text { CS-\# } & \text { Chemical spill number } \\ \text { CVM } & \text { Cesium vapor magnetometer } \\ \text { DANT } & \text { Diaminonitrotoluene } \\ \text { DBC } & \text { Dibenzochrysenedione (Vat yellow 4 dye) } \\ \text { DDA } & \text { 1,4-diaminodihydroanthraquinone (Disperse violet } 1 \\ & \text { dye) } \\ \text { DDE } & \text { Dichlorodiphenyldichloroethylene } \\ \text { DDT } & \text { Dichlorodiphenyltrichloroethane } \\ \text { Demo } 1 & \text { Demolition Area 1 } \\ \text { DNB } & \text { 1,3-dinitrobenzene } \\ \text { DNT } & \text { Dinitrotoluene } \\ \text { DNX } & \text { Dinitroso-hexahydro-1,3,5-triazine } \\ \text { DO } & \text { Dissolved oxygen } \\ \text { DoD } & \text { Department of Defense } \\ \text { DREV } & \text { Canadian Defence Research Establishment Valcartier } \\ \text { ECD } & \text { Electron capture detector } \\ \text { EOD } & \text { Explosive and Ordnance Disposal } \\ \text { ERDC } & \text { Engineer Research and Development Center } \\ \text { f }_{\text {oc }} & \text { Fraction of soil organic carbon } \\ \text { ft } & \text { Feet } \\ \text { g } & \text { Gram } \\ \text { g/mol } & \text { Grams per mole } \\ \text { GC/MS } & \text { Gas chromatography/mass spectrophotometry } \\ \text { HA } & \text { USEPA lifetime health advisory } \\ \text { HE } & \text { High explosives } \\ \text { HMX } & \text { Octahydro-1,3,5,7-tetranitro-1,3,5,7-tetrazocine } \\ \text { HPLC } & \text { High-performance liquid chromatography } \\ \mathrm{K}_{\mathrm{d}} & \text { Soil distribution coefficient } \\ \mathrm{K}_{\mathrm{oc}} & \text { Organic carbon-based water partition coefficient } \\ \mathrm{K}_{\text {ow }} & \text { Octanol-water distribution coefficient } \\ \text { LAW } & \text { Light Anti-tank Weapon } \\ \text { LCMS } & \text { Liquid chromatography mass spectrophotometry } \\ \text { LITR } & \text { Low-cost indirect training round } \\ \text { L/kg } & \text { Liters per kilogram } \\ \mathrm{m} & \text { Meter } \\ & \end{array}$




$\begin{array}{ll}\mathrm{mg} / \mathrm{kg} & \text { Milligram per kilogram (parts per million [ppm]) } \\ \mathrm{mg} / \mathrm{L} & \text { Milligram per liter (parts per million [ppm]) } \\ \mathrm{MIC} & \text { Microbially mediated corrosion } \\ \mu \mathrm{g} / \mathrm{L} & \text { Micrograms per liter (parts per billion [ppb]) } \\ \mu \mathrm{m} & \text { Micrometer } \\ \mathrm{mL} / \mathrm{min} & \text { Milliliter per minute } \\ \mathrm{mm} & \text { Millimeter } \\ \mathrm{MMR} & \text { Massachusetts Military Reservation } \\ \mathrm{MNX} & \text { Nitroso-dinitro-hexahydro-1,3,5-triazine } \\ \text { MOMO } & \text { Metal oxidizing microorganisms } \\ \mathrm{mv} & \text { Millivolt } \\ \text { NC } & \text { Nitrocellulose } \\ \text { NG } & \text { Nitroglycerine } \\ \mathrm{ng} / \mathrm{L} & \text { Nanogram per liter } \\ \text { NOM } & \text { Natural organic matter } \\ \text { OB/OD } & \text { Open Burn/Open Detonation } \\ \text { OE } & \text { Ordnance and Explosive } \\ \text { PA } & 2,4,6-\text { trinitrophenol or picric acid } \\ \text { PAH } & \text { Polynuclear aromatic hydrocarbon } \\ \text { PCB } & \text { Polychlorinated biphenyl } \\ \text { PCN } & \text { Polychlorinated naphthalene } \\ \text { PETN } & \text { Pentaerythritol tetranitrate } \\ \text { picramic acid } & 2 \text {-amino-4,6-dinitrophenol } \\ \text { ppb } & \text { Parts per billion } \\ \text { ppm } & \text { Parts per million } \\ \text { PVC } & \text { Polyvinyl chloride } \\ \text { RDX } & \text { Hexahydro-1,3,5-trinitro-1,3,5-triazine } \\ \text { SESOIL } & \text { Seasonal Soil Compartment Theory and Model } \\ \text { SVOC } & \text { Semi-volatile organic compound } \\ \text { TAT } & 2,4,6-\text { triaminotoluene } \\ \text { Tetryl } & 2,4,6-\text { trinitro-phenylmethylnitramine } \\ \text { TNB } & 1,3,5 \text {-trinitrobenzene } \\ \text { TNBa } & 2,4,6-\text { trinitrobenzylaldehyde } \\ \text { TNRCC } & \text { Texas Natural Resource Conservation Commission } \\ \text { TNT } & 2,4,6 \text {-trinitrotoluene } \\ \text { TNX } & \text { Tri-nitroso-hexahydro-1,3,5-triazine } \\ \text { TOC } & \text { Total organic carbon } \\ \text { TOW } & \text { Tube launched, optically tracked, wire guided missile } \\ \text { USAEC } & \text { US Army Environmental Center } \\ \text { USEPA } & \text { US Environmental Protection Agency } \\ & \end{array}$




$\begin{array}{ll}\text { USGS } & \text { US Geological Survey } \\ \text { UXO } & \text { Unexploded ordnance } \\ \text { VOC } & \text { Volatile organic compound } \\ \text { WP } & \text { White phosphorus } \\ \text { WWII } & \text { World War II }\end{array}$




\section{Introduction}

The fate and transport of munition energetic compounds is of considerable interest to the Department of Defense (DoD) due to the potential for groundwater impacts (Clausen et al. 2004a). For instance, the US Environmental Protection Agency (USEPA) issued Administrative Order \#2 (AO2), ceasing military training with ordnance containing energetic compounds at Camp Edwards, Massachusetts (USEPA 1997). Given the current geopolitical climate, DoD needs military ranges to train soldiers and must balance military training requirements with environmental impacts. To that end, DoD must evaluate how energetic compounds observed in groundwater are linked to military training and whether conditions at Camp Edwards are typical of other military ranges.

The objectives of this report are to integrate published and unpublished data regarding fate and transport from ordnance and explosives (OE) and related materials to develop a conceptual model for the transport of contaminants from the ground surface to groundwater. Compilations of the published literature, conversations with experts, and observations from studies at several military ranges have been evaluated. The resulting conceptual model permits an assessment of the linkage between contaminants of potential concern (COPCs) identified in shallow surface soil to COPCs identified in groundwater. This document was developed by

- Reviewing and integrating the extensive existing documents produced for Camp Edwards, Massachusetts; Camp Grayling, Michigan; Cold Lake Air Weapons Range, Alberta, Canada; Canadian Forces Base (CFB) Gagetown, Canada; and focused range studies at other US military facilities and Canadian Forces Bases;

- Reviewing and integrating energetic research documents developed by the US Army Engineer Research and Development Center (ERDC), Cold Regions Research and Engineering Laboratory (CRREL), Environmental Laboratory (EL), Construction Engineering Research Laboratory (CERL), the US Army Environmental Center (USAEC), Sandia National Laboratory, Canadian Defence Research EstablishmentValcartier (DREV), and other research groups; and 
- Reviewing and integrating research currently performed to assess the parameters affecting fate and transport of energetic compounds from surface sources to groundwater.

\section{Report organization}

This report is organized as follows:

- Section 1 (this introduction) presents an overview of studies conducted at various military sites, a summary of geologic and hydrogeologic considerations, and the identification of potential COPCs.

- Section 2 reviews the potential contribution from corroding unexploded ordnance (UXO).

- Section 3 describes a general conceptual model.

- Section 4 summarizes the fate-and-transport properties of the potential COPCs.

- Section 5 discusses the potential COPCs with respect to the types of ranges and activities where they are introduced to the environment.

- Section 6 refines the information from Section 5 into a series of general conclusions describing the link between training and groundwater contamination.

- Section 7 summarizes the major conclusions from this work.

- Section 8 identifies data gaps and provides recommendations for filling those gaps, and

- Section 9 lists all referenced publications.

- Appendix A is a table with a comprehensive listing of physical and chemical properties of explosives and other compounds of interest.

\section{Background}

The level of activity at most military ranges has varied over their operational history. The most intensive training activity occurred during World War II (WWII) and in conjunction with demobilization after the war. Other periods of heightened training include the Korean and Vietnam Wars and the current Iraq and Afghanistan conflicts.

A typical training area at military installations consists of a central impact area surrounded by a number of training ranges. The training ranges are oriented such that firing is directed toward the impact area (Fig. 1). The types of training ranges present can include small arms, anti-tank rocket, mortar, and artillery. 


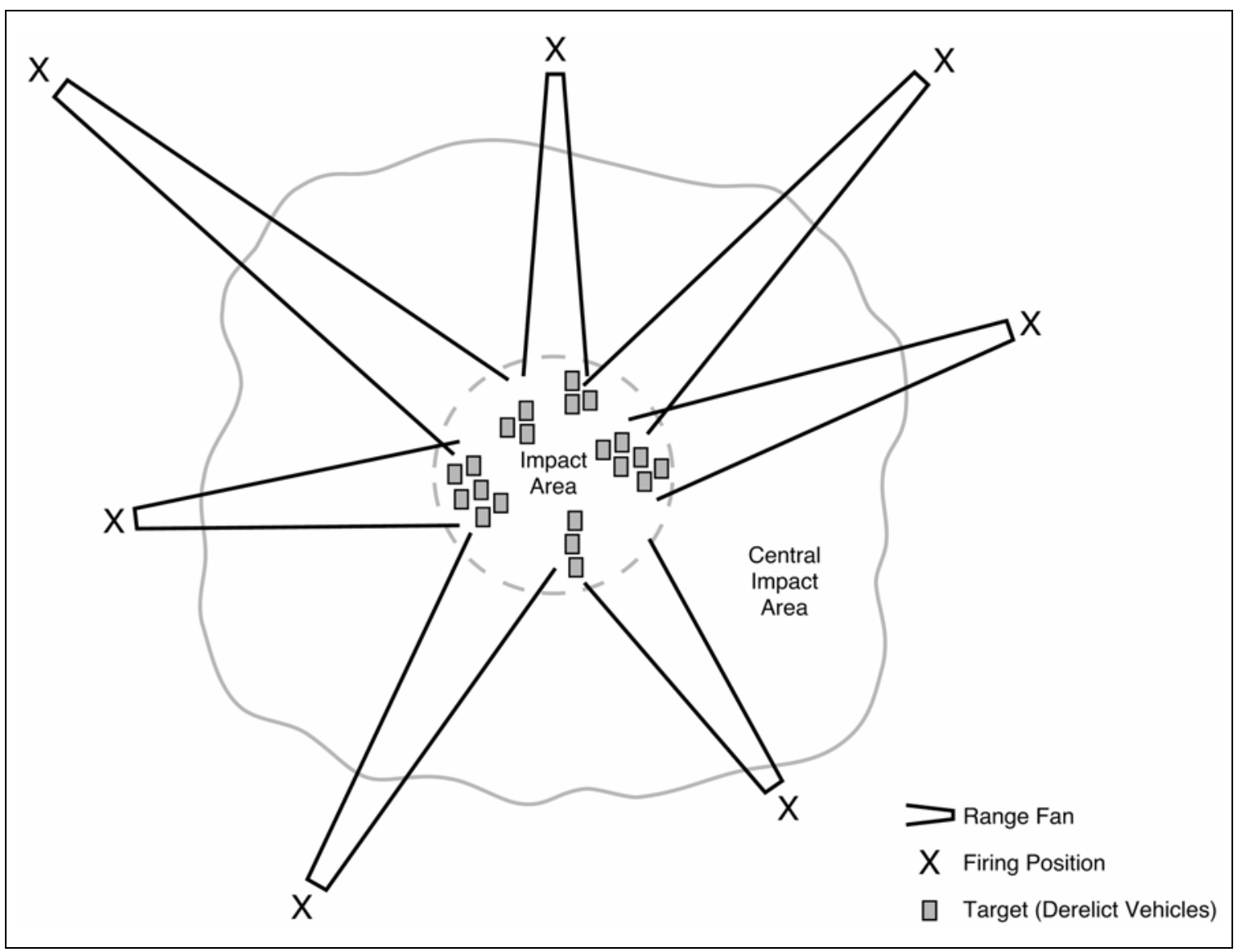

Figure 1. Typical layout of an artillery training range showing firing points, range safety fan, and impact areas. (From Jenkins et al. 2006.)

Ordnance employed at Army installations includes projectiles from small arms, machine guns, hand grenades, artillery, mortar, and rockets. PreWWII munitions primarily contained 2,4,6-trinitrotoluene (TNT) as the principal explosive. The predominant explosive used in post-WWII artillery and mortar munitions is Composition B (Comp B), composed of hexahydro-1,3,5-trinitro-1,3,5-triazine (RDX) and TNT. Anti-tank rocket rounds primarily contain an explosive mixture called octol, composed of octahydro-1,3,5,7-tetranitro-1,3,5,7-tetrazocine (HMX) and TNT. Tetryl (2,4,6-trinitro-phenylmethylnitramine) was used in some munitions but was discontinued in the 1950s. Propellants primarily consist of 2,4dinitrotoluene (2,4-DNT), nitrocellulose (NC), nitroglycerin (NG), and nitroguanidine (NQ).

\section{Overview of supporting investigations}

The conceptual model presented in Section 3 was derived from an integration of site investigations and field and laboratory research. Focused stud- 
ies have been conducted at more than 25 military ranges in the United States and Canada (Jenkins et al. 2005b, 2004a; Pennington et al. 2005, 2004, 2003a, 2002a, 2001; AMEC 2004, 2003a, 2001a, 2001d, 2001h; Ampleman 2004, 2003a, 2003b, 2000, 1998; Thiboutot et al. 2004, 2003a, 2003b, 2000a, 2000b, 1998a, 1998b; Walsh et al. 2004a, 2001; USCHPMM 2003; Ogden 200ob, 2000c, 1999a, 1998a; Dube 1999; Martel et al. 1998, 1996; ESE 1997, 1995, 1994, 1993, 1987). This report focuses solely on investigations at artillery, mortar, and anti-tank rocket ranges and does not cover small arms ranges. Details of the investigations and their application to understanding the fate and transport of energetic compounds are provided in the "Field Studies" subsections in Section 4. These studies encompass a variety of physical conditions ranging from relatively sandy, aerobic systems to clayey, anaerobic systems with shallow groundwater.

Many of the site investigations cited were narrow in scope or addressed only a single energetic compound, single release process, or range activity. They should not be considered as comprehensive range assessments. However, by evaluating the results of numerous range studies and placing them into context of specific fate-and-transport studies, one can develop a picture of energetic introduction and movement in the environment. The most comprehensive range assessment of an artillery and mortar impact area is the compilation of numerous studies conducted at Camp Edwards, Massachusetts.

\section{Hydrogeology}

Hydrogeologic considerations are a major component when evaluating energetic compound fate and transport. Geochemical, microbiological, and hydrogeologic conditions are all interrelated and it is important for the results of the various investigations to be self-consistent. Ensuring and evaluating self-consistency provides an important reality check regarding the conclusions drawn for a particular site. Usually, detailed hydrogeologic information is available early in a site investigation and can be used to guide other types of data collection. For example, coarse-grained substrata generally indicate aerobic conditions. Such strata are also generally more conducive to energetic compound migration than are clayey sites. Also, the velocity of groundwater flow and, therefore, contaminant flow velocity will be faster at coarse-grained sites, so off-site impacts are usually more likely. 
Depth to groundwater is also important. Although clay may inhibit migration, if the groundwater is only a few meters deep, significant groundwater impacts might still occur in this soil type.

A site's hydrogeology is investigated by combining a review of previous local and regional investigations with site-specific drilling, sampling, and measurements. A sufficient number of monitoring wells should be used to understand both the nature of the subsurface strata and the groundwater's hydraulic and chemical characteristics. Sufficient hydraulic testing is necessary to measure adequately the hydraulic conductivity and porosity, which are used to estimate the average groundwater velocity. Sections 4 and 5 discuss numerous previous investigations of energetic compound fate and transport in various hydrogeologic circumstances.

\section{Geochemical conditions}

Geochemical conditions are critically important to consider when assessing fate and transport of energetic compounds and potential UXO corrosion. Geochemical conditions can be broadly assessed by considering redox potential, $\mathrm{pH}$, the identity and concentration of soluble salts, the organic carbon content of soil and groundwater, and the cation exchange capacity (CEC) of the soils. Considerable insight into geochemical conditions is usually obtained from the initial hydrogeologic investigation.

Redox potential can be considered an indirect assessment of the amount of oxygen present. The presence of oxygen in soil and groundwater creates an oxidizing (aerobic) environment; absence of oxygen results in a reducing (anaerobic) environment. A familiar example demonstrating the importance of the redox environment (all other geochemical conditions being equal) is the fate of hexavalent chromium $\left(\mathrm{Cr}^{+6}\right)$. In an oxidizing environment, $\mathrm{Cr}^{+6}$ is relatively stable and mobile; in a reducing environment, $\mathrm{Cr}^{+6}$ is rapidly reduced to immobile chromate $\left(\mathrm{Cr}^{+3}\right)$ species. Similarly, the extent of biodegradation and the mechanisms and organisms involved can be evaluated based on redox conditions. A relevant example is RDX, which is subject to microbial attack under anaerobic but not aerobic conditions.

Soil $\mathrm{pH}$ also may govern the identity and mobility of chemical species present. Most metals (e.g., copper, lead, and zinc) are relatively immobile at alkaline $\mathrm{pH}$, but become increasingly mobile as $\mathrm{pH}$ decreases. Microbial activity is also affected, usually decreasing at extremes of $\mathrm{pH}$. The identity and availability of soluble salts affects both contaminant migration and 
microbial activity. For example, the ability of soil minerals to sorb contaminants from water is affected by competing ions in solution as well as by the chemical and physical properties of the mineral surface. Also, nitrogen and phosphorous species and certain trace elements are required for most microorganisms of environmental importance. On the other hand, high concentrations of certain inorganics may be toxic. Dissolved organic matter, whether from natural or anthropogenic sources, may chelate with metals and enhance their mobility. Moreover, with large discharges, the quantity of organic matter can be sufficient to affect the redox potential. In contrast, high soil organic matter retards the mobility of organic and inorganic contaminants.

\section{Contaminants of potential concern (COPC)}

This subsection reviews specific compounds expected from range training, based on results of the extensive investigations performed to date at Camp Edwards (Clausen et al. 2004b; AMEC 2001b, 2001f) as well as more focused studies conducted at other ranges (Jenkins et al. 2005b, 2004a; Pennington et al. 2005, 2004, 2003a, 2002a, 2001; Ampleman 2004, 2003a, 2003b, 2000, 1998; Thiboutot et al. 2004, 2003a, 2003b, 2000a, 2000b, 1998a, 1998b; USCHPMM 2003; Walsh et al. 2004a, 2001; Dube 1999; Martel et al. 1998, 1996; ESE 1997, 1995, 1994, 1993, 1987). The following discussion and additional detail in Section 4 evaluates possible compounds from military and non-military sources that could be potential COPCs on military ranges, including impact areas and firing points. It provides a rationale to eliminate several of the compounds from the COPC list. Table 1 briefly summarizes the COPC status of the several compounds evaluated with this rationale.

\section{Energetic compounds}

High-explosive (HE) filler of munitions and propellants contains energetic compounds. Hence, most energetic residues identified at military ranges are nitro-substituted molecules used in explosives and propellants. These nitro-substituted compounds fall into three categories:

- Nitroaromatics such as TNT, 2-amino-4,6-dinitrotoluene (2aDNT), 4-amino-2,6-dinitrotoluene (4a-DNT), 2,4-DNT, 2,6dinitrotoluene (2,6-DNT), tetryl, and 2,4,6-trinitrophenol (picric acid or PA);

- Nitroamines such as RDX and HMX; and 
- Nitrate esters such as pentaerythritol tetranitrate (PETN), NG, and NC.

The energetic residues identified in soil at the various impact areas include RDX, HMX, TNT, 2a-DNT, and 4a-DNT (Jenkins et al. 2005b; Pennington et al. 2005, 2004, 2003a, 2002a, 2001; Clausen et al. 2004a; Walsh et al. 2004a; USCHPMM 2003; AMEC 2001a). Those identified at artillery and mortar firing points are primarily NG and 2,4-DNT (Clausen et al. 2004a; Jenkins et al. 2005b; Pennington et al. 2005, 2004, 2003a, 2002a, 2001; Hewitt 2002; AMEC 2001a, 2001i). The explosive compounds RDX and TNT are the principal compounds in Comp B, although HMX can be present as well. These materials are the HE filler used in most artillery and mortar munitions, whereas octol, which contains HMX and TNT, is the HE filler used in anti-tank rockets. NG and NC are the primary propellants for the anti-tank rockets and can be found at firing positions (Jenkins et al. 2005b; Pennington et al. 2005, 2004, 2003a, 2002a, 2001; Clausen et al. 2004a; AMEC 2001a; Ogden 2000b, 2000c; Thiboutot et al. 1998b). DNT is the principal propellant seen at mortar and artillery firing positions (Clausen et al. 2004a). The energetic compounds TNT, 2a-DNT, 4a-DNT, RDX, HMX, 2,4-DNT, and perchlorate have been detected in groundwater at several installations associated with impact areas and open burn/open detonation (OB/OD) sites (AMEC 2004, 2001b; Martel et al. 1998, 1996; ESE 1997). The fate-and-transport properties and field data for each of these compounds are examined further in Sections 4 and 5, since they are the primary COPCs for military ranges.

\section{Dyes}

Dyes are used in pyrotechnics such as smokes, flares, and spotting charges. In their study of 20 disperse and solvent dyes, Baughman and Weber (1991) reported solubilities of less than $0.1 \mathrm{mg} / \mathrm{L}$ with octanol water distribution coefficients $\left(K_{\text {ow }}\right)$ greater than $10^{4}$. (See Section 4 for a definition of $\mathrm{K}_{\mathrm{ow}}$ and other coefficients used in this subsection.) Such a high $\mathrm{K}_{\mathrm{ow}}$ demonstrates a strong tendency to partition to particles or organic material. Dyes also have high organic carbon-based water partition coefficients $\left(\mathrm{K}_{\mathrm{oc}}\right.$ ), which range from 2,000 to 3,000,000, or on a logarithmic scale from $\log \mathrm{K}_{\mathrm{oc}}$ of 3.3 to 6.5. These high $\mathrm{K}_{\mathrm{oc}}$ values confirm that, once deposited, dyes sorb strongly to soil or sediment particles, even in most coarsegrained, low-organic-matter surface soils, and have very little or no mobility. 
Table 1. Evaluation of potential contaminants of concern.

\begin{tabular}{|c|c|c|c|}
\hline \multirow{2}{*}{ Component } & \multirow{2}{*}{ Training source } & \multicolumn{2}{|c|}{ Potential contaminant of concern } \\
\cline { 3 - 4 } & Ses & Yes & Groundwater \\
\hline Energetics & Yes & No & No \\
\hline Dyes & Yes (limited) & Yes (anoxic) & No \\
\hline White phosphorus & No & No & No \\
\hline Pesticide / Herbicide / PCB & Yes & Yes & No \\
\hline PCN & Yes (OB/OD) & Yes & No \\
\hline Dioxin / Furan & No & No & No \\
\hline VOCs & Yes & Yes (OB/OD) & No \\
\hline SVOCs (phthalates / PAHs) & Yes & Yes & No \\
\hline Metals & & &
\end{tabular}

Dyes also undergo rapid biodegradation and photodegradation (Baughman and Weber 1994, 1991; Adams et al. 1993; Hou and Baughman 1992; Hou et al. 1991; Yen and Perenich 1991; Yen et al. 1989). These research results indicate that dye particles deposited on the surface of soil or vegetation rapidly degrade into by-products subject to greater degradation than the parent dye. For example, azo, anthraquinone, and quinoline dyes disappeared from sediment with half-lives of less than ten days (Baughman and Weber 1994).

The only known study assessing the presence of dyes at a military installation is the work conducted at Camp Edwards. One dye detected in soil at low concentrations was not detected in monitoring wells located downgradient (AMEC 2003a, 2001f, 2001g). Fate-and-transport evaluation of dyes, combined with the studies at Camp Edwards, suggests dyes are not expected to be found to any significant degree at military installations. If present in soil, they are not a likely threat for groundwater (Zakikhani et al. 2005, 2004).

\section{White phosphorus (WP)}

White phosphorus is used in some rounds as a substitute for HE. When a WP round is fired, the majority of the WP is consumed upon detonation. WP sublimes and the vapor oxidizes, ultimately forming relatively insoluble phosphate salts. If a low-order detonation occurs, chunks of WP are deposited on the soil surface. Under reducing conditions, a protective 
crust can form on larger pieces, preventing sublimation and oxidation, i.e., burning. As long as the WP is not disturbed, it will remain inert on the soil surface. If disturbed and the protective crust ruptures, the WP sublimes and oxidizes. Upon oxidation, the WP is consumed (converted to phosphate) and thus does not pose a threat to groundwater.

WP is rarely present at sites with sandy, oxygenated soil. For example, WP detections occurred in only two aerobic soil samples at Camp Edwards (AMEC 2002b). In contrast, WP was commonly found in the anoxic soil at Eagle River Flats, Alaska (Walsh et al. 2004b, 1996, 1995). Once soil with WP present becomes dry, the WP will combust spontaneously.

In summary, WP fate-and-transport properties suggest it could be problematic as a surface exposure risk at sites having anoxic soil or shallow water, but it is not typically a groundwater COPC (Zakikhani et al. 2005, 2004).

\section{Pesticides/herbicides/polychlorinated biphenyls (PCBs)}

Pesticides, herbicides, and PCBs are not constituents of military munitions. However, these classes of compounds are used at military reservations for weed and pest control or in routine industrial applications. The only known studies of pesticides, herbicides, or PCBs on military ranges are those conducted at Camp Edwards.

Although 30 different pesticides were detected from more than 500 soil samples collected from the impact area at Camp Edwards, most were reported in less than one percent of the samples (Ogden 2000b, 2000c). The most commonly reported compound from this group was dichlorodiphenyltrichloroethane (DDT). DDT reported in 26 percent of the impact area samples was at relatively low concentrations (AMEC 2002c, 2001a; Ogden 1999a, 1998a, b, c). The only samples with high DDT concentrations were a few samples collected at a demolition area where burning of munitions and fireworks occurred (AMEC 2001d). DDT is commonly quite persistent in soils, as illustrated by a study of forest soils in Maine (Dimond and Owen 1996). Concentrations of DDT and its metabolites declined in the 30 years after application, but residues persisted such that some concentrations still exceeded $1 \mathrm{mg} / \mathrm{kg}$.

As with soil, herbicides and pesticides reported in Camp Edwards' groundwater have been sporadic and not reproducible through repeated 
sampling. These results are not surprising. The US Geological Survey (USGS), through its National Water Quality Assessment Program, has shown pesticides are ubiquitous in US groundwater at very low concentrations (Stackelberg et al. 1997). Examples include dieldrin detected in almost 14 percent of the New Jersey wells and dichlorodiphenyldichloroethylene (DDE, a DDT metabolite) in almost three percent. In a study of 20 major hydrologic basins nationwide, the USGS reported more than half of 1,034 sites sampled contained pesticides (Kolpin et al. 1998).

The environmental chemistry of PCBs is very similar to that of the persistent chlorinated pesticides. Aqueous solubility is very low, with reported values for individual PCB congeners (there are 209 PCB congeners, and Aroclors are mixtures of various congeners) ranging from 0.007 to 5.9 $\mathrm{mg} / \mathrm{L}$ (NIOSH 1985). Another report states that the lower end of the range begins at $0.00095 \mathrm{mg} / \mathrm{L}$ (Waid 1986), while the total solubility of the common PCB mixture Aroclor 1254 was reported to be $0.056 \mathrm{mg} / \mathrm{L}$ (Haque et al. 1974). Finally, measurements in water demonstrate that PCBs detected are usually not dissolved, but are associated with particulate matter (Froese et al. 1997, Hargrave et al. 1992, Crane and Sonzogni 1992).

As with the persistent chlorinated pesticides, PCBs are ubiquitous in the environment. The median concentration in soils in the United Kingdom has been estimated at $0.030 \mathrm{mg} / \mathrm{kg}$ (Harrad et al. 1994); amounts in Canadian agricultural soils range from 0.015 to $0.235 \mathrm{mg} / \mathrm{kg}$, with most soils containing < $0.050 \mathrm{mg} / \mathrm{kg}$ (Stenhouse and Badsha 1990). The only range study known to evaluate the presence of PCBs has been the work at Camp Edwards. Consistent with the regional studies just cited, sporadic traces (detection frequency < $0.5 \%$ ) of Aroclor 1260 were reported from more than 600 soil samples. The maximum value was $0.069 \mathrm{mg} / \mathrm{kg}$ (Ogden 200ob, c). The source of the PCBs appears unrelated to training activities with military munitions.

In summary, fate-and-transport properties of herbicides, pesticides, and PCBs and their limited usage suggest that they are not expected to be found to any significant degree at military installations and, if present in soil, are not a likely threat for groundwater (Zakikhani et al. 2005, 2004). If herbicides or pesticides are observed in soil or groundwater, their likely source is unrelated to the usage of military munitions. 


\section{Polychlorinated napthalenes (PCNs)}

Fate-and-transport properties of PCNs are very similar to PCBs-they have low water solubility, low vapor pressure, and adsorb strongly to soil (Corsolini et al. 2002). There are 75 congeners based on the naphthalene ring system where chlorines can substitute on up to eight ring positions. PCN concentrations in surface soils at a Camp Edwards test range exceeded 1,000 mg/kg (AMEC 2002a). However, overall, PCNs had only limited presence at Camp Edwards (AMEC 2001h). The apparent PCN source is a formulation called Halowax, which is used as filler in inert munitions to simulate the weight of HE. A larger presence of PCNs is possible at military installations that utilized inert munitions, principally artillery and mortars, containing wax. A limited study, unpublished, found no consistent pattern between munition types and PCN formulations detected at Camp Edwards. Given the fate-and-transport properties of PCNs, it is unlikely they will be a COPC for groundwater, although they could pose a surface soil exposure risk.

\section{Dioxins and furans}

Dioxins and furans, like PCBs and PCNs, have a multi-ring structure on which various numbers of chlorines are substituted. Both dioxins and furans form from a myriad of combustion processes, including burning of wood and fossil fuels and any fire involving a source of chlorine and hydrocarbons (Deutsch and Goldfarb 1988, Fielder 1998). Dioxins and furans are not constituents of munitions but may be formed through the incomplete combustion of munitions at $\mathrm{OB} / \mathrm{OD}$ sites. There are 75 dioxin positional isomers or congeners (135 for furans), and the octa-substituted are approximately 1,000 times less toxic than the tetra-, the latter being the primary health concern (Van den Berg et al. 1998). The fate-andtransport properties of dioxins are also very similar to PCBs. For example, water solubilities are in the ng/L range with all congeners $<10 \mathrm{ng} / \mathrm{L}$ and many $<1 \mathrm{ng} / \mathrm{L}$ (Fletcher and McKay 1993). Consequently, dioxins do not leach significantly, have no measurable impact on groundwater (Hites 1990) and, therefore are not a likely groundwater COC for military ranges (Zakikhani et al. 2005, 2004).

Dioxins were detected in soil at Camp Edwards, in particular at an OB/OD location (AMEC 2001d). The dominance of the octa-substituted dioxins, and the fact they also were reported for background locations, indicates predominantly anthropogenic input unrelated to site activities. The fate- 
and-transport properties of dioxins make it unlikely they will be a $\mathrm{COC}$ for groundwater (Zakikhani et al. 2005, 2004), although they could pose a surface exposure risk, primarily at demolition areas.

\section{Volatile organic compounds (VOCs)}

Some VOCs are used in manufacturing various energetic compound formulations; however, their high volatility makes it unlikely they would persist in a munition item once manufactured and stored. Most VOCs are highly mobile and would not persist in surface soil unless released to the environment in very large quantities or as a pure phase. Also, there are no known activities on military ranges releasing VOCs. Range investigations evaluated to date indicate no evidence of significant VOC contamination (AMEC 2004, 2003a, b, 2001a, b, i; Ogden 2000a, b, 1999a, 1998a; ESE 1996). A few studies showed consistent detection of acetone, methyl ethyl ketone (MEK), and toluene in soil samples from Camp Edwards, but this was found to be a function of the preservation methods (Clausen et al. 2004b, 2001; Hewitt and Meyers 1999).

Groundwater contamination of VOCs at non-range areas of military installations is another matter. Spilled fuels and fire training activities using spent solvents and fuels have resulted in groundwater contamination at numerous installations. It appears, however, that such activities are not typical for ranges. Therefore, VOCs are not likely to be COPCs at military ranges associated with training, although they could be present at military installations related to non-training activities.

\section{Semi-volatile organic compounds (SVOCs)}

Phthalates are a group of SVOCs utilized in some energetic compound formulations. Nonetheless, the majority of the detections of phthalates are probably a result of sampling or laboratory cross-contamination (AMEC 2001b, Lopez-Avila et al. 1990). Cross-contamination is difficult to avoid because phthalates, especially bis-2-ethylhexyl phthalate (BEHP), are used as non-reactive plasticizers to increase the flexibility and workability of high molecular weight polymers. As such, BEHP is commonly found in materials used for sampling and at laboratories, such as polyvinyl chloride (PVC), plastic tubing, floor tiles, furniture, insect repellants, and cosmetics. Phthalate esters can account for up to 60 percent of the total weight of a plastic (USEPA 1975). 
Di-n-butyl phthalate and diethyl phthalate, also used as plasticizers, are also components of propellants. Thus, their detection in certain soil samples (OB/OD, artillery, mortar, and rocket firing positions) is not surprising. Phthalates are sparingly soluble with the solubility of BEHP approximately $0.003 \mathrm{mg} / \mathrm{L}$ (Staples et al. 1997) and are highly adsorbed or complexed with soil. Furthermore, numerous experiments have shown bioaccumulation limited by biotransformation to nontoxic products (Chauret et al. 1996, Staples et al. 1997). Given their low solubility and high degree of sorption, phthalates have not been consistently detected in groundwater and are not likely an important groundwater COPC (AMEC 2001b; Ogden 1999a, 1998a). Although di-n-butyl phthalate and diethyl phthalate are often found in soil, it is unlikely that sufficient mass would accumulate at firing points to result in a soil risk (Zakikhani et al. 2005, 2004).

Polynuclear aromatic hydrocarbons (PAHs) are another class of SVOCs detected in surface soils at military ranges (Ogden 1999a, 1998a). PAHs are typically associated with petroleum (including asphalt) or its combustion by-products (Jones et al. 1989), but are not known to be present in munition items. They also comprise 80 to 85 percent of creosote used in wood preservation (Gevao and Jones 1998) and are produced by burning wood and paper (Freeman and Cattell 1990). PAHs quickly adsorb to soil and are sparingly soluble. The solubility decreases as the number of rings increases. For example, the solubility of the four-ringed benzo(a)anthracene is $0.013 \mathrm{mg} / \mathrm{L}$, while the solubility of the five-ringed benzo(a)pyrene is $0.002 \mathrm{mg} / \mathrm{L}$.

Both controlled and accidental fires have occurred at many military ranges and undoubtedly account for some of the PAHs reported. PAHs, however, have so many potential sources that source-apportionment almost never can be conclusive. Nonetheless, where low concentrations are reported, a review of potential source strengths is instructive. At Camp Edwards, the sample with the highest concentration contained less than $50 \mathrm{mg} / \mathrm{kg}$ (Ogden 1998a), which is similar to commonly reported values for road dust (Rogge et al. 1993), but considerably less than reported values for house dust (Chuang et al. 1991), urban air particulates (Sheu et al. 1997), and urban lake sediments (Heit 1979). Furthermore, most of the PAHs detected at Camp Edwards are five- and six-ring compounds, suggesting old diffuse sources, including burning of vegetation or propellants and atmospheric deposition (Wild and Jones 1995). Specifically, of more than 600 
soil samples from the Central Impact Area, only pyrene, fluoranthene, and chrysene were reported as often as approximately 10 percent of the time (AMEC 2001a). These four-ringed compounds are among the most abundant PAHs in creosote wood preservative (Elder and Dresler 1988). Fluoranthene also tends to be a dominant $\mathrm{PAH}$ in atmospheric deposition (Broman et al. 1991), and pyrene and chrysene are among the more common PAHs found in motor vehicle particulate emissions. Four other PAHs were detected in approximately 7 to 8 percent of the samples at Camp Edwards: benzo(b)fluoranthene, benzo(k)fluoranthene, benzo(a)anthracene, and benzo(a)pyrene. Benzo(a)anthracene has four rings; the rest have five (Ogden 1998a). The two fluoranthenes are common products of diesel emissions (Hering et al. 1984). Benzo(a)pyrene is common in creosote and motor vehicle particulate emissions (Wild and Jones 1995). Benzo(a)anthracene is common in motor vehicle particulate emissions. Other PAHs were reported, but with frequencies less than approximately 3 percent (Ogden 1998a).

PAH concentrations reported at Camp Edwards are less than those found in typical urban environments; the compounds' low solubilities preclude their being a concern regarding groundwater (Zakikhani et al. 2005, 2004; AMEC 2001b). In general, PAHs detected at military ranges are associated with on-site vegetative burning, diesel exhaust, and atmospheric deposition.

\section{Metals}

Metal oxides and salts are present in some energetic compound formulations and alloys that are the primary components of munition casings. Bang Box studies suggest the following species, all of which occur naturally, may be released in gaseous or particulate form from the detonation of ordnance: aluminum, antimony, arsenic, barium, beryllium, cadmium, chromium, cobalt, copper, iron, lead, magnesium, manganese, mercury, nickel, phosphate, selenium, and zinc (Radian 2001, 1999a, b). However, the mass released is very small. Moreover, it is uncertain whether Bang Box studies conducted in an enclosed, oxygen-limited chamber are applicable to an open detonation on a range.

Migration of metals to groundwater and within the aquifer depends on the redox status and $\mathrm{pH}$ of the environment in which they are released as well as their own chemical form. Generally, aerobic soil and groundwater conditions can promote migration of oxyanion-forming elements such as $\mathrm{Cr}^{+3}$ 
(Barnhart 1997, James et al. 1997). However, there is no suggestion of widespread use or disposal of $\mathrm{Cr}^{+3}$ or other oxyanion forming elements (arsenic, selenium, uranium, and vanadium) on military ranges (Ampleman et al. 2004, 2003a, 2000; AMEC 2001a; ESE 1996). The chromium present in munitions and their casings would be trivalent, which does not undergo significant oxidation under environmental conditions (Barnhart 1997). In contrast to oxyanion-forming elements, aerobic surface conditions inhibit dissolution and migration of elements such as copper and lead, which tend to form sparingly soluble oxides. Metals such as copper and lead are mobilized only under highly acidic conditions such as acid mine-drainage, or sometimes in small amounts when ample dissolved organic matter is available for complexation (Sedlak et al. 1997).

Soil samples at Camp Edwards (AMEC 2001a), Jefferson Proving Ground (USCHPMM 2003), and CFB Shilo (Ampleman et al. 2004) did contain somewhat elevated concentrations of some metals-probably related to the quantity of metal fragments present on the soil surface. Nevertheless, average metal concentrations for surface soils within the Central Impact Area at Camp Edwards are still within the Massachusetts Department of Environmental Protection (MADEP) background range, crustal averages, and other background studies (AMEC 2004, 2003a, 2001a). The conclusion drawn for Camp Edwards was that there was no evidence for significant metal contamination in soil within the Central Impact Area or Demolition Area 1 (Demo 1) OB/OD area (AMEC 2004, 2003a). Furthermore, because of their low concentrations, a Human Health Risk Evaluation for soil and groundwater did not identify any metals as COCs (AMEC 2004, 2003a, 2001a, b) although the Zakikhani et al. (2005, 2004) studies suggested that hexavalent chrome posed a risk. However, given the soil and aquifer conditions at Camp Edwards, hexavalent chrome is not likely to be the predominant chrome species present at the site. Studies at other impacts areas (USCHPPM 2003) and OB/OD (Ampleman et al. 1998; ESE $1997,1994)$ sites have shown the presence of metals in soils and groundwater, but at non-elevated levels. The conclusion drawn from these studies was that the observed metals are likely representative of background conditions. These results are believed applicable to other ranges with similar training activities. 


\section{UXO Corrosion}

Corrosion of UXO provides the potential to contaminate soil and groundwater at a military range. The specific concern is the rate at which munitions casings may be breached, exposing HE filler to the environment. This section reviews the effects of ordnance composition and site-specific physical, chemical, and biological factors on corrosion mechanisms. Both qualitative predictions and the results of calculations are presented.

\section{Ordnance composition}

Steel is the predominant casing material for most artillery and mortar rounds. Aluminum is typically used in anti-tank rounds. Other materials employed in munitions casings include a variety of alloys containing aluminum, copper, and zinc (Papadopoulos 2003). Specific types of steel were not identified, but varying amounts of chromium, nickel, and carbon were listed. Chromium and nickel concentrations were similar to Type 304 stainless steel; however, munitions casings have higher carbon content. Chromium and nickel are added to steel to increase strength and resistance to corrosion; higher carbon content yields greater temperature resistance.

\section{Surface features}

Heat treatment, surface condition, and fabrication procedures (e.g., time, temperature, and polishing) can change the response of a steel or alloy from relative inertness to unacceptable reactivity (Lula 1986, SzklarskaSmialowska 1986). Alloying increases corrosion resistance, but structural defects still occur. Shoesmith (1987) concluded, "For a metal or alloy to corrode evenly, the anodic and cathodic sites must be interchangeable. This implies that every site on the surface is energetically equivalent and therefore equally susceptible to dissolution. This is never the case." A lack of surface uniformity probably characterizes any round fired and impacting the land surface. Welds can affect corrosion because the local heating of a material involved in welding can lead to phase transformation and the formation of secondary precipitates. Welding also can induce stress in and around the weld. Such changes can lead to significant local differences in electrochemical properties as well as the onset of such processes as intergranular corrosion (Shoesmith 1987). 
Any relationship between the dud rate and imperfections in the casings is unknown; however, the firing process likely creates imperfections in most instances. It is also likely that time to perforation is longer for munitions with thicker shell walls. It is important to note that munitions are typically painted and that paint can significantly delay the onset of corrosion.

Corrosion could start from the interior of an item, but this seems unlikely for intact UXO, even though older UXO items, in particular, normally do not have an interior coating of paint. Corrosion requires moisture and intact UXO have minimal internal moisture. When loading ordnance items during manufacturing, moisture is avoided since it is harmful to the operational efficiency of HE. Cracked munitions, on the other hand, could allow precipitation or water vapor from the atmosphere to enter the broken or cracked UXO. Water inside the munition item then could initiate corrosion from within.

\section{Corrosion mechanisms}

\section{Water}

A review of corrosion processes in water provides insight into mechanisms that may affect UXO. Chemical attack in water is typically classified as either pitting or crevice corrosion. Pitting and crevice corrosion involve oxidation of the corroding material and reduction of a constituent of the corrosive environment at a point and along a line, respectively (Lula 1986). Crevice corrosion requires the metal to have undergone stress and exposure to a sufficient concentration of salt. Chloride (often represented as high ionic strength) is the leading cause of pitting in stainless steel, aluminum, iron, nickel, and, to a lesser extent, zinc and copper (Lula 1986, Szklarska-Smialowska 1986). Nevertheless, chloride is not explicitly necessary for corrosion to occur. Combination effects also can occur. For example, a low sulfate-to-chloride ratio provides protection to stainless steels at low chloride content, but can enhance corrosion when chloride is high (Kain 1990).

Crevice corrosion occurs when the metal inside a tiny gap acts as an anode while the remaining metal surface in contact with the bulk electrolyte, water, acts as a cathode. The anodic dissolution of metal in the crevice results in local accumulation of metal cations. To maintain neutrality, anions (usually chloride) migrate from the bulk electrolyte into the crevice. Because of the hydrolysis of the metal, acidity increases, and the protective 
film is disrupted. The depth and narrowness of the crevice, or a "critical geometry effect," can be more important than the chemical composition of the water. Even a high-grade stainless steel otherwise impervious to corrosion can be susceptible if damaged appropriately. For example, Kain et al. (1984) reported that Type 304 stainless steel would corrode under conditions of severe (narrower and deeper) crevice geometry. Highlighting the critical effect of crevice geometry, the investigation demonstrated that increased exposure time had little effect on promoting additional corrosion. Furthermore, the study showed crevice corrosion would occur when chloride content was as low as $100 \mathrm{mg} / \mathrm{L}$, but Type 304 was resistant in 90 percent of the cases where chloride was between 100 and 1,000 mg/L. Thus, minor variations in the crevice gap, especially in the range of 0.1 to $1 \mu \mathrm{m}$, can have greater significance than variations in bulk environmental chemistry (Kain 1990, Oldfield and Sutton 1980).

As an example, modeling predictions indicate that a variation of a fraction of a micrometer makes the difference between resistance and susceptibility to corrosion. Hence, localized attack in natural waters is not usually due to pitting but to crevice corrosion (Kain et al. 1984). Nevertheless, obvious physical damage to a UXO may not increase susceptibility to corrosion. In sufficiently wide crevices, the access of oxygen and the exchange with the external solution is not significantly affected because the corrosion rate measured inside of a crevice decreases as its width increases. For example, studies have shown little or no observable crevice corrosion in aluminum or stainless steels for crevices greater than approximately 0.25 mm (Szklarska-Smialowska 1986).

Pisigan and Singley (1985) attempted to evaluate water corrosivity using the Langelier index and relative corrosion rate models. The Langelier Index is used in the drinking water industry as a measure of calcium carbonate saturation. The work was performed with immersed mild steel and showed that carbonate-bearing waters are relatively less corrosive than waters with chloride and sulfate salts. An empirically formulated model defining corrosion rate as a function of chloride, sulfate, alkalinity, dissolved oxygen (DO), calcium, buffer capacity, saturation index, and exposure time yielded a satisfactory graphical fit to experimental data. Later work by these same authors demonstrated that the identical list of parameters can be used to predict corrosion in black steel (Pisigan and Singley 1987). A number of other indices have been developed in attempts to relate solution characteristics to corrosion. 
Dissolved oxygen, present in soil moisture, promotes oxidation of ferrous iron by aiding the release of ferrous iron $\left(\mathrm{Fe}^{2+}\right)$ from the corroding metal. Hence, corrosion increased twofold as DO increased from 1.5 to $5 \mathrm{mg} / \mathrm{L}$ and another 3.5 times as DO was raised to $9 \mathrm{mg} / \mathrm{L}$ (Pisigan and Singley 1987, Manahan 1994). In contrast, if oxygen is in great excess, such as with exposure of the metal to the atmosphere, oxide films form on the metal surface and provide protection from corrosion.

\section{Soil and atmosphere}

In the case where UXO lie exposed on the ground surface, soil and atmospheric conditions can significantly impact corrosion processes. When an ordnance enters the soil, it compacts the soil adjacent to the round, resulting in compressed soil pore spaces, a decrease in soil permeability, and an increase in matric potential. Consequently, water in the compressed soil pores will take longer to drain than in the uncompressed surrounding soil. Therefore, water in the soil matrix immediately adjacent to UXO may be in contact with it longer than expected based on soil type.

Because corrosion involves current flowing from one location to another (i.e., a corrosion cell), corrosion rate increases with decreasing soil resistivity. Soil resistivity is a function of the soil texture. That is, sandy soils tend to have more resistance and are less conducive to corrosion than finer-grained soils. Also, corrosion in soil is a function of several interacting parameters, including $\mathrm{pH}$, moisture content, soluble salts, oxygen content, and bacterial activity. Acidic soils are more corrosive than soils with a neutral $\mathrm{pH}$. Corrosion is also greater in poorly drained (high moisture content) soils. The high moisture content provides the required bulk electrolyte as described above and inhibits formation of a protective oxide layer.

Atmospheric effects can be important, especially near industrialized areas with ample sources of sulfur and nitrogen oxides and in marine locations where chloride deposition occurs. For example, corrosion of copper, zinc, and aluminum, as well as an unidentified steel and galvanized steel, was evaluated in coastal, urban-industrial, and rural areas for up to 18 months (Mendoza and Corvo 2000). In this study, the most important corrosive agents identified were sulfur oxides and chlorides. Chloride deposition rate, duration of rainfall, and duration of wetness at temperatures between 5 and $25^{\circ} \mathrm{C}$ were also significant variables. Also, atmospheric particulates accelerated corrosion by increasing the conductivity of the surface layer after dissolution of soluble ions from the particulate, an example being the 
deposition of ammonium sulfate. The complex relationships observed were 1) sulfur dioxide and nitrogen oxide synergism on copper corrosion when relative humidity is greater than 90 percent, 2) sulfur dioxide and nitrogen oxide synergism on steel corrosion when relative humidity is low, and 3) no synergistic effects with nickel. High relative humidity and temperature promoted copper corrosion, as did acid and strongly alkaline solutions containing oxidizing agents. Ozone and ammonia increased the corrosion of copper. Zinc reacted with ammonium sulfate from atmospheric deposition, forming hydroxysulfates, which directly corrode the metal. Coastal samples had higher rates because proximity to the ocean increased chloride exposure (Mendoza and Corvo 2000). Precipitation enhances zinc corrosion because water-soluble zinc salts, which would provide some surface protection, are periodically washed off by rain. Chloride is the primary cause of aluminum corrosion, thus explaining why corrosion rates were highest at a coastal location (Romanoff 1957). Aluminum corrosion decreased with time as a mineral scale protected the metal. Moreover, sheltered samples corroded faster than exposed samples because rain did not wash off corrosive particulates. Overall, the authors reported aluminum was most resistant, followed by zinc and then copper (Mendoza and Corvo 2000). Steel corroded faster than the pure metals and the corrosion rate increased with time. With respect to galvanized steel, however, a protective film eventually formed and corrosion ceased.

\section{Bacteria}

Much corrosion is bacterially or microbially induced (BIC or MIC). MIC may occur with metal oxidizing microorganisms (MOMO) that are "able to deposit oxides or hydroxides of metals, usually iron or manganese, by biological oxidation of $\mathrm{Fe}^{2+}$ or $\mathrm{Mn}^{2+}$ ions dissolved in the ambient water" (Linhardt 1997). All steels are subject to microbial attack because none are perfectly uniform. Small galvanic cells start up and stop in milliseconds at many locations along the length of the piece of steel. With appropriate microorganisms present (e.g., Gallionella), some $\mathrm{Fe}^{2+}$ from the small galvanic corrosion cell is snatched up, strengthening the anode of the cell before the iron hydroxide is deposited. Eventually, sufficient bacteria grow to produce slime. Sulfur-reducing bacteria may be harbored in the accumulated slime, are attracted to the anodes, and congregate there. The iron hydroxide hardens and begins to close the new tubercle (corrosion pit). Sulfur-reducing bacteria are the organisms most closely identified with MIC (Little et al. 2000). The microbes produce sulfides that attack the steel. Corrosion can continue chemically (from chloride, once there is a pit 
or crevice and the passivation layer or protective layer is destroyed) and/or biologically.

At some locations, combined chemical and microbiological attack has been identified (Sarouhan et al. 1998). As described above, bacteria can detect the locations most vulnerable to attack and colonize there. Bacteria cells are approximately 0.2 to $5 \mu \mathrm{m}$ wide and 1 to $10 \mu \mathrm{m}$ long, and colonies can easily attach in defects only $25 \mu \mathrm{m}$ deep. At one military location, Schedule 40 mild steel and Type 304 stainless steel screens were used with PVC in well installations. Corrosion of pumps was attributed to water that had total dissolved solids $>1,000 \mathrm{mg} / \mathrm{L}$, manganese and iron $>5$ micrograms per liter $(\mu \mathrm{g} / \mathrm{L})$, sodium with an average concentration of $88 \mathrm{mg} / \mathrm{L}$, and calcium "10 to 20 times higher than typical corrosion and incrustation cutoff concentrations" (Sarouhan et al. 1998). The Riddick Corrosion Index indicated that the water was corrosive to carbon steel, but Type 304 stainless steel should have been impervious. Hence, MIC was believed responsible for the corrosion. Optimal abiotic factors favoring growth of MIC in water are $\mathrm{pH}$ between 6.5 and 9 , redox potential between -50 and 150 millivolts (mv), and total organic carbon (TOC) at least in the part per billion ( $\mathrm{ppb}$ ) range. A usual source of $\mathrm{Fe}^{2+}$ in the field is reduction of magnetite by bacteria. Magnetite is found at low levels in most soils and natural organisms have been shown to reduce it (Kostka and Nealson 1995, Kostka et al. 1996). In highly weathered and coarse-grained soils that are aerobic and low in organic matter, this mechanism does not occur because the "mounds" or slimes of bacteria required for corrosion to progress to the extent where perforation occurs (Tatnall 1981) are unlikely to form.

\section{UXO corrosion studies}

Studies specifically examining corrosion of UXO have focused only on corrosion from the outside in. Although corrosion can and does occur from the inside out, it is negligible in undamaged UXO, as no oxygen or moisture can permeate the casing (Bucci and Buckley 1999). There are also relatively few studies specific to the corrosion of UXO. A Maryland study stated a 155-mm shell would not perforate for 69 years in clay soils, but the penetration time of the thinnest section for most ordnance was predicted to be $<30$ years (Epstein et al. 1973). UXO in Halifax Harbor, Canada, was evaluated by extracting 2,4-DNT and TNT from multiple sediment samples collected adjacent to ordnance undisturbed for 50 years (Darrach et al. 1998). UXO deemed intact by visual inspection yielded 
good explosive compound signatures at the part-per-billion levels, indicating that slow leakage was occurring.

Bucci and Buckley's (1999) work addressed only undamaged UXO, excluding rounds that suffered cracks or compromises other than normal abrasions to their casings during firing. In agreement with the general review of corrosion mechanisms presented above, Bucci and Buckley (1999) stated that, in landlocked soil, where steel-shelled UXO is never immersed in water, corrosion depends largely upon soil resistivity, $\mathrm{pH}$, and redox potential. They also noted that, under typical conditions, corrosion creates a layer of rust or calcium carbonate, protecting the ordnance against additional deterioration, and concluded that there is a critical thickness above which corrosion is not likely under normal soil conditions. Others (e.g., Adams 2001) have noted the protective effect of mineral scales. However, all steels are subject to microbial attack; therefore, given sufficient time, all steels will eventually corrode to the point of perforation.

UXO corrosion also has been investigated by the Corrosion Research Center at the University of Louisiana-Lafayette for the Army Research Laboratory at Aberdeen, Maryland. The research has shown a strong correlation between corrosion and soil resistivity, iron concentration, and bicarbonate concentration. A corrosion model incorporating the geochemical model Solmineq 88 was developed. The model the Army is developing for UXO corrosion focuses on pitting corrosion with diffusion of oxygen into the pit and production of dissolved iron controlling the rate of corrosion (Packer et al. 2002).

As part of the current study, we compared the results of four corrosion model approaches: 1) the Lafayette Regression Equation that employs resistivity, bicarbonate, and cations; 2) a US Department of Energy (DOE) model based largely on time and temperature; 3) the "California Chart" that predicts corrosion of corrugated steel versus time for various field conditions; and 4) the Romanoff prolific data (a data set based on measurements of long-term exposure of metals in various soils). It is assumed pitting, MIC, crevice, and structural failure all are being considered in each of these approaches.

In Figure 2, data from an undisclosed site, Site A, are compared with predictions made with the above-described models. Predictions were developed based on the site-specific soil conditions at Site A. Five models pre- 
dict similar results-the DOE, California, Romanoff Aerated + Acid, Romanoff Sulfide, and Romanoff Alkaline. Two models (Romanoff Anaerobic and Lafayette) produce results significantly different from the others. The Romanoff Anaerobic model is not appropriate for Site A because the soil at the site is likely under aerobic conditions. It is possible that micro-sites exist where anaerobic conditions prevail, but these conditions are likely to be the exception rather than the rule. Similarly, the Lafayette Equation appears not to be applicable for the conditions at Site A. For a comparison of pit depth versus time, the Lafayette Equation predicts the least corrosion with formation of a half-inch pit requiring centuries. Using the Romanoff work, an aerated acid soil such as Site A would cause corrosion of 0.27 inches of steel in 100 years (Fig. 2). The remaining models suggest that 0.5-inch-thick steel at Site A would take 60 to 200 years to corrode. For several of the models, it was necessary to extrapolate to 0.5 inches. For example, artillery rounds such as 105- and 155-mm varieties have a minimum wall thickness slightly greater than 0.5 inches. On the other hand, a number of mortar rounds have a much thinner minimum wall thickness. The 60- and 81-mm mortar varieties have a minimum wall thickness ranging from 0.078 to 0.201 inches, suggesting a time to perforation of less than 50 years. Given that munitions (including mortars) from the WWII era have been found at Site A, these models predict that some of these varieties already could have completely corroded.

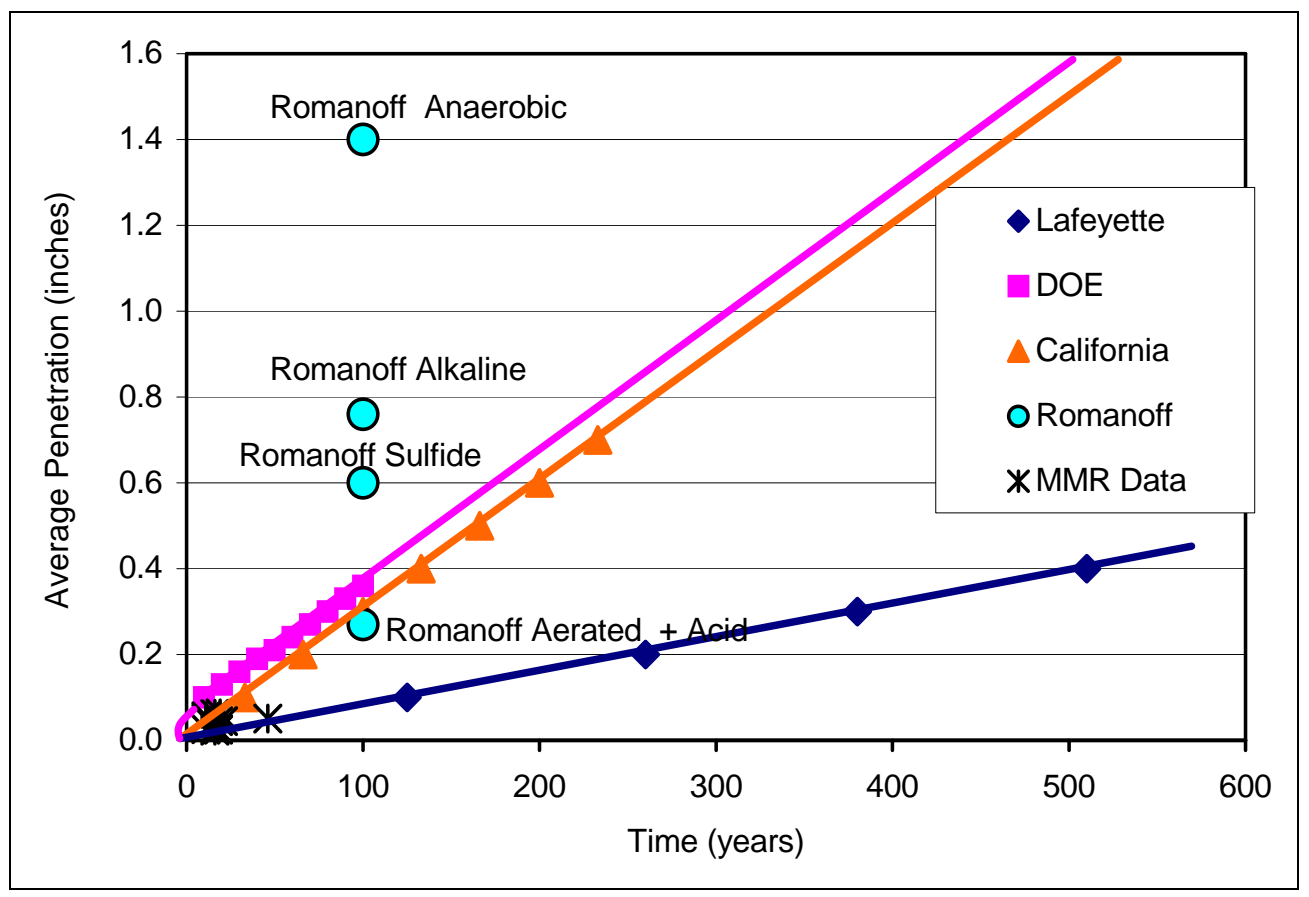

Figure 2. Corrosion rates for Camp Edwards intact UXO using various corrosion models. 


\section{Potential for corrosion at ranges}

The following discussion presents an example of a process for assessing the corrosion potential of UXO at military sites. A variety of soil samples was collected at Camp Edwards to support a corrosion study of munitions (TT 2003). Also, 61 ordnance items were examined specifically to determine their degree of corrosion (Packer et al. 2002). All ordnance was found near the ground surface, with portions of most items exposed to the atmosphere. All steel items showed some surface corrosion. Figure 3 compares pit density versus pit depth for 29 of 30 steel items. One sample (not plotted) had a pit depth beyond the scale of the figure; all but two others show relatively good correlation between the number of pits and maximum pit depth.

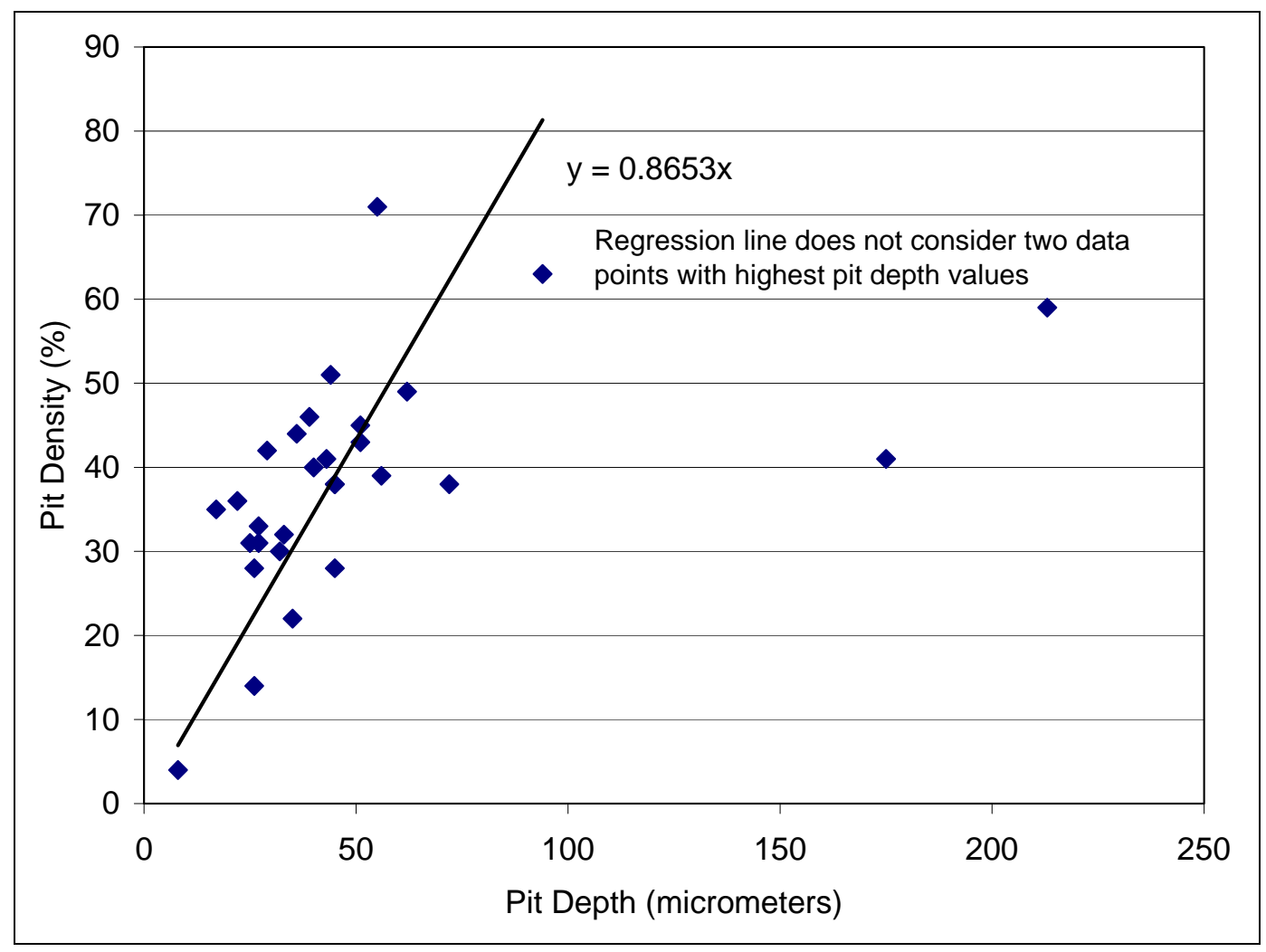

Figure 3. Unexploded ordnance (UXO) pit density versus pit depth for ordnance from Camp Edwards.

It is important to realize that pit presence does not necessarily mean perforation will occur. Corrosion studies refer to a "pit initiation potential"the potential above which stable pit growth is detected. However, pitting is often initiated well below the initiation potential. In such circumstances, spontaneous repassivation occurs and pits fail to propagate, leading to 
their classification as "metastable pits." Generally, presence of metastable pits is not important, as these pits do not lead to perforation of the metal (Bossia and Cragnolino 2000). Furthermore, pits often undergo a "broadening effect in that the pits will tend to grow laterally rather than increase in depth" (Bossia and Cragnolino 2000). Again, the broadened pits are susceptible to repassivation and the pits fail to propagate (Chendorain et al. 2005).

An evaluation of the Camp Edwards ordnance samples was reported by the USAEC (Packer et al. 2002). The study focused on eleven 155-mm low-cost indirect training rounds (LITR) less than 22 years old, nine 155-mm LITRs in the ground for 10 to 17 years, and the nose cone from a $155-\mathrm{mm}$ round that spent between 46 to 56 years on the ground surface. The study used the age of the ordnance and the maximum pit depth to estimate corrosion rate. This work assumed "steel" with a 0.5-in. thickness, and selectively included rounds with dates known to within one year. The study addressed in-ground corrosion. Pitting corrosion was observed, with no evidence of crevice corrosion. The study concluded that the approximate time to perforation of 0.5-in. steel UXO at Camp Edwards would be at least 170 years. These conclusions were extrapolated from relatively young rounds, and the rate of steel corrosion often declines with time because the initial corrosion products protect the underlying surface. Pit depths in one round dated to be 50 years old fell directly along the line projected from the younger munitions (Packer et al. 2002). Also, the composition of the ordnance found at Camp Edwards varies, as does the wall thickness. Mortar rounds typically have a thinner wall thickness than artillery rounds. For example, 60-mm M495A rounds have a wall thickness of 0.201 inches.

Table 2 presents corrosion rates calculated in the USAEC study assuming a 1-in. steel alloy shell. Both a regression model and California Method 643 (CDOT 1999) were used. For approximately 21 of these locations, the corrosion rate also was measured based on actual pitting depth of the ordnance. The measured rates ranged from $<0.028$ to $0.129 \mathrm{~mm}$ per year $(\mathrm{mm} / \mathrm{y})$, with the average being approximately $0.066 \mathrm{~mm} / \mathrm{y}-\mathrm{a}$ result consistent with the predicted values in Table 2. Ultimately, the conclusions from the various evaluations are consistent with those of Chendorain et al. (2005), "The UXO studied in this effort were not a significant source of explosives to the unsaturated soil environment." 
Table 2. Corrosion rates calculated by Army Environmental Center.

\begin{tabular}{|l|c|c|c|c|c|}
\hline \multicolumn{1}{|c|}{ Parameter } & Mean & $\begin{array}{c}\text { Standard } \\
\text { deviation }\end{array}$ & Median & Maximum & Minimum \\
\hline California chart \\
\hline Corrosion rate (mm/y) & 0.0770 & 0.0254 & 0.0749 & 0.1524 & 0.0371 \\
\hline Estimated life of 1-in. shell (yrs) & 367 & 121 & 339 & 684 & 170 \\
\hline Estimated life of 0.5-in. shell (yrs) & 190 & 63 & 179 & $359 *$ & 86 \\
\hline Regression \\
\hline Corrosion rate (mm/y) & 0.0886 & 0.886 & 0.0709 & 0.5334 & 0.0254 \\
\hline Estimated life of 1-in. shell (yrs) & 449 & 235 & 469 & 1001 & 47 \\
\hline * The study by Packer et al. (2002) predicted 170 years estimated life for a 0.5-in. shell. \\
\hline
\end{tabular}




\section{Conceptual Models of Fate and Transport for Energetic Compounds}

Initial belief was that conventional point sources were responsible for groundwater contamination with energetic compounds at training ranges. Subsequently, this was proven incorrect by data collected from more than 25 ranges (Clausen et al. 2004b, Jenkins et al. 2005b, Pennington et al. 2005). Hypotheses considered initially included unidentified disposal activities, buried caches of munitions, leaching from individual UXO items, or washout facilities. However, when the latter activities were ruled out (Ogden 1998a, b), it was impossible to establish a link between extensive $\mathrm{RDX}$ groundwater contamination and deposition to the ground surface. The apparent absence of RDX at significant levels in soil samples from range areas suggested it was 1) never present, 2) already leached out of surface soil, 3) diluted to levels below current analytical capabilities, 4) too heterogeneously distributed to be delineated, 5) degraded via chemical or microbial processes, or 6) transformed to unextractable metabolites. Thus, the first revision to the conceptual model was the realization that conventional point sources were usually not to blame and that different release mechanisms should be expected for different types of munitions as well as propellants versus explosives (AMEC 2001b). As will be described subsequently, the principal contributor to any groundwater contamination at impact ranges is now believed to be heterogeneously distributed particulate residues caused principally by low-order detonations (Hewitt et al. 2005, 2003; Jenkins et al. 2005b, 2002).

\section{Mechanisms of contaminant deposition for non-impact range areas}

In contrast to impact ranges, explosive and ordnance disposal (EOD), demolition, and OB/OD areas generally can be treated as point sources. Activities are concentrated in a small geographical area (generally less than one acre). $\mathrm{C}_{4}$ and TNT blocks also are used at EOD, OB/OD, and demolition sites, but not elsewhere.

Gun and mortar firing positions, rocket firing positions, and rocket targets may employ chemicals unique to those sites, but such compounds are typically not significant sources of contamination. Nonetheless, the distinction between impact range and non-range areas is arbitrary and, at some loca- 
tions, frequency, duration, and a multiplicity of uses could give any of the following sites the characteristics of impact ranges.

\section{Open burn/open detonation (OB/OD) sites}

The use and incomplete detonation of $\mathrm{C}_{4}$ and TNT blocks results in the random distribution of chunks of explosives as well as fine particulates. Energetic compounds of interest at $\mathrm{OB} / \mathrm{OD}$ sites include perchlorate, HMX, RDX, TNT, 2a-DNT, and 4a-DNT. Depending on the munitions types detonated, some propellants, such as 2,4-DNT, 2,6-DNT, and NG, as well as N-nitrosodiphenylamine, di-n-butyl phthalate, and diethyl phthalate, may also be present. The latter three compounds, although present in soil, do not represent COPCs for soil or groundwater since they have little potential for migration (see Section 4).

For example, OB/OD activities were conducted at Camp Edwards site Demo 1 for several decades in a small-enough area to be considered a point source (AMEC 2003a). Demo 1 resides in a kettle hole depression where recharge to the aquifer is increased. Moreover, a silty/clayey soil at the bottom of the kettle hole results in temporary ponding of water. The standing water allows RDX, HMX, and perchlorate to attain higher dissolved concentrations as a result of the longer contact between the HE residues and precipitation. Consequently, pore-water concentrations are also likely to be much higher. The depth to groundwater at Demo 1 also is much shallower than elsewhere at Camp Edwards ( $44 \mathrm{ft}$ compared to the typical $120 \mathrm{ft}$ ), thereby providing less opportunity for attenuation and dilution during vertical migration. These factors explain why 2a-DNT, 4aDNT, 2,4-DNT, and TNT have been consistently observed in groundwater at Demo 1 and not elsewhere, and why RDX, HMX, and perchlorate concentrations are much higher than at other areas at Camp Edwards.

The previous discussion demonstrates why the contamination pattern of the groundwater plumes at an OB/OD site and an impact area should be different. At OB/OD sites a narrower plume and higher groundwater concentrations are expected, owing to a point source release (AMEC 2003a). In impact areas the groundwater plume is expected to be wider with much lower concentrations, owing to the distributed source (AMEC 2004). The nature of the plume emanating from the Demo 1 kettle hole at Camp Edwards satisfies this description for the following reasons: 1 ) the plume is narrow; 2) the highest concentrations of explosives are consistently detected at the water table directly beneath, or immediately downgradient of, 
the source area; 3) downgradient of the kettle hole, explosive compounds are not detected in groundwater from shallow wells screened above the plume; and 4) explosives concentrations decrease with distance from the source. In contrast, the plume from the impact area at Camp Edwards is much wider and much less concentrated.

\section{Gun and mortar firing positions}

Energetic compounds are released at gun and mortar firing positions by two basic methods. The first is particulate deposition as a result of propellant detonation from the barrel or breach of the gun, releasing smoke that contains gasses and particles. In the past, a second method involved OB/OD of excess propellant bags on the ground surface. Present Army procedures require burning propellant bags on metal trays.

The energetic compounds of interest at gun and mortar firing positions include 2,4-DNT, 2,6-DNT, NG, N-nitrosodiphenylamine, di-n-butyl phthalate, and diethyl phthalate. As discussed in Section 1 and in Section 4 , these compounds usually are not COPCs because they typically are found in low concentrations and only in surface soil (Camp Edwards is an example [AMEC 2002b, 2001a]).

\section{Anti-tank rocket firing positions}

Exhaust gasses from anti-tank rockets deposit NG particulates or NG bound to $\mathrm{NC}$ particulates in the back-blast gas. Thus, the energetic compounds of interest are the same as those at the gun and mortar firing positions. NG will be the predominant compound found at anti-tank rocket firing points. As will be discussed in Section 4, NG seldom is a COPC due to its physical form in propellant, fate-and-transport properties, and low toxicological risk.

\section{Anti-tank rocket targets}

Unlike the targets in an impact area, anti-tank rocket targets are line-ofsight direct fire. Consequently, energetic residues are found immediately in front of the target and to a lesser degree to the sides, with minimal residue found on the backside of the target. The same list of energetic compounds is of interest at the target locations as those at the firing positions, plus the energetics HMX, RDX, and TNT. Anti-tank rockets often shear apart on impact, disgorging their contents. Because of a high dud rate (47 
percent) and thin aluminum skins, larger chunks of energetic compounds can be expected (Jenkins et al. 1997a). Also, if the propellant is not exhausted by the time the rocket reaches the target, propellant residues or chunks can be expected. Therefore, most of the energetic compound material is concentrated immediately in front of the target (Hewitt 2002). If the energetic compound material is mobile enough and the depth to groundwater is shallow, then contamination could be manifested at the water table as a point source.

\section{Current conceptual model for ranges}

Figure 4 presents the current conceptual model of energetic compound fate and transport for ranges. This conceptualization is based on work conducted by ERDC (Jenkins et al. 2005b, 2002, 2001a; Pennington et al. 2003a, 2002a, b) and at Camp Edwards (AMEC 2003a, 2001a). This figure applies principally for an impact area, but may be applicable to other sites as noted above. The commonality for applicable sites is airborne deposition of particulates.

\section{Principal release mechanism}

Recent work sampling particulates from detonations on snow (Fig. 5) indicates that the quantity of explosives residues from a single high-order detonation is so small that even a great number of high-order detonations cannot produce enough mass to cause groundwater contamination (Hewitt et al. 2003; Jenkins et al. 2001b, 2000a). Thus, the most likely contamination sources on ranges (impact areas) are deposits of energetic compound particulates as a distributed source from low-order detonations, and-to a lesser extent-ruptured munitions (Hewitt et al. 2003; Jenkins et al. 2002, 2001b, 2000a; Pennington et al. 2002a, b). Contamination also may result from blow-in-place (BIP) of UXOs. The charge used and cleanup procedures following BIP activities will affect the amount of HE residue.

Hence, the conceptual model for ranges begins with the deposition of particulates onto the soil surface from low-order detonations or rounds that have cracked open. Their release is as a distributed source, i.e., a lowconcentration, non-random pattern of widely dispersed energetic compound residues on soil (Jenkins et al. 2005b; Hewitt et al. 2003; Pennington et al. 2002a, b). The pattern results from the random nature of targeting, inaccuracy of indirect fire weapon systems, multiple firing locations with overlapping firing fans, multiple targets, possible movement of tar- 
gets over time, and randomness of low-order detonations and secondary detonation of UXO.



Figure 4. Propellants, explosives, and pyrotechnics fate-and-transport conceptual model. 


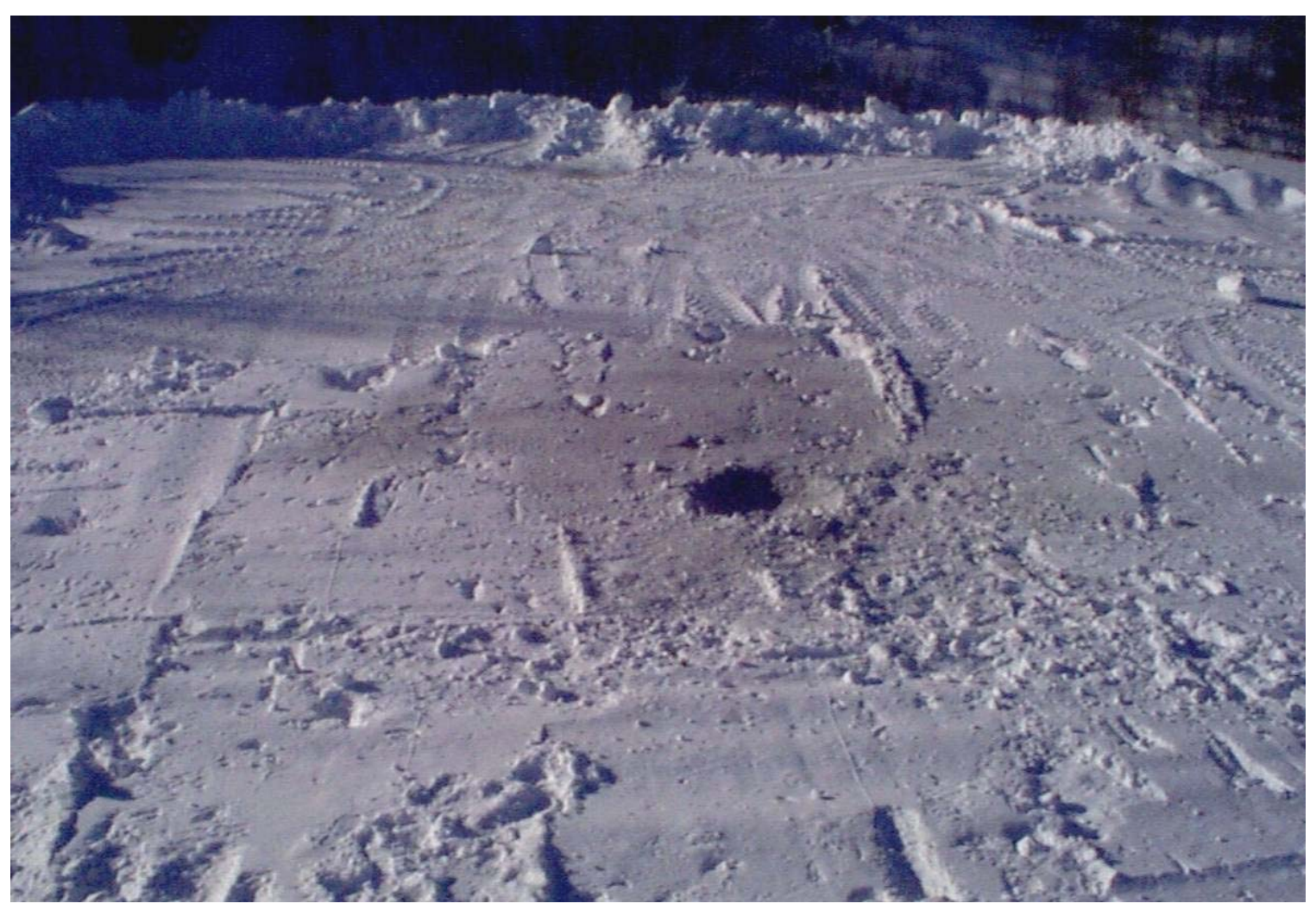

Figure 5. Distribution of explosives residue after open detonation on snow.

The conclusion that particulate energetic compounds must be present is supported by physical observation (Jenkins et al. 2005a, b, 2002, 2000a; Pennington et al. 2005; Hewitt et al. 2003) and by calculating whether there is sufficient RDX in pore water to explain the groundwater contamination observed. The following illustration uses data from Camp Edwards.

It should be recalled that most soil samples from this impact area contained no detectable RDX (detection frequency less than 10 percent) and that those samples with contamination were more or less randomly distributed (see Section 5). Nonetheless, the presence of a contaminant plume extending two miles from the impact area clearly shows that RDX has leached through approximately $120 \mathrm{ft}$ of vadose zone. Based on information in Table A1, the solubility of RDX (approximately $42.0 \mathrm{mg} / \mathrm{L}$ ), the soil-water distribution coefficient $\left(0.38 \mathrm{~cm}^{3} / \mathrm{g}\right)$, and the dimensionless Henry's Constant for RDX (2.58E-6), it is possible to calculate the maximum RDX soil concentration, assuming all the RDX is dissolved (Feenstra et al. 1991). The equation is

$$
\mathrm{Cw}=\mathrm{Ct} * \mathrm{~Pb} /(\mathrm{Kd} * \mathrm{~Pb}+\mathrm{Ow}+\mathrm{Hc} * \mathrm{Oa})
$$


where

$$
\begin{aligned}
\mathrm{C}_{\mathrm{w}} & =\mathrm{RDX} \text { concentration in the pore-water }(\mu \mathrm{g} / \mathrm{L}) ; \\
\mathrm{C}_{\mathrm{t}} & =\text { Total soil RDX concentration }(\mu \mathrm{g} / \mathrm{g}=\mathrm{mg} / \mathrm{kg}) ; \\
\mathrm{P}_{\mathrm{b}} & =\text { Dry bulk density of soil }=1.68 \mathrm{~g} / \mathrm{cm}^{3} ; \\
\mathrm{K}_{\mathrm{d}} & =\text { Distribution coefficient for } \mathrm{RDX}\left(\mathrm{cm}^{3} / \mathrm{g}\right)=0.38 ; \\
\mathrm{O}_{\mathrm{w}} & =\text { Water-filled porosity }=0.0975 ; \\
\mathrm{O}_{\mathrm{a}} & =\text { Air-filled porosity }=0.2925 ; \\
\mathrm{H}_{\mathrm{c}} & =\text { Dimensionless Henry's Constant for } \mathrm{RDX}=2.58 \mathrm{E}-6 .
\end{aligned}
$$

Using an RDX solubility of $42 \mathrm{mg} / \mathrm{L}$ (Sikka et al. 1980) as the maximum pore-water concentration yields a maximum RDX soil concentration of $18.54 \mathrm{mg} / \mathrm{kg}$ for Camp Edwards. This solubility value is very conservative because it is based on pure water and $20^{\circ} \mathrm{C}$. Nevertheless, soil concentrations in excess of $18.54 \mathrm{mg} / \mathrm{kg}$ cannot be explained solely by RDX dissolved in the soil pore-water, sorbed to soil, and partitioned into soil gas. Of the 173 detections of RDX in soil samples collected from o to $2 \mathrm{ft}$ in the impact area at Camp Edwards, almost ten percent (16 samples) had concentrations of RDX greater than $18.54 \mathrm{mg} / \mathrm{kg}$ (AMEC 2001a). If a more realistic value for the solubility of RDX is used, such as $30 \mathrm{mg} / \mathrm{L}$ (Speitel et al. 2002), the above equation yields a soil concentration of $13.3 \mathrm{mg} / \mathrm{kg}$. Thus, total soil concentrations above 13 to $18 \mathrm{mg} / \mathrm{kg}$ cannot be explained simply by dissolved, sorbed, and gas-phase RDX. Particulate RDX must be present.

For the purposes of the conceptual model, therefore, microscopic particles of RDX and other energetics are assumed to be present in shallow surface soil even where they have not been visually observed or detected by chemical analysis. These conclusions (AMEC 2001b) are consistent with a dispersed, low-level source term, or distributed source, originating from loworder HE detonations (Jenkins et al. 2005b, 2001b, 2000a; Hewitt et al. 2003). These particulates originating from low-order detonations are dissolved by precipitation passing through the upper soil profile (i.e., 1 to 2 $\mathrm{ft}$ ). The fraction dissolved is controlled by many factors: composition of the energetic compound material, the size (i.e., surface area), shape, and type of the particulate (neat explosive, soot containing energetic compounds, energetic-compound-impregnated metal), intensity and duration of the precipitation event, temperature, soil characteristics, and drainage patterns. 
Another mechanism potentially accounting for energetic compound residues on ranges is the breaking open or corroding of previously intact UXO. The USAEC has compiled information on the dud rates (percentage of rounds fired that fail to function at the target) for various items based on live firing (209,390 rounds fired) (US Army Defense Ammunition Center 2000). The average dud rates for all munitions studied is 3.5 percent, ranging from o to 11.7 percent (US Army Defense Ammunition Center 2000). Table 3 provides the dud rates for various rounds utilized at most training areas based on the Defense Ammunition Center study. The dud rate under training conditions may be higher than those encountered during the study, as operator error can account for increases in dud rates. Recent work at Fort Lewis, Washington, indicates a dud rate of 4.4 percent for 105-mm rounds under actual field conditions (Jenkins et al. 2001a). In any case, training ranges can have a significant number of UXO.

These UXO might be breached by the nearby detonation of an incoming $\mathrm{HE}$ round or by corrosion of the intact projectile. Jenkins et al. (2001a) and Phelan (2001) suggest most rounds that do not undergo a high- or low-order detonation do not rupture upon impact with the ground surface because of their thick wall casings. Range personnel disagree as to whether range fires can detonate $\mathrm{HE}$ rounds. If fires cause $\mathrm{HE}$ rounds to detonate, they might undergo low-order detonations and spread explosives residues onto the ground surface. Otherwise, UXO could act as a very small point release if the round ruptured or breached due to corrosion. Once the metallic body of the UXO is compromised, infiltrating precipitation could be exposed to the explosive filler. In many cases, the explosive filler is poured into shells, creating a large continuous block of HE. (A 105-mm round contains $1.38 \mathrm{~kg}$ of Comp B.) Thus, the explosive surface area would be small relative to a particulate resulting from detonations. Energetic compounds in a corroded UXO would dissolve in a manner similar to that previously discussed, and would undergo similar fate-and-transport processes. However, owing to the smaller surface area, the degree of dissolution would be much less. Finally, based on the rates of corrosion discussed previously and data collected to date from Camp Edwards (TT 2003, 2002), corroding UXO are usually not a significant source of groundwater contamination (Sections 2 and 5). 
Table 3. Dud and low-order rate by ammunition size. (From USAEC report of findings for study of ammunition dud and low-order detonation rates, July 2000.)

\begin{tabular}{|c|c|c|}
\hline Size & Dud percentage & Low-order percentage \\
\hline Fuse & $3.96 \%$ & $0.02 \%$ \\
\hline $105 \mathrm{~mm}$ & $4.65 \%$ & $1.07 \%$ \\
\hline 106 mm & $2.68 \%$ & $0.20 \%$ \\
\hline $120 \mathrm{~mm}$ & $2.59 \%$ & $0.00 \%$ \\
\hline $152 \mathrm{~mm}$ & $0.00 \%$ & $0.00 \%$ \\
\hline $155 \mathrm{~mm}$ & $2.26 \%$ & $0.99 \%$ \\
\hline $165 \mathrm{~mm}$ & $1.63 \%$ & $1.09 \%$ \\
\hline 2.75 inch & $11.70 \%$ & $0.00 \%$ \\
\hline 3.5 inch & $1.08 \%$ & $0.00 \%$ \\
\hline 4.2 inch & $5.13 \%$ & $0.14 \%$ \\
\hline $40 \mathrm{~mm}$ & $1.37 \%$ & $0.15 \%$ \\
\hline $57 \mathrm{~mm}$ & $0.53 \%$ & $0.00 \%$ \\
\hline $60 \mathrm{~mm}$ & $2.34 \%$ & $0.02 \%$ \\
\hline $66 \mathrm{~mm}$ & $4.52 \%$ & $0.04 \%$ \\
\hline $75 \mathrm{~mm}$ & $5.70 \%$ & $0.20 \%$ \\
\hline $76 \mathrm{~mm}$ & $8.72 \%$ & $0.12 \%$ \\
\hline 8 inch & $0.99 \%$ & $0.00 \%$ \\
\hline $81 \mathrm{~mm}$ & $2.33 \%$ & $0.11 \%$ \\
\hline $83 \mathrm{~mm}$ & $1.96 \%$ & $1.25 \%$ \\
\hline $84 \mathrm{~mm}$ & $0.00 \%$ & $0.15 \%$ \\
\hline $90 \mathrm{~mm}$ & $8.06 \%$ & $0.40 \%$ \\
\hline Average & $3.45 \%$ & $0.28 \%$ \\
\hline
\end{tabular}

The conceptual model (Fig. 4) is most applicable to perchlorate, RDX, and HMX. Under appropriate hydrogeochemical conditions, perchlorate, RDX, and HMX are relatively conservative and are rapidly transported through the unsaturated zone with little or incomplete sorption. For a precipitation event of one day, the wetting front containing the dissolved energetic compound is likely small and moves in plug-type fashion, i.e., there is little tailing effect because RDX, HMX, and perchlorate are conservative and behave like tracers. The longer and more intense the precipitation event, the deeper the slug of elevated RDX-, HMX-, and perchlorate-contami- 
nated water moves vertically through the soil. Once the wetting front has migrated below the zone of soil containing source material, RDX, HMX, and perchlorate are typically not detected because the particulates are not present at depth and the mass of the contaminant dissolved in the soil pore-water is small in comparison to the total mass of soil analyzed. Specifically, the analytical method used (Method 8330) detects approximately the same amount of mass whether the sample is water or soil. However, pore-water comprises only a few percent of the soil sample mass. Thus, if the explosives are found only in the pore-water and not in the soil, substantial dilution occurs as a result of the much greater mass of soil relative to water. To test this hypothesis, pore-water sampling was conducted at Camp Edwards (Clausen et al. 2004c) and CFAD Dundurn (Martel et al. 1998) and demonstrated the presence of energetic compounds consistent with concentrations measured for surface soils. Besides dilution with soil, as the wetting front moves deeper, energetic compounds are probably dispersed heterogeneously, as has been shown in migration studies involving non-aqueous phase liquids (Pankow and Cherry 1996). Moreover, porewater affected by the dissolution of explosive particulates in surface soil is just as randomly distributed as the particulates. Therefore, dissolved explosives may not be present in every sample collected from the vadose zone (i.e., below $0.6 \mathrm{~m}$ bgs). These factors explain why RDX, HMX, and perchlorate are not observed in subsurface soil samples despite the presence of underlying groundwater contamination.

In contrast to the compounds discussed in the preceding paragraph, TNT, 2a-DNT, 4a-DNT, 2,4-DNT, 2,6-DNT, and NG are susceptible to degradation and adsorption processes such as attachment to soil humus (Thorne and Leggett 1997). The degradation of TNT is often apparent from the presence of degradation products 2a-DNT, 4a-DNT, and 2,4-diamino-6nitrotoluene (2,4-DANT) in the upper few feet of soil. At most sites a thick vadose zone and low initial soil concentrations result in the attenuation of NG and the dinitrotoluenes (DNTs) before reaching groundwater. Furthermore, Jenkins et al. (2003) estimated the half-life of NG in moist, vadose soils to be less than one day and concluded NG is too unstable to leach significantly to groundwater. Therefore, groundwater contamination resulting from DNTs and NG in soil is not expected at most military installations. 


\section{Contaminant migration in groundwater}

Once energetic compounds such as RDX, HMX, and perchlorate reach the water table, they will migrate downgradient toward discharge points. Perchlorate moves essentially at the velocity of groundwater, while RDX, HMX, aminodinitrotoluenes (aDNT), TNT, and DNTs are attenuated to some extent. This is apparent at the Camp Edwards Demo 1 plume where RDX, HMX, aDNTs, DNTs, and TNT are retarded in groundwater relative to perchlorate (AMEC 2003a). In the impact area at Camp Edwards, only perchlorate, RDX, and HMX are consistently observed in the groundwater, with occasional detections of 2a-DNT and TNT at two locations (AMEC 2004). At Camp Edwards, the plumes migrate deeper into the unconfined aquifer as they move downgradient as a result of the accretion of uncontaminated recharge (precipitation) and gravity flow. This eventually creates vertically discrete plumes, i.e., a contaminant plume sandwiched between zones of clean water (Section 5). If energetic compounds are present at military installations and have migrated to a confined aquifer, then any contaminant plume will be manifested at the top of the water table. 


\section{Fate and Transport of Energetic Compounds}

This section discusses the fate-and-transport properties (sorption, biodegradation, phototransformation, phytotransformation, dilution, advection, dispersion, diffusion, and dilution) of energetic compounds observed in soil and groundwater. The literature on the environmental fate and mobility of energetic compounds is focused primarily on TNT, RDX, HMX, DNTs, and perchlorate. Thus, these compounds are discussed individually, while a group of less well-studied energetic compounds (tetryl, TNB, NG, PA, PETN) are discussed together. Under each energetic compound, the text is subdivided into sorption, degradation, phototransformation, phytotransformation, dilution, advection, dispersion, diffusion, dissolution, volatilization, and field studies. Explanations of these terms are provided below.

\section{Physical processes}

\section{Sorption to soil}

Sorption is a non-specific term that describes the processes by which a compound leaves a solution and associates with the solid phase (i.e., suspended particles, soil particles, or aquifer solids). Usually, sorption refers to adsorption or absorption. Adsorption is the association of the chemical onto a two-dimensional surface (e.g., complexation on surface of a mineral), whereas absorption refers to association with a three-dimensional surface (partitioning of organic contaminants onto soil organic matter). The term sorption is often used because a solute's interaction with the solid matrix is complex and may involve several simultaneous processes. The subsections below discuss the primary mechanisms comprising sorption. Unfortunately, some published reports do not distinguish among the various processes or use the terms erroneously. Thus, in the chemicalspecific reviews, the original terminology was preserved or the less specific term sorption was used when the description of the process was ambiguous.

Affinity among solutes and the porous media through which they flow can take such forms as surface reactions or the partitioning of a hydrophobic organic molecule into organic material associated with the solids. These 
reactions can range in their degree of reversibility. Sorption is often more efficient and linear at very low contaminant concentrations because the propensity for a compound to associate with solids is often subject to saturation. That is, non-linear sorption may occur with increased chemical concentration in water (i.e., at high solution concentration, sorption becomes less efficient because specific binding sites become filled). The sorption behavior of the energetic compounds varies substantially because of the intrinsic differences between the chemicals as well as site-specific conditions.

Many of the energetic compounds will adsorb onto soil particles or absorb into organic material in the soil. The degree to which this occurs is expressed as the partitioning coefficient $\left(\mathrm{K}_{\mathrm{d}}\right)$ for the compound in the particular soil. A $K_{d}$ value of zero indicates no sorption. Higher $\mathrm{K}_{d}$ values indicate that a greater quantity will sorb to soil. Partitioning coefficients can be affected by a variety of site-specific factors, such as organic matter content, redox conditions, $\mathrm{pH}$, soil texture, identity of clay minerals, etc. As described below, the $\mathrm{K}_{\mathrm{d}}$ values for RDX, HMX, and perchlorate are often less than $1 \mathrm{~L} / \mathrm{kg}$, indicating high mobility in most soils. The $\mathrm{K}_{\mathrm{d}}$ values of SVOCs (which include the propellant compounds), pesticides, herbicides, and PCBs typically range from 10 to $10,000 \mathrm{~L} / \mathrm{kg}$. These compounds are generally immobile in soil/aquifer material. Table A1 summarizes physical and chemical properties, including $\mathrm{K}_{\mathrm{d}}$ values, of most of the energetic compounds of interest. Note that a less specific term describing a soil's ability to sorb a solute is Cation Exchange Capacity (CEC). CEC is affected by the same factors listed above for partitioning coefficients.

\section{Chemisorption (absorption) and adsorption}

The term chemisorption often has been misused or misinterpreted. Chemisorption or absorption might best be described as a chemical process. Nevertheless, because chemisorption is closely linked with and often confused with adsorption, the two processes are discussed together in this subsection. Moore (1962) defines chemisorption as adsorption in which the "adsorbed molecules are held to the surface by bonds comparable with those in chemical compounds." This definition is consistent with the discussion by Huang et al. (1992), which separates chemisorption (absorption) from electrostatic interactions (adsorption). These authors refine the definition by describing inner-sphere bonding (absorption-that requires partial desolvation of the ion) and outer-sphere bonding (adsorption-that involves retention of its solvation sphere), both of which depend on the 
ion's "ionic radius and charge, the strength of water coordination, and other ionic properties." Solvation refers to the interaction of a solute and a solvent. An example is a calcium ion near a silicon dioxide surface. The calcium is hydrated with up to four water molecules. Some of the calcium ions may approach the surface more closely to form weak outer-sphere surface complexes through electrostatic binding or ion-pairing or stronger inner-sphere complexes, primarily through chemical bonding. The latter example is chemisorption or absorption. These differences between ionpairing and chemical bonding are sometimes indistinct and may be a continuum at times. Ion pairing or adsorption means the electrons are not shared from the calcium to the silicon dioxide, but the electrostatic attraction promotes the association. Chemical bonding or absorption means the electrons are shared. Surface analysis methods such as Scanning Tunneling Microscopy have been used to look at surfaces and determine the amount of sharing and conclude whether the complexes are inner or outer sphere.

\section{Organic carbon-based water partition coefficient}

Partitioning coefficients $\left(\mathrm{K}_{\mathrm{d}}\right)$ for organic compounds may be estimated using the measured organic carbon content of the soil and literature values describing a compound's tendency to partition between water and organic matter. The partition coefficient of an organic compound in soil is related to its organic carbon-based water partition coefficient $\left(\mathrm{K}_{\mathrm{OC}}\right)$ by the equation

$$
K d=f O C * K O C
$$

where

$$
f_{\mathrm{OC}}=\text { soil organic carbon content as a mass fraction } .
$$

$\mathrm{K}_{\mathrm{OC}}$ values can be obtained from the literature or may be calculated using empirical formulas relating the octanol-water partitioning coefficient (Kow) to the Koc.

\section{Octanol-water partitioning coefficient}

Octanol-Water Partitioning Coefficient (Kow) values are used to estimate the tendency of a chemical to partition between environmental phases of different polarity. These have been measured for most organic compounds 
and can be found in the literature (Howard 1989, Howard and Meylan 1997, Verschueren 1983, Lyman et al. 1982). Organic compounds with log Kow values less than one are highly hydrophilic, meaning they easily partition to the water phase. Compounds with log Kow values greater than four are nearly insoluble in water and will partition strongly to soil particles. Most SVOCs and pesticides have log $\mathrm{K}_{\mathrm{OW}}$ values greater than four, indicating preferential partitioning to soil. The $\mathrm{K}_{\mathrm{ow}}$ is also used to determine the propensity to bioaccumulate, and if $\log \mathrm{K}_{\mathrm{OW}}$ is less than 3.5, little bioaccumulation occurs (Major et al. 2002).

The most commonly used formula to relate $\mathrm{K}_{\mathrm{OW}}$ to $\mathrm{K}_{\mathrm{OC}}$ is the following:

$$
\mathrm{KOC}=0.63 * \mathrm{KOW} .
$$

\section{Fraction of organic carbon}

Partitioning of a solute onto soil organic carbon can be important if the $f_{o c}$ of the soil or aquifer material is above some critical value. The $f_{o c}$ is the fraction of the soil, on a mass-per-mass basis, composed of organic carbon. Values for $\mathrm{f}_{\text {oc }}$ can be measured directly or they can be estimated based upon the TOC. In areas where the soil has little or no carbonate to interfere with the measurement, TOC values can be directly converted to $\mathrm{f}_{\mathrm{oc}}$.

\section{Solubility}

Water solubility is a measure of the propensity of a compound to dissolve in water. In general, high solubility indicates high mobility in the soil and aquifer and less persistence of the source. Reliable data on water solubility are generally available in the literature. Typically, compounds with solubilities less than $100 \mathrm{mg} / \mathrm{L}$ are considered to have a low solubility. Compounds with solubilities ranging from 100 to $1,000 \mathrm{mg} / \mathrm{L}$ are moderately soluble. Compounds considered highly soluble have solubility values 1,000 $\mathrm{mg} / \mathrm{L}$ and above. When more than one sparingly soluble compound is present, solubility is competitive and is controlled by the mole fraction of the compounds. A consequence of the latter concept is that if two sparingly soluble compounds are present, neither can dissolve to the full extent of its reported aqueous solubility.

Besides competitive solubility, sparingly soluble compounds released to the environment usually do not approach laboratory-derived solubility limits because natural waters have a higher salt content and often lower 
temperatures. Similarly, conditions utilized for determining solubility in laboratory experiments (fine solids, pure solid phase, fast stirring rate, large solution-to-solid ratio, fixed temperature, etc.) are rarely found in natural environments. The size and surface area of individual explosive particles, the degree of weathering, and the rate of dissolution all affect the concentration of explosives in groundwater (Lynch et al. 2002a, b), a fact clearly supported by the studies by Speitel et al. (2002). In the latter studies, RDX, TNT, NG, and DNT achieved only 43 to 60 percent of their respective maximum solubilities. The work by Speitel et al. (2002) also indicated that differences in dissolution rate were apparent between $\mathrm{C}_{4}$, Comp B, and “neat” RDX particulates.

\section{Volatilization}

Volatilization is the movement of the organic compound from a pure phase or water phase into vapor. The vapor may be contained within soils or released to the atmosphere. The tendency of a chemical to volatilize from water is evaluated through its Henry's Law constant $\left(\mathrm{K}_{\mathrm{H}}\right)$ and vapor pressure. Henry's Law constant is the ratio of a compound's vapor pressure to its aqueous solubility and the diffusion coefficients in water and air. Compounds with a Henry's Law Constant greater than $10^{-3}$ atm $/ \mathrm{m}^{3} / \mathrm{mol}$ will volatilize rapidly and compounds with Henry's Law Constant less than $10^{-7} \mathrm{~atm} / \mathrm{m} 3 / \mathrm{mol}$ will volatilize slowly (Lyman et al. 1982). The organic compounds of most relevance to this report are not subject to significant volatilization due to their low vapor pressures and Henry's Law Constants (Table A1).

\section{Advection, dispersion, and dilution}

Once a chemical dissolves in water, advection, dispersion, and dilution reduce the concentration as it migrates away from the source. Advection is the movement of water in the direction of groundwater flow. In the vadose zone, vertical flow dominates; horizontal flow is dominant in the aquifer. Movement of water is not constant throughout a porous media because tortuosity in the flow path causes water in some areas to move faster or slower relative to other areas. This phenomenon "smears out" and dilutes dissolved contaminants. Similarly, dispersion is the longitudinal and transverse spreading of a solute as it moves. In circumstances where a low permeability layer exists, water is deflected around this unit, although minor leakage through the unit also occurs. Dilution involves the mixing of a solution with water that does not contain the solute. For example, as a 
dissolved compound migrates through porous media, mixing of clean and contaminated water occurs, resulting in progressively lower concentrations with increasing distance from the source.

\section{Diffusion}

Diffusion is the incorporation of a compound or metal into the pore water or soil matrix with concentration gradients being the driving force. The magnitude of diffusion is also governed by a compound-specific constant called the diffusivity. Diffusion, therefore, is movement of a solute from a location of high concentration to low concentration. Organic compounds or metals can diffuse into the soil matrix and thus reduce concentrations in the surrounding water. Organic compounds or metals also may diffuse into what are termed "dead-end pores." These are areas of water located between sand grains that are not hydraulically connected with the surrounding water.

\section{Chemical and biological transformations}

Compounds can be transformed because of biological processes, hydrolysis, phototransformation, and reactions with other environmental constituents. The propensity for biological and chemical transformation can often be assessed by the oxidation-reduction status of an environmental system. The oxidation-reduction status is affected by and helps determine which microorganisms are present and determines the dominance of various inorganic species that may affect the sorption of some contaminants. Phototransformation reactions are those requiring natural light. These reactions often require the presence of water as well.

Biological degradation is transformation of the compound by microorganisms. These reactions are controlled by the type of microorganisms present, their adaptation to the chemical of interest, presence of cometabolites, oxidation-reduction status, concentration of the chemical of interest (including its potential toxic effects to microbes), and availability of nutrients. Biodegradation typically reduces the toxicity of an organic compound, but in some cases more toxic products are formed. The environmental half-life (the time necessary for half the chemical mass to be degraded) of an organic compound can vary from minutes to years, depending on the chemical structure of the compound and environmental conditions. 
Biological uptake, other than brief comments on phytoremediation, is not discussed separately in this report, but may be inferred from the fate-andtransport discussions presented below. Phytotransformation is a subset of biological degradation referring to uptake and possible transformation by plants. Because there has been much recent interest and research, phytotransformation is briefly discussed for each of the energetic compounds.

\section{Hydrolysis}

Hydrolysis is an abiotic reaction where a compound or metal reacts with water. A hydrolysis reaction involves the substitution of a water molecule or hydroxyl ion for another atom (or group of atoms) present in an organic molecule. The compound is transformed into a different compound with different properties. There are three forms of aqueous hydrolysis (acid, neutral, and base), which depend on the presence of different species in solution. Thus, different hydrolysis mechanisms can dominate at different $\mathrm{pH}$. A hydrolysis reaction is essentially irreversible. One of the most familiar examples is the hydrolysis reaction for iron, i.e., the formation of rust (Stumm and Morgan 1981). Hydrolysis of iron results in the formation of a host of iron oxyhydroxide species depending upon the $\mathrm{pH}$, concentration of iron, and effects of competing ions. There is a great deal of inorganic chemical research and information on hydroxo and oxo-complexes and the stability of hydrolysis species.

There is also a great deal of information regarding the hydrolysis and rates of hydrolysis of organic compounds (Washington 1995). An example is the reaction of 1,1-dichloroethane with water forming, among other things, chloroethene. Most of these reactions are not environmentally significant because they are more favored at extremes of $\mathrm{pH}$. They can, however, account for occasional, spurious, trace detections of an unexpected compound. Explosive organic compounds are generally resistant to hydrolysis except at pHs greater than 9.0 (McGrath 1995).

\section{Aqueous speciation}

Speciation refers to the chemical form in which a compound occurs in natural waters. Besides the more familiar examples of acid/base forms (e.g., ammonia to ammonium $\left[\mathrm{NH}_{3} / \mathrm{NH}_{4}{ }^{+}\right]$), examples mentioned by Stumm and Morgan (1981) include colloidal metal-ion precipitates such as iron hydroxy oxides or organic substances assisting in the formation of stable colloidal dispersions. These authors note that only recently has the 
research community adequately realized the complexity of speciation and its importance in determining what can occur in natural waters.

\section{Aqueous complexation}

A complex is "a dissolved species formed from two or more simpler species, each of which can exist in aqueous solution" (Drever 1988). Hence, complexation usually refers to a metal ion being associated with various ligands. A familiar example is the hardness titration using ethylenediaminetetraacetic acid (EDTA) to tie up calcium and/or magnesium. Another example is the complexation of uranium with carbonate. Depending on the $\mathrm{pH}$ and carbonate content, neutral to doubly charged compounds can be formed, which vary considerably in size and mobility. The term aqueous also refers to aqua-compounds, that is, to complexation with water. Again, iron and aluminum are familiar examples (Drever 1988), but many metastable (or momentary associations) aqua-complexes involving organics are present in natural waters. Complexation processes are unlikely to be important at most military sites because of the low concentration of complexing species (e.g., dissolved organic matter) in the water and because of the chemical nature of the COPCs (i.e., unionized species).

\section{Abiotic reduction}

Numerous mineral reduction reactions are usually considered abiotic. An example is the reduction of $\mathrm{Cr}^{6+}$ by iron and manganese oxides. Research by Chapelle (1993) suggests most or all classically described abiotic reduction reactions are microbially mediated, although the microbes have not been identified in every case. An example is the reduction of ferric iron $\left(\mathrm{Fe}^{+}\right)$to $\mathrm{Fe}^{2+}$, which was considered abiotic in the 1970s, but is now known to be microbially mediated. An example of an organic abiotic reaction is the spontaneous dehydrohalogenation of 1,1,1-trichloroethane (1,1,1-TCA) to 1,1-dichloroethene. 1,1,1-TCA can also degrade abiotically to acetic acid. Compounds often will undergo a series of reactions that include both abiotic and biotic reactions, such as the interaction of TNT and 4a-DNT with humic monomers in the presence of oxidative enzymes (Wang et al. 2002). In this case, both an enzymatic reaction and an abiotic reaction are involved in the transformation. 


\section{Polymerization and dimerization}

True polymerization (Morrison and Boyd 1968) is the more-or-less infinite repeating of identical units (such as the formation of PVC). This is different from the formation of polynuclear complexes, which are usually structurally different as more ligands are added. A true organic polymer may have a link R-X and the polymer itself is RX-RX-RX, i.e., a long linear string. An inorganic polynuclear complex can grow in all directions; therefore, it does not satisfy the classic definition of a polymer. Dimerization is a subset of polymerization where only a dimer (two repeating links) is formed. Hydrolysis reactions are common examples. An example from Stumm and Morgan (1981) is the dimerization of cupric hydroxide $\left(\mathrm{CuOH}^{+}\right)$to cuprous hydroxide, $\mathrm{Cu}_{2}(\mathrm{OH})_{2}{ }^{+2}$. Compounds such as these can be precursors to polynuclear complexes. Study of these complexes is difficult because they age (slowly change structure and composition with time) and can be truly metastable (never a clear-cut structure). The interest with aluminum and iron, in particular, is that the more polynuclear the complex becomes, the more blurred the distinction between dissolved and solid becomes. Colloids of these polynuclear types pass through filters and can be efficient adsorbers of contaminants.

\section{Energetic compound fate-and-transport properties}

\section{2,4,6-trinitrotoluene (TNT)}

Trinitrotoluene is a single-ring nitroaromatic compound (Fig. 6), a crystalline solid at room temperature with an empirical formula of $\mathrm{C}_{7} \mathrm{H}_{5} \mathrm{~N}_{3} \mathrm{O}_{6}$, and a molecular weight of $227 \mathrm{~g} / \mathrm{mol}$. TNT's water solubility (approximately $150 \mathrm{mg} / \mathrm{L}$ ) and vapor pressure are relatively low, but greater than those of RDX and HMX (Table A1).

Sorption

Partition coefficients reported by most investigators indicate soils have a high capacity for rapid sorption of TNT. For example, at a concentration of $6.3 \mathrm{mg} / \mathrm{L}, 85$ percent of the applied TNT was retained on the soil with sorption occurring in fewer than seven days (McGrath 1995). Greene et al. (1985) reported that a soil they investigated had a TNT carrying capacity of $630 \mathrm{mg} / \mathrm{kg}$. Similarly, Willis (2002) reported 95 percent of the TNT released by a land mine was retained by the soil, with most of the remaining five percent associated with water. TNT, however, is not retained significantly by a soil's sand fraction, because only two percent of the applied 
TNT was retained on pure sand (Myers et al. 1998a). The $\mathrm{K}_{\mathrm{d}}$ for this sand was $1.5 \mathrm{~L} / \mathrm{kg}$ (Townsend et al. 1995), demonstrating that soils low in clay and organic matter sorb very little TNT. More extensive studies by Townsend and Myers (1996) report a range of $\mathrm{K}_{\mathrm{d}} \mathrm{s}$ from o to $56 \mathrm{~L} / \mathrm{kg}$, depending on soil type. There is apparently a concentration effect for adsorption, because Comfort et al. (1995) reported a smaller percentage of TNT flushed through the soil when initial TNT soil concentrations were lowest and a higher percentage migrated at very high concentrations. Non-linear sorption is typical for organic compounds and may explain conflicting results reported by several of the investigators (Myers et al. 1998a, Townsend and Myers 1996).

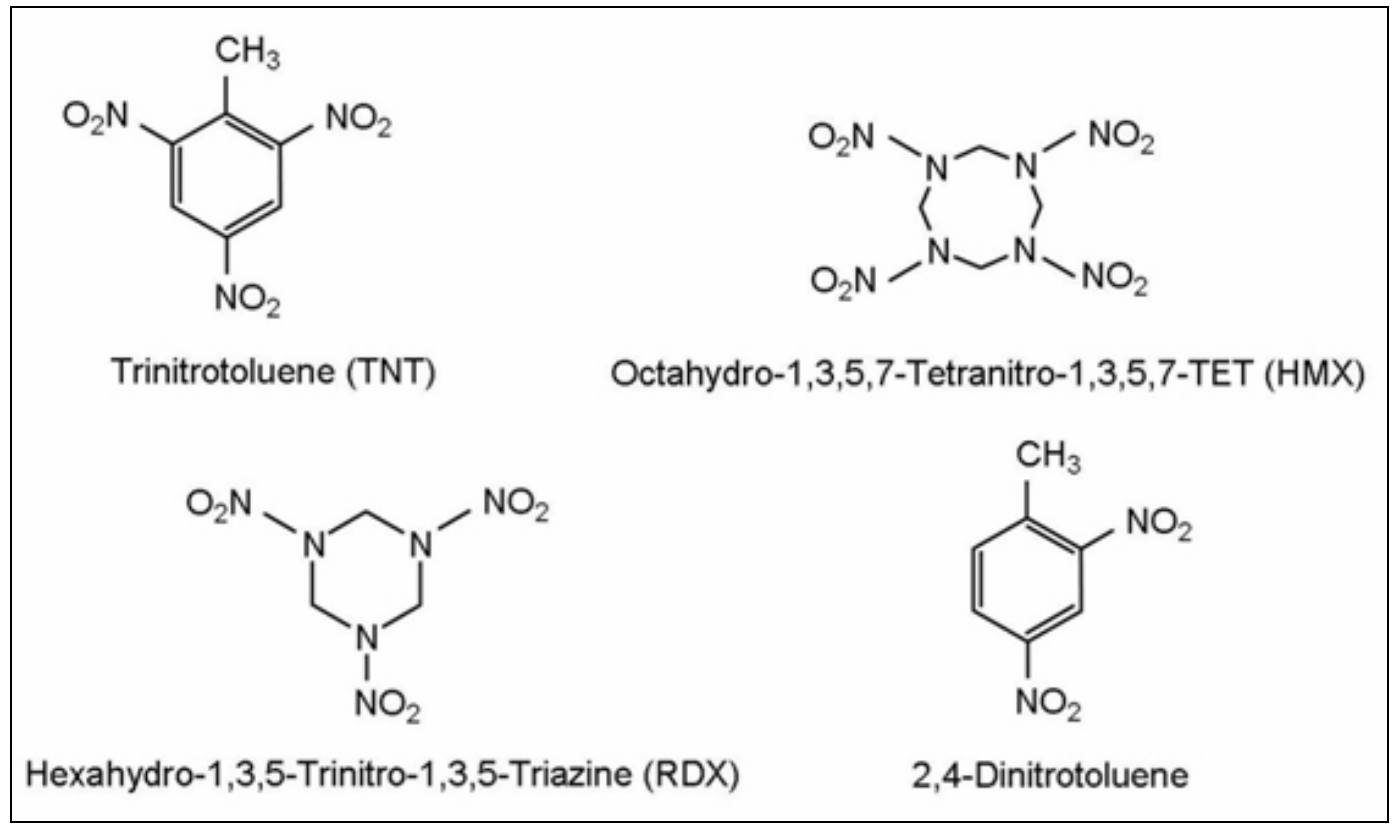

Figure 6. Chemical structures of trinitrotoluene (TNT), hexahydro-1,3,5-trinitro-1,3,5-triazine (RDX), octahydro-1,3,5,7-tetranitro-1,3,5,7-TET (HMX), and 2,4-dinitrotoluene (2,4-DNT).

Typical redox conditions have little effect on TNT sorption. One study reported that up to 50 percent of the total TNT mass was removed from solution by the soil (Selim and Iskandar 1994) under both aerobic and anaerobic conditions (Myers et al. 1998a, Brannon et al. 1992, Hale et al. 1979). Another study examined $\mathrm{Eh}, \mathrm{pH}$, and clay content. Eh and $\mathrm{pH}$ exerted no influence on the degree of adsorption or desorption, whereas a higher clay content resulted in greater adsorption (Pennington 1988). In other studies, however, highly reducing conditions (Eh $<-150 \mathrm{mv}$ ) consistently enhanced removal (Pennington 1988, Pennington and Patrick 1990). Caution is necessary when reviewing early studies because the degree of sorption versus transformation was not differentiated. The 
critical role of transformation processes was not recognized until the late 1990s.

Another difficulty in describing and predicting TNT removal by the soil matrix is that degradation products compete with the parent compound for sorption sites (Brannon et al. 1992) and may be irreversibly bound (Harvey et al. 1990). Hence, the extent of degradation and subsequent production of transformation products may affect results from adsorption studies. Although irreversibly bound TNT and degradation products have been reported, some investigators (Haderlein et al. 1996, Xue 1995, Ainsworth et al. 1993) found TNT sorption reversible under certain conditions. In contrast, Pennington et al. (1995), Pennington (1988), Kaplan and Kaplan (1983, 1982a, b), and Comfort et al. (1995) found a significant portion of the TNT irreversibly bound to the soil. For example, laboratory column studies of soils from 14 Army Ammunition Plants (AAP) by Pennington (1988) indicated rapid adsorption and significant retention of TNT to all soils. Site-specific soil conditions and the duration of the various experiments may explain the apparently divergent results. For instance, Pennington (1988) reported that TNT and its degradation products, probably because of humification, became less easily extractable with time. It may be noted that the extraction methods referred to in this paragraph are considerably harsher than percolating rainwater. Hence, if the TNT cannot be extracted readily using strong solvents, acids, or bases, it is unlikely to be available for leaching and migration through the vadose zone.

Effects of soil organic matter were examined by Price et al. (1997a), who found sorption occurred under a wide range of conditions when 1 to 3 percent organic carbon was present. Li et al. (1997) reported TNT and the aDNTs were bound in soil by humic acids. Kaplan and Kaplan (1983) also found TNT bound to organic material. Nevertheless, most studies report that the inorganic components of soil (clay, iron oxyhydroxides, base saturation) are more important than the organic matter content in predicting sorption (Weissmahr et al. 1999; Myers et al. 1998b; Haderlein et al. 1996; Leggett 1991, 1985; Pennington 1988).

Demonstrating the role of inorganic surfaces, studies by Larson et al. (1998) reported TNT and one of its degradation products, 2,4,6triaminotoluene (TAT), sorb within the interlayer of expandable clays. Pennington and Patrick (1990) observed a positive correlation between TNT sorption (as represented by a single $K_{d}$ value of 4.0), extractable iron, 
and CEC. Taken together, these studies indicate TNT sorbs readily whether a high or low fraction of organic carbon is present. Field studies demonstrate most TNT is retained in the top 3 to 6 inches of soil (Checkai et al. 1993a, b, c). Consequently, sorption is usually less in aquifer soils than in surface soils, presumably due to lower clay and organic matter content (Price et al. 2000).

The study of Weissmahr et al. (1999) provides the most comprehensive examination of the competing processes affecting TNT sorption. Trinitrotoluene sorption to NOM (natural organic matter) was low compared to clays, although the interaction with clays depends strongly on the type of exchangeable cations (i.e., base saturation). The authors did acknowledge reports of TNT and the aDNTs being removed from aqueous solution by colloidal NOM, but the nature of these interactions had not been described. According to Weissmahr et al. (1999), the dominant sorption mechanism to clay is an electron-donor complex formation between siloxane oxygen's (sigma-donors) and the nitroaromatics (pi-acceptors). High surface densities of strongly hydrated cations (sodium and calcium) reduce the accessibility of siloxane sites for nitroaromatics, whereas weakly hydrated and less bulky ions such as potassium or ammonium promote inner sphere complexes at siloxane sites. The singular feature of this work is that it evaluated mixed ionic conditions and complex natural matrices. Aquifer material with less than 1 percent NOM and 3 to 5 percent clays had similar sorption features as pure clay minerals, suggesting that sorption to the bulk aquifer matrix was dominated by complex formation at the clays. These lab findings were applied to a two-step field process designed to manipulate mobility of the explosives by injection of electrolytes using 4-nitrotoluene (4-NT) as a test compound. When injected with potassium chloride, much of the 4-NT was sorbed, but it was remobilized with subsequent injection of calcium chloride. These results were confirmed by subsequent experiments with TNT and related nitroaromatics. Soil distribution coefficient values were compared for TNT and 1,3-dinitrotoluene (DNB) for various aquifer background electrolyte concentrations. The $\mathrm{K}_{\mathrm{d}}$ for TNT approached $10 \mathrm{~L} / \mathrm{kg}$ when the electrolyte was potassium, but dropped to less than $1 \mathrm{~L} / \mathrm{kg}$ when the electrolyte was high in calcium.

\section{Degradation}

Trinitrotoluene transformation is reported to occur in any aerobic environment and many organisms are capable of aiding transformation (Spanggord et al. 1980b). Hence, transformation will occur in surface 
water and groundwater. For example, Townsend and Myers (1996) calculated a TNT half-life in groundwater of 28-360 days. Similarly, in a test of aquifer soils from the Louisiana Army Ammunition Plant, Price et al. (2000) found TNT to be unstable under any Eh or $\mathrm{pH}$ conditions, particularly in the presence of glucose. Significant biotransformation products have been identified in several studies (Table 4). These same processes occur in groundwater, although typically to a lesser extent, because there is usually less clay and organic matter than in surface soils.

Table 4. Biotransformation products of 2,4,6-trinitrotoluene (TNT).

\begin{tabular}{|l|l|}
\hline \multicolumn{1}{|c|}{ Product } & \multicolumn{1}{c|}{ Reference } \\
\hline 1,3,5-trinitrobenzene (TNB) & Kaplan 1995, Burlinson et al. 1973 \\
\hline 3,5-dinitroaniline (3,5-DNA) & Jenkins et al. 1998, Spanggord et al. 1980b \\
\hline 2-amino-4,6-dinitrotoluene (2a-DNT) & Spanggord et al. 1980b, Hoffsommer et al. 1978 \\
\hline 4-amino-2,6-dinitrotoluene (4a-DNT) & Spanggord et al. 1980b, Hoffsommer et al. 1978 \\
\hline 2,4-diamino-6-nitrotoluene (2,4-DANT) & Spanggord et al. 1980b, Hoffsommer et al. 1978 \\
\hline 2,6-diamino-4-nitrotoluene (2,6-DANT) & Spanggord et al. 1980b, Hoffsommer et al. 1978 \\
\hline
\end{tabular}

Trinitrotoluene not sorbed onto soil is usually transformed rapidly. The half-life of TNT added to soils in an aqueous solution is typically on the order of days (Jenkins et al. 200ob). Previous work by Rodacy and Leslie (1992) determined the half-life of TNT to be one year in a desert environment based on a field study by DuBois and Baytos (1972). Pseudo firstorder rate constants of 0.0017 to $0.14 / \mathrm{hr}$ with half-lives equaling four weeks to 12 months also have been reported (Townsend and Myers 1996). Similarly, column studies by Greene et al. (1985) indicated all of the TNT had been biotransformed or retained onto the soil, irreversibly bound, over a 110-day period. Although rapidly transformed, TNT and some of its degradation by-products are persistent in natural systems because of incomplete degradation. Indeed, complete mineralization of TNT has not been demonstrated even under optimal laboratory conditions (Achtnich et al. 1999, Van Beelen and Burris 1995). Complete mineralization is possible only under highly controlled conditions with a co-metabolic process. Also, at concentrations greater than $50 \mathrm{mg} / \mathrm{kg}$, TNT is sufficiently toxic to inhibit the growth of most fungi, yeasts, and gram-positive bacteria (Major 1999).

Biological reduction of one or more of TNT's nitro groups occurs in both aerobic and anaerobic environments, with the reaction rate increasing as 
conditions become more reducing (Price et al. 2001). Trinitrotoluene biotransforms to the aDNTs, which transform to several other products, including azo, azoxy, acetyl, and phenolic derivatives. All biotransformations leave the aromatic ring intact (Hawari et al. 2000a, b). Transformation products identified in TNT "pink water" (usual color of wastewater from TNT manufacturing plants) were 2a-DNT, 4a-DNT, 2,4-DANT, and 2,6diamino-4-nitrotoluene (2,6-DANT) before culminating in the formation of TAT (Hwang et al. 1999).

Some aerobic bacteria and numerous bacterial strains can degrade daughter products of TNT, but Rosser et al. (2001) concluded "the scope for complete mineralization of TNT" by aerobic systems "may be of limited use" because of the "formation of dead-end metabolites." Hydroxylamines and the mono and di-amino nitrotoluenes are the principal microbial transformation products. Hydroxylamines are reactive unstable compounds, which are not typically observed in natural environments. Formation of unknown transformation products or products unextractable without destruction of the molecule have been observed by several researchers (Myers et al. 1998b, Price et al. 1997a) and accounted for 50 percent of the mass loss with a clay soil (Brannon and Myers 1997).

Degradation of aromatic pollutants similar to TNT by aerobic bacteria usually occurs initially by electrophilic attack by oxygenases on the ring system (Rosser et al. 2001). While occurring to a certain degree with mononitroaromatic and dinitroaromatic compounds, the ring becomes more resistant to attack with increasing nitro groups. Thus, electrophilic attack has not been reported for TNT. Instead, the nitro groups are reduced via a rarely isolated nitroso-intermediate and a hydroxyl aminointermediate to an amine. Hydroxylamines and amines also can form a wide range of covalent adducts, including attachments with biological molecules.

In anaerobic systems, complete transformation of TNT to by-products is common (Price et al. 1997a). The predominant by-products are 2a-DNT (Thorne and Leggett 1999; Myers et al. 1998b; Brannon and Myers 1997; Price et al. 1997a, b; Checkai et al. 1993a, b, c; Walsh and Jenkins 1992; Pennington 1988; Kayser and Burlinson 1982; Craig et al. 1997), as well as 4a-DNT, 2,4-DANT (Townsend et al. 1995), and 2,6-DANT (Townsend et al. 1995, Pennington 1988). Olin et al. (1996), Townsend et al. (1995), and Pennington (1988) observed a preponderance of 4a-DNT over 2a-DNT. 
Townsend and Myers (1996) also report the preferred reduction pathway as TNT $\rightarrow 4 \mathrm{a}-\mathrm{DNT} \rightarrow 2,4$-DANT. Other transformation products observed include 1,3,5-trinitrobenzene (TNB), 2,4,6-trinitrobenzaldehyde (TNBa), and 3,5-dinitroaniline (3,5-DNA) (Walsh and Jenkins 1992). Townsend et al. (1995) also reported 2,4-DNT, 2,6-DNT, and 3,5-DNA. Brannon and Myers (1997) and Townsend et al. (1995) found that increasing contact time resulted in increased production of transformation products and decreased TNT concentration with the formation of azoxy compounds favored when the soil $\mathrm{pH}$ is greater than 7 . Deep aquifer soils under reducing conditions had only 4a-DNT and 2,4-DANT present (Price et al. 2001).

Conditions for forming TAT typically occur only with facultative anaerobes and added nutrients in the absence of oxygen and light. Although such conditions yield TAT, ring cleavage still is not observed. The fermentative bacteria Clostridium (obligate anaerobes found in soil, lake sediments, and the intestinal tracts of certain animals) have been identified as eventually transforming TNT to TAT. The initial primary products of TNT transformation by Clostridia, however, are not aminated derivatives but aryl hydroxylamines. Such intermediates of the DNTs had been proposed, but not isolated. Recent research (Hughes et al. 1999) isolating these intermediates is important because hydroxyl amino intermediates often are more mutagenic than their parent compounds. Previous studies using diverse anaerobic inocula generally have cited aDNTs as primary end products from 2,4- and 2,6-DANT. Apparently, the recent isolation of these intermediates was due to improved sample handling and analysis methods.

Triaminotoluene formation in "pink water" has been reported as stoichiometric (actually greater than 75 percent) (Hwang et al. 1999). Under anaerobic conditions, therefore, TNT undergoes step-wise reduction to TAT wherein the formation of 2,4-DANT is the rate-limiting step. Triaminotoluene is sometimes considered a dead-end by-product, which binds irreversibly in the soil. Triaminotoluene, however, was amenable to further anaerobic degradation, but its fate was not determined, although the authors believe it is mineralized to methane and carbon dioxide or bound to organic matter. Experiments with TAT by Thorne and Leggett (1999) indicate that reduction of the nitro groups appears to be necessary for it to bind to soil organic matter. Adsorption increases with the number of amine groups. However, when all three nitro groups are replaced with amines to form TAT, covalent bonding to soil humic acid occurs. In contrast, aDNTs and 2,4-DANT interact reversibly with the soil. Triami- 
notoluene can degrade under aerobic conditions in the presence of certain metals, especially manganese. Denitration of TNT or of the amino-reduced metabolite (TAT) would be a desired degradation route because such a process might lead to ring cleavage and mineralization, but evidence for the occurrence of such processes is controversial.

Abiotic reduction of TNT also has been observed with the following transformation products identified: 4,4,'6,6-Tetranitro-2,2' azoxytoluene (4,4AZOX) and 2,2,6,6'-tetranitro-4,4' azoxytoluene (2,2AZOX) (Brannon et al. 1998). Price et al. (2000) saw the transformation products 4a-DNT, 2a-DNT, and 4,4AZOX, with the 4,4AZOX disappearing within 24 hours in surface soils.

Oxidative coupling of nitroaromatic compounds to soil organic matter was examined by Wang et al. (2002). Humic monomers were used as surrogates for soil humic substances. Oxidative biocatalysts were used to transform TNT and 4a-DNT. Without the humic monomer for a co-substrate, only 30 percent of the 4a-DNT and none of the TNT were transformed. Adding various humic monomers demonstrated that the xenobiotics are preferentially bound to quinoid and phenolic moieties. For example, in the presence of the humic monomer catechol, up to 100 percent of the 4a-DNT and up to 80 percent of TNT were transformed. A pH effect was observed with $4 \mathrm{a}-\mathrm{DNT}$ transformations reaching a maximum at 6.8 , whereas higher $\mathrm{pH}$ values increased TNT transformation. A two-step reaction mechanism was proposed: initial oxidation of the humic polymer to a semi-quinone radical followed by oxidative coupling with additional humic monomers or anilinic products derived from TNT to form anilinoquinone via nucleophilic addition or a benzoquinone-imine through condensation.

Abiotic and biotic mechanisms have been considered for TNT dissolved in water. With respect to the former, Hoffsommer and Rosen (1972) demonstrated that a seawater solution at a pH of 8.1 with $95 \mathrm{mg} / \mathrm{L}$ of TNT underwent no change in concentration after 108 days. The results of Hoffsomer's study suggest that TNT does not hydrolyze in water under neutral conditions. Apparently, nitroaromatics are, in general, resistant to hydrolysis (Lyman et al. 1982).

\section{Phototransformation}

Photodegradation of TNT is possible if standing water is present for any length of time and TNT present in the soil dissolves into the water 
(Schmelling et al. 1996; LeFaivre and Peyton 1994; Spanggord et al. 1980a, b; Burlinson 1980; Andrews and Osmon 1975). TNT photodegradation is reportedly faster than biodegradation by a factor of 1,000 (Spanggord et al. 1980b). A study using Potomac River water spiked with $20 \mathrm{mg} / \mathrm{L}$ TNT and microbial sediments showed complete disappearance of TNT in 6 to 8 days in sunlight, while up to 730 days were required for 90 percent disappearance in shade (Burlinson 1980). The reaction is presumed to occur via a triplet-sensitized mechanism that either permits a weak nucleophile to attack and remove a $\mathrm{NO}_{2}$ or $\mathrm{X}$ group, or allows the formation of a complex with humic acid increasing the favorability of ultraviolet absorbance and, therefore, photodegradation (Spanggord et al. 1980b, Rosenblatt et al. 1989, Mabey et al. 1983).

Other laboratory tests demonstrated that the phototransformation half-life ranged from 3 to 22 hours, depending on the length of light exposure (Spanggord et al. 1980b). It is important to realize, however, that photocatalytic degradation is not an effective method for TNT removal because end products often are as toxic and mobile, if not more so, than the parent compound (Schmelling et al. 1996). Burlinson et al. (1973) identified a number of photolytic by-products, including TNBa, TNB, and trace amounts of 2,2AZOX, 4,4AZOX, and 2,4'-dimethyl-3,3',5,5'-tetranitroONN-azoxybenzene. Apparently, fewer by-products are produced with less exposure time (Burlinson 1980; Spanggord et al. 1980a, b). The compound 3,5-DNA (also reported by Schmelling et al. 1996) was observed when both TNT and RDX were present (LeFaivre and Peyton 1994). Andrews and Osmon (1975) reported unidentifiable volatile products.

\section{Phytotransformation}

TNT does not seem to bioaccumulate in animals, but is taken up by plants. Plant uptake, however, is inversely proportional to soil organic matter, indicating that TNT bound to humic acids is no longer available.

A study by Thorne (1999) exposed Kenaf (Hibiscus cannabinus) to TNT, either in soil or in irrigation water. Little growth was observed in soil containing TNT, but normal growth occurred when the soil was irrigated with water containing TNT. Uptake and transformation of TNT was sufficient for Kenaf to be considered a candidate for phytoremediation. Trinitrotoluene was found mostly in the roots. When the exposed plants were permitted to humify in the soil, TNT and its by-products were not recovered. 
These results suggest that, for certain plant species, phytotransformation may be an important fate-and-transport process for TNT.

Larson et al. (1999) used liquid scintillation counting, high performance liquid chromatography (HPLC), and gel permeation chromatography to examine plant tissues following irrigation with water contaminated with TNT and its metabolites. The objective was to identify explosives and their by-products in plant tissues following irrigation. Water contaminated with 1 to $2 \mathrm{mg} / \mathrm{L}$ of an explosive was used to irrigate a variety of plants, including food plants such as radish and tomato. Results demonstrated that the by-products had higher molecular weight, water solubility, and polarity than the parent compound. Moreover, accumulation of low $\mathrm{mg} / \mathrm{L}$ levels was found per $100 \mathrm{mg}$ of green tomato. Results also demonstrated differences in uptake between terrestrial and aquatic plants. Furthermore, both 2a- and 4a-DNT were found in plant tissues. Concentrations of the latter two compounds did not change after one month of irrigation. The authors assumed plant uptake had not stopped, but the presence of 2a- and 4aDNT had reached a steady state and some was being transformed in the plant.

Soil-plant transfer, translocation in the plant, and the extent to which various explosive compounds were metabolized were studied by Cataldo et al. (1993a, b). After 60 days, only 30 percent of the amended TNT remained unchanged. The order of plant availability was, in decreasing order, RDX, tetryl, and TNT, with the extent of plant uptake being dependent on soil type (sand being the greatest, followed by silt and organic soil) and plant species. Trinitrotoluene residues were found mostly in the roots while RDX was found mostly in the leaves and seeds. The principal transport form of TNT was as an acid-labile conjugate of aDNT. On roots and leaves, highly polar and non-extractable TNT metabolites dominated with the aDNT isomers, accounting for less than 20 percent of the residues present. Only a few percent were present as the parent TNT.

In summary, TNT is transformed in plants, and most of the parent compound and transformation products are found in the roots. Hence, phytotransformation may have some applicability for TNT. Any use of phytoremediation, however, requires more research regarding the fate and toxicity of the metabolites (Thompson et al. 1998). 


\section{Dilution/advection/dispersion/diffusion}

Dilution, advection, and dispersion will cause spreading of the TNT in soil and vadose zone. Two studies specifically discussed diffusion and reported it as the limiting step for the leaching of TNT from soil into water (Valsaraj et al. 1998, Qaisi et al. 1996). The diffusive nature of the process was demonstrated by a decrease in the aqueous effluent TNT concentration and flux from soil with time. The average effective diffusivity obtained was $1.18 \mathrm{E}-7 \pm 8.32 \mathrm{E}-8 \mathrm{~cm}^{2} / \mathrm{s}$. From these experiments, Valsaraj et al. (1998) calculated a characteristic time for transport of approximately seven years as compared to the first-order degradation rate by plant enzymes of 70 minutes. Hence, slow transport of TNT from the soil bed is a limiting factor in the phytoremediation or bioremediation of TNT. Fluxes were, in decreasing order, TNT, tetryl, DNT, and TNB. A lysimeter study conducted by Conley and Mikucki (1976) also indicated limited TNT migration. Similarly, laboratory studies of intact sandy loam soil cores from the Radford AAP indicated that TNT, TNB, 2,4-DNT, 2,6-DNT, 2a-DNT, and 4a-DNT migrated less than three inches over a nine-month period (Checkai et al. 1993a, b, c).

In the vadose zone and in groundwater, TNT and its remaining byproducts (adsorption and degradation) undergo mixing, which results from advective transport through the porous media (dispersion). This spreading of the dissolved contaminant mass reduces the concentration. For example, at Demo 1 at Camp Edwards (Section 6), TNT is found in the groundwater, but persists for only a short distance before being removed by natural processes.

\section{Dissolution}

Trinitrotoluene's solubility (typically reported as approximately $130 \mathrm{mg} / \mathrm{L}$

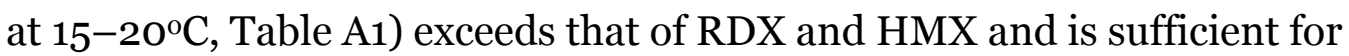
dissolved concentrations to exceed USEPA lifetime health advisory (HA) limits (Lynch et al. 2002a, 2001; Phelan and Barnett 2001). Recent research demonstrated that there is no significant effect on solubility over the $\mathrm{pH}$ range 4.2 to 6.2, but temperature exerts a large influence, with the solubility being approximately $50 \mathrm{mg} / \mathrm{L}$ near $2^{\circ} \mathrm{C}$, approximately $100 \mathrm{mg} / \mathrm{L}$ near $20^{\circ} \mathrm{C}$, and approximately $210 \mathrm{mg} / \mathrm{L}$ near $36^{\circ} \mathrm{C}$ (Lynch et al. 2001).

The dissolution rates of TNT, RDX, and HMX as functions of temperature $\left(10,20\right.$, and $\left.30^{\circ} \mathrm{C}\right)$, surface area, and energy input (mixing rate) also have 
been examined recently (Lynch et al. 2002b). Particle sizes encountered in the field were assumed to vary from $0.04 \mathrm{~mm}$ in diameter (for HMX crystals) to greater than $4 \mathrm{~mm}$ in length for TNT flakes. Surface areas for RDX and HMX were estimated using mass-to-surface-area ratios for each explosive based on military specifications for acceptable granulation distribution. TNT's surface area was obtained by weighing and measuring flakes after selection with a microscope. The nominal surface areas used did not account for surface roughness observed microscopically. Measurements were made while two variables were held constant and one was varied. Each variable yielded a linear correlation with temperature exerting the most influence over the range of conditions evaluated. For example, at $10^{\circ} \mathrm{C}$, the dissolution rate of TNT varied from approximately 0.03 to 0.09 $\mathrm{mg} / \mathrm{min}$ as the mixing rate varied by a factor of slightly more than 2 . Under the same mixing conditions, but at $30^{\circ} \mathrm{C}$, TNT's dissolution rate varied from approximately 0.14 to approximately $0.34 \mathrm{mg} / \mathrm{min}$. Similarly, varying TNT's surface area from approximately 6 to $9 \mathrm{~cm}^{2}$ with a constant temperature at $10^{\circ} \mathrm{C}$ yielded dissolution rates varying from approximately 0.05 to approximately $0.07 \mathrm{mg} / \mathrm{min}$. However, at $30^{\circ} \mathrm{C}$ and otherwise the same conditions, the dissolution rate varied from approximately 0.23 to approximately $0.31 \mathrm{mg} / \mathrm{min}$. These data demonstrated that dissolved concentrations could exceed the USEPA HA limit of $0.002 \mathrm{mg} / \mathrm{L}$ for TNT. Trends were similar for RDX and HMX, although ranges in dissolution rates were significantly less compared to the more soluble TNT. TNT also had a faster dissolution rate than RDX or HMX.

Correlation equations incorporating the three test variables were developed and might have applicability to sites such as Camp Edwards. The major difficulties are to determine how best to estimate mixing rate and surface area, and how to account for seasonal variations in temperature and rainfall. Although the developers of the correlation equations used realistic surface areas based on military formulations, there is evidence for much larger "chunks" (e.g., baseball-sized) of HE at other sites (Hewitt et al. 2005; Jenkins et al. 2005b, 2004a, c; Taylor et al. 2004b; M. R. Walsh et al. 2005). Similarly, as described below, the dissolution rate varies greatly depending on the manner in which the water and $\mathrm{HE}$ are combined. An additional problem is the slower dissolution rate presumed because the HE compounds may be protected by sorbing to soot produced during the blast (see Sections 6 and 7). The soot provides a non-wetting surface and inhibits direct contact of the HE with water. 
Solubility and dissolution rates also have been determined for TNT, RDX, and HMX in the formulations octol, Comp B, and LX-14, as well as mixtures of the three individual compounds comprising these formulations (Lynch et al. 2002b). Experiments were conducted at 10, 20, and $30^{\circ} \mathrm{C}$ with a constant mixing rate of 2.5 revolutions per second. The solubilities of the individual compounds from formulations and mixtures were comparable to those of the individual compounds as measured independently. Although dissolution rates for TNT and HMX were slightly higher and RDX slightly lower from the mixtures, the rates were comparable to those of the individual compounds. The authors believed the latter effects resulted from differences in physical abrasion of particles during mixing. NT and HMX particles were entrained during mixing, whereas the RDX fell to the bottom of the container and was shielded. Dissolution rates were suppressed somewhat in octol but not in the other formulations as compared to the individual compounds. Other observations included the following: 1) military-grade RDX had sufficient HMX for the latter to attain its solubility limit in solution; 2) TNT contained detectable quantities of TNB; 3) Comp B contained sufficient HMX for the compound to attain saturation in solution and also contained detectable quantities of TNB, DNB, and 2,4DNT; and 4) octol contained detectable quantities of RDX and TNB.

Other relevant data come from column experiments conducted to evaluate dissolution from HE particles at Camp Edwards (Speitel et al. 2002). Experiments were performed with two different flow conditions using $\mathrm{C}_{4}$ and Comp B in 2-inch-diameter glass columns. The flow conditions used were continuous flow and flow/no-flow cycling. The columns were prepared with $0.5 \mathrm{~g}$ of Comp B mixed with $80 \mathrm{~g}$ of clean deep soil from Camp Edwards. A total of 160 and $80 \mathrm{~g}$, respectively, of clean deep soil were placed above and below the soil-explosive mixture. For the continuous flow tests, simulated rainwater was pumped at $0.14 \mathrm{~mL} / \mathrm{min}$ for the first 72 hours, then at $0.42 \mathrm{~mL} / \mathrm{min}$ until 96 hours, when it was increased again to 0.7 $\mathrm{mL} / \mathrm{min}$. Flow rates were increased during the test to assess the effect of flow rate on the dissolution rate. For the flow/no-flow tests, the rainwater was set at $0.14 \mathrm{~mL} / \mathrm{min}$ for the first 24 hours. No-flow periods of 1, 2, 3, 8 , and 24 hours were applied, each of which was followed by 24 hours of flow. The surface area of the Comp B particles was measured prior to the column experiments. Dissolution rates were calculated from graphs of the column effluent concentrations over time and were expressed in three different ways: mass per time, mass per time per mass of explosive, and mass per time per surface area of explosive. The observed TNT dissolution rates 
for the continuous flow conditions increased from 0.00009 to 0.00062 $\mathrm{mg} / \mathrm{hr} / \mathrm{cm}^{2}$ between 24 and 120 hours. For the flow/no-flow conditions, observed dissolution rates ranged from 0.0003 to $0.00038 \mathrm{mg} / \mathrm{hr} / \mathrm{cm}^{2}$. These values are approximately 0.01 percent of the much larger value, 4.16 $\mathrm{mg} / \mathrm{hr} / \mathrm{cm}^{2}$, reported by Brannon et al. (1999), who used stirring in an aqueous solution to measure the dissolution rate.

\section{Volatilization}

Volatilization of TNT from surface water to air or from soil moisture to soil gas is not a significant fate-and-transport mechanism (McGrath 1996, Spanggord et al. 1981, Leggett et al. 1977). This conclusion is demonstrated by the values in Table A1. TNT has a low vapor pressure (values are $10^{-6}$ to $10^{-8} \mathrm{~mm} \mathrm{Hg}$ ) and a low Henry's Law constant (values are $10^{-7}$ to $10^{-9} \mathrm{~atm}-$ $\mathrm{m} 3 / \mathrm{mol}$ ). The low Henry's Law constant indicates that TNT's volatilization from water cannot be significant. This conclusion is supported by an experiment in which only 8 to 10 percent of the TNT was volatilized over an 18-day stripping experiment in which wastewater from a TNT manufacturing process was aerated (Howard 1989).

\section{Field studies}

Field studies at the Weldon Spring Ordnance Work in Missouri indicate TNT presence in soil up to $30 \mathrm{mg} / \mathrm{kg}$, 50 years after manufacturing operations ceased. However, biodegradation has prevented the TNT from reaching groundwater (Bradley et al. 1997). Using aquifer materials from Weldon Springs, studies indicate that complete disappearance (in most cases) of the source compound from the dissolved phase was achieved in 20 to 70 days (Bradley et al. 1994). Soil drying, however, significantly inhibited TNT mineralization under aerobic and anaerobic conditions (Bradley and Chapelle 1995). These findings are consistent with observations at Camp Edwards, indicating rapid degradation in the surface soil and vadose zone. The presence of TNT in the aquifer at Camp Edwards' OB/ OD site 1 suggests that the mass of TNT has overwhelmed biodegradation processes, possibly as a result of toxic effects (Section 6). Although limited TNT migration is occurring, what little is reaching the aquifer is rapidly degraded. Evidence for degradation is the presence of TNT only in the source areas with an absence of TNT in down-gradient locations where only the transformation by-products 2a-DNT and 4a-DNT are present (AMEC 2004). 
A study at Eagle River Flats, Alaska, was conducted to assess the impacts from artillery training (Racine et al. 1992). The compounds 2,4-DNT as well as TNT, 2,6-DNT, 2a-DNT, and 4a-DNT were detected in sediment located next to an ordnance disposal site. Whole grains of propellants were found on the site, indicating incomplete detonation. The TNT and 2,6DNT are by-products of the manufacture of DNT propellants and the aDNT compounds are breakdown products of TNT.

In general, TNT is not found in surface and groundwater at most sites where it was used or disposed. For example, several locations along both US coastlines where waste munitions were discarded at sea have been investigated for TNT contamination. TNT was not detected in ocean waters near a dump site 200 miles off the coast of Florida nor one 45 miles west of San Francisco, nor was it detected in seawater off the coast of Charleston, South Carolina, or 85 miles west of Flattery, Washington (Hoffsommer and Rosen 1972). TNT has been found in groundwater under certain conditions, such as the aforementioned Demo 1 at Camp Edwards, the Louisiana AAP, Umatilla AAP, Iowa AAP, and Cornhusker AAP. High concentrations (2.2 mg/L) were found at the Milan AAP (Best et al. 1997a). TNT also was reported in the groundwater at the Sierra Army Depot in Herlong, California (Balasco et al. 1996). The TNT originated from leaching beds and was detected in groundwater over a 22-acre area. Nonetheless, degradation processes dominate fate and transport, and natural attenuation was selected as the remedial option for the site. As noted at the beginning of this paragraph, TNT has been found in soil and groundwater at the Iowa AAP (Fleming et al. 1996), the Umatilla Army Depot Activity in Hermiston, Oregon, and at the Louisiana Army Ammunition Plant. The commonality between all the sites with TNT groundwater contamination mentioned above is shallow depth to water. At these sites, TNT migrates to groundwater before microorganisms in the vadose zone can attenuate it.

\section{Summary}

TNT is rapidly degraded in most soil and aquifer systems and, therefore, its presence is typically restricted to areas near its introduction to the environment. The major fate-and-transport processes for TNT in soil and groundwater are dissolution, adsorption, abiotic transformation, biotransformation, diffusion, advection, and hydrodynamic dispersion (Townsend and Myers 1996, McGrath 1995). The transformation rates are sufficiently fast at most sites for TNT to be attenuated fully in the surface soil, thereby preventing contamination of the vadose zone or groundwater. In the case 
of impact areas, the majority of the TNT may be degraded in the surface soil, but small quantities can reach shallow groundwater. At OB/OD areas, the mass of TNT may be sufficient to overwhelm the attenuation mechanisms, resulting in TNT reaching groundwater. However, the TNT usually continues to undergo transformation in groundwater, limiting its mobility.

\section{Hexahydro-1,3,5-trinitro-1,3,5-triazine (RDX)}

Hexahydro-1,3,5-trinitro-1,3,5-triazine (RDX, Royal Demolition Explosive or cyclonite) belongs to a class of compounds known as nitramines (Fig. 6). RDX is a crystalline solid at room temperature with a molecular weight of $222 \mathrm{~g} / \mathrm{mol}$. RDX has a low water solubility (42 mg/L) and vapor pressure and its $\mathrm{K}_{\text {ow }}$ indicates a low affinity for hydrophobic substances (Table A1).

\section{Sorption}

Most studies indicate that sorption of RDX is not a significant process, although a few have reported some retention on sediments and clays (Myers et al. 1998a, Xue et al. 1995, Leggett 1985). McGrath (1995) reported that RDX and HMX passed through laboratory columns with minimal retardation and reduction. Myers et al. (1998a) found RDX sorption levels to be below MDLs for a variety of soil types. Such results are consistent with studies by Pennington et al. (1995), who found both RDX and HMX to be totally leached from clay loam soils from several sites. Reported $\mathrm{K}_{\mathrm{d}}$ values further support the assertion that RDX is not significantly retained by most soils: Partition coefficients of 0.05 to $0.38 \mathrm{~L} / \mathrm{kg}$ were determined for soils collected from Camp Edwards (Speitel et al. 2002), $0.72 \mathrm{~L} / \mathrm{kg}$ for RDX in a clay soil (Selim and Iskander 1994), less than $1 \mathrm{~L} / \mathrm{kg}$ for 15 soils ranging from clay to clayey sand (Ainsworth et al. 1993), o to $6.75 \mathrm{~L} / \mathrm{kg}$ (Townsend and Myers 1996), and 1 to $3 \mathrm{~L} / \mathrm{kg}$ (Hale et al. 1979). Similarly, Checkai et al. (1993a, b, c) reported that RDX and HMX were highly mobile in soils with low clay content and low CEC. Ainsworth et al. (1993) reported that the sorbed mass of RDX ranged from 0.64 to 36 percent of the total mass applied. Similar to research with TNT, these investigators found only a poor correlation between $\mathrm{K}_{\mathrm{d}}$ and $\mathrm{f}_{\mathrm{oc}}$, suggesting that the amount of organic matter in the soil is of limited importance.

Effects of Eh and pH were examined by Price et al. (1998). Their study demonstrated no effect of $\mathrm{pH}$ for neutral or acid conditions. Eh also had little effect except under highly reducing conditions $(-150 \mathrm{mv})$. Even in 
the latter case, however, $\mathrm{K}_{\mathrm{d}} \mathrm{S}$ were near to or less than $1 \mathrm{~L} / \mathrm{kg}$ when the $\mathrm{pH}$ was between 5 and 7 .

Most studies report that when RDX is sorbed, it is fully reversible (Myers et al. 1998a, Xue 1995, Selim and Iskander 1994, Townsend et al. 1996, Ainsworth et al. 1993). Similarly, laboratory investigations employing a variety of soils ranging from clay to sandy loam found that less than two percent of the RDX was bound as a nonextractable residue (Cataldo et al. 1990). What RDX sorption does occur has been variously or in combination attributed to $\mathrm{CEC}, \mathrm{pH}$, clay content, organic carbon, and extractable iron.

\section{Degradation}

Natural removal of RDX from soil was observed in a study at the Iowa AAP (Best et al. 1997a, b). Although the mechanism was not identified, the authors concluded that removal appeared to be the result of adsorption and biodegradation. Similarly, Kayser and Burlinson (1982) reported transformation of RDX in laboratory and field lysimeter studies, but did not specify the redox conditions. Rodacy and Leslie (1992) determined the half-life of RDX in soil to be 36 years based on work by DuBois and Baytos (1972) from an arid site using powdered RDX as the starting material. Jenkins et al. (2003) found the half-life of pre-dissolved RDX in moist unsaturated soil to range between 94 and 154 days.

RDX degrades most easily anaerobically (Price et al. 1998, Spanggord et al. 1980a), although there are limited reports of aerobic degradation. At low contaminant concentrations (less than $20 \mathrm{mg} / \mathrm{kg}$ ), the bioavailability of RDX, HMX, TNT, and their degradation products also is controlled by desorption from the soil matrix (Pennington et al. 1995).

An evaluation of RDX degradation at three redox potentials (500, 250, and $-150 \mathrm{mv}$ ) and four $\mathrm{pH}$ levels (5.0, 6.0, 7.0, and 8.0), employing a solution spiked with $10 \mathrm{mg} / \mathrm{L} \mathrm{RDX} \mathrm{(Price} \mathrm{et} \mathrm{al.} \mathrm{2001)} \mathrm{demonstrated} \mathrm{that} \mathrm{RDX} \mathrm{was}$ unstable under highly reducing conditions $(-150 \mathrm{mv})$, but relatively stable over the short-term (15 days) under oxidizing and moderately reducing conditions, irrespective of the $\mathrm{pH}$. The authors concluded that RDX would not persist in areas where reduction is intense, but would be mobile and persistent in oxidizing or moderately reducing environments. The $\mathrm{pH}$ did have a significant effect on anaerobic degradation with 80 percent mineralization at $\mathrm{pH} 7$ compared to 18 percent at $\mathrm{pH} 5$ and 8 . 
Anaerobic transformation products of RDX are hexahydro-1-nitroso-3,5dinitro-1,3,5-triazine (MNX), hexahydro-1,3-dinitroso-5-nitro-1,3,5triazine (DNX), and hexahydro-1,3,5-trinitroso-1,3,5-triazine (TNX) when the soil pH is greater than 8 (Price et al. 1998). These authors used HPLC to confirm the loss of RDX and the formation of MNX, DNX, and TNX as transient intermediates. Also, by using liquid chromatography mass spectrophotometry (LC/MS), this series of experiments produced the first experimental evidence for the formation of hydroxylamino-dinitroso-1,3,5triazine. Other reported transformation products include formaldehyde, methanol, hydrazine, 1,1-dimethylhydrazine, and 1,2-dimethylhydrazine (McCormick et al. 1984a, b). In general, when RDX is degraded anaerobically, hydroxylamines are formed initially. Eventually ring cleavage occurs, resulting in a series of hydrazines. Nitrosamine intermediates formed in this process are believed to be genotoxic carcinogens (Major et al. 2002). The hydrazines may be short-lived with one set of experiments, indicating that the hydrazines rapidly disappeared under aerobic, anaerobic, and methanogenic conditions, with half-lives ranging from 4.1 to 6 hours (Price et al. 1998).

Mixed results have been reported with respect to aerobic environments. Price et al. (1998) and Cataldo et al. (1990) reported no degradation while Ainsworth et al. (1993) and McCormick et al. (1984a) both observed aerobic degradation of RDX. Myers et al. (1998a) reported degradation for both aerobic and anaerobic environments. Also under aerobic conditions, experiments with the strain Cornyebacterium showed cometabolic degradation of RDX-contaminated soils (40 to $60 \mathrm{mg} / \mathrm{L}$ in effluent) with more than 90 percent degraded within 1 to 3 days. These experiments show that the presence of ammonium inhibited the microbial degradation of RDX because organisms used RDX as a nitrogen source (Yang et al. 1983).

Bioreactors have been used to reduce RDX concentrations significantly, and a few studies with isolates and controlled conditions have shown some aerobic utilization. Apparently, isolates from contaminated areas can utilize or at least tolerate both RDX and HMX. A number of microorganisms degrade RDX and HMX via sequential denitration, resulting in formation of the parent alcohol and the release of nitrogen as nitrate, nitrite, or nitric oxide. Reduction can be induced in a bioreactor but requires repeated addition of cell extracts. Moreover, RDX is not reduced anaerobically if nitrate is present (Rosser et al. 2001). Apparently, as with the study described above (Yang et al. 1983), the nitrate provides a more readily usable 
nitrogen source for the microbes. Unlike TNT, RDX and HMX undergo ring cleavage and extensive mineralization (6o percent with anaerobic sludge). However, identification of the biodegradation pathway with respect to the microbial populations and enzymes involved is incomplete.

Nevertheless, a clear conclusion from current work is that once the ring in a cyclic nitramine cleaves, the degradation products are thermally unstable and hydrolyze readily in water. Such abiotic reactions compete with biotic reactions during biodegradation, making it very difficult to evaluate the mechanisms at the microbial level. Hence, the actual fate of RDX and HMX in terms of phytoremediation and natural attenuation remains uncertain, and laboratory studies may not be applicable to the field because there will be more complex conditions, including the presence of other organic and inorganic contaminants (Hawari 2000).

Thermal and chemical degradation of RDX resulting in the formation of methylenenitramine may also occur. Methylenenitramine undergoes spontaneous degradation to produce formaldehyde and nitrous oxide (Hawari 2000).

\section{Phototransformation}

Phototransformation of RDX in soil is not significant (Thiboutot et al. 2002). Photodegradation of RDX can occur in water, however, and provides the basis for a wastewater treatment process employing ultraviolet radiation and ozonation.

Various photolytic half-lives have been reported for field conditions: 1.2 to 5.0 days (Spanggord et al. 1980b), 10.7 hours (Sikka et al. 1980), and seven days (Spanggord et al.1983, Bedford et al. 1996). Phototransformation products include nitrate, nitrite, ammonia, formaldehyde, nitrous oxide, formamide, and N-nitroso-methylenediamine (Glover and Hoffsommer 1979, Kubose and Hoffsommer 1977). Nitrate, nitrite, and ammonia have been reported at Camp Edwards, but the observed concentrations do not appear to be elevated (AMEC 2004, 2003a, 2001a, d; Ogden 1999a, 1998a). Formamide and N-nitroso-methylenediamine have not been detected. 


\section{Phytotransformation}

Thompson et al. (1999) stated that information was lacking regarding the fate and transformation of RDX in plants. Their study using hydroponic solutions containing RDX to grow poplar trees, however, is representative of other recent work. The study demonstrated that 60 percent of the RDX uptake went into leaf tissue. Over a seven-day period, there was no significant transformation of RDX in the plant tissue, suggesting both RDX accumulation and stability. Similarly, Harvey et al. (1991) found "undeniable evidence for plant bioaccumulation of RDX." In their study, bush bean plants were grown in $10 \mathrm{mg} / \mathrm{L}$ RDX hydroponic solutions. The results demonstrated that the RDX was rapidly taken up and that it bioaccumulated in the plant tissue, particularly in the leaves. Over a seven-day exposure period, limited evidence of plant metabolism of RDX was observed. The authors concluded that bioconcentration by plants may be a significant mode of transfer of RDX from soils into the food chain.

\section{Dilution/advection/dispersion/diffusion}

Once dissolved, advection, dispersion, and diffusion are the dominant concepts for evaluating RDX mobility. The net effect of these processes is to spread the RDX over a greater area, thereby reducing the concentration at the groundwater interface.

\section{Dissolution}

$\mathrm{RDX}$ has an aqueous solubility of $42 \mathrm{mg} / \mathrm{L}$ at $20^{\circ} \mathrm{C}$, and from a kinetic point of view, dissolves slowly into aqueous solution. There is no significant effect on solubility over the pH range 4.2-6.2 (Lynch et al. 2002b). Because of a slow dissolution rate, high concentrations can persist in nearsurface soils for decades (Jenkins et al. 1997a). For example, a study was conducted in Nevada at an explosives test facility used for one year and abandoned in the mid 1950s (Haywood et al. 1995). Solid chunks of RDX and HMX were visible on the soil in the 1990s. Likewise, when applied to the top of laboratory columns containing soils ranging from silt to sand, RDX migration was observed as water was applied, but some always remained in the surface sample (Hale et al. 1979). The latter experiments suggest that particulate RDX residues are slow to dissolve even in humid environments. More recently, Taylor et al. (2004a) conducted a laboratory study on a single Comp B particulate, approximately 5 inches in length, collected from an active artillery and mortar firing range. The experiment 
was conducted for 60 days before being terminated. The results suggested that complete dissolution of the particulate would take decades to centuries.

Lynch et al. (2002a) examined the solubility and dissolution rate of RDX (as well as HMX and TNT) as a function of temperature (10, 20, and $30^{\circ} \mathrm{C}$ ), surface area, and energy input. Surface area for RDX was estimated using mass-to-surface-area ratios based on military specifications for acceptable granulation distribution. The surface areas did not account for surface roughness observed microscopically. Measurements were made while two variables were held constant and one was varied. RDX had the slowest dissolution rate, although the data demonstrated that dissolved concentrations could exceed the USEPA HA limits established for RDX (0.002 $\mathrm{mg} / \mathrm{L}$ ). Each variable yielded a linear correlation. Temperature dominated the other two variables in exerting the most influence over the range of conditions evaluated. Correlation equations incorporating the three test variables were developed and might have applicability to field sites. Major difficulties are to determine how best to estimate mixing rate and surface area, and how to account for seasonal variations in temperature and rainfall. Although the developers of the correlation equations used realistic surface areas based on military formulations, chunks of HE have been found at OB/OD sites (Schofield Barracks, Pohakuloa Training Center, Camp Shelby, Camp Edwards, and Fort Richardson) and impact areas (Fort Hood, Fort Bliss, Fort Carson, Fort Polk, Cold Lake Air Weapons Range, Holloman AFB, Yakima Training Center, Schofield Barracks, CFBValcartier, CFB-Gagetown, Eglin AFB, Camp Edwards, and Fort Richardson).

Similarly, as described below, the dissolution rate varies greatly depending on the manner in which the water and $\mathrm{HE}$ are combined. An additional problem is the slower dissolution rate presumed because the HE compounds may be protected by sorbing to soot produced during the blast (see Section 5). The soot would provide a non-wetting surface and prevent direct contact of the $\mathrm{HE}$ with water. It is also possible that RDX develops a passivation layer as a result of weathering, thereby limiting complete dissolution. With respect to temperature, RDX's solubility was approximately $13 \mathrm{mg} / \mathrm{L}$ at $2-3^{\circ} \mathrm{C}$ and approximately $37 \mathrm{mg} / \mathrm{L}$ at $20^{\circ} \mathrm{C}$ (Speitel et al. 2002). Thus, the value of $30 \mathrm{mg} / \mathrm{L}$ used for MMR in the calculations supporting the conceptual model (see Section 3) is reasonable, and probably somewhat conservative. 
Solubility and dissolution rates also have been determined for RDX, TNT, and HMX in the formulations octol, Comp B, and LX-14, as well as mixtures of the three individual compounds composing these formulations (Lynch et al. 2002b). Experiments were conducted at 10, 20, and $30^{\circ} \mathrm{C}$, with a constant mixing rate of 2.5 revolutions per second. The solubilities of the individual compounds from formulations and mixtures were comparable to those of the individual compounds as measured independently. Although dissolution rates for RDX were slightly lower than for TNT and HMX from the mixtures, the rates were comparable to those of the individual compounds. The authors believed that the latter effects resulted from differences in physical abrasion of particles during mixing. TNT and HMX particles were entrained during mixing, whereas the RDX fell to the bottom of the container and was shielded. Dissolution rates were suppressed somewhat in octol, but not in the other formulations as compared to the individual compounds. Other observations included the following: 1) military-grade RDX had sufficient HMX for the latter to attain its solubility limit in solution; 2) Comp B contained sufficient HMX for the compound to attain saturation in solution and also contained detectable quantities of TNB, DNB, and 2,4-DNT; and 3) octol contained detectable quantities of RDX and TNB.

\section{Volatilization}

Table A1 provides the Henry's Law constant, vapor pressure and solubility demonstrating that volatilization is not an important fate-and-transport mechanism for RDX (McGrath 1996, Cataldo et al. 1990, Spanggord et al. 1981).

\section{Field studies}

Detonation on snow provides insight regarding the amount of HE released by training activities. For example, detonation of 60-mm, 81-mm, and 120-mm mortar rounds, $105-\mathrm{mm}$ artillery rounds, and 40-mm rifle grenades using common military live-fire techniques was used to examine how much RDX is released to the environment from a high-order detonation (Hewitt et al. 2003). Thin samples of snow containing visible soot were collected with a clean shovel and samples were analyzed by gas chromatography-electron capture detector (GC-ECD) and reversed phase HPLC (RP-HPLC). The primary charge was Comp B and the residues were primarily RDX and TNT with lesser amounts of NG, HMX, and DNTs. The presence of NG recovered from the surface of two 120-mm mortar fins 
suggests that the source of NG is most likely the ignition cartridge. The study concluded that a higher percentage of TNT is consumed upon detonation as compared to RDX or HMX. Overall, the detonation experiments demonstrated that the same round could yield from 0.086 to $2.9 \mathrm{mg} / \mathrm{kg}$ of RDX in surface soil and 0.0033 to $0.130 \mathrm{mg} / \mathrm{kg}$ of TNT.

CFB Valcartier, in Quebec, Canada, has sandy and well-drained soils. Multi-increment samples were collected within $20 \mathrm{~m}$ of targets (Jenkins et al. 1997a). Firing activities consisted of anti-tank weapons training. The munition used was a 66-mm M72 anti-tank rocket, which does not contain significant RDX. The warhead is composed of octol. Nevertheless, some RDX probably was present in the HMX as an impurity and the rockets contain an explosive booster with approximately $6 \mathrm{~g}$ of RDX. Soil contamination was principally limited to the surface soil. RDX and other explosives were found in the groundwater, indicating that some component of the original contaminant mass had migrated completely through the vadose soil column.

Walsh et al. (2001) performed work in an impact area at Fort Greely, Alaska, which covers more than 85,000 acres. More than half of the 107 soil samples analyzed had no detectable explosives residues. The most common contaminant identified was RDX, followed by TNT, with some HMX, NG, and 2,4-DNT. The median concentration for those samples in which RDX was detectable was $0.021 \mathrm{mg} / \mathrm{kg}$. The highest concentrations were associated with low-order detonations, but only one sample contained RDX and TNT above risk-based concentrations for residential areas. The latter sample, however, was collected adjacent to a UXO containing Comp B. The investigators concluded that properly functioning $\mathrm{HE}$ leaves little residue and the most efficient approach for sampling such a large area is a composite sampling approach.

Consistent with the evaluations of adsorption and degradation described previously, Walsh et al. (1993) reported RDX (along with TNT) as the most common munition found in soil and groundwater. In contrast, a field study of natural attenuation at the Joliet AAP in Illinois did not find detectable levels of RDX in the soil (Pennington et al. 1998a). The low levels of RDX mineralization observed suggested that RDX had disappeared from the soil some time ago. The removal process, whether leaching or biological, was not identified. Field studies at the Cornhusker AAP indicate that RDX groundwater contamination is being attenuated by microbio- 
logical processes (Comfort et al. 1995). When water is not present, RDX is persistent in the soil, as reported by DuBois and Baytos (1972), who observed little disappearance of RDX in an arid soil environment over a three-year period.

A study specific to Camp Edwards aquifer materials by Speitel et al. (2002) measured a $K_{d}$ of $1.23 \mathrm{~L} / \mathrm{g}$, which equates to RDX being retarded approximately 25 percent in comparison with water. Such mobility of RDX in aerobic groundwater environments is reflected by the many locations besides Camp Edwards where it has been reported as a groundwater and surface water contaminant. For example, RDX is found in groundwater at Milan AAP (Fleming et al. 1996), where soil (silty sand) concentrations range from 290 to $43,000 \mathrm{mg} / \mathrm{kg}$ (Etnier 1986) and the depth to groundwater less than $20 \mathrm{ft}$. Interestingly, no biodegradation products were found, even in locations where conditions were anaerobic (Spalding and Fulton 1988).

RDX is also present in groundwater at the Picatinny Arsenal, Virginia, at concentrations less than $0.005 \mathrm{mg} / \mathrm{L}$ (Fleming et al. 1995). The Picatinny Arsenal was used for testing various munitions. The groundwater contamination originated from a site where propellants were processed, mixed, and utilized. RDX is also found in groundwater at the Joliet AAP, Illinois. Concentrations ranged from 0.0003 to $12.1 \mathrm{mg} / \mathrm{L}$. Depth to groundwater at this site is approximately $20 \mathrm{ft}$.

RDX is also the primary groundwater contaminant at the Iowa AAP, with TNT and TNB present (Best et al. 1997a). The mean groundwater concentration of RDX is $12.8 \mathrm{mg} / \mathrm{L}$. An extensive RDX groundwater plume is also present at Cornhusker AAP in Nebraska. Again, no evidence of anaerobic degradation metabolites has been observed (McCormick et al. 1978).

\section{Summary}

Under intense anaerobic conditions (e.g., approximately $-150 \mathrm{mv}$ ) and a near-neutral $\mathrm{pH}$, biodegradation can be an efficient removal mechanism, although toxic intermediates (nitrosamines) are formed during the process. Migration to groundwater is limited by a relatively slow dissolution, which is a function of the contact time between the HE particulate and infiltrating precipitation. Once dissolved in aerobic aquatic environments, however, RDX is persistent and mobile. The primary fate-and-transport mechanisms in groundwater, therefore, are advection, dispersion, and 
dilution. The principal unknown factors governing predictions of RDX leaching rate are the lack of knowledge regarding particle size, conditions after dispersal in the environment (e.g., whether coated with soot), and contact time with water, all of which are data gaps hindering estimates of the source terms (see Section 8).

\section{Octahydro-1,3,5,7-tetranitro-1,3,5,7-tetrazocine (HMX)}

Octahydro-1,3,5,7-tetranitro-1,3,5,7-tetrazocine (HMX, High Melting Explosive) is a nitramine like RDX (Fig. 6). HMX is a crystalline solid at room temperature with a molecular weight of $296 \mathrm{~g} / \mathrm{mol}$. HMX has a low water solubility (approximately $7 \mathrm{mg} / \mathrm{L}$ ) and vapor pressure, and its $\mathrm{K}_{\mathrm{ow}}$ indicates a low affinity for hydrophobic substances (Table A1).

\section{Sorption}

Most studies indicate that sorption of HMX is not a significant process. McGrath (1995) reported that HMX passed through laboratory columns with minimal retardation and Checkai et al. (1993a, b, c) reported that HMX was highly mobile in soils with low clay content and low CEC. Such results are consistent with studies by Pennington et al. (1995), who found HMX to be totally leached from clay loam soils from several sites. Distribution coefficients reported in the literature for HMX also indicate little retardation under typical conditions (Table A1). Values reported range from as low as o to as high as $13.25 \mathrm{~L} / \mathrm{kg}$ (Townsend and Myers 1996). Price et al. (1998) examined effects of Eh and pH. Their study demonstrated little or no effect for $\mathrm{pH}$ 5 7 for moderately oxidizing conditions (250 mv). Lowering the Eh to highly reducing conditions ( $-150 \mathrm{mv})$ decreased the measured $K_{d} s$ by a factor of 10 .

HMX adsorption is reversible according to laboratory work by Myers et al. (1998a) and Townsend et al. (1996) for several soils studied. However, Xue et al. (1995) reported that the release is a slow process. Jenkins et al. (1989) reported a $\mathrm{K}_{\mathrm{ow}}$ value of $1.15 \mathrm{~L} / \mathrm{kg}$ for HMX, indicating greater partitioning to water than is actually observed. Apparently, strong intermolecular bonds within the crystalline structure explain the inconsistency of low aqueous solubility and the tendency not to partition out of solution. Rosenblatt et al. (1989) reported a $\mathrm{K}_{\mathrm{oc}}$ value of $3.47 \mathrm{~L} / \mathrm{kg}$, which suggests a moderate propensity to adsorb to organic matter. 


\section{Degradation}

A few studies employing bioreactors with isolates and controlled conditions have shown some aerobic utilization (Rosser et al. 2001), but degradation of HMX apparently does not occur in the field under aerobic conditions (Greene et al. 1985). In contrast, HMX degradation is observed anaerobically (Price et al. 1998 and McCormick et al. 1984b). Rodacy and Leslie (1992) determined the half-life of HMX to be 39 years based on work by DuBois and Baytos (1972) in an arid environment. Spanggord et al. (1983) identified the anaerobic end products as nitrite, nitrate, and formaldehyde. Nitroso derivatives were observed in batch experiments but not in column experiments (Greene et al. 1985, McCormick et al. 1984b). HMX was biotransformed in an anaerobic sludge with a glucose carbon source to yield octahydro-1-nitroso-3,5,7-trinitro-1,3,5,7-tetrazocine, octahydro-1,3-dinitroso-5,7-dinitro-1,3,5,7-tetrazocine, and its isomer octahydro-1,5-dinitroso-3,7-dinitro-1,3,5,7-tetrazocine and the tentatively identified compounds methylenedinitramine and bis (hydroxymethyl) nitramine (Hawari et al. 2001a, b). The intermediates did not accumulate and were further degraded to nitrous oxide, formaldehyde, and formic acid. The formaldehyde degraded to carbon dioxide and the nitrous oxide rapidly degraded to nitrogen in the absence of glucose. Methane was formed by mineralization. Hydrazine and dimethylhydrazine were not detected. HMX degradation also has been reported under sulfate-reducing conditions by fungi (Rosser et al. 2001).

Unlike TNT, which biotransforms rather than mineralizes, HMX (as does RDX) undergoes ring cleavage and extensive mineralization (6o percent with anaerobic sludge). However, the biodegradation pathway with respect to microbial populations and the enzymes involved has not been identified with certainty. Nevertheless, it is clear that once the ring cleaves, the degradation products are thermally unstable and hydrolyze readily in water. The latter abiotic reactions compete with biotic reactions during attempted biodegradation and complicate evaluations of the degradation process at the microbial level. Hence, the actual fate of HMX in terms of natural attenuation remains uncertain and laboratory studies may not be applicable to the field where conditions are more complex (Hawari et al. 2001a, b).

Price et al. (2001) examined removal of HMX at three redox potentials $(-150,250$, and $500 \mathrm{mv})$ within $\mathrm{pH}$ range $5-8$. Their results demonstrated little or no degradation at $\mathrm{pH} 5$ under any redox environment. Similarly, 
there was little removal unless redox conditions were anaerobic (e.g., at $-150 \mathrm{mv})$.

\section{Phototransformation}

Phototransformation of HMX in soil is not significant (Thiboutot et al. 2002), although dissolved HMX does photodegrade with reported halflives ranging from one week (Bedford et al. 1996) to 17 days (Spanggord et al. 1983). Reported degradation products include nitrite, nitrate, and formaldehyde (Spanggord et al. 1983).

\section{Phytotransformation}

The limited numbers of studies having evaluated phytoremediation of HMX do not indicate a useful role. Kenaf was exposed to HMX in soil and irrigation water. Little growth was observed in soil containing HMX, but normal growth occurred when irrigated with water containing HMX. HMX was not taken up significantly, and what was taken up was found in the aboveground portion of the plants. When the exposed plants were permitted to humify in the soil, HMX was still present (Thorne 1999). Groom et al. (2002), who examined selected terrestrial and aquatic plants for their capacity to accumulate and degrade HMX, reported similar results. Plants grown in a controlled environment and plants from a firing range (CFB Wainwright, Central Alberta, Canada) were assessed. HMX accumulated in leaves of most of the selected species to levels significantly above soil concentrations. Also, there was no direct evidence of plant-mediated HMX transformation.

\section{Dilution/advection/dispersion/diffusion}

Dissolved HMX that migrates through the vadose zone and into groundwater is not subject to significant sorption or degradation processes. Hence, dilution, advection, and dispersion are the primary factors governing HMX distribution in the aquifer. These processes collectively cause spreading of the plume. Diffusion is reportedly more important for HMX than for RDX (Townsend et al. 1996). The net effect of these processes is to spread the HMX over a greater area, thereby reducing the concentration at the groundwater interface. 


\section{Dissolution}

The maximum solubility for HMX is typically reported as 7 to $8 \mathrm{mg} / \mathrm{L}$. There is no significant effect on solubility over $\mathrm{pH}$ range 4.2-6.2 (Lynch et al. 2002b). Lynch et al. (2002a) examined the solubility of HMX as a function of temperature, surface area, and energy input. Each variable yielded a linear correlation. Temperature dominated the other two variables in terms of exerting the most influence over the range of conditions evaluated. Correlation equations incorporating the three test variables were developed and might have applicability to field sites. Major difficulties will be to determine how best to estimate mixing rate and surface area and how to address seasonal variations in temperature and rainfall. Although the developers of the correlation equations used realistic surface areas based on military formulations, there is evidence for much larger (e.g., baseballsized) chunks of HE at Camp Edwards. Similarly, as described below, the dissolution rate varies greatly depending on the manner in which the water and $\mathrm{HE}$ are combined. An additional problem is the slower dissolution rate presumed because the $\mathrm{HE}$ compounds may be protected by sorbing to soot produced during the blast. The soot would provide a non-wetting surface and prevent direct contact of the HE with water. The experiments performed by Lynch et al. (2002a) showed only a small effect of mixing rate as dissolution varied by a factor of less than two as the mixing rate was doubled. Solubility at 2 to $4^{\circ} \mathrm{C}$, however, was less than $1 \mathrm{mg} / \mathrm{L}$, increasing to approximately $4 \mathrm{mg} / \mathrm{L}$ as the temperature was raised to $22-24^{\circ} \mathrm{C}$. Only at temperatures exceeding $30^{\circ} \mathrm{C}$ did the solubility exceed $7 \mathrm{mg} / \mathrm{L}$.

Solubility and dissolution rates also have been determined for HMX, TNT, and RDX in the formulations octol, Comp B, and LX-14, as well as mixtures of the three individual compounds composing these formulations (Lynch et al. 2002b). Experiments were conducted at 10, 20, and $30^{\circ} \mathrm{C}$, with a constant mixing rate of 2.5 revolutions per second. The solubilities of the individual compounds from formulations and mixtures were comparable to those of the individual compounds as measured independently. Although the dissolution rates for HMX and TNT were slightly higher and RDX slightly lower from the mixtures, the rates were comparable to those of the individual compounds. The authors believed the latter effects resulted from differences in physical abrasion of particles during mixing. HMX and TNT particles were entrained during mixing, whereas the RDX fell to the bottom of the container and was shielded. Dissolution rates were suppressed somewhat in octol, but not in the other formulations as compared to the individual compounds. Other observations included the fol- 
lowing: 1) military-grade RDX had sufficient HMX for the latter to attain its solubility limit in solution; 2) Comp B contained sufficient HMX for the compound to attain saturation in solution and also contained detectable quantities of TNB, DNB, and 2,4-DNT; and 3) octol contained detectable quantities of RDX and TNB.

\section{Volatilization}

Table A1 provides the Henry's Law constant, vapor pressure and solubility demonstrating volatilization is sufficiently slow that it is not an important mechanism regarding HMX transport and redistribution (McGrath 1996, Spanggord et al. 1981).

\section{Field Studies}

Composite samples were collected at CFB Valcartier, Canada, within $20 \mathrm{~m}$ of the target from a sandy, well-drained soil (Jenkins et al. 1997a). Activities conducted at Valcartier included anti-tank weapons training. Thiboutot et al. (1998a, b) report that these munitions have a high dud rate based on a study conducted at Western Area Training Center Wainwright, Alberta, Canada. Contamination was principally limited to the surface soil, in which concentrations of HMX ranged from 1.8 to more than $2,000 \mathrm{mg} / \mathrm{kg}$. There was a pronounced concentration gradient as distance from the target increased, with the highest HMX concentrations adjacent to the target. Similarly, HMX at the 3.0- to 5.9-inch depth was generally a factor of five less than at $\mathbf{0}-0.3$ inches. Although deeper soil samples were not collected, HMX was found in the shallow groundwater (approximately $12 \mathrm{ft}$ bgs), indicating that some component of the original contaminant mass had migrated through the vadose zone. In a similar study at the Arnhem anti-tank firing range at CFB Valcartier (Thiboutot et al. 1998a, b), HMX contamination as great as $800 \mathrm{mg} / \mathrm{kg}$ was observed in surface soil, with concentrations decreasing a hundredfold by $1 \mathrm{ft}$ in depth. In all, high levels of HMX have been reported for at least five Canadian anti-tank ranges (Thiboutot et al. 1998a, b). In every case, correlations were evident between soil contaminant concentrations, frequency of use, and the location of the samples relative to the targets.

Field studies at Fort Ord, California, were conducted in 1997 (Jenkins et al. 1998). A set of 280 soil samples was collected at two inland firing ranges at depths ranging from o to $15 \mathrm{~cm}$ to 105 to $120 \mathrm{~cm}$. Similar to the Valcartier study, explosives residues were primarily confined to the sur- 
face soils near tank targets. In general, concentrations of HMX in the surface soil (up to $587 \mathrm{mg} / \mathrm{kg}$ ) were significantly higher than the subsurface soil concentrations. Some locations showed concentrations greater than 5 $\mathrm{mg} / \mathrm{kg}$ at a depth of 105-120 cm, but it is not known whether this can be attributed to particle migration and/or physical soil disruptions (such as explosions) rather than by aqueous leaching.

Studies also were conducted at anti-tank firing Ranges 13 and 22 at Western Area Training Center Wainright, Alberta, Canada (Thiboutot et al. 1998a, b). The site has a sandy loam soil with a high level of potash. Range 13 has been used daily since WWII. The munitions used were $66-\mathrm{mm}$ rockets and occasionally 81- and 105-mm rounds containing octol. High HMX concentrations, up to $3,700 \mathrm{mg} / \mathrm{kg}$, were found near targets at Range 13 . The HMX concentrations decreased with increasing distance away from the target. HMX was found at Range 22, but at lower levels than at Range 13 (up to $290 \mathrm{mg} / \mathrm{kg}$ ).

Studies also have been conducted at Range 2 and the Dundurn Cougar Range at the Canadian Forces Ammunition Depot, Dundurn, Canada (Thiboutot et al. 1998a, b). These sites have a sandy loam soil, but were not used as recently or as frequently as the previously described sites. Anti-tank rockets of the 66- and 84-mm variety were used at Range 2 from 1945 to 1970 . HMX concentrations up to $12 \mathrm{mg} / \mathrm{kg}$ were observed at Range 2 and the Cougar Range. Collectively, these studies show little degradation of HMX. Migration to the water table also was evident in several cases.

\section{Summary}

HMX undergoes anaerobic degradation resulting in the formation of mono and dinitroso products with retention of the ring system. Similar to RDX, HMX does not undergo significant transformations in an aerobic environment, nor is adsorption to soil particles an important process at most sites. Migration of HMX to groundwater is limited by slow dissolution of particulates, which is a function of contact time between the HE particulate and infiltrating precipitation-slower even than RDX. The principal fate-and-transport mechanisms in soil and water, therefore, are dissolution, advection, dispersion, and diffusion, unless anaerobic conditions exist. 


\section{Dinitrotoluenes (DNT)}

The DNTs are nitroaromatic compounds (Fig. 6) differing from TNT only in that they lack a third $\mathrm{NO}_{2}$ group attached to the aromatic ring. The isomers of environmental importance are 2,4- and 2,6-DNT. Both compounds are by-products in the TNT manufacturing process and are typically found in a 4:1 ratio of 2,4 to 2,6-DNT (Popp and Leonard 1985). DNTs also are intermediates in the manufacture of toluene diisocyanate, which is used in many consumer products. Besides their presence as manufacturing impurities, DNTs are used as plasticizers in propellants and, consequently, have been identified at the firing points at Camp Edwards. The DNTs have higher water solubilities (approximately $180 \mathrm{mg} / \mathrm{L}$ for 2,6-DNT and $270 \mathrm{mg} / \mathrm{L}$ for 2,4-DNT) than TNT. Vapor pressures are low and their $\mathrm{K}_{\mathrm{ow}} \mathrm{s}$ indicate a moderate affinity for hydrophobic substances (Table A1).

\section{Sorption}

DNT embedded within NC fibers is deposited primarily on the soil surface near artillery firing positions as a result of particulate and gaseous deposition from the use of propellants (Walsh et al. 2004a). DNT mobility is not significant, consistent with various research demonstrating that DNTs are strongly retained in near-surface soil (Pennington et al. 2003b; Checkai et al. 1993a, b, c). Moreover, sorption experiments were conducted specifically for Camp Edwards to determine the partitioning of 2,4-DNT for various experimental conditions and site soils. Results from these experiments are summarized in Table 5 (Speitel et al. 2002). The average $K_{d}$ value for the shallow soil experiments was $3.2 \mathrm{~L} / \mathrm{kg}$, a value indicating significant sorption to soil at the surface. The retention in the surface soils is probably a consequence of increased organic matter or protection of the DNT from environmental exposure via the $\mathrm{NC}$ casing. The latter conclusion is consistent with studies showing relatively high levels of 2,4-DNT (0.01-100 mg/ $\mathrm{kg}$ ) remaining on the soil surface near active firing points (M. R. Walsh et al. 2005, Walsh et al. 2004a, Jenkins et al. 2001a). Indeed, surface soils must be carefully collected from the top $1 \mathrm{~cm}$ of soil, without the vegetation removed, to get an accurate measure of the surface concentration. In summary, strong retention by the soil matrix of DNT precludes significant migration of the DNTs (Pennington et al. 2003b). 
Table 5. 2,4-dinitrotoluene (DNT) distribution coefficients.

\begin{tabular}{|c|c|c|c|c|}
\hline \multirow[t]{2}{*}{ Incubation period } & \multirow[t]{2}{*}{$\begin{array}{l}\text { Initial concentration } \\
\qquad(\mu \mathrm{g} / \mathrm{L})\end{array}$} & \multirow[t]{2}{*}{$\begin{array}{l}\text { Temperature } \\
\left({ }^{\circ} \mathrm{C}\right)\end{array}$} & \multicolumn{2}{|c|}{$\begin{array}{l}\text { Equilibrium distribution coefficient } \\
\qquad(\mathrm{L} / \mathrm{kg})\end{array}$} \\
\hline & & & Surface soil & Deep soil \\
\hline 24 hours & & * & 3.1 & 0.14 \\
\hline 120 hours & & * & 3.6 & 0.063 \\
\hline \multicolumn{5}{|c|}{ Effect of initial concentration } \\
\hline 120 hours & 28 & * & 3.7 & 0.26 \\
\hline 120 hours & 60 & * & 3.5 & 0.42 \\
\hline 120 hours & 82 & * & 3.0 & 0.42 \\
\hline \multicolumn{5}{|c|}{ Effect of temperature } \\
\hline 120 hours & 82 & 4 & 3.2 & \\
\hline 120 hours & 82 & 32 & 2.3 & \\
\hline Average & & & 3.2 & 0.26 \\
\hline \multicolumn{5}{|c|}{ * Room temperature } \\
\hline
\end{tabular}

\section{Degradation}

Several researchers have identified biodegradation as the key fate-andtransport mechanism for DNTs in the vadose zone (Spanggord et al. 1980b; Pennington 1988). Similarly, recent work indicates ample evidence for aerobic transformation (Spain et al. 2000). Brannon (2002) recently found DNT transformation rates too rapid to measure in a surface soil. Degradation pathways for 2,4-DNT and 2,6-DNT have been elucidated for aerobic systems (Nishino et al. 2000). Individual bacteria have been identified capable of growing on a single DNT isomer (Nishino et al. 1999, 2000) and have been isolated at contaminated sites (Nishino et al. 2000). Any dissolved DNT, therefore, has a high potential to degrade biologically.

Evidence for anaerobic degradation is mixed. According to Spain et al. (2000), anaerobic degradation processes have not been identified for the DNTs. However, co-metabolic anaerobic degradation processes have been described (Cerniglia and Somerville 1995, Liu et al. 1984, McCormick et al. 1976) and transformation rates for 2,4-DNT ranging from 0.0017 to $0.017 /$ $\mathrm{hr}$ in anaerobic aquifer soils have been reported (Pennington et al. 1999). As discussed below, evidence also has been presented for anaerobic degradation by Clostridium acetobutylicum. 
A scheme for the biotransformation of DNT was presented in McCormick et al. (1978). The mechanism included some postulated intermediates as well as some identified in other research. The products of microbial transformation of 2,4-DNT by Mucrosporium sp. as identified by thin-layer chromatography and by gas chromatography-mass spectrophotometry (GC/MS) were 2-amino-4-nitrotoluene (2a-4-NT), 4-amino-2-nitrotoluene (4a-2-NT), 2,2'-dinitro-4,4'azoxytoluene, 4,4'-dinitro-2,2' azoxytoluene, and 4-acetamido-2-nitrotoluene. Another compound, possibly a mixed type, was isolated but not identified. Studies by Liu et al. (1984) found similar results, identifying the microbial transformation products as 2a-4-NT, 4a-2-NT, 2-nitroso-4-nitrotoluene, and 4-nitroso-2-nitrotoluene. The latter compound was only tentatively identified. Liu et al. (1984) wrote that the biological reduction of 2,4-DNT proceeded through the nitroso hydroxylamine compounds. More recent work by Spain et al. (2000) suggests that the aerobic degradation pathway for 2,4-DNT is to 4-methyl-5nitrocatechol to 2-hydroxy-5-methylquinone, to 2,4,5-trihydroxytoluone to 2,4-dihydroxy-5-methyl-6-oxo-2,4-hexadienoic acid. Similarly, Spain et al. (2000) and Nishino et al. (2000) identified the 2,6-DNT degradation pathway to be 2,6-DNT to 3-methyl-4-nitrocatechol to 2-hydroxy-5-nitro6-oxo-2,4-heptadienoic acid to 2-hydroxy-5-nitro-2,4-pentadienoic acid to nitrite.

Work performed with microbial isolates usually has not resulted in so many intermediates. For instance, one study demonstrated that DNT in liquid cultures could be completely degraded without the production of aminonitrotoluenes (aNTs) (Nishino et al. 1999). When 2,4-DNT and 2,6DNT-degrading microbial strains were added to a mixture of 2,4-DNT and 2,6-DNT in a soil slurry, disappearance of DNT was accompanied by the release of carbon dioxide and stoichiometric appearance of nitrite. When the experiment was performed with historically contaminated soil, 99 percent of the DNT was removed. Although traces of extractable DNT remained, soil toxicity was low. After an extended acclimation period, first the 2,4-DNT and then the 2,6-DNT was degraded in an uninoculated control. Thus, the 2,4-DNT is preferentially consumed relative to 2,6-DNT, and high concentrations of 2,4-DNT can inhibit the transformation of 2,6DNT.

Activated sludge typically transforms 2,4- and 2,6-DNT to 2a-4-NT or 2amino-6-nitrotoluene (2a-6-NT), which often accumulate with no further degradation (Nishino et al. 2000). This research identified 30 additional 
isolates (e.g., Burkholderia sp. strain DNT) with the ability to mineralize 2,4-DNT by the same pathway.

Intermediates and products of 2,4-DNT and 2,6-DNT anaerobic metabolism by Clostridium acetobutylicum also have been isolated and identified. Clostridia are important because of their ability to reduce aryl nitro groups, but before this study, the examination of 2,4-DNT and 2,6-DNT had not been rigorously performed. The initial products were hydroxylaminonitrotoluenes. Subsequent transformation favored the formation of dihydroxylaminotoluenes with a limited reduction to amino nitrotoluene (aNT) isomers. Nitroso products were not observed. In cell cultures, metabolism beyond dihydroxylaminotoluene was not observed. In cell extracts, where activity could be maintained beyond that in cell cultures, further transformation yielded amino-hydroxylaminotoluenes and eventually diaminotoluenes. These findings further demonstrate the potential for hydroxylamines to be significant intermediates of nitroaromatic transformation under anaerobic fermentative conditions. In contrast to previous studies, rearrangement of dihydroxylaminotoluenes was not observed. Dihydroxylaminotoluenes were found to be quite unstable, decomposing rapidly under exposure to oxygen (Nishino et al. 2000).

The compound 4a-DNT, a prominent degradation product of TNT and a groundwater contaminant at some ranges, has been infrequently evaluated. However, biodegradation reportedly results in the formation of 4amino-6-nitrotoluene (4a-6-NT). It also has been reported that 4a-DNT degrades to 2,6-DANT and 2a-DNT (another TNT transformation product) degrades to 2,4-DANT, although not in significant quantities (Pennington 1988).

The literature reviewed suggests rapid aerobic degradation of the DNTs. The reason for the apparent persistence of 2,4-DNT at some sites (Walsh et al. 2004a, AMEC 2001i, Jenkins et al. 2001a) seems likely related to being embedded with a NC matrix (Hewitt and Bigl 2005, Walsh et al. 2004a). Being bound in NC, the DNTs are protected from microbial attack until the $\mathrm{NC}$ is weathered. $\mathrm{NC}$ is not susceptible to dissolution processes. Once the DNT is exposed to precipitation, it can be dissolved and migrate through the vadose zone.

Biodegradation of the DNTs can occur rapidly in surface water with reported half-lives of 2.7 hours to 1.7 days (Cook 1997). The compound 2,4- 
DNT was biodegraded to 4A-A-2-NT and 2A-4-NT and 2,6-DNT to 2A-6NT at the Weldon Springs site (Bradley et al. 1997). Transformations are typically sufficiently rapid to prevent groundwater contamination.

\section{Phototransformation}

Photodegradation of DNTs is possible if standing water is present for any length of time and DNT present in the soil dissolves into the water. However, photodegradation is not an important mechanism if there is no ponded water because of the slow dissolution rate of DNT. DNT is readily photolyzed with up to 50 percent loss of 2,4-DNT in five days and 2,6-DNT in one day. Other studies have indicated a photodegradation half-life of less than 10 hours with the photodegradation rate accelerated by the presence of humic materials (Spanggord et al. 1980b). The photodegradation product of 2,4-DNT is 2,4-dinitrobenzoic acid, which itself is photodegradable to carbon dioxide, water, and nitric acid.

\section{Phytotransformation}

Specific studies with the DNTs were not found. In a study with hybrid poplar trees, TNT was strongly bound and transformed in root tissues, but translocated very little to leaves. The trees did transform TNT to 4a-DNT, 2a-DNT, and to a number of unidentified compounds more polar than TNT. However, no plant respiration of labeled carbon dioxide (evidence of mineralization) was observed. Consequently, the use of phytoremediation requires consideration of the fate and toxicity of the metabolites (Thompson et al. 1998). An experiment employing Johnson Grass (warm season) and Canadian wild rye (cool season), and a rotation of the two grasses plus a fallow period led the authors to conclude that the effect of the plants on DNT was negligible. Compared to soil degradation or sorption processes, freshly contaminated soils probably have sufficient capability for natural bioremediation, and plants do not necessarily provide an enhancement (Sung et al. 2002).

\section{Dilution/advection/dispersion/diffusion}

These processes are expected to be of minor importance in relation to DNT's greater susceptibility to adsorption and biodegradation. 


\section{Dissolution}

Only sparse data exist regarding the solubility of 2,4-DNT and 2,6-DNT (Nishino and Spain 2001) (Table A1). Literature values indicate a solubility of approximately $250 \mathrm{mg} / \mathrm{L}$ for 2,4-DNT and approximately $180 \mathrm{mg} / \mathrm{L}$ for 2,6-DNT. Solubility was measured in one experiment by direct sampling of a crystalline suspension in deionized water (Phelan and Barnett 2001). The resulting data were comparable whether measured with rising or falling temperatures. The 2,4-DNT solubility measured in this study, however, was different from that reported by the US Army Materiel Command (USAMC 1971), the historical reference for 2,4-DNT. The 2,4-DNT solubility from this study was 30 percent less at $22^{\circ} \mathrm{C}$ and 65 percent greater at $50^{\circ} \mathrm{C}$.

Other relevant data come from column experiments conducted to evaluate dissolution of TNT from HE particles. Although the experiments did not measure 2,4-DNT, the results for TNT are probably representative. For TNT, the observed dissolution rates (0.00009 to $0.00062 \mathrm{mg} / \mathrm{hr} / \mathrm{cm}^{2}$ ), approximately 0.01 percent, were much slower than the literature value of $4.16 \mathrm{mg} / \mathrm{hr} / \mathrm{cm}^{2}$ (Brannon et al. 1999).

\section{Volatilization}

Table A1 provides the Henry's Law constant; vapor pressure and solubility demonstrating volatilization of 2,4-DNT is 20 times that of TNT (Pennington 1988) and rapid enough that it may be useful for UXO detection (Phelan and Barnett 2001). Nonetheless, volatilization is not an important fate and transport process for the DNTs because the process is still very slow (Spanggord et al. 1981). For example, depletion of a DNT source was not observed even after 30 years (Leggett et al. 1977).

\section{Field studies}

Field studies have documented TNT residuals following detonations, but not nearly as many have evaluated the presence of the DNTs. One study that did evaluate DNT was performed at an impact area at Fort Greely, Alaska. The compound 2,4-DNT was identified in a few samples, but only at very low concentrations (Walsh et al. 2001).

Studies collecting soil samples immediately after the cessation of firing artillery at Fort Lewis, Washington, (Jenkins et al. 2001a) found much 
higher DNT levels in soil (as high as $237 \mathrm{mg} / \mathrm{kg}$ ) than those observed at Camp Edwards (maximum $6 \mathrm{mg} / \mathrm{kg}$ ) (Pennington et al. 2002a). These soil samples were collected directly in front of two 105-mm howitzer firing points. Surface soils showed the highest concentrations of explosives residues. The surface soils were collected from 0 - to 5 - $\mathrm{cm}$ depth, including surface organic matter and roots. Whether 2,4-DNT is leaching deeper is uncertain because only two subsurface soils were collected. These investigators also found some of the 2,4-DNT incorporated into NC fibers. NC is affected neither by degradation nor adsorption and is not mobile due to its size. Consequently, some level of immobile DNT will be found in artillery firing position soils. However, DNT residue tied up in this manner probably poses no threat to groundwater. At Camp Grayling in Michigan, soil samples were collected around an $\mathrm{OB} / \mathrm{OD}$ area and indicated the presence of 2,4-DNT (ESE 1994, 1987). However, groundwater monitoring wells installed downgradient of the OB/OD site did not indicate the presence of 2,4-DNT (ESE 1997). As will be discussed in Section 5, 2,4-DNT has not been detected in groundwater monitoring wells located downgradient of artillery and mortar firing points at Camp Edwards (AMEC 2001i).

Field studies at the Weldon Springs Ordnance Works in Missouri found DNT present in soil up to $3 \mathrm{mg} / \mathrm{kg}$, 50 years after manufacturing operations ceased. The site had both solid residuals and liquid waste streams. Although this was a load, assembly, and packing facility, what is instructive is the persistence of the DNTs in soil even in an environment with significant precipitation. Groundwater contamination with the DNTs at the Weldon Springs Ordnance Works site (Bradley et al. 1997) demonstrates that degradation processes are not always sufficient to prevent migration. This is an issue at sites with very high DNT levels, which overwhelm or are toxic to the native microorganisms. The Badger AAP is such a site where DNT has reached the groundwater table, suggesting the native bacteria were overwhelmed before all of the DNT could be degraded. Depth to groundwater at the Badger AAP is less than 30 feet. In contrast, at the Camp Edwards OB/OD site, what little DNT reaches the groundwater is quickly attenuated by sorption and degradation processes (AMEC 2003a).

\section{Summary}

The DNTs are adsorbed rapidly onto soil and are subject to rapid aerobic biodegradation. Evidence for anaerobic degradation is mixed. According to Spain et al. (2000), anaerobic degradation processes have not been identified for the DNTs. However, co-metabolic anaerobic degradation processes 
have been described (Cerniglia and Somerville 1995, Liu et al. 1984, McCormick et al. 1976) and transformation rates for 2,4-DNT ranging from 0.0017 to $0.017 / \mathrm{hr}$ in anaerobic aquifer soils have been reported (Pennington et al. 1999). The DNTs, therefore, are not persistent and mobile in an aerobic environment. The principal fate-and-transport mechanisms in soil, therefore, are adsorption and abiotic and biotic transformation.

\section{Other explosive compounds}

Other explosive compounds present at military ranges include 2a-DNT, 4a-DNT, 2,4-DANT, 2,6-DANT, NG, PA, tetryl, TNB, and PETN. With respect to the aDNTs and diaminonitrotoluenes (DANTs), all are intermediate degradation products of TNT. The latter compounds are much more soluble (Table A1) and, therefore, more mobile than TNT.

Nitroglycerin and PETN are nitrate esters unlike the nitroaromatics (aDNTs, DANTs, PA, tetryl, and TNB). Table A1 summarizes physical and chemical properties of these compounds. Nitroglycerine's most common use is as a secondary component ( $0-43$ percent by weight) in propellants. Surface deposition may occur during rocket launching.

Tetryl was widely employed as a booster and was used in some munitions as an explosive until discontinued in 1979 (US Army 1984). Tetryl may have been used after 1979 as old stock was used up. Studies have shown extensive heating of tetryl at $120^{\circ} \mathrm{C}$ yields picric acid (US Army 1984).

TNT-containing mixtures such as Comp B contain detectable quantities of TNB. Also, TNT exposed to sunlight can undergo photo-catalyzed oxidation of the methyl carbon to form a carboxylic acid. Subsequent decarboxylation forms TNB. Hence, as noted by Walsh and Jenkins (1992), when TNT is present in soil, TNB also can be present.

Finally, PETN is an explosive commonly found in detonation cord and high-efficiency blasting caps, as well as pentolite booster charges, used for BIP detonations of UXO. Pentolite is a 50:50 mixture of TNT and PETN. PETN is not volatile and has low solubility in water. 


\section{Sorption}

There is a paucity of data regarding the fate and transport of these compounds. Much can be inferred, however, by considering similar compounds. Also, these compounds are seldom used, spilled, or disposed of in environmentally significant amounts.

Some insight into the mobility of tetryl and TNB can be obtained from a study of bioremediation in soil. Valsaraj et al. (1998) measured relative flux from a soil bed and reported the following compounds in decreasing order: TNT, tetryl, DNT, and TNB. The flux for TNT, however, is not consistent with a lysimeter study conducted by Conley and Mikucki (1976). Valsaraj et al. (1998) calculated a characteristic time for TNT transport of approximately seven years as compared to the first-order degradation rate by plant enzymes of 70 minutes. Thus, transport of TNT from the soil bed is considered slow, but is still more rapid than tetryl and TNB.

Humic substances and other organic materials can adsorb ammonium picrate (AP) and PA, but, if absent, PA and picrate can be mobile (Kayser and Burlinson 1982, Goodfellow et al. 1983, Layton et al. 1987, Thorne and Jenkins 1995). Apparently, solutions containing calcium ions or calcium clays cause rapid flocculation, resulting in the removal of picrate from solution (Thorne and Jenkins 1995).

NG and PETN mobility is inferred from the case studies reviewed below. Based on these studies, PETN is expected to be retained in soil. NG is sufficiently biodegradable that mobility is seldom an issue.

Picric acid is expected to be mobile if dissolved and if it reaches groundwater. It is rapidly degraded in surface soils. Nitroglycerin, PETN, TNB, and tetryl all are subject to significant sorption and/or degradation and usually will be attenuated before reaching groundwater.

\section{Degradation}

Nitroglycerin contains a hydrocarbon chain, which renders it susceptible to aerobic biodegradation. Hence, Jenkins et al. (2003) reported that NG degrades rapidly in soil and described it as generally not persistent. However, when the NG is bound with NC it is not susceptible to degradation until the NC is weathered away. In such circumstances, a low-level of NG will remain in the soil but will have no impact on groundwater. 
There have been a few studies of the closely related compounds PA and tetryl. Degradation of PA to picramic acid (2-amino-4,6-dinitrophenol) is possible under anaerobic conditions (Thorne and Jenkins 1995). Several investigators have reported tetryl as biologically degradable to picrate (Kayser and Burlinson 1982, Kayser et al. 1984, Jenkins et al. 1995). Walsh (1990), however, reported no success identifying degradation products, but did acknowledge that tetryl was environmentally unstable. Natural biodegradation of picrate does not occur, but may be possible using adapted organisms (Wyman et al. 1979).

Biological reduction of one or more of TNB's nitro groups can occur in both aerobic and anaerobic environments, with the reaction rate increasing as conditions become more reducing. For example, TNB is subject to biotransformation to 3,5-DNA, which has been recommended as an additional target analyte at ranges (Crockett et al. 1998a). The compound 3,5DNA has been added to the explosive analyte suite used at Camp Edwards, but has been infrequently detected (AMEC 2004, 2003a, 2001a, d; Ogden 1999a, 1998a).

Mechanisms of biological degradation of nitrate esters such as PETN are not fully understood, but it is known that the cleavage of the ester linkage is required prior to degradation of the organic skeleton of the molecule (Major 1999). Rodacy and Leslie (1992) determined the half-life of PETN to be 92 years based on work by DuBois and Baytos (1972), who reported little disappearance of PETN in an arid soil environment over a three-year period. Rosser et al. (2001) reviewed the degradation of nitrate esters, including PETN, and concluded it was unlikely that bacteria will be discovered satisfying all of the requirements needed to degrade this compound.

To summarize, NG is the most degradable of this group, while TNB is itself a common degradation product. Picric acid may degrade to picrate, as does tetryl. Picrate itself is not biodegradable (Layton et al. 1987). The nitrate ester, PETN, is very persistent in soil due to lack of degradation. However, none of these compounds is expected to reach groundwater in most environments.

\section{Phototransformation}

Little information was found regarding the photodegradation of NG, PA, tetryl, TNB, and PETN. Tetryl is photodegradable, yielding picrate, N- 
methylpicramide, methylnitramine, nitrate, and nitrite, but the half-life is rather long (Kayser et al. 1984). Moreover, picrate does not photodegrade.

\section{Phytotransformation}

Among the many studies examining soil-plant relationships of energetic compounds, no specific studies examining NG, PA, and PETN were found. Only limited work with tetryl was found (Cataldo et al. 1993a, b). After 60 days, only 8 percent of the tetryl remained unchanged in the soil. The study reported that the order of plant availability was RDX $>$ tetryl $\geq$ TNT, with the extent of plant uptake being dependent on soil type (sand $>$ silt $>$ organic soil) and plant species. Explosive and propellant residues were found mostly in the roots. Tetryl was metabolized to N-methyl-2,4,6trinitroaniline and a variety of polar metabolites. TNB biotransforms to 3,5-DNA (Crockett et al. 1998a). Although finding the compounds and byproducts in the roots is a positive consideration, more research is needed regarding the fate and toxicity of the metabolites (Thompson et al. 1998).

\section{Dilution/advection/dispersion/diffusion}

Dissolution is the primary mechanism controlling the persistence of these compounds at the source. Once dissolved, these compounds are easily degraded or sorbed. There is no evidence of groundwater contamination, either because of limited mobility or the limited mass available for transport. Hence, it is not possible to assess the impact of physical transport processes such as dilution, advection, dispersion, and diffusion on these compounds.

Picric acid and picrate (formed either from PA or tetryl) are relatively soluble and mobile if they reach groundwater. Hence, dilution, advection, dispersion, and diffusion may govern their mobility. Nitroglycerin, TNB, tetryl, and PETN are not sufficiently soluble and are too subject to adsorption processes for these processes to be important.

\section{Dissolution}

Nitrate esters such as NG and PETN vary widely in their solubility, ranging from "almost totally insoluble" to approximately $100 \mathrm{mg} / \mathrm{L}$ (Major 1999). Specifically, $\mathrm{NG}\left(1500 \mathrm{mg} / \mathrm{L}\right.$ at $\left.20^{\circ} \mathrm{C}\right)$ and $\mathrm{PA}(10,000 \mathrm{mg} / \mathrm{L}$ at an unspecified temperature $)$ are relatively soluble and PETN $\left(2.1 \mathrm{mg} / \mathrm{L}\right.$ at $\left.25^{\circ} \mathrm{C}\right)$ is relatively insoluble (Table A1) (Lyman et al. 1982). Tetryl's solubility was 
reported as $80 \mathrm{mg} / \mathrm{L}$ (Table A1) at an unspecified temperature and the solubility of TNB was reported as $3,500 \mathrm{mg} / \mathrm{L}$, also at an unspecified temperature.

\section{Volatilization}

Table A1 provides limited data regarding the Henry's law constants, vapor pressures, and solubilities of these compounds. As reported by McGrath (1995), volatilization is not a significant mechanism for NG, PA, tetryl, TNB, and PETN due to their low vapor pressures.

\section{Field studies}

A few studies have identified the presence of PA, tetryl, TNB, and PETN, but none have identified these compounds as major contaminants at military sites (Clausen et al. 2004b, Jenkins et al. 2005b, Pennington et al. 2005, 2004, 2003a, 2002a, 2001). For example, Walsh et al. (2001) collected 107 soil samples at an impact area at Fort Greely, Alaska. More than half of the samples had no detectable explosives residues. The most common contaminant identified was RDX, followed by TNT with some HMX, NG, and 2,4-DNT. PETN, which is often used in detonation cord, was found in two samples from Camp Edwards (Ogden 1999a).

Similarly, Jenkins et al. (2001b) evaluated whether blasting on snow provides a facile means of collecting residue from a single detonation. Thin samples of snow containing visible soot were collected with a clean shovel. When the primary charge was Comp B, the principal residues identified were RDX and NG. Although the overall pattern and degree of contamination varied considerably from round to round, the concentration of NG was similar each time. The NG was likely to be present at higher concentrations than live-fire would have produced, since the propellant initiator (containing NG) was not fired for the blow-in-place experiments. Canadian studies (Ampleman et al. 2004, 2003a, b, 2000, 1998; Thiboutot et al. 2004, 2003a, b, 1998b) are consistent with those reported from US sites (Clausen et al. 2004b; Jenkins et al. 2005b; Pennington et al. 2005, 2004, 2003a, 2002a, 2001). For example, an investigation was conducted at the Arnhem anti-tank firing range at CFB Valcartier. The site has sandy soil with a depth to groundwater of $12 \mathrm{ft}$. HMX was the primary contaminant, but about half the samples had detectable levels of tetryl and TNB (Thiboutot et al. 1998a, b). Studies also were conducted at anti-tank firing ranges 13 and 22 at WATC Wainwright (Thiboutot et al. 1998a, b). The site 
has a sandy loam soil with a high level of potash. Range 13 has been used daily since WWII. HMX was again the most prominent contaminant with minor levels of TNB, and tetryl also was reported. Another investigation was performed at Range 2 and the Dundurn Cougar Range at the Canadian Forces Ammunition Depot, Dundurn, Canada (Thiboutot et al. 1998a, b). The site has a sandy loam soil. Anti-tank rockets of the 66- and 84-mm variety were used at Range 2 infrequently from 1945 to 1970 . The Dundurn Cougar Range has not been used for many years. TNB was occasionally detected at concentrations less than $1 \mathrm{mg} / \mathrm{kg}$ at both ranges. These studies are all consistent with results from Camp Edwards (AMEC 2004, 2003a, 2001a, d; Ogden 1999a, 1998a). All report PETN, TNB, tetryl, and PA to be minor in comparison to TNT, RDX, and HMX at military ranges. Also, none of the range studies conducted to date has identified NB, DNB, NTs, or DANTs to be present to any significant degree, if at all (Clausen et al. 2004b; Jenkins et al. 2005b; Pennington et al. 2005, 2004, 2003a, 2002a, 2001).

Even in the presence of high concentrations of TNT and RDX (greater than $3,000 \mathrm{mg} / \mathrm{L}$ ) at explosive manufacturing facilities, the presence of PETN, tetryl, TNB, and PA is minimal to non-existent. At the Milan AAP, the average TNB concentration is $0.308 \mathrm{mg} / \mathrm{L}$ (Best et al. 1997a). Likewise, RDX is the primary groundwater contaminant at the Iowa AAP, with some TNT and TNB present (Best et al. 1997a). TNB also was detected in groundwater at the Joliet AAP, where depth to groundwater is approximately 20 $\mathrm{ft}$. The commonality of all these sites is that they are manufacturing facilities where very high explosives concentrations are expected. Given the low concentrations and dispersed nature of their source terms, these compounds are not expected to be significant contaminants at training ranges.

\section{Summary}

The fate and transport of NG, PA, TNB, and PETN have not been widely studied, since they are infrequently detected and have not been observed in groundwater. The only exception is TNB, which has been observed at some TNT manufacturing facilities. This review yielded the following fate and transport summary for these compounds:

- Nitroglycerin is soluble when present as a "neat" particulate and is subject to rapid biodegradation, but when present with nitrocellulose is insoluble; 
- Picric acid and picrate are adsorbed if humic materials are present, but can be water soluble and mobile in a sandy environment;

- Tetryl is less mobile than TNT, and typically degrades rapidly to picrate;

- Trinitrobenzene is less mobile than tetryl;

- Pentaerythritol tetranitrate (PETN) adsorbs strongly to soil and its migration is further inhibited by its low water solubility and rapid degradation; and

- The NTs, DANTs, PA, tetryl, NB, DNB, TNB, and PETN are not likely to be COPCs at firing points and impact areas.

The primary conclusion from a review of PA, tetryl, TNB, and PETN is that these compounds are not likely to be found at military ranges except in the presence of much higher concentrations of the more abundantly used explosives (e.g., TNT, RDX, and HMX) and their primary metabolites or impurities (e.g., DNT and aDNTs). Therefore, these compounds are not likely to be found in impact areas or firing points but may be present at $\mathrm{OB} / \mathrm{OD}$ sites with concentrated demolition activity. However, even at Camp Edwards, PA, tetryl, TNB, and PETN have been infrequently observed at the $\mathrm{OB} / \mathrm{OD}$ site, and when present the concentrations are very low, less than $10 \mathrm{ppb}$. In contrast, NG can be expected at artillery and anti-tank rocket firing points, but its fate-and-transport properties preclude migration to groundwater.

\section{Perchlorate}

Perchlorate $\left(\mathrm{ClO}_{4}^{-}\right)$is introduced into the environment as the solid salt of ammonium, potassium, or sodium perchlorate. Ammonium and potassium perchlorate are used as the oxidizer component and primary ingredient in solid propellants for rockets, missiles, and fireworks. Perchlorates also are used in flares, smokes, tracers, and other pyrotechnics, as well as in automobile air bags, as an additive in lubricating oils, and in some batteries. Perchlorate is going to be principally found at OB/OD sites, especially those sites where fireworks have been burned. There is some evidence from Camp Edwards (AMEC 2004) that the use of artillery and mortar spotting charges containing perchlorate can contribute enough mass, resulting in groundwater impacts. Perchlorates are highly soluble, non-volatile, and typically mobile in the environment (Table A1). 


\section{Sorption}

Based on summary work by Urbansky (1998), perchlorate should behave as a conservative tracer. $\mathrm{A} \mathrm{K}_{\mathrm{d}}(0.32 \mathrm{~L} / \mathrm{kg})$ as reported by the Texas Natural Resource Conservation Commission is indicative of most measurements (TNRCC 2002).

Similarly, although a $\mathrm{K}_{\mathrm{d}}$ for perchlorate at Camp Edwards has not been measured, the experimentally determined $\mathrm{K}_{\mathrm{d}}$ for the somewhat less mobile RDX was $0.049 \mathrm{~L} / \mathrm{kg}$ for deep soil (Speitel et al. 2002). Perchlorate field data from the $\mathrm{OB} / \mathrm{OD}$ site at Camp Edwards indicate less retardation of perchlorate as compared to RDX (AMEC 2003a). Thus the site-specific $\mathrm{K}_{\mathrm{d}}$ for perchlorate must be less than $0.049 \mathrm{~L} / \mathrm{kg}$, assuming the perchlorate and RDX were released at the same time and the appropriate assumption is that perchlorate will behave as a conservative tracer.

In summary, perchlorate is readily soluble in water. Once dissolved in water, perchlorate is not significantly retarded by sorption and migrates at essentially the same rate as water.

\section{Degradation}

Perchlorate salts are persistent in the environment and are not readily degraded by either chemical or biological means. This persistence is a consequence of kinetics, not because of a lack of thermodynamic favorability (Urbansky 1998). Recent research does indicate that bacteria capable of perchlorate degradation are widely distributed in nature, but this degradation is usually not a viable path in soil or groundwater under normal environmental conditions (Logan et al. 2001, Tipton et al. 2003). Microbial reduction of perchlorate, when it does occur, results in ultimate transformation to chloride and oxygen, with degradation intermediates including chlorate $\left(\mathrm{ClO}_{3}{ }^{-}\right)$and chlorite $\left(\mathrm{ClO}_{2}{ }^{-}\right)$. The slowest step, however, is the initial reduction of the perchlorate ion; consequently no intermediates accumulate during perchlorate biodegradation.

Numerous studies have been performed to evaluate the biological treatment of perchlorate-contaminated groundwater. The research ranges from identification of specific perchlorate-degrading organisms to bench-scale fluidized-bed reactors. Although engineered biological reduction of perchlorate for drinking water has been demonstrated, the application of this 
technology is limited due to societal and engineering challenges (Urbansky 2000).

Because perchlorate is chemically stable, natural chemical reduction in the environment is not expected to be significant. Treatment of contaminated water with common reducing agents is not a practical option because the reactions are too slow, and catalysts that may speed the process have not been identified (Urbansky 1998).

\section{Phototransformation}

Perchlorate does not undergo phototransformation (Urbansky 1998).

\section{Phytotransformation}

Recent studies with vascular plants have demonstrated that perchlorate may accumulate in tissues of plants grown in soil containing perchlorate. Bulrushes, crabgrass, goldenrod, and cup grass grown in perchlorate-rich areas accumulated perchlorate. Crabgrass seeds contained perchlorate at a concentration of $1,880 \mathrm{mg} / \mathrm{kg}$. For goldenrod, perchlorate concentrations were highest in leaves $(1,030 \mathrm{mg} / \mathrm{kg})$, but it also was present in stems, roots, and seeds (Smith et al. 2001). Tobacco grown in soils treated with Chilean caliche fertilizers accumulated perchlorate in its leaves (Ellington et al. 2001).

In some instances, perchlorate can be reduced by higher plants without involvement of facultative anaerobic microorganisms (Van Aken and Schnoor 2002). Ammonium perchlorate was exposed to hydroponically grown trees and plant nodules. The work was performed under sterile conditions to ensure microbial activity did not contribute to perchlorate reduction. No toxic effects were noted and uptake was still occurring at the end of 30 days. Approximately 50 percent of the labeled perchlorate was removed from solution by poplar trees and plant nodules in 30 days, with 27.4 percent translocated in the leaves of the trees. Of the radioactivity remaining in solution, 68 percent had remained with the perchlorate ion. Both in solution and in the leaves, labeled chlorine was associated with unmetabolized perchlorate, chlorate $\left(\mathrm{ClO}_{3}{ }^{-}\right)$, chlorite $\left(\mathrm{ClO}_{2}{ }^{-}\right)$, and chloride. The authors reviewed other work involving perchlorate uptake and concluded that poplar trees are midway in the range of the performances reported for other terrestrial trees. 
Willow trees also have proven capable of perchlorate degradation, with two distinctly different phyto-processes at work. Perchlorate can be taken up and degraded in the leaves and branches while degradation can occur in the rhizosphere by perchlorate-degrading microorganisms (Nzengung et al. 1999). The presence of competing terminal electron acceptors, such as nitrates and other nutrients, interfered with the rhizodegradation of perchlorate.

Aquatic plants also may take up perchlorate and accumulate it in various tissues. Bulrushes growing in ponds with perchlorate contamination at 30 to $31 \mathrm{mg} / \mathrm{kg}$ were found to accumulate perchlorate in tissues, $7 \mathrm{mg} / \mathrm{kg}$, both above and below the waterline and in roots, with the highest accumulation in tissues above the waterline (Smith et al. 2001).

In summary, these studies indicate that perchlorate is readily taken up by certain plants. Unfortunately, transformation of the perchlorate was limited in some species, indicating that phytoremediation may have limited applicability and would require carefully managed and selected vegetation.

\section{Dilution/advection/dispersion/diffusion}

Because of its high solubility in water and low tendency to adsorb to most soils, perchlorate is readily leached from soil. Soil concentrations will be reduced by the physical mass transport processes dilution, advection, dispersion, and diffusion. The net effect of these processes is to spread the $\mathrm{RDX}$ over a greater area, thereby reducing the concentration at the groundwater interface.

Various physical processes act to reduce the concentration of perchlorate as it migrates in groundwater away from a source area. For example, recharge to the aquifer in areas downgradient of the source can result in dilution of the dissolved plume. Advective transport of dissolved contaminants through porous media results in a mixing process termed dispersion, resulting in decreasing concentration with distance from the source area. Diffusion of contaminants into low permeability layers can reduce contaminant concentrations in high permeability layers.

\section{Dissolution}

The perchlorate ion is large with a single negative charge; the resulting low charge density reduces its affinity for positively charged ions and makes it 
a very poor complexing agent. Because there are no strong binding forces at work, dissolution of perchlorate from soil to water occurs readily. The aqueous solubility of common perchlorate salts can achieve 25 percent or more on a mass/mass basis in water (Table 6).

Table 6. Perchlorate solubility.

\begin{tabular}{|c|c|c|}
\hline Perchlorate salt & $\begin{array}{c}\text { Solubility at } 25^{\circ} \mathrm{C} \\
(\mathrm{mg} / \mathrm{L})\end{array}$ & Reference \\
\hline Ammonium perchlorate & 200,000 & Ashford 1994 \\
\hline Potassium perchlorate & 15,000 & Ashford 1994 \\
\hline Sodium perchlorate & 17,000 & Kim et al. 2001 \\
\hline
\end{tabular}

These solubilities $(100,000$ 's $\mathrm{mg} / \mathrm{L})$ are far greater than the other energetic compounds most frequently detected at ranges. For comparison, Phelan (2001) reported the solubility of TNT as $115 \mathrm{mg} / \mathrm{L}$ at $23^{\circ} \mathrm{C}$, while the solubility of RDX is only $64 \mathrm{mg} / \mathrm{L}$ at $25^{\circ} \mathrm{C}$ (Yalkowsky and Dannenfelser 1992).

\section{Volatilization}

Perchlorate salts are essentially non-volatile at ambient temperatures, so losses through the vapor pathway are not significant.

\section{Field studies}

The majority of studies related to perchlorate in the environment are remediation case studies examining bioremediation and phytoremediation processes. Camp Edwards is the only military installation, to our knowledge, that has been extensively sampled (soil and groundwater) for perchlorate. Groundwater contamination is evident originating from an $\mathrm{OB} / \mathrm{OD}$ site and the artillery/mortar impact area, and will be discussed in greater detail in Section 5. Perchlorate has been found in shallow soil and groundwater near an OB/OD site at the Indian Head Naval Surface Warfare Center (Cramer 2006).

\section{Summary}

Although a strong oxidant, the perchlorate ion is kinetically stable and not reactive when dissolved in water under environmental conditions. Reduction of the chlorine in perchlorate from the +7 oxidation state to the chlo- 
ride ion ( -1 oxidation state) does not occur readily (Urbansky 1998). A high input of energy (e.g., heat, light, or physical shock) or the presence of a catalyst is necessary to initiate significant reduction. This high activation energy is an advantage in munitions and fireworks, but such chemical stability also results in environmental persistence. Perchlorates are also highly soluble and the ion has a limited tendency to interact with other dissolved chemical species or to adsorb to aquifer materials under typical environmental conditions. Consequently, the fate and transport of perchlorate released to soils and water is controlled primarily through physical rather than chemical or biological processes. Because of perchlorate's high solubility and mobility, it is not expected to remain in soil at significant concentrations. Dilution, advection, and dispersion have the most effect on perchlorate migration. 


\section{Case History: Application of Conceptual Model and Fate-and-Transport Concepts to Camp Edwards}

This section reviews data from Camp Edwards at Massachusetts Military Reservation (MMR) demonstrating the applicability of the conceptual model (Section 3) and fate and transport review (Section 4) to a comprehensive site investigation. Camp Edwards represents, to some extent, a "worse-case" scenario for migration of energetic compounds to groundwater because of 1) sandy soil with little silt, clay, or organic matter, 2) generally unsuitable (aerobic) redox conditions for the biodegradation of RDX, HMX, and perchlorate, 3) high rainfall, and 4) high aquifer flow velocities. The primary explosive mixture used in post-WWII munitions fired into the Camp Edwards Impact Area is Comp B-a mixture of RDX and TNT. HMX also is present because it is typically an impurity in RDX and is the primary component of octol-an explosive mixture used in many antitank rockets. Perchlorate is present in artillery shells containing spotting charges fired into the impact area and munitions and fireworks burned at the OB/OD site. RDX and HMX, along with perchlorate, are the principal COPCs identified, regardless of media, based both on their presence in many munition types and the heavy usage of these munitions.

\section{Impact area}

\section{Soil}

The Conceptual Model described in Section 3 is based on low-level, nonrandomly distributed particulates - a distributed source. This model is consistent with data from the Central Impact Area at Camp Edwards where 58 targets fired on from gun and mortar positions have been investigated. More than 3,500 soil samples have been collected and analyzed (AMEC 2001a, Clausen et al. 2002).

Soil sampling was conducted initially by placing two concentric rings around each target. The radii of the rings were dependent upon the dimensions of the target. Each ring grid was composed of eight evenly distributed sample points. Samples collected at these eight points were composited with discrete samples collected at the cardinal points of the compass. 
The sampling intervals for the ring grids were $0^{-}$to $3^{-}, 3^{-}$to $6-$, and 6- to 12-inch bgs.

This soil-sampling program indicated that RDX, HMX, TNT, and TNT degradation products $2 \mathrm{a}-\mathrm{DNT}$ and $4 \mathrm{a}-\mathrm{DNT}$ are the primary energetic compounds present (AMEC 2001a). The results are consistent with the Conceptual Model described in Section 3. HE residues were reported in only approximately $5 \%$ of the samples and near only 11 of 58 targets. Also, detections within a target grid were sporadic, i.e., not all sample grids had detections (AMEC 2001a). Where found, contaminants were generally more concentrated near the targets and decreased rapidly with depth. Indeed, no explosives were detected below $4 \mathrm{ft}$ bgs. As discussed below and with regard to the Conceptual Model (Section 3), the quantity and distribution of soil contamination identified with this sampling method is not consistent with the quantity and distribution of groundwater contamination.

Detection frequencies for minor contaminants were consistent with the fate-and-transport conclusions described in Section 4. For example, in the initial program (AMEC 2001a), 2,6-DNT was detected four times and 2,4DNT 14 times. Pentaerythritol tetranitrate (PETN) was detected 32 times and PA 18 times. Trinitrobenzene was not detected and 2-nitrotoluene (2NT) was detected 26 times. All of the 2-NT detections are suspect because they were associated with two sampling dates. Similarly, detections of TNB, 2-NT, PETN, and PA also are believed to have been false positives (AMEC 2001a). In summary, the soil sampling results indicated heterogeneously distributed surface soil contamination with RDX, HMX, TNT, and TNT degradation products in the impact area.

\section{Groundwater}

More than 300 individual monitoring wells have been installed at over 100 separate locations within and downgradient of the Camp Edwards Impact Area (Clausen et al. 2002, AMEC 2001c). In excess of 1,000 groundwater profile and 1,500 groundwater monitoring well samples have been collected and analyzed. Profile samples are collected from the water table down to the terminus depth of the well boring on ten-foot intervals. The monitoring wells have been sampled for energetic compounds from one to seven times. 


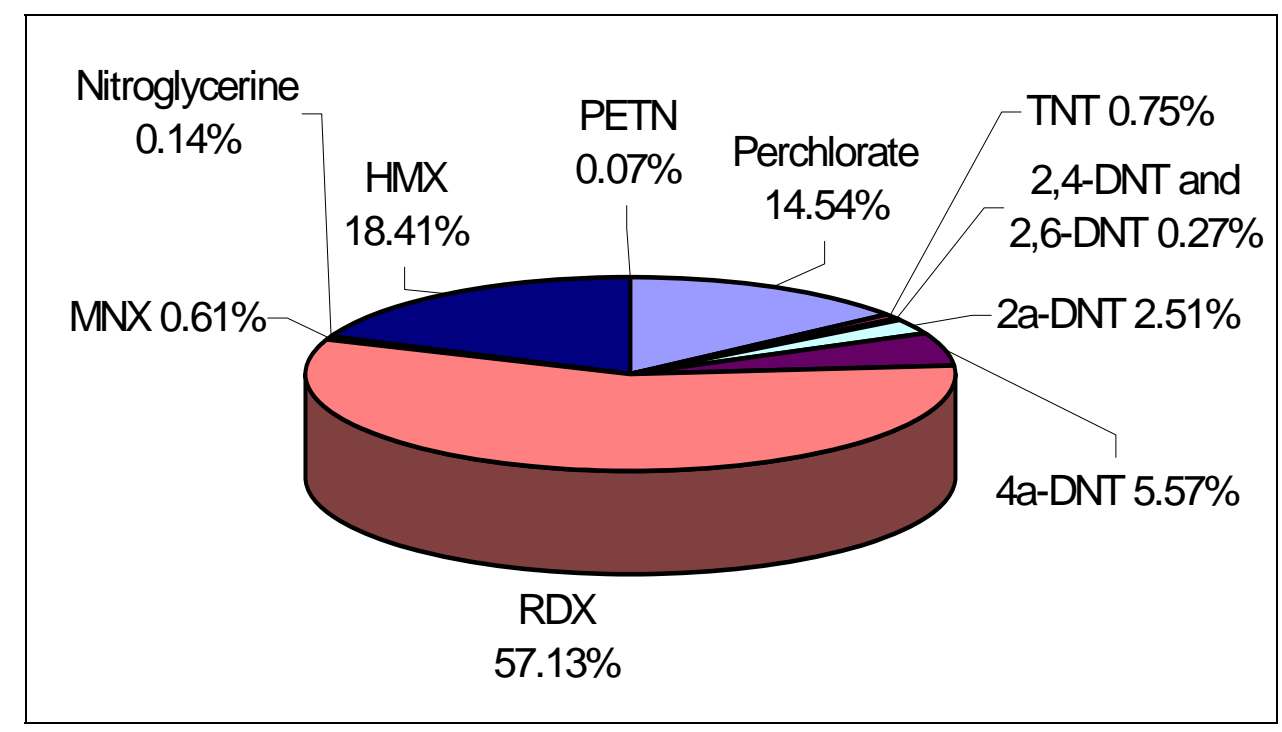

Figure 7. Relative percentage of detections of munition explosive constituents in groundwater at Camp Edwards impact area.

Figure 7 shows the relative percentage of detections of the various explosive compounds detected in groundwater. The largest percentage of detections has been of RDX, perchlorate, and HMX (AMEC 2001a). RDX concentrations typically are less than $0.010 \mathrm{mg} / \mathrm{L}$, with the maximum having been $0.029 \mathrm{mg} / \mathrm{L}$. Perchlorate has been detected at a maximum concentration of $0.005 \mathrm{mg} / \mathrm{L}$ and the HMX maximum was $0.0097 \mathrm{mg} / \mathrm{L}$. TNT was detected in four monitoring wells with a maximum concentration of $0.00066 \mathrm{mg} / \mathrm{L}$. The maximum detected concentrations of 2a-DNT and 4aDNT are 0.00076 and $0.0012 \mathrm{mg} / \mathrm{L}$, respectively. TNT and the 2a-DNTs have been identified only at locations close to the targets and have not been detected farther downgradient (AMEC 2001c).

There is a broad area of RDX contamination within the impact area spanning a width of over 4,000 $\mathrm{ft}$ (AMEC 2004, 2001a). The plume covers an area approximately 11,000 $\mathrm{ft}$ long by 5,000 $\mathrm{ft}$ wide. Approximately 880 million to 1.3 billion gallons of water encompassing an area of $2.5 \mathrm{~km}^{2}$ (618 acres) have been contaminated. The amount of RDX dissolved in this volume of contamination is approximately 30 to $80 \mathrm{lbs}$. Within the center of the impact area, RDX is present from the water table to a depth of approximately $87 \mathrm{ft}$ bwt. Along the western boundary (downgradient) of the impact area, RDX is present from approximately 22 to $96 \mathrm{ft}$ but. RDX concentrations are highest under the targets even though training activities with $\mathrm{HE}$ artillery munitions have not been conducted for more than 11 years, and with HE mortars for more than five years. Hence, sufficient contaminant mass must reside in the soil and vadose zone to maintain the 
RDX levels observed at the water table. The latter conclusion, however, was not supported by analytical data because RDX was not detected in the vadose zone and the distribution and mass in soil was not consistent with the groundwater plume. These apparent inconsistencies are resolved by applying the Conceptual Model presented in Section 3.

For example, groundwater flow modeling with particle backtracking supports the distributed source Conceptual Model (AMEC 2004). Modeling results for RDX, HMX, and perchlorate indicate the target locations are a common source for the RDX. However, the particle tracks don't converge to a single or limited number of areas but to a large area of approximately 330 acres (AMEC 2004, 2001c). This convergence area is coincidental with the known target locations, greatest cratering density and surface debris, elevated HE detections in soil, and largest airborne magnetometry anomalies (TT 2003, 2002).

The extent of perchlorate contamination is less than that of RDX, encompassing an area of approximately 500 acres (AMEC 2004, 2001a). The plume orientation is consistent with the groundwater flow direction and measures 4,200 ft at its widest. As observed for RDX and HMX, dissolved perchlorate migrates in the direction of groundwater flow and migrates deeper with increasing distance because of accretion of infiltrating precipitation onto the water table.

There appear to be two source areas for perchlorate: a particular target separate from the impact area (CS-19) and the Central Impact Area itself. Perchlorate extends 3,100 ft from the CS-19 area and 7,500 ft from the middle of the Central Impact Area. The volume of contaminated water is estimated as 8.2 to 11.1 billion L or 2.2 to 2.8 billion gallons with the mass of dissolved perchlorate equal to 3 to $4 \mathrm{~kg}$ ( 21 to $27 \mathrm{lbs}$ ). As with RDX, the distribution of perchlorate in groundwater at the Central Impact Area indicates the source may not yet be exhausted.

The maximum downgradient extent of the HMX plume is approximately $7,500 \mathrm{ft}$ or approximately three-fourths the distance of the RDX plume. Based on the groundwater flow calculations, the release dates ( $\sim 45$ years before present) for both RDX and HMX are comparable. (AMEC 2004). Lynch (2002) reported dissolution studies in which HMX dissolved faster than RDX in formulations such as octol and Comp B, but individual formulations dissolved at nearly the same rate as RDX (Section 4). Therefore, 
differences in dissolution kinetics between RDX and HMX cannot account for the differences in plume extent. The fact that the downgradient extent of HMX is less than that of RDX may suggest HMX is attenuated to a greater degree, but processes that would be responsible are unknown and the literature indicates that the degree of sorption of HMX onto aquifer solids is similar to RDX (Section 4). A more likely explanation is the low concentrations present. Because HMX is typically reported at values only slightly higher than the MDL, the physical processes of dispersion and dilution may be sufficient to reduce the concentration of HMX to levels below the MDL. Therefore, it is possible HMX is co-located throughout the RDX extent but not detectable because concentrations are below the MDL.

\section{OB/OD area}

Demolition and EOD training at Demo 1 as well as OB/OD operations began sometime in the mid-1970s and included the destruction of various types of ordnance using explosive charges of $\mathrm{C}_{4}$, TNT, and detonationcord (AMEC 2001d, 2001g). The mode of energetic compound deposition at Demo 1 is similar in some respects to the mechanisms for the Central Impact Area. Energetic residues are produced through the detonation of various rounds and OB/OD activities, and both low- and high-order detonations probably occurred. Also, starting in the mid 1980s, the State Police burned fireworks, the principal component of which is potassium perchlorate. Unlike the impact area, however, activities were concentrated in a small area, and the site is located in a kettle hole depression through which water is funneled.

Perchlorate, RDX, HMX, 2a-DNT, 4a-DNT, TNT, and 2,4-DNT have been repeatedly detected in soil and groundwater at Demo 1 (AMEC 2001e). RDX (22 percent) and HMX (13 percent) were most frequently detected with highest concentrations in discrete surface soil samples collected beneath $\mathrm{C}_{4}$ residuals. Deep soil borings provided continuous sampling data to the water table, located approximately $44 \mathrm{ft}$ bgs. Unlike the impact area, soil sampling beneath Demo 1 indicated sporadic contamination of energetic compounds within the vadose zone. The number of energetic compounds and the associated concentrations decreased with depth in the soil column, but RDX was reported in concentrations as high as $3.4 \mathrm{mg} / \mathrm{kg}$ at a depth of 24-26 ft bgs in the kettle hole. RDX detections in one boring extended almost to the water table. 
TNT also was heavily used in demolition training. Consistent with the fateand-transport discussions in Section 5, TNT was infrequently detected (2 percent), presumably because of rapid degradation to daughter products 2a-DNT (detected in 7 percent of samples) and 4a-DNT (5 percent).

The perchlorate plume at Demo 1 extends approximately 9,000 ft downgradient while the RDX plume extends approximately 5,000 $\mathrm{ft}$ (AMEC 2003a). Again, these results are consistent with the fate-and-transport properties of perchlorate and RDX (Section 4). Once introduced at the water table, perchlorate essentially moves at the velocity of groundwater, whereas RDX, HMX, 4a-DNT, 2a-DNT, and TNT are retarded in the order listed (2,4-DNT is retarded similarly to TNT). Based on laboratory column experiments and groundwater flow modeling, the retardation rate of RDX is estimated at 1.23 or 25 percent of the perchlorate rate of movement.

\section{Gun and mortar firing positions}

Thirty-seven gun and mortar firing positions were used to fire artillery and mortars at targets established within the impact area (AMEC 2001i). The propellant is not attached to the ordnance itself but rather is enclosed within bags, which are consumed within the gun with some residual fallout in and around the gun. Thus, propellants related to gun and mortar training activities are expected at the ground surface from the deposition of airborne particulates from firing the weapon. The other means of propellant introduction are from burning excess propellant bags and cleaning the artillery tubes. The munitions are shipped with the maximum number of bags needed to fire the shells their full distance. If the target is nearer than the weapon's maximum range, extra bags of propellant must be disposed. In the past, the extra propellant bags were burned on the ground behind the position, in a ditch, or along the road at the position.

The type of propellant (M1, M2, M3, etc.) is dependent on the munition. Double-base propellants contain NC as the primary constituent, with varying amounts of $\mathrm{NG}(\mathrm{O}-43$ percent by weight) as a secondary component. Nitroguanidine is used only in triple-based propellants such as M3o (for 105-mm projectiles) in which it is a major constituent. NG containing triple-based propellants were not used at Camp Edwards. Other secondary compounds used in propellants include DNTs, di-n-butylphthalate, diphenylamine, and ethylcentralite, each ranging from o to 10 percent depending on the mixture specifications. Diphenylamine is not persistent in the environment and during combustion is transformed to N-nitrosodi- 
phenylamine (see Section 4). Barium nitrate, potassium nitrate, potassium sulfate, and graphite, at $\mathbf{0}-\mathbf{1 . 5}$ percent, also are present in propellant mixtures. 2,4-DNT composes 10 percent of single-based propellants, although the overall mass of 2,4-DNT in the explosives filler in the projectile is less than one percent.

More than 1,300 soil samples were collected and analyzed for DNT at gun and mortar positions at Camp Edwards (AMEC 2001d). More than 500 samples were analyzed for other energetic compounds. Overall, 2,4-DNT was detected in four percent of these samples, approximately four times more often than 2,6-DNT. 2,4-DNT was reported from 38 separate sampling locations at 15 different gun and mortar positions. The majority (29) of the detections were in samples collected o-1 ft deep. 2,6-DNT was reported from 11 separate sample locations at eight positions, all at which 2,4-DNT was also detected. NG and PETN were detected at two locations. The two detections of PETN occurred early (March 1998) in the field investigation, prior to the use of an improved analytical technique (PDA spectral analysis with explosive Method 8330), and are likely false positives (Clausen et al. 2004a, 2002).

Diethyl phthalate and N-nitrosodiphenylamine were detected at low frequencies-3 and 6 percent, respectively. Di-n-butyl phthalate was detected at a higher frequency (18 percent), but was also present in control samples (5 percent). Those positions where N-nitrosodiphenylamine were detected also had 2,4-DNT detections. Concentrations of all constituents were low (less than $10 \mathrm{mg} / \mathrm{kg}$ ).

Twenty monitoring wells at eight locations were installed downgradient of four gun positions and four mortar positions. The groundwater data indicate that military training activities at the gun and mortar positions have not impacted the aquifer. These results are consistent with the fate-andtransport discussions in Section 4, which indicated that the compounds associated with these activities are either not mobile or are easily degraded in the environment.

\section{Rocket range}

The Known Distance (KD) Rocket Range at Camp Edwards comprises approximately 98 acres of land southeast of the impact area. The range consists of a $25-\mathrm{m}$ rifle range with 55 firing points, a $365-\mathrm{m}$-distance rifle range with 20 firing points, two firing points for Dragon missiles and 90- 
$\mathrm{mm}$ recoilless rifle training, and one firing point for Tube Launched, Optically Tracked, Wire Guided (TOW) missiles (Ogden 200ob). A portion of the range also has been used for helicopter gunship, machine gun, and grenade launcher training (USACE 1999). Live tank gunnery also was performed in this area. Records indicate 240 40-mm cannons and $80-$ and 90-mm rifle grenades were fired in 1989 and 14 TOW rockets were fired in 1994. No firing occurred in 1995 and 1996. No other firing records exist.

The mode of contaminant deposition at a rocket range is different from the areas previously discussed. At the target locations, rockets that hit the target but do not detonate will often shear apart because of their thin aluminum casing. Therefore, explosives residues and chunks of material can be expected around the target. Anti-tank rockets contain octol, a mixture of HMX and TNT. A small quantity of RDX is present in the booster of the light anti-tank weapon (LAW) rocket. NG and NC are the primary propellants used in anti-tank rockets and can be expected at the firing positions as a result of the rocket back-blast.

More than 300 soil samples were collected at firing points and targets. Nitroglycerin was the most widespread energetic compound detected (Ogden 200ob, c). NG was likely deposited on the surface as residue along with other propellant compounds from the ejected gasses and particles contained in the smoke produced by detonation during launching. NG's distribution in soil (highest concentrations at or near the surface and decreasing with depth) at the firing points is consistent with the presumed airborne deposition of propellant compounds. NG was detected in 22 of 215 samples collected between o to 2 feet in depth (Ogden 200ob, c), but in none of the six samples collected from greater than 2 feet (Ogden $2000 b, c)$. Detected concentrations ranged from an estimated high of 130 $\mathrm{mg} / \mathrm{kg}$ in a discrete sample collected at the surface to an estimated 2.9 $\mathrm{mg} / \mathrm{kg}$ in the composite sample collected from a back-blast grid at a former 90-mm rocket firing point (Ogden 200ob, 1999b). As discussed in Section 4 , NG is very susceptible to degradation processes. However, the propellants used at Camp Edwards contained NC as well as NG. If NG is bound to NC it is not as likely to dissolve and be degradable, explaining why NG persists at the rocket firing points even though training activities ceased over a decade ago.

Other explosive compounds such as HMX, RDX, and TNT were discovered only in the primary target grids (Ogden 200ob, c). These compounds were 
found in the grids positioned south and east of the target and are consistent with the known use of explosive ordnance at the range. Again, the higher concentrations were found in the upper six inches of soil, consistent with the presumed surface deposition. These findings are consistent with other anti-tank rocket range impact areas studied (Jenkins et al. 1998; Thiboutot et al. 1998a, b). The lack of detectable concentrations of explosives in soil around two other range targets suggests that live rounds may not have been used, or that the frequency of use was much lower than for the primary target.

Monitoring wells located downgradient of the primary and secondary targets and TOW firing position do not indicate any contaminants present in groundwater. The absence of NG is consistent with its physical and chemical properties. RDX and HMX were presumably not deposited in sufficient quantities to affect groundwater.

\section{Summary}

This review of data from Camp Edwards, MMR, demonstrates the consistency of the Conceptual Model (Section 3) with data from a field site. A large impact area can be described as a distributed source such that conventional sampling did not show a direct link (vadose zone contamination) between contamination in surface soil and in groundwater. The "link" between surface soil and groundwater contamination, as related to specific military training activities, is described in Section 6. Finally, despite the consistency of the conceptual model and the field data, a number of data gaps should be addressed in order to improve predictions regarding fate and transport. Those data gaps are described in Section 8. 


\section{Training, Surface Soil, and Groundwater Relationship}

Table 7 summarizes the link between training, surface soil, and groundwater based on the Conceptual Model (Section 3), fate-and-transport properties of energetic compounds (Section 4), and on the Camp Edwards case histories (Section 5). This section reviews the relative effects of the various release mechanisms and includes sample groundwater source term calculations for Camp Edwards.

In general, if munitions containing RDX and TNT such as Comp B or $\mathrm{C}_{4}$ have been used, then there is a high probability that RDX, HMX, and TNT will be present in the surface soil. If RDX and HMX are observed in soil at an impact (artillery, mortar, and anti-tank rocket) or OB/OD area, then there is a possibility for groundwater impacts. Because of perchlorate's fate-and-transport properties, it is not expected to be detectable in soil. However, if site history suggests the use of spotting charges in an impact area or the demolition of pyrotechnics, fireworks, or other devices containing perchlorate, then there is a reasonable potential for groundwater impacts. The fate-and-transport properties of RDX, HMX, and perchlorate favor movement in the environment. If RDX, HMX, or perchlorate reach the water table, then it is likely that a groundwater plume is present to some degree. The length of the plume and associated RDX, HMX, or perchlorate concentrations will be dependent on the history of munition usage and geological, geochemical, and hydrogeological conditions of the site.

The fate-and-transport properties of TNT favor its sorption and transformation within shallow surface soil, so even though TNT may be present in soil it may be precluded from reaching groundwater. However, at military installations with low organic carbon contents or shallow depths to groundwater, the presence of TNT is possible. Also, the presence of the aDNTs can be expected in soil and groundwater if the site has a history of TNT usage. Locations with concentrated activities such as OB/OD sites will have the highest probability of TNT and aDNTs being present in soil and groundwater. However, even if TNT and the aDNTs reach the water table, they continue to be sorbed by the aquifer material and undergo transformation process limiting their mobility. 
Table 7. Summary table showing link between training and environmental impacts.

\begin{tabular}{|c|c|}
\hline Area & Release mechanisms \\
\hline \multirow[b]{6}{*}{ Impact areas } & $\begin{array}{l}\text { High-order detonations release very small amounts of HE because the energetic } \\
\text { compounds are essentially consumed completely in the explosion. }\end{array}$ \\
\hline & $\begin{array}{l}\text { Low-order detonations release chunks and particulates of HE onto the ground, } \\
\text { yielding a more concentrated potential source to soil and groundwater. }\end{array}$ \\
\hline & $\begin{array}{l}\text { Rupturing of an intact UXO round by an incoming munition can release particu- } \\
\text { lates or chunks of } \mathrm{HE} \text {, depending on the degree of detonation. }\end{array}$ \\
\hline & $\begin{array}{l}\text { Low-order or high-order BIP activities result in higher explosives residue levels } \\
\text { than a high-order fired munition. }\end{array}$ \\
\hline & $\begin{array}{l}\text { Corrosion of intact UXO may eventually expose energetic compounds present in } \\
\text { filler or fuzes to the environment. However, UXO do not appear to be a signifi- } \\
\text { cant, current source of groundwater contamination at most military installations. }\end{array}$ \\
\hline & $\begin{array}{l}\text { The primary COPCs for soil are RDX, HMX, TNT, and aDNTs. The primary ground- } \\
\text { water COPCs are RDX, HMX, and perchlorate. }\end{array}$ \\
\hline \multirow{3}{*}{$\begin{array}{l}\text { Demo sites and } \\
\text { other explosive } \\
\text { and ordnance } \\
\text { disposal (EOD) or } \\
\text { (OB/OD) areas }\end{array}$} & $\begin{array}{l}\text { High-order detonations can release particulate energetic compounds residue as } \\
\text { described above. }\end{array}$ \\
\hline & $\begin{array}{l}\text { Low-order detonations can release chunks of HE from the incomplete consump- } \\
\text { tion of C4 or TNT blocks and UXO sent to demolitions sites for destruction. } \\
\text { Demolition sites generally have a small areal extent resulting in a more focused } \\
\text { source term than for an impact area. }\end{array}$ \\
\hline & $\begin{array}{l}\text { The primary soil COPCs are RDX, HMX, TNT, aDNTs, and DNTs. Potential soil } \\
\text { COPCs include NG, SVOCs, and dioxins. The primary groundwater COPCs are } \\
\text { RDX, HMX, TNT, aDNTs, and perchlorate. }\end{array}$ \\
\hline \multirow[b]{3}{*}{$\begin{array}{l}\text { Gun and mortar } \\
\text { firing positions }\end{array}$} & $\begin{array}{l}\text { Particulate deposition can occur because of the detonation of a propellant from } \\
\text { the barrel or breach of a gun. }\end{array}$ \\
\hline & $\begin{array}{l}\text { Particulate energetic compound deposition can also occur because of residuals } \\
\text { associated with incomplete combustion from the burning of excess propellant } \\
\text { bags. }\end{array}$ \\
\hline & $\begin{array}{l}\text { The primary soil COPCs are 2,4-DNT, NG, diethyl phthalate, di-n-butyl phthalate, } \\
\text { N-nitrosodiphenylamine, and possibly NG where triple-base propellant was used. } \\
\text { Unless the depth to groundwater is very shallow, migration to groundwater is not } \\
\text { expected. }\end{array}$ \\
\hline \multirow[b]{3}{*}{$\begin{array}{l}\text { Anti-tank rocket } \\
\text { ranges }\end{array}$} & $\begin{array}{l}\text { Rockets often shear apart on impact, discharging their contents. Because of a } \\
\text { high dud rate and their thin aluminum skins, larger chunks of HE can be ex- } \\
\text { pected in the target area. Also, if the propellant has not been exhausted by the } \\
\text { time the rocket reaches the target, energetic compound residues or chunks can } \\
\text { be expected. }\end{array}$ \\
\hline & $\begin{array}{l}\text { At the rocket firing positions, small energetic compound particulates can be re- } \\
\text { leased from the rocket's back-blast. }\end{array}$ \\
\hline & $\begin{array}{l}\text { The primary soil COPCs at the target locations are NG, RDX, HMX, TNT, and } \\
\text { aDNTs, whereas the primary groundwater COPCs are RDX, HMX, and aDNTs. At } \\
\text { the firing positions, the primary soil COPCs are DNTs, NC, NG, and possibly NQ, } \\
\text { whereas unless the depth to groundwater is very shallow, migration to ground- } \\
\text { water is not expected. }\end{array}$ \\
\hline
\end{tabular}


Although the presence of DNTs, NC, NG, and possibly NQ is observed in surface soils at gun and mortar firing positions as well as at anti-tank rocket firing positions, their fate-and-transport properties limit mobility in the environment. Therefore, the DNTs, NC, NG, and possibly NQ are not likely to be found in groundwater, except for those sites with very shallow aquifers, a few tens of feet below the ground surface. The presence of NQ at firing points has not been studied to date.

\section{Surface soil sample result uncertainty}

Before discussing source term estimates, problems with sample collection must be reviewed. The Conceptual Model (Section 3) and case history information from Camp Edwards (Section 5) are self-consistent. This judgment, however, is based somewhat on inference because contamination has been detected in surface soils and groundwater, but not in the intervening subsoil. Although the latter data gap has been successfully addressed with some limited pore water sampling (Clausen et al. 2004c), it remains important to address how to obtain an accurate value for a soil source of HE. Numerous studies have demonstrated the difficulty of assessing the degree of contamination on military ranges because the distribution of explosive particulates is so heterogeneous (M. R. Walsh et al. 2005; Pennington et al. 2002a; Radtke et al. 2002; Thiboutot et al. 2002; Walsh et al. 2001; AMEC 2001a; Ogden 2000d; Jenkins et al. 2001a, 1999, 1998, 1997a, b, 1996; Crockett et al. 1998b, 1996; USEPA 1993). These investigators have agreed that discrete, random samples are ineffective for characterizing energetic compound particulate residues. The only way to capture a representative sample is through multi-increment sampling. Furthermore, investigations reported by M. R. Walsh et al. (2005) and Pennington et al. (2002a) suggest that the number of subsamples per increment is an important factor and that increasing the number of increments increases the probability of encountering an explosive particulate without diluting the sample. Higher maximum and average soil concentrations were observed using a 30-point multi-increment sample versus 9and 5-point multi-increment samples (AMEC 2001a). Recently published work (Jenkins et al. 2005a, M. R. Walsh et al. 2005) suggests that 30- to 100-point multi-increment samples may be appropriate to address the heterogeneity issue for most ranges and also suggests grinding the sample (Walsh et al. 2002). 


\section{Impact and source-term estimates for specific military activities}

\section{High-order detonations}

A high-order detonation occurs from the inside out with most of the HE consumed prior to rupture of the munition casing. Determining a highorder detonation versus low-order can be accomplished by measuring the speed of the explosive shock wave and the detonation peak pressure. Highorder detonations result in very small quantities of explosives residues (Hewitt et al. 2005, 2003), but the quantity produced is so small that it does not contribute significantly to overall explosives contamination. Hewitt et al. (2003) further suggest that high-order detonations are not a source of significant residues and are unlikely to account for HE levels measured in soils at ranges through the United States and Canada. The following discussion, based on data from Camp Edwards, is consistent with this assessment. Data available from Range Control at Camp Edwards on the number and types of ordnance fired in 1989 is presented in Table 8. The records indicate that combinations of 60-, 81-, 105-, and 155-mm projectiles were fired into the impact area from various firing positions with a total of 10,380 projectiles fired in 1989. Records indicate that the 60-, 81-, $105^{-}$, and 155-mm projectiles each contain approximately 114, 567, 1,383, and 4,200 g of RDX, respectively (Kitchens et al. 1978). Note that the mass of HE is different for different model types of the same munition class. For example, the mass of HE filler in Model numbers M362, M374, M43, and M56 for an 81-mm mortar is 1,000, 1,000, 1,570, and 2,000 g, respectively (Kitchens et al. 1978). The first three models contain Comp B, whereas the M56 model contains only TNT. Assumptions had to be made regarding the munition model in order to determine the mass of RDX contained within the HE filler. Thus, approximately $26,000 \mathrm{lbs}$ or $12,000 \mathrm{~kg}$ of RDX is assumed to be contained in the 10,380 projectiles (Table 8). High-order detonations of 60-, 81-, and 120-mm mortars and 105- and 155-mm artillery rounds detonated on snow using common military live-fire techniques conducted by Hewitt et al. (2003) indicate that RDX residues of 0.000007 to 0.002 percent are deposited on the ground surface. Based on the 1989 firing information for Camp Edwards, the annual loading of RDX from high-order detonations would be approximately 0.83 to $237 \mathrm{~g}$. 
Table 8. Munitions fired at Camp Edwards in 1989 and estimate of cumulative RDX contamination during the 44-year period 1945 to 1989.

\begin{tabular}{|c|c|c|c|c|c|c|c|}
\hline \multicolumn{8}{|c|}{ a. Low estimate } \\
\hline $\begin{array}{l}\text { Position } \\
\text { name }\end{array}$ & $\begin{array}{l}\text { Weapon } \\
\text { system }\end{array}$ & $\begin{array}{c}\text { Annual } \\
\text { munition } \\
\text { usage } \\
1989 \\
\end{array}$ & $\begin{array}{c}\text { Total } \\
\text { annual } \\
\text { RDX mass } \\
\text { (kg) }\end{array}$ & $\begin{array}{c}\text { High-order } \\
\text { residue mass } \\
(0.000007 \%) g\end{array}$ & $\begin{array}{c}\text { Correction } \\
\text { for soot } \\
\text { sorption } \\
(8 \%) g\end{array}$ & $\begin{array}{l}\text { Cumulative } \\
\text { high-order } \\
\text { residue } \\
\text { (44 years) } \\
\text { (g) }\end{array}$ & $\begin{array}{c}\text { Concentration } \\
\text { contaminated } \\
\text { soil }(44 \text { years) } \\
\quad(\mu \mathrm{g} / \mathrm{kg})\end{array}$ \\
\hline GP6 & $155 \mathrm{~mm}$ & 117 & 490 & 0.0343 & 0.0371 & 1.6312 & $7.25 \mathrm{E}-02$ \\
\hline GP7 & $155 \mathrm{~mm}$ & 126 & 528 & 0.0370 & 0.0399 & 1.7567 & 7.81E-02 \\
\hline GP8 & $155 \mathrm{~mm}$ & 70 & 293 & 0.0205 & 0.0222 & 0.9759 & 4.34E-02 \\
\hline GP9 & $155 \mathrm{~mm}$ & 90 & 377 & 0.0264 & 0.0285 & 1.2548 & $5.58 \mathrm{E}-02$ \\
\hline GP10 & $155 \mathrm{~mm}$ & 162 & 679 & 0.0475 & 0.0513 & 2.2586 & 1.00E-01 \\
\hline GP11 & $155 \mathrm{~mm}$ & 144 & 604 & 0.0422 & 0.0456 & 2.0076 & 8.92E-02 \\
\hline GP12 & $155 \mathrm{~mm}$ & 75 & 314 & 0.0220 & 0.0238 & 1.0456 & 4.65E-02 \\
\hline GP14 & $155 \mathrm{~mm}$ & 112 & 469 & 0.0329 & 0.0355 & 1.5615 & $6.94 \mathrm{E}-02$ \\
\hline GP16 & $155 \mathrm{~mm}$ & 182 & 763 & 0.0534 & 0.0577 & 2.5374 & 1.13E-01 \\
\hline GP17 & $155 \mathrm{~mm}$ & 43 & 180 & 0.0126 & 0.0136 & 0.5995 & 2.66E-02 \\
\hline GP18 & $155 \mathrm{~mm}$ & 43 & 180 & 0.0126 & 0.0136 & 0.5995 & $2.66 \mathrm{E}-02$ \\
\hline GP20 & $155 \mathrm{~mm}$ & 172 & 721 & 0.0505 & 0.0545 & 2.3980 & 1.07E-01 \\
\hline GP22 & $155 \mathrm{~mm}$ & 184 & 771 & 0.0540 & 0.0583 & 2.5653 & $1.14 \mathrm{E}-01$ \\
\hline \multirow{2}{*}{ MP1 } & $60 \mathrm{~mm}$ & 452 & 52 & 0.0036 & 0.0039 & 0.1719 & $7.64 \mathrm{E}-03$ \\
\hline & $81 \mathrm{~mm}$ & 713 & 408 & 0.0285 & 0.0308 & 1.3555 & $6.02 \mathrm{E}-02$ \\
\hline \multirow{3}{*}{ MP2 } & $60 \mathrm{~mm}$ & 186 & 21 & 0.0015 & 0.0016 & 0.0707 & 3.14E-03 \\
\hline & $81 \mathrm{~mm}$ & 293 & 167 & 0.0117 & 0.0127 & 0.5570 & $2.48 \mathrm{E}-02$ \\
\hline & $105 \mathrm{~mm}$ & 704 & 973 & 0.0681 & 0.0736 & 3.2377 & 1.44E-01 \\
\hline \multirow{3}{*}{ MP3 } & $60 \mathrm{~mm}$ & 346 & 40 & 0.0028 & 0.0030 & 0.1316 & 5.85E-03 \\
\hline & $81 \mathrm{~mm}$ & 545 & 311 & 0.0218 & 0.0235 & 1.0361 & 4.61E-02 \\
\hline & $105 \mathrm{~mm}$ & 375 & 518 & 0.0363 & 0.0392 & 1.7246 & 7.66E-02 \\
\hline \multirow{3}{*}{ MP4 } & $60 \mathrm{~mm}$ & 452 & 52 & 0.0036 & 0.0039 & 0.1719 & $7.64 \mathrm{E}-03$ \\
\hline & $81 \mathrm{~mm}$ & 713 & 408 & 0.0285 & 0.0308 & 1.3555 & $6.02 \mathrm{E}-02$ \\
\hline & $105 \mathrm{~mm}$ & 725 & 1002 & 0.0702 & 0.0758 & 3.3343 & 1.48E-01 \\
\hline \multirow{3}{*}{ MP5 } & $60 \mathrm{~mm}$ & 106 & 12 & 0.0008 & 0.0009 & 0.0403 & 1.79E-03 \\
\hline & $81 \mathrm{~mm}$ & 167 & 95 & 0.0067 & 0.0072 & 0.3175 & $1.41 \mathrm{E}-02$ \\
\hline & $105 \mathrm{~mm}$ & 196 & 271 & 0.0190 & 0.0205 & 0.9014 & 4.01E-02 \\
\hline \multirow{2}{*}{ MP6 } & $60 \mathrm{~mm}$ & 372 & 43 & 0.0030 & 0.0032 & 0.1414 & $6.29 \mathrm{E}-03$ \\
\hline & $81 \mathrm{~mm}$ & 587 & 335 & 0.0235 & 0.0254 & 1.1160 & 4.96E-02 \\
\hline \multirow{2}{*}{ MP7 } & $60 \mathrm{~mm}$ & 426 & 49 & 0.0034 & 0.0037 & 0.1620 & 7.20E-03 \\
\hline & $81 \mathrm{~mm}$ & 671 & 384 & 0.0268 & 0.0290 & 1.2757 & 5.67E-02 \\
\hline \multirow{2}{*}{ MP8 } & $60 \mathrm{~mm}$ & 324 & 37 & 0.0026 & 0.0028 & 0.1232 & $5.48 \mathrm{E}-03$ \\
\hline & $81 \mathrm{~mm}$ & 507 & 290 & 0.0203 & 0.0219 & 0.9639 & $4.28 \mathrm{E}-02$ \\
\hline Total & & 10,380 & 11,839 & 0.829 & 0.895 & 39.380 & 1.750 \\
\hline
\end{tabular}


Table 8 (cont'd.). Munitions fired at Camp Edwards in 1989 and estimate of cumulative RDX contamination during the 44-year period 1945 to 1989.

\begin{tabular}{|c|c|c|c|c|c|c|c|}
\hline \multicolumn{8}{|c|}{ b. High estimate } \\
\hline $\begin{array}{l}\text { Position } \\
\text { name }\end{array}$ & $\begin{array}{l}\text { Weapon } \\
\text { system }\end{array}$ & $\begin{array}{c}\text { Annual } \\
\text { munition } \\
\text { usage } \\
1989\end{array}$ & $\begin{array}{c}\text { Total } \\
\text { annual } \\
\text { RDX mass } \\
(\mathrm{kg})\end{array}$ & $\begin{array}{l}\text { High-order } \\
\text { residue } \\
\text { mass } \\
(0.002 \%) \mathrm{g}\end{array}$ & $\begin{array}{l}\text { Correction } \\
\text { for soot } \\
\text { sorption } \\
(20 \%) g\end{array}$ & $\begin{array}{l}\text { Cumulative } \\
\text { high-order } \\
\text { residue } \\
\text { (44 years) } \\
\text { (g) }\end{array}$ & $\begin{array}{c}\text { Concentration } \\
\text { contaminated } \\
\text { soil (44 years) } \\
(\mu \mathrm{g} / \mathrm{kg})\end{array}$ \\
\hline GP6 & $155 \mathrm{~mm}$ & 117 & 490 & 10 & 12 & 518 & $2.30 \mathrm{E}+01$ \\
\hline GP7 & $155 \mathrm{~mm}$ & 126 & 528 & 11 & 13 & 558 & $2.48 \mathrm{E}+01$ \\
\hline GP8 & $155 \mathrm{~mm}$ & 70 & 293 & 6 & 7 & 310 & $1.38 \mathrm{E}+01$ \\
\hline GP9 & $155 \mathrm{~mm}$ & 90 & 377 & 8 & 9 & 398 & 1.77E+01 \\
\hline GP10 & $155 \mathrm{~mm}$ & 162 & 679 & 14 & 16 & 717 & $3.19 \mathrm{E}+01$ \\
\hline GP11 & $155 \mathrm{~mm}$ & 144 & 604 & 12 & 14 & 637 & $2.83 E+01$ \\
\hline GP12 & $155 \mathrm{~mm}$ & 75 & 314 & 6 & 8 & 332 & $1.48 \mathrm{E}+01$ \\
\hline GP14 & $155 \mathrm{~mm}$ & 112 & 469 & 9 & 11 & 496 & $2.20 \mathrm{E}+01$ \\
\hline GP16 & $155 \mathrm{~mm}$ & 182 & 763 & 15 & 18 & 806 & $3.58 \mathrm{E}+01$ \\
\hline GP17 & $155 \mathrm{~mm}$ & 43 & 180 & 4 & 4 & 190 & $8.46 \mathrm{E}+00$ \\
\hline GP18 & $155 \mathrm{~mm}$ & 43 & 180 & 4 & 4 & 190 & $8.46 \mathrm{E}+00$ \\
\hline GP20 & $155 \mathrm{~mm}$ & 172 & 721 & 14 & 17 & 761 & $3.38 \mathrm{E}+01$ \\
\hline GP22 & $155 \mathrm{~mm}$ & 184 & 771 & 15 & 19 & 814 & $3.62 \mathrm{E}+01$ \\
\hline \multirow{2}{*}{ MP1 } & $60 \mathrm{~mm}$ & 452 & 52 & 1 & 1 & 55 & $2.42 \mathrm{E}+00$ \\
\hline & 81 mm & 713 & 408 & 8 & 10 & 430 & $1.91 \mathrm{E}+01$ \\
\hline \multirow{3}{*}{ MP2 } & $60 \mathrm{~mm}$ & 186 & 21 & 0 & 1 & 22 & 9.98E-01 \\
\hline & $81 \mathrm{~mm}$ & 293 & 167 & 3 & 4 & 177 & $7.86 \mathrm{E}+00$ \\
\hline & $105 \mathrm{~mm}$ & 704 & 973 & 19 & 23 & 1028 & $4.57 \mathrm{E}+01$ \\
\hline \multirow{3}{*}{ MP3 } & $60 \mathrm{~mm}$ & 346 & 40 & 1 & 1 & 42 & $1.86 \mathrm{E}+00$ \\
\hline & $81 \mathrm{~mm}$ & 545 & 311 & 6 & 7 & 329 & $1.46 \mathrm{E}+01$ \\
\hline & $105 \mathrm{~mm}$ & 375 & 518 & 10 & 12 & 547 & $2.43 E+01$ \\
\hline \multirow{3}{*}{ MP4 } & $60 \mathrm{~mm}$ & 452 & 52 & 1 & 1 & 55 & $2.42 \mathrm{E}+00$ \\
\hline & $81 \mathrm{~mm}$ & 713 & 408 & 8 & 10 & 430 & $1.91 \mathrm{E}+01$ \\
\hline & $105 \mathrm{~mm}$ & 725 & 1002 & 20 & 24 & 1058 & 4.70E+01 \\
\hline \multirow{3}{*}{ MP5 } & $60 \mathrm{~mm}$ & 106 & 12 & 0 & 0 & 13 & 5.69E-01 \\
\hline & $81 \mathrm{~mm}$ & 167 & 95 & 2 & 2 & 101 & $4.48 \mathrm{E}+00$ \\
\hline & $105 \mathrm{~mm}$ & 196 & 271 & 5 & 7 & 286 & $1.27 \mathrm{E}+01$ \\
\hline \multirow{2}{*}{ MP6 } & $60 \mathrm{~mm}$ & 372 & 43 & 1 & 1 & 45 & $2.00 \mathrm{E}+00$ \\
\hline & $81 \mathrm{~mm}$ & 587 & 335 & 7 & 8 & 354 & $1.57 \mathrm{E}+01$ \\
\hline \multirow{2}{*}{ MP7 } & $60 \mathrm{~mm}$ & 426 & 49 & 1 & 1 & 51 & $2.29 \mathrm{E}+00$ \\
\hline & $81 \mathrm{~mm}$ & 671 & 384 & 8 & 9 & 405 & $1.80 \mathrm{E}+01$ \\
\hline \multirow{2}{*}{ MP8 } & $60 \mathrm{~mm}$ & 324 & 37 & 1 & 1 & 39 & $1.74 \mathrm{E}+00$ \\
\hline & $81 \mathrm{~mm}$ & 507 & 290 & 6 & 7 & 306 & $1.36 \mathrm{E}+01$ \\
\hline Total & & 10,380 & 11,839 & 237 & 284 & 12,502 & 555.6 \\
\hline
\end{tabular}


Jenkins et al. (2000a) suggest that the amount of RDX residue from a high-order detonation might be underestimated as a result of sorption of RDX onto soot particles. Current soil preparation analytical procedures may be unable to retrieve the soot-laden RDX from the soil matrix because of strong sorption or incorporation into the soot particle. Work by Pennington et al. (2002a) is attempting to address this analytical issue. The amount of RDX mass being underestimated could range from 8 to 20 percent (Pennington et al. 2002a). If this factor is taken into consideration, the annual RDX loading presented in the previous paragraph is approximately 0.90 to $284 \mathrm{~g}$, suggesting that sorption of RDX onto soot at Camp Edwards is insignificant. Assuming the 1989 firing information is consistent for activities occurring from 1945 to 1989, the estimated amount of $\mathrm{RDX}$ introduced into the impact area from high-order detonations is roughly 0.04 to $12.5 \mathrm{~kg}$. Previously, the amount of RDX present in the groundwater plume was estimated to be 13 to $36 \mathrm{~kg}$ (AMEC 2004, 2001b), suggesting that high-order deposition likely is not responsible for the observed RDX in groundwater at Camp Edwards.

It is also instructive to review high-order deposition rates with regard to soil contamination. Assuming that all the rounds were detonated around targets in the 330 -acre $\left(1.3365-\mathrm{km}^{2}\right)$ Central Impact Area and that RDX is present in only the top $1 \mathrm{~cm}$ of the soil, the volume of contaminated soil is $1.34 \mathrm{E} 10 \mathrm{~cm}^{3}$. The bulk density of the soil is $1.68 \mathrm{~g} / \mathrm{cm}^{3}$ (AMEC 2001a). Therefore, the mass of soil over 330 acres to a depth of $1 \mathrm{~cm}$ is $2.25 \mathrm{E} 1 \mathrm{~g}$. The average soil concentration for the 330 acres can be determined by dividing the estimated mass of RDX residue from high-order detonations by the estimated mass of the soil. The calculations yield an average soil concentration for 44 years (1945 to 1989) of high-order detonations of 1.75 to $556 \mu \mathrm{g} / \mathrm{kg}$ of RDX. Actual soil sample results (factoring in the non-detects using one half of the MDL [0.005 mg/kg]) suggest an average RDX soil concentration in the Central Impact Area of $1.6 \mathrm{mg} / \mathrm{kg}$ (AMEC 2001a). However, surface soil sampling at Target 42 using improved sampling techniques yielded average soil concentrations nearly an order of magnitude higher (Clausen et al. 2004c). These results strongly suggest that high-order detonations cannot account for the mass of RDX observed in soil within the Central Impact Area at Camp Edwards.

\section{Low-order detonations}

A low-order detonation is a deflagration of an ordnance item that does not detonate as intended. The round is partially detonated with solid explosive 
filler either ejected onto the ground surface or remaining within the shell body. The work by Jenkins et al. (2006, 2005b) and Pennington et al. (2002a) suggests that the major source of explosives residues from military training is low-order detonations resulting in solid chunks of percent level explosive filler being heterogeneously distributed on a range. Some low-order detonations also may be associated with blow-in-place activities: when a UXO is deemed unsafe to move they are BIP. The amount of HE residue produced varies with the type of charge used and postdetonation cleanup activity.

If the 1989 Camp Edwards range-use data discussed previously are used in conjunction with an assumption that the low-order rate is consistent over the time span from 1945 to 1989 using rates determined below (US Army Defense Ammunition Center 2000), a total of 1,276 rounds could have undergone low-order detonations (approximately 29 per year) in the impact area. To date, 57 rounds have been identified indicative of low-order detonations within the impact area. Figure 8 is an example of a 4.2-inch mortar low-order detonation discovered during BIP crater excavation. The explosive filler is exposed from an incomplete detonation. The photo shows the wall structure of the ordnance item to be intact and not corroding to a great extent. Although there appears to have been some initial surface corrosion, the round has not corroded through to the filler. A protective layer of metal oxides probably formed and is providing protection from further corrosion, or at least greatly reducing the rate of continued corrosion.

The following calculation illustrates the potential loading of HE to the environment through low-order detonations. A low-order rate (percentage of munitions fired that undergo low-order detonations) of 0.02 percent for 60-mm projectiles, 0.11 percent for $81-\mathrm{mm}$ projectiles, 1.07 percent for 105-mm projectiles, and 0.99 percent for $155-\mathrm{mm}$ projectiles was used for this calculation (US Army Defense Ammunition Center 2000, Table 3). For this example, it is assumed that all the low-order detonations occurred within the Central Impact Area. Further, it is assumed that 50 percent of the explosive ignited and that 50 percent is residue. Then approximately 2.10E6 $\mathrm{g}$ of RDX could be present, taking into account the 60:40 RDX: TNT mixture of Comp B. Using the mass of soil previously calculated for the 330 acres yields an average soil concentration of $93 \mathrm{mg} / \mathrm{kg} \mathrm{RDX}$. This is significantly above the current estimated average soil concentration of $1.6 \mathrm{mg} / \mathrm{kg}$, suggesting that low-order detonations could be the principal contributor to groundwater contamination. As discussed earlier, given the 
heterogeneity issue with the dispersal of explosive particulates, it is possible the current sampling protocols have underestimated the mass of explosives introduced into the environment.

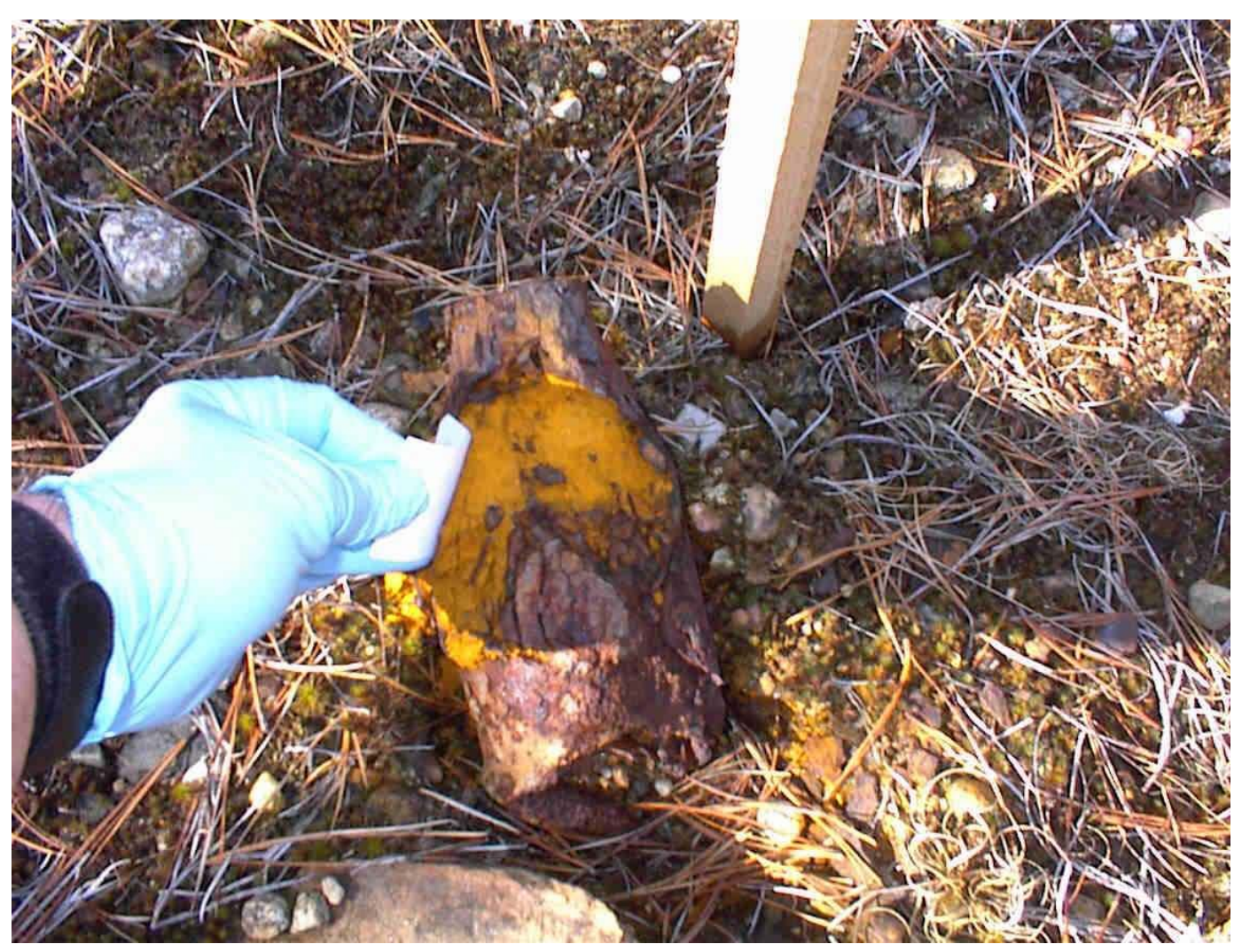

Figure 8. Example of a low-order detonation.

For example, a typical soil composite sample consists of a $0.25-\mathrm{cm}-$ diameter core and thus represents much less than $1 / 10$ of 1 percent of the area being investigated-a 15 - or $25-\mathrm{ft}$ radius around a target-even with eight increments making up a multi-increment soil sample. Comparisons between multi-increment soil samples containing eight increments and 100-increment multi-increment samples indicated an order of magnitude difference in results (Clausen et al. 2004c). The likelihood that low-order detonations are the primary mechanism for introducing explosives into the environment at Camp Edwards is consistent with the work of Jenkins et al. (2006, 2005b) and Pennington et al. (2002a, b).

As discussed above, few low-order detonations have been found at Camp Edwards. It is possible explosive filler from the low-order detonations is present in the field but cannot be recognized because of similarity in color and texture to the native soil and because of concealment by vegetation. 
An example is a sample of soil collected beneath a chunk of $\mathrm{C}_{4}$ from a partial detonation at the Demo 1 site at Camp Edwards. Although the soil result indicated an RDX concentration of $14,000 \mathrm{mg} / \mathrm{kg}$, neither the field nor laboratory technicians observed HE present in the soil sample. Given the weathered appearance of Comp B, it is quite possible that chunks of $\mathrm{HE}$ could be incorporated in soil samples without recognition by field or laboratory personnel. Also, the probability of encountering a chunk in a sample is quite low. Radtke et al. (2002) present a method to calculate the probability of encountering solid HE based on the size of the material. This work suggests a greater probability for encountering small particles and a lower probability for finding large particles (see Section 8).

\section{Unexploded ordnance}

Unexploded ordnance consists of rounds fired or fuzed that have not undergone a detonation. Although present at ranges, UXO do not appear to be the primary source of groundwater contamination. Estimates of the rate to perforation based on corrosion chemistry suggest most existing UXO will not be perforated for many decades or even centuries (Section 2). However, there is potential for older mortar rounds with thin walls to have completely corroded through to the filler.

A limited amount of information is available on the quantity and types of rounds fired at individual military installations. If the estimates of rounds fired at Camp Edwards in 1989 (Table 8) are extrapolated over time (i.e., 44 years), approximately 457,000 rounds have been fired into the impact area. This probably underestimates the actual number of rounds fired, because the 1989 estimate represents peacetime military training. The Range Use History report (Ogden 1997) suggests that the amount of munitions fired into the impact area could have been much greater during times of military conflicts such as WWII and the Korean and Vietnam Wars.

Records of all UXO encountered during field operations at MMR from January 2000 through November 2002 (TT 2003, 2002) were supplemented with records of all rounds BIP by AMEC and from July 2000 through June 2002. This combined dataset has records for over 50,000 items, including UXO/OE, debris/scrap, geologic features, inert rounds, large segments of rounds, shrapnel/fragments, and other military materials discovered at the impact area and other locations. Approximately 195 HE UXO items have been found in the impact area, suggesting a dud rate of 0.04 percent based on the 1989 data. However, the entire 330 acres of 
the Central Impact Area have not been intrusively cleared, so the dud rate is likely to be higher. The US Army Defense Ammunition Center (2000) estimates the average dud rate for all munitions is 3.45 percent. A similar dud rate was obtained in a study at Fort Lewis, Washington, in 1989 (Jenkins et al. 2000a). Based on the latter rates and the 1989 Range Control munition usage rate at Camp Edwards, the estimated number of UXO containing HE in the impact area at Camp Edwards could be greater than 15,000 .

The following discussion illustrates the potential impact of a perforation of a UXO with a small portion of the HE filler diffusing into the environment. These calculations were conducted to discern the mass loading to the environment, that is, to determine whether a single UXO with slow leakage of HE filler could pose a threat to groundwater.

The scenario involves perforation of a UXO many years after emplacement into the environment. Precipitation would diffuse into the perforation, come to the saturation limit with the HE, and then diffuse back out of the hole as precipitation fills the shell. The calculation evaluates RDX and a single 155-mm HE round, which contains 7,000 g (15.4 pounds) of Comp B. RDX comprises 60 percent or 4,200 g of Comp B. For the sake of calculation it is assumed that $10 \mathrm{~mL}$ of $\mathrm{RDX}$-contaminated water at a concentration of $42 \mathrm{mg} / \mathrm{L}$ comes in contact with the soil. It is assumed this $10 \mathrm{~mL}$ of water mixes with $125 \mathrm{~cm}^{3}$ of soil, roughly a $5^{-} \times 5^{-\mathrm{cm}}$ area $5 \mathrm{~cm}$ thick. Mixing $10 \mathrm{~mL}$ of water with $125 \mathrm{~cm}^{3}$ of soil results in a soil concentration of $2 \mathrm{mg} / \mathrm{kg}$. With a vadose thickness of $120 \mathrm{ft}$, the resulting RDX groundwater concentration immediately beneath the round would be $3.6 \mu \mathrm{g} / \mathrm{L}$ based on simulation using the Seasonal Soil Compartment Theory and Model (SESOIL). Thus, a single UXO HE round periodically releasing HE filler does have the potential to result in an RDX groundwater concentration greater than $0.002 \mathrm{mg} / \mathrm{L}$, the USEPA HA under this scenario. However, dispersion would quickly, within tens of feet, dilute the RDX below current analytical detection limits. Moreover, the scenario just described is unrealistic. Perforations occurring through corrosion processes would permit only a portion of the explosive filler to be dissolved at any one time. The mechanism of release would be complex with an initial corrosion pit forming, exposing the explosive filler, which would not come in contact with soil until mobilized by precipitation. The location and size of the perforation would determine how much water is available and how long it is in contact with the explosive material. Considering the variables involved 
(temperature, depth to the water table, etc.), it is not possible to predict accurately a groundwater concentration arising from corrosion of UXO and subsequent slow dissolution of filler material. Nevertheless, as described in Section 2, most UXO will not corrode through for decades to centuries, so they are not a primary source of groundwater contamination at present. Also, breaching is apt to be so heterogeneous in terms of time and rate of loss of filler that UXO may never be a significant contamination source to groundwater.

\section{Open burning/open detonation}

OB/OD activities have resulted in energetic compounds being released into the environment (Pennington et al. 2005; AMEC 2001d; Ampleman 2000, 1998; Martel et al. 1998). Because a concentrated activity is being conducted in a small space, the potential for energetic compounds to reach groundwater is increased along with the expectation of higher soil and groundwater energetic compound concentrations. As discussed in Section

3 , the highest energetic compound concentrations in soil and groundwater have been observed at an OB/OD area (Demo 1) at Camp Edwards (AMEC 2003a). Since a wider variety of actions, intensity of use, and concentration of activities occurred in the Demo areas, a greater variety of contaminants are likely to be present. Thus, OB/OD activities concentrated in a single area can be expected to result in point-source groundwater contamination as observed at other military installations (Ampleman et al. 1998; Martel et al. 1998, 1996).

\section{Summary}

Vadose zone modeling results at Camp Edwards are consistent with field observations, indicating that HMX, RDX, and perchlorate will migrate to the water table (AMEC 2004, 2003a). Similarly, groundwater flow modeling results based on known contaminant detections and distance of migration are consistent with the previously described mechanisms identifying the impact area and Demo 1 as sources of groundwater contamination at Camp Edwards. Therefore, it can be concluded that artillery and mortar training (impact area), OB/OD, and EOD activities potentially can cause groundwater contamination of HMX, RDX, and perchlorate at other military installations. Also, the compounds TNT, 2a-DNT, and 4a-DNT have been found in groundwater at some locations, although the extent of migration for these compounds is limited. It can be assumed that HMX, $\mathrm{RDX}$, and perchlorate are potential COPCs for other military installations 
with geologic, meteorological, and training activities similar to those at Camp Edwards. It may also be concluded that not all energetic compounds are a significant risk to groundwater. Specifically, soil contamination with several other energetic compounds (TNT, 2a-DNT, 4a-DNT, 2,4-DNT, 2,6DNT, 2,4-DANT, NG, and TNB) has been linked to training activities associated with firing of artillery, mortars, and rockets, but most of these compounds (2,4-DNT, 2,6-DNT, 2,4-DANT, NG, and TNB) are typically not found in groundwater. Some compounds, such as PA, PETN, tetryl, NTs, $\mathrm{NB}, \mathrm{DNB}$, and TNB, are rarely detected, and for the most part are not present in munitions. Occasional detections suggest the possibility that some of these observances are false-positive detections (Clausen et al. 2004a).

TNT at Camp Edwards is almost completely sorbed/biodegraded before reaching groundwater except at Demo 1, where a larger source term and shorter distance to the water table permitted trace concentrations to reach groundwater. Periodic detections also have been observed at two locations in the Central Impact Area at Camp Edwards (AMEC 2004). In both cases, TNT is rapidly degraded in the aquifer and is no longer present a few hundred feet from the sources. However, according to studies at explosive and propellant manufacturing and OB/OD sites (Section 4, Pennington et al. 1999, 1998b), immobile by-products of TNT remain in the soil. A significant percentage of the TNT biotransformation products may be irreversibly bound and unextractable and therefore unidentifiable and unquantifiable. Moreover, TNT photodegrades readily if surface water is sufficiently persistent and shallow. These fate-and-transport properties make TNT preferable to RDX and HMX for HE training on military ranges.

The concentration of DNTs deposited during firing is low, as illustrated by accumulations of 2,4-DNT typically less than $1 \mathrm{mg} / \mathrm{kg}$ for surface soils collected at Camp Edwards (AMEC 2001i) and elsewhere (Walsh et al. 2004b). Furthermore, there is significant propensity for adsorption and biodegradation to remove the DNTs (Nishino et al. 2000, 1999; Spain et al. 2000). The latter mechanism is supported by field sampling work conducted at the Camp Edwards gun and mortar firing positions (AMEC 2002d). Soil sampling found 2,4- and 2,6-DNT to be limited to the top $2 \mathrm{ft}$. Modeling without a biodegradation component indicated that 2,4and 2,6-DNT could reach the aquifer depth of $120 \mathrm{ft}$, but only at concentrations well below current detection limits. If a biodegradation component is included in the vadose zone model, then the DNTs do not migrate more than a few feet (AMEC 2003a). The modeling conclusions are sup- 
ported by the absence of DNT in groundwater downgradient of the gun and mortar positions and within the impact area. Although 2,4-DNT has been sporadically detected in groundwater at the Demo 1 source area, in one well it has not been detected consistently (AMEC 2003a). If the DNT detections at Demo 1 are accurate, they could be the result of two sitespecific factors: (1) rapid recharge resulting from funneling of water through the kettle hole, and (2) sufficiently large contaminant mass to overload the microorganisms' capability to degrade the 2,4-DNT.

Data from the Camp Edwards KD Rocket Range indicate that NG is not mobile in soil (Ogden 2000a). The sampling program identified NG in the o- to 6-inch interval in nine grids, but only two of nine contained NG in the 6- to 12-inch interval. NG is relatively water-soluble, but once dissolved it is rapidly adsorbed and degraded and is lost from the system. Where NG is retained and measured in soil, its persistence may be its occurrence in association with $\mathrm{NC}$, the primary component of certain propellants. $\mathrm{NC}$ is a large polymeric molecule that is insoluble and immobile and may adsorb and immobilize NG.

Literature evidence (Section 4) suggests that NG, PA, tetryl, TNB, and PETN are not likely to be found at military ranges, including Camp Edwards, except in the presence of much higher concentrations (>10,000 parts per million) of the more commonly used explosives (e.g., TNT, RDX, and HMX) and their primary metabolites or impurities (e.g., DNT and aDNTs). This conclusion, based on other field studies in the United States and Canada, is consistent with the results obtained at Camp Edwards.

Finally, a review of corrosion mechanisms and site conditions indicates that environmental conditions at Camp Edwards are not conducive to corrosion of UXOs (Section 2). Although the $\mathrm{pH}$ and buffer capacity are low, the coarse-grained soils maintain a low-to-moderate moisture content and limit accumulation of aggressive anions such as chloride. Alternate wetting and drying cycles also inhibit corrosion. These conditions support the results of the preliminary work performed on site (Packer et al. 2002) and inferences based on work performed elsewhere (Adams 2001, Chendorain et al. 2005). It is estimated that perforation of 0.5-inch steel at Camp Edwards would require more than a century. Unfortunately, as described in Section 2, several interacting factors (e.g., alloy composition, water composition, temperature, condition of the metal, etc.) make prediction of localized penetration in an individual UXO at a site difficult. 


\section{Conclusions}

The major conclusions that can be drawn from this evaluation of range assessment investigations are as follows:

1. Although based partially on indirect evidence, low-order detonations and cracked or ruptured UXO are likely to be the primary sources of RDX, HMX, and perchlorate groundwater contamination in impact areas at military training ranges. The contamination is manifested in surface soil as a heterogeneous, diffuse, low-concentration, distributed source term.

2. High-explosive residues are present on the soil surface as solid particulates and undergo slow dissolution, therefore the source is persistent, remaining in soil for years to come.

3. Direct evidence indicates that $\mathrm{OB} / \mathrm{OD}$ activities can be pointsources for RDX, HMX, TNT, aDNTS, 2,4-DNT, and perchlorate groundwater contamination.

4. At most locations, soil conditions are not sufficiently conducive for corrosion of UXO to be a primary source of groundwater contamination for decades.

5. Trinitrotoluene, 2a-DNT, 4a-DNT, and 2,4-DNT at OB/OD sites and impact areas result in minor impacts to groundwater at most installations.

6. Even though detected in surface soils, NG, 2,6-DNT, N-nitrosodiphenylamine, di-n-butyl phthalate, metals, and PAHs are not found in sufficient concentrations, nor or they sufficiently mobile, to represent a potential source of groundwater contamination. 


\section{Recommendations}

This section identifies data gaps for understating the fate and transport of energetic compounds. The gaps are listed initially and then followed by a discussion and recommendations for research or data collection. These data gaps were selected based on the need to determine the extent of soil remediation necessary to eliminate energetic compound impacts to groundwater. These data gaps are discussed in order of their importance.

1. Determination of forms (i.e., sorbed to soil or soot or incorporated into molten metal produced from detonation) and size of HE particulate residues (nuggets, crystals, or microcrystalline particles).

2. Determination of a realistic rate of dissolution of energetic compound particulates through laboratory studies using realistic wet/drying oscillations.

3. Calculation of site-specific dissolution rates of explosive compounds and incorporation into fate-and-transport model codes.

4. Determination of a relationship between energetic compound concentrations in soil and mass flux through the vadose zone.

\section{Nature and particle size of high-explosive residues}

Key to understanding the rate of contaminant mobility in the vadose zone and to predicting future groundwater concentrations is knowledge of the nature of the HE residue. The primary effort should be focused on determining the size of particulates. The particulate size is necessary to determine the adequate number of composite subsamples to quantify the amount of explosives residue in soil. Radtke et al. (2002) suggested that the only way to establish the appropriate number of samples to composite is by first measuring the size of HE particulates present. A second reason for understanding the particulate size distribution is the effect of size and shape on dissolution rate. Smaller particulates have greater surface area and will dissolve more quickly than larger particles. Also, by knowing the size of the particulates, a better estimation of the mass of HE present can be calculated, which in turn will produce more accurate soil cleanup criteria. The proposed evaluation would consist of collecting and sieving soil 
samples followed by analysis of various fractions under a microscope. CRREL has performed such studies (Taylor et al. 2004b). Also, the surface area of the particulates could be measured using the BET or other suitable technique.

In addition to the size of the particulate, the nature of the particulates is important for predicting the rate of dissolution. Work by Taylor et al. (2004b) suggests that HE residues can be sorbed or incorporated in soot particles produced during detonation. HE also can be incorporated into the slag produced by molten metal as a consequence of detonation. The proposed evaluation would employ the methods discussed in the preceding paragraph coupled with surface analyses to evaluate the structure and composition of the particulates. It is also possible that weathering of $\mathrm{HE}$ residues may cause formation of a passivation layer or crust that slows or inhibits dissolution. Surface analysis techniques to explore this possibility include scanning electron microscope (SEM), x-ray photoelectron spectroscopy (XPS), proton induced $\mathrm{x}$-ray emission (PIXE), proton induced $\mathrm{x}$ ray emission with the scanning proton microprobe (micro-PIXE), surfaceenhanced Raman spectroscopy (SERS), or electron spin resonance (ESR) spectroscopy.

Once improved particle size information is available, new calculations can be performed based on dissolution equations from the literature. The results will improve the evaluation of the flux rate of energetic compounds to the vadose zone. By understanding this flux rate, predictions of groundwater impacts can be improved.

\section{Laboratory dissolution rate evaluations}

As noted above, the rate of dissolution of solid-phase HE particles, as they occur in the field, has not been adequately characterized. Additional experiments should be designed to enhance knowledge of the dissolution process. Experiments should focus on the relationship between observed particle sizes and dissolution rates. Experiments also may be designed to improve simulation of expected wetting and drying cycles. To accurately simulate the site wetting and drying cycles, these experiments would need to be conducted over a period of several months. The experiment would consist of using a column containing site-specific soil impregnated with HE similar in particle size to what is found in the field, or actual particles from the field. The experiments should include HE incorporated into soot or metal as necessary. 


\section{Lysimeter studies of pore-water}

The analytical detection limit associated with analysis of soil samples is often an order of magnitude higher than the detection limit using the same method for water samples because of differences in sample volumes extracted and concentration techniques that can be applied to water extracts. Thus, pore-water samples can be used to better track the movement of contaminant residues or tracers in vadose zone media. A study conducted at the Milan Army Ammunition Plant (Clayton and Wirth 2000) successfully sampled soil pore-water in sandy soils at an OB site. This research found virtually no relationship between RDX concentrations in soil porewater collected using lysimeters with paired soil samples taken during lysimeter installation. This is not surprising in that the dissolution rate is a function of the particle size (surface area) rather than the actual mass of the contaminant in the soil. This lack of correlation could also be due to difference between the soil and water detection limits and inconsistencies in analytical subsampling and extraction techniques. In contrast, Clausen et al. (2004c) found a reasonable relationship between soil and pore-water concentrations. If energetic compound residues were detectable in surface soil samples, then they were detectable in the soil pore-water. However, there were a number of instances where energetic compounds were not detectable in the soil samples, but the lysimeters indicated very low levels of energetic compounds in the soil pore-water. These results suggest that reliance on soil data could provide erroneous estimates of the impacts of soil contamination to groundwater and may cause development of unrealistic site-specific soil cleanup standards. Regardless of the interpretation, these results suggest soil pore-water sampling may be a more accurate tool to identify and rank source areas because the concentration of energetic compounds in soil pore-water represents the fraction of contamination that has dissolved and is migrating toward groundwater. Lysimeters are inexpensive and can be easily and quickly installed as compared to a typical monitoring well. Soil moisture samples collected for energetic compound analysis can aid remedial design efforts and be used to track the effectiveness of remedial efforts.

A possible approach is to install an initial phase of lysimeters at one depth interval (less than $1 \mathrm{~m}$ ) at a location known to have fine-grained soil with elevated energetic compound concentrations at the surface. This will allow an evaluation of the fate and transport of energetic compounds migrating from ordnance and explosives, including UXO, high-order detonations, and low-order detonations to groundwater. Using one initial shallow test- 
ing interval will save money on drilling costs and will allow for easier installation while the efficacy of the sampling technique is being evaluated. If the initial phase of testing proves useful and effective, lysimeters could be installed at additional depth intervals.

Lysimeters collect only small amounts of pore-water. However, there are several steps that can be taken to compensate for the small volume. First, the lysimeters can be installed at a 45-degree angle so the overlying soil is not disturbed, and the surface area in contact with downward percolating water is maximized. Second, each lysimeter can have the most permeable tip available and be packed in silica flour, which provides a fine-grained conduit for maintaining a vacuum and drawing in more pore-water. Third, placing several lysimeters in a row compensates for lateral variability in dissolution rate and provides additional volumes necessary to satisfy minimum analytical method requirements. Finally, efforts could be made by the analytical laboratory to lower the required sample volume for each sample while still maintaining low detection levels by developing sample concentration techniques that produce more concentrated extracts and/ or by employing more sensitive or selective detection techniques. Another alternative, if sufficient volume is available, is to pre-concentrate the water sample, with the degree of pre-concentration dependent on the volume of water available. Unlike soil samples, water samples can be pre-concentrated to lower the detection limit.

In addition to the field-deployed lysimeters, a "positive control" evaluation would be performed to demonstrate that lysimeters can be used to detect energetic compounds in soil moisture. This can be accomplished by inserting the lysimeter into a solution with known concentrations of energetic compounds and then collecting and analyzing the aqueous sample from within the lysimeter. Such an experiment would establish the extent to which energetic compound in solution can migrate through the porous cup into the sampler. Indeed, this series of experiments should yield a standard practice for collecting pore-water for analysis of energetic compound at training sites.

\section{Improved soil sampling methodologies}

As discussed previously, there are uncertainties with regard to what is an adequate composite sample to characterize large areas such as impact ranges. The question is how many subsamples or increments are needed to have a sufficient probability of encountering small explosives residues 
as well as larger chunks. The probability of encountering small HE residues from a high-order detonation will be different from the probability of encountering a large chunk from a low-order detonation. This issue can be addressed in several ways.

The first approach would be to collect soil samples around a target with a large number of subsamples forming composites with varying subsample size. For example, a 25 - by 25 - $\mathrm{ft}$ grid could be sampled with 50 subsamples. Composites could be made up of $5,10,20,30,40$, and 50 subsamples. The variance about the mean for each composite sample could be assessed through collection of field replicates. The smaller the variance, the more accurately the composite sample reflects actual site conditions. Studies conducted by Jenkins et al. (2005a) using such an approach have shown that the variance decreases with increasing number of increments and plateaus at a certain point. This should be a standard approach prior to initiating any range assessments.

The second approach is similar to that utilized by Radtke et al. (2002) and involves collection of one shallow but very large soil sample from a $10-\mathrm{ft}^{2}$ grid. The sample is then homogenized in the field in a small cement mixer and is extracted in the field using acetone. The mass of HE in solution will be reflective of the total mass of HE over that area. The acetone will dissolve the HE particulates and the mixing process will abrade the soil particle, ensuring that all the HE residue is removed from soot particles.

\section{Summary}

The presence of energetic compounds on military ranges is a potential problem for the United States, with more than 50 million domestic acres potentially impacted and responsibility for ranges in countries and climates as varied as Germany and Pakistan (Armstrong 1999a, b; Clausen et al. 2004b). Only in the past decade or so has research demonstrated that conventional site characterization (conventional soil and groundwater sampling, assuming point-sources and random contaminant distribution) is often inadequate for establishing a link between military training and the energetic residues. The importance of this inadequacy is magnified when confronted with the need to develop remediation alternatives. This report suggests that research is needed to determine more effective soil sampling schemes, to ensure appropriate media (e.g., pore-water) are sampled, and to determine the physical size and state of energetic compounds deposited on ranges. 


\section{References}

Achtnich, C., U. Sieglen, H.-J. Knackmuss, and H. Lenke. 1999. Irreversible binding of biologically reduced 2,4,6-trinitrotoluene to soil. Environmental Toxicology and Chemistry 18: 2416-2423.

Adams, C. 2001. Modeling the Corrosion Rate of Unexploded Ordnance. GSA Annual Meeting, Session No. 48. November 5-8, 2001.

Adams, R. L., E. J. Weber, G. L. Baughman. 1993. Photolysis of Smoke Dyes on Soils. Environmental Toxicology and Chemistry 13:889-896.

Ainsworth, C. C., S. D. Harvey, J. E. Szecsody, M. A. Simmons, V. I. Cullinan, C. T. Resch, and G. H. Mong. 1993. Relationship Between the Leachability Characteristics of Unique Energetic Compounds and Soil Properties. Project Order No. 91PP180o. Pacific Northwest Laboratory, Richland, WA, for US Army Biomedical Research and Development Laboratory. Fort Detrick, Frederick, MD.

AMEC. 2001a. Draft IAGWSP Technical Team Memorandum 01-13 Central Impact Area Soil Report for the Camp Edwards Impact Area Groundwater Quality Study, Massachusetts Military Reservation, Cape Cod, Massachusetts (MMR-3915). July 2001. AMEC Earth and Environmental, Inc. Westford, MA.

AMEC. 2001b. Final IAGWSP Technical Team Memorandum 01-6 Central Impact Area Groundwater Report for the Camp Edwards Impact Area Groundwater Quality Study, Massachusetts Military Reservation, Cape Cod, Massachusetts (MMR3757). AMEC Earth and Environmental, Inc. Westford, MA.

AMEC. 2001c. Final Rapid Response Action Mortar Target 9 and Former H Range Field Sampling Plan for the Camp Edwards Impact Area Groundwater Quality Study, Massachusetts Military Reservation, Cape Cod, Massachusetts (MMR-4217). March 2001. AMEC Earth and Environmental, Inc. Westford, MA.

AMEC. 2001d. Draft Final IAGWSP Technical Team Memorandum 01-10 Demo 1 Soil Report for the Camp Edwards Impact Area Groundwater Quality Study, Massachusetts Military Reservation, Cape Cod, Massachusetts (MMR-4675). December 2001. AMEC Earth and Environmental, Inc. Westford, MA.

AMEC. 2001e. Draft IAGWSP Technical Team Memorandum 01-17 Feasibility Study Report, Demo 1 Groundwater Operable Unit for the Camp Edwards Impact Area Groundwater Quality Study, Massachusetts Military Reservation, Cape Cod, Massachusetts (MMR-4252). October 2001. AMEC Earth and Environmental, Inc. Westford, MA.

AMEC. 2001f. Final IAGWSP Technical Team Memorandum 01-2, Demo 1 Groundwater Report for the Camp Edwards Impact Area Groundwater Quality Study, Massachusetts Military Reservation, Cape Cod, Massachusetts (MMR-3444). April 2001. AMEC Earth and Environmental, Inc. Westford, MA. 
AMEC. 2001g. Contaminant of Concern Identification Demolition Area 1-Soil Operable Unit for the Camp Edwards Impact Area Groundwater Quality Study, Massachusetts Military Reservation Cape Cod, Massachusetts (MMR-3254). March 2001. AMEC Earth and Environmental, Inc. Westford, MA.

AMEC. 2001h. Draft Tech Team Memo 01-16 J-1, J-3, L Ranges Interim Results Report No. 2 for the Camp Edwards Impact Area Groundwater Quality Study, Massachusetts Military Reservation, Cape Cod, Massachusetts (MMR-4117). August 2001. AMEC Earth and Environmental, Inc. Westford, MA.

AMEC. 2001i. Revised Draft IAGWSP Technical Team Memorandum 01-14 Gun and Mortar Firing Positions. Volume I of II for the Camp Edwards Impact Area Groundwater Quality Study, Massachusetts Military Reservation, Cape Cod, Massachusetts (MMR-4425). October 2001. AMEC Earth and Environmental, Inc. Westford, MA.

AMEC. 2002a. Draft J-2 Range Interim Data Report (Technical Team Memorandum o18) for the Camp Edwards Impact Area Groundwater Quality Study, Massachusetts Military Reservation, Cape Cod, Massachusetts (MMR-3642). AMEC Earth and Environmental, Inc. Westford, MA.

AMEC 2002b. White Phosphorus Analysis Recommendations. Letter report from AMEC to USEPA. Impact Area Groundwater Study Program, Massachusetts Military Reservation, Cape Cod, Massachusetts (MMR-5859). April 2002. AMEC Earth and Environmental, Inc. Westford, MA.

AMEC. 2002c. Draft Supplemental Background Investigation Report for the Camp Edwards Impact Area Groundwater Study Program, Massachusetts Military Reservation, Cape Cod, Massachusetts (MMR-3487). September 2002. AMEC Earth and Environmental, Inc. Westford, MA.

AMEC. 2002d. Final Revised BIP Field Sampling and Excavation Plan for the Camp Edwards Impact Area Groundwater Study Program, Massachusetts Military Reservation, Cape Cod, Massachusetts (MMR-6807). December 2002. AMEC Earth and Environmental, Inc. Westford, MA.

AMEC. 2003a. Draft Demo 1 Groundwater Report Addendum to TM 01-2, Camp Edwards, Massachusetts Military Reservation, Cape Cod, Massachusetts (MMR7702). July 2003. AMEC Earth and Environmental, Inc. Westford, MA.

AMEC. 2003b. Draft Final Phase IIB Report Technical Team Memorandum 02-6, Camp Edwards, Massachusetts Military Reservation, Cape Cod, Massachusetts (MMR7264). March 2003. AMEC Earth and Environmental, Inc. Westford, MA.

AMEC. 2004. Draft Addendum to Final IAGWSP Technical Team Memorandum TM 01-6 Central Impact Area Groundwater Report, Camp Edwards Impact Area Groundwater Study Program, Massachusetts Military Reservation, Cape Cod, Massachusetts. MMR-8334. March 2004. AMEC Earth and Environmental, Inc. Westford, MA.

Ampleman, G., S. Thiboutot, A. Gagnon, A. Marois, R. Martel, and R. Lefebvre. 1998. Study of the Impacts of OB/OD Activity on Soils and Groundwater at the Destruction Area in CFAD Dundurn. Defence Research Establishment Valcartier, Quebec, Canada. DREV-R-9827. 
Ampleman, G., S. Thiboutot, S. Desilets, A. Gagnon, and A. Marois. 200o. Evaluation of the Soils Contamination by Explosives at CFB Chilliwack and CFAD Rocky Point. Defence Research Establishment Valcartier, Quebec, Canada. DREV-TR-2000102.

Ampleman, G., S. Thiboutot, L. Lewis, A. Marois, S. Jean, A. Gagnon, M. Bouchard, T. Jenkins, A. Hewitt, J. C. Pennington, and T. A. Ranney. 2003a. Evaluation of the Contamination by Explosives in Soils, Biomass and Surface Water at Cold Lake Air Weapons Range (CLAWR), Alberta, Phase 1 Reports-Annex. Defence Research Establishment Valcartier, Quebec, Canada. DRDC TR-2003-208.

Ampleman, G., S. Thiboutot, J. Lewis, A. Marois, A. Gagnon, M. Bouchard, R. Martel, R. Lefebvre, C. Gauthier, J. M. Ballard, T. M. Ranney, and T. F. Jenkins. 2003b. Evaluation of the Impacts of Live Fire Training at CFB Shilo. Defence Research Establishment Valcartier, Quebec, Canada. DRDC TR-2003-066.

Ampleman, G., S. Thiboutot, J. Lewis, A. Marois, A. Gagnon, M. Brouchard, T. Jenkins, T. A. Ranney, and J. C. Pennington. 2004. Evaluation of the Contamination by Explosives and Metals in Soils, Vegetation, Surface Water and Sediment at Cold Lake Air Weapons Range (CLAWR), Alberta, Phase II Final Report. DRDCValcartier-TR-2004-204. Defence Research Establishment Valcartier, Quebec, Canada.

Andrews, C. C., and J. L. Osmon. 1975. The Effects of Ultraviolet Light on TNT in Aqueous Solutions. WQEC/C 75-197. Naval Weapons Support Center. Crane, IN.

Armstrong, D. 1999a. More Costly Cleanup on Horizon. Boston Globe, November 14.

Armstrong, D. 1999b. US Presence on Foreign Soil is Tainted. Boston Globe, November 15 .

Balasco, A. A., R. C. Bowen, K. R. Cahill, and J. L. Mahannah. 1996. Review of the Utility of Natural Attenuation for Remediating Contaminated Army Sites. Contract Report IRRP-96-1. Prepared by Arthur D. Little, Inc., Cambridge, MA, for the US Army Engineer Waterways Experiment Station. Vicksburg, MS.

Barnhart, J. 1997. Chromium Chemistry and Implications for Environmental Fate and Toxicity. J ournal of Soil Contamination. 6:561-568.

Basunia, S., and S. Landsberger. 2001. Contents and leachability of heavy metals ( $\mathrm{Pb}, \mathrm{Cu}$, $\mathrm{Sb}, \mathrm{Zn}, \mathrm{As}$ ) in soil at the Pantex Firing Range, Amarillo, Texas. J ournal of the Air \& Waste Management Association 51:1428-1435.

Baughman, G. L., and E. J. Weber. 1991. Estimation of Water Solubility and Octanol/ Water Partition Coefficient of Hydrophobic Dyes. Part I: Relationship Between Solubility and Partition Coefficient. Dyes and Pigments 16:261-271.

Baughman, G. L., and E. J. Weber. 1994. Transformation of Dyes and Related Compounds in Anoxic Sediment: Kinetics and Products. Environmental Science and Technology 28:287-276.

Bedford, C. D., P. S. Carpenter, and M. P. Nadler. 1996. Solid-State Photodecomposition of Energetic Nitramines (RDX and HMX). NAWCPNS TP 8271. Department of the Navy, Naval Air Warfare Center Weapons Division. China Lake, CA. 
Best, E. P. H., M. E. Zappi, H. L. Fredrickson, S. L. Sprecher, S. L. Larson, and M. Ochman. 1997a. Screening of Aquatic and Wetland Plant Species for Phytoremediation of Explosives-Contaminated Groundwater from the Iowa Army Ammunition Plant. In Bioremediation of Surface and Subsurface Contamination; Annals of the New York Academy of Sciences 829:179-194.

Best, E. P. H., M. E. Zappi, H. L. Fredrickson, S. L. Sprecher, S. L. Larson, and J. L. Miller. 1997b. Screening of Aquatic and Wetland Plant Species for Phytoremediation of Explosives-Contaminated Groundwater from the Iowa Army Ammunition Plant. Technical Report EL-97-2. US Army Corps of Engineers Waterways Experiment Station. Vicksburg, MS.

Best, E. P. H., J. L. Miller, M. E. Zappi, H. L. Fredrickson, S. L. Larson, and T. Streckfuss. 1998. Explosives Removal from Groundwater of the Iowa Army Ammunition Plant in Continuous-Flow Laboratory Systems Planted with Aquatic and Wetland Plants. Technical Report EL-98-13. US Army Engineer Waterways Experiment Station, Vicksburg, MS.

Bossia, C., and G. Cragnolino. 2000. Effect of Environmental Variables on Localized Corrosion of Carbon Steel. Corrosion 56(5):505-514.

Bradley, P. M., and F. H. Chapelle. 1995. Factors Affecting Microbial 2,4,6-Trinitrotoluene Mineralization in Contaminated Soil. Environmental Science and Technology 29:802-806.

Bradley, P. M., F. H. Chapelle, J. E. Landmeyer, and J. G. Schumacher. 1994. Microbial Transformation of Nitroaromatics in Surface Soils and Aquifer Materials. Applied and Environmental Microbiology 60:2170-2175.

Bradley, P. M., F. H. Chapelle, J. E. Landmeyer, and J. G. Schumacher. 1997. Potential for Intrinsic Bioremediation of DNT-Contaminated Aquifer. Ground Water 35:1217.

Brannon, J. M., and T. E. Myers. 1997. Review of Fate and Transport Processes of Explosives. Technical Report IRRP-97-2. US Army Corps of Engineers, Waterways Experiment Station. Vicksburg, MS.

Brannon, J. M., and J. C. Pennington. 2002. Environmental Fate and Transport Process Descriptors for Explosives. ERDC/EL TR-02-10. US Army Corps of Engineers, Environmental Laboratory. Vicksburg, MS.

Brannon, J. M., D. D. Adrian, J. C. Pennington, T. E. Myers, and C. A. Hayes. 1992. Slow Release of PCB, TNT, and RDX from Soils and Sediments. Technical Report EL92-38. US Army Corps of Engineers, Waterways Experiment Station. Vicksburg, MS.

Brannon, J. M., C. B. Price, and C. Hayes. 1998. Abiotic Transformation of TNT in Montmorillonite and Soil Suspensions Under Reducing Conditions. Chemosphere 36:1453-1462.

Brannon, J. M., P. Deliman, C. Ruiz, C. Price, and M. Qasim. 1999. Conceptual Model and Process Descriptor Formulations for Fate and Transport of UXO. Technical Report IRRP-99-1. US Army Corps of Engineers, Waterways Experiment Station. Vicksburg, MS. 
Broman, G., C. Naf, and Y. Zebuhr. 1991. Long-Term High and Low-Volume Air Sampling of PCDDs, PCDFs, and PAHs Along a Transect from Urban to Remote Areas on the Swedish Baltic Coast. Environmental Science and Technology, 25:18411850.

Bucci, J. E., and P. F. Buckley. 1999. Modeling the Degradation of Unexploded Ordnance (UXO) and Its Use as a Tool in the Development of Risk Assessments. Presented at 1999 UXO Forum. Atlanta, GA.

Burlinson, N. E., L. A. Kaplan, C. E. Adams. 1973. Photochemistry of TNT: Investigation of the "Pink Water" Problem. NOLTR-73-173. Naval Ordnance Laboratory. White Oak, Silver Spring, MD.

Burlinson, N. E. 1980. Fate of TNT in the Aquatic Environment: Photodegradation versus Biotransformation. NSWC/TR-79-445. Naval Surface Weapons Center.

Burrows, E. P., D. H. Rosenblatt, W. R. Mitchell, and D. L. Palmer. 1989. Organic Explosives and Related Compounds: Environmental and Health Considerations. Technical Report 8901. USA Biomedical Research and Development Laboratory, Fort Detrick, Maryland.

Cataldo, D. A., S. D. Harvey, and R. J. Fellows. 1990. An Evaluation of the Environmental Fate and Behavior of Munitions Material (TNT, RDX) in Soil and Plant Systems. PNL-7529. Pacific Northwest Laboratory. Richland, WA.

Cataldo, D. A., S. D. Harvey, and R. J. Fellows. 1993a. The Environmental Behavior and Chemical Fate of Energetic Compounds (TNT, RDX, Tetryl) in Soil and Plant Systems. Presented at the $17^{\text {th }}$ Annual Army Environmental R\&D Symposium and $3^{\text {rd }}$ USACE Innovative Technology Transfer Workshop. June 22-24. Williamsburg, VA.

Cataldo, D. A., S. D. Harvey, and R. J. Fellows. 1993b. The Environmental Behavior and Chemical Fate of Energetic Compounds (TNT, RDX, Tetryl) in Soil and Plant Systems. PNL-SA-22362. Pacific Northwest Laboratory. Richland, WA.

CDOT. 1999. Method for estimating the service life of steel culverts. California Test Method 643, Engineering Service Center, California Department of Transportation. Sacramento, California.

Cerniglia, C. E., and C. C. Somerville. 1995. Reductive Metabolism of Nitroaromatic and Nitropolycyclic Aromatic Hydrocarbons. In Biodegradation of Nitroaromatic Compounds. J. C. Spain, Ed. New York, NY: Plenum Publishing Co. pp. 99-115.

Chapelle, F. 1993. Ground-Water Microbiology and Geochemistry. New York, NY: John Wiley and Sons.

Chauret, C., W. E. Inniss, and C. I. Mayfield. 1996. Biotransformation at 10 Degrees Centigrade of Di-n-butyl Phthalate in Subsurface Microcosms. Ground Water 34:791-794. 
Checkai, R. T., M. A. Major, R. O. Nwanguma, C. T. Phillips, and M. C. Sadusky. 1993a. Transport and Fate of Nitroaromatic and Nitramine Explosives in Soils from Open Burning/Open Detonation Operations: Anniston Army Depot (AAD). ERDEC-TR-135. Edgewood Research, Development and Engineering Center, Aberdeen Proving Ground, MD.

Checkai, R. T., M. A. Major, R. O. Nwanguma, C. T. Phillips, and M. C. Sadusky. 1993b. Transport and Fate of Nitroaromatic and Nitramine Explosives in Soils from Open Burning/Open Detonation Operations: Milan Army Ammunition Plant (MAAP). ERDEC-TR-136. Edgewood Research, Development and Engineering Center, Aberdeen Proving Ground, MD.

Checkai, R. T., M. A. Major, R. O. Nwanguma, C. T. Phillips, and M. C. Sadusky. 1993c. Transport and Fate of Nitroaromatic and Nitramine Explosives in Soils from Open/Open Detonation Operations: Radford Army Ammunition Plant (RAAP). ERDEC-TR-133. Edgewood Research, Development and Engineering Center, Aberdeen Proving Ground, MD.

Chendorain, M. D., L. D. Stewart, and B. Packer. 2005. Corrosion of Unexploded Ordnance in Soil-Field Results. Environmental Science and Technology $39: 2442-2447$.

Chuang, J. C., G. A. Mack, M. R. Kuhlman, and N. K. Wilson. 1991. Polycyclic Aromatic Hydrocarbons and Their Derivatives in Indoor and Outdoor Air in an EightHome Study. Atmospheric Environment 25B:369-380.

Clausen, J. L., M. Grant, B. Gregson. 2001. Distribution and Fate of Energetics at the MMR Impact Area and Training Ranges. SERDP and ESTCP Symposium. November 27-29, 2001. Washington, DC.

Clausen, J., D. Curry, J. Robb, and B. Gregson. 2002. Comprehensive List of Chemicals Likely to Be Found at Military Ranges-A Case Study of Camp Edwards, Massachusetts. SERDP and ESTCP Symposium. December 3-5, 2002. Washington, DC.

Clausen, J., J. Robb, D. Curry, and N. Korte. 2004a. A Case Study of Contaminants on Military Ranges: Camp Edwards, Massachusetts, USA. Environmental Pollution. 129:13-21.

Clausen, J. L., E. Wessling, M. Hoyt, B. Stearns, B. Ramirez, and N. Korte. 2004b. Acetone Production as a Result of Sodium Bisulfate Preservation of Soil Samples. Soil and Sediment Contamination 13(3):245-254.

Clausen, J., J. Robb, E. Gorman, A. Hewitt, M. E. Walsh, M. R. Walsh, and R. Montemayor. 2004c. Relationship Between Soil and Pore Water Concentrations of Energetic Materials. SERDP \& ESTCP Technical Symposium and Workshop. November 30-December 2, 2004. Washington, DC.

Clayton, W. S., and P. Wirth. 2000. Comparison of Vadose Zone Soil and Water Analytical Data for Characterization of Explosives Contamination. In Vadose Zone Characterization and Monitoring. B. Looney and R. W. Falta, Ed. Battelle Press. pp. 423-428. 
Comfort, S. D., P. J. Shea, L. S. Hundal, Z. Li, B. L. Woodbury, J. L. Martin, and W. L. Powers. 1995. TNT Transport and Fate in Contaminated Soil. J ournal of Environmental Quality 24:1174-1182.

Conley, K. A., and W. J. Mikucki. 1976. Migration of Explosives and Chlorinated Pesticides in a Simulated Sanitary Landfill. CERL Technical Report N-8. US Army Corps of Engineers, Construction Engineering Research Laboratory. Champaign, IL.

Cook, D. 1997. Military Impact Areas as a Source of Environmental Contamination. Masters Thesis. Massachusetts Institute of Technology. Cambridge, MA.

Craig, H. D., W. E. Sisk, M. D. Nelson, and W. H. Dana. 1997. Bioremediation of Explosives-Contaminated Soils: A Status Review. Proceedings of the $10^{\text {th }}$ Annual Conference on Hazardous Waste Research. pp. 146-179.

Cramer, R. J. Personal communication with J. L. Clausen. October 25, 2006. Applied Technology Directorate, Indian Head Division, Naval Surface Warfare Center. Indian Head, MD.

Crane, J. L., and W. C. Sonzogni. 1992. Temporal Distribution and Fractionation of Polychlorinated Biphenyls in a Contaminated Wisconsin Lake. Chemosphere 24:1921-1941.

Crockett, A. B., H. D. Craig, T. F. Jenkins, and W. E. Sisk. 1996. Field Sampling and Selecting On-Site Analytical Methods for Explosives in Soil. Federal Facilities Forum Issue USEPA/540/R-97/501. US Environmental Protection Agency. Washington, DC.

Crockett, A. B., T. F. Jenkins, H. D. Craig, and W. E. Sisk. 1998a. Overview of On-Site Analytical Methods for Explosives. CRREL Special Report 98-4. US Army Corps of Engineers, Cold Regions Research and Engineering Laboratory. Hanover, NH.

Crockett, A. B., H. D. Craig, and T. F. Jenkins. 1998b. Field Sampling and Selecting OnSite Analytical Methods for Explosives in Water. Federal Facilities Forum Issue USEPA/600/3-89/002. US Environmental Protection Agency. Washington, DC.

Darrach, M. R., A. Chutjian, and G. A. Plett. 1998. Trace explosives signatures from World War II unexploded undersea ordnance. Environmental Science \& Technology 32:1354-1358.

Deliman, P. N., and J. A. Gerald. 1998. Development of a Multimedia Exposure Assessment Model for Evaluating Ecological Risk of Exposure to Military-Related Compounds (MRCs) at Military Sites. Technical Report IRRP-98-9. US Army Corps of Engineers, Waterways Experiment Station, Vicksburg, MS.

Deutsch, D. G., and T. D. Goldfarb. 1988. PCDD/PCDF Contamination Following a Plastics Fire in a University Lecture Hall Building. Chemosphere 17:2423-2431.

Dimond, J. B., and R. B. Owen. 1996. Long-Term Residue of DDT Compounds in Forest Soils in Maine. Environmental Pollution 92:227-230.

Drever, J. I. 1988. The Geochemistry of Natural Waters. Englewood Cliffs, NJ: Prentice Hall, Inc. 
Dube, P., G. Ampleman, S. Thiboutot, and A. Gagnon. 1999. Characterization of potentially explosives-contaminated sites at CFB Gagetown, 14 Wing Greenwood and CFAD Bedford. Defence Research Establishment Valcartier. Valcartier, Quebec, Canada.

DuBois, F. W., and J. F. Baytos. 1972. Effect of Soil and Weather on the Decomposition of Explosives. LA-4943. Los Alamos National Laboratory, Los Alamos, NM.

Elder, J. F., and P. V. Dresler. 1988. Accumulation and Bioconcentration of Polycyclic Aromatic Hydrocarbons in a Nearshore Estuarine Environment Near a Pensacola (Florida) Creosote Contamination Site. Environmental Pollution 49:117-132.

Ellington, J. J., N. L. Wolfe, A. G. Garrison, J. J. Evans, J. K. Avants, and Q. Teng. 2001. Accumulation of Perchlorate in Tobacco Plants and Tobacco Products. Environmental Science and Technology 35: 3213-3218.

Epstein, J., D. H. Rosenblatt, A. Gallacio, and W. F. McTeague. 1973. Summary Report on a Data Base for Predicting Consequences of Chemical Disposal Operations. EASP 1200-12, Edgewood Arsenal, MD.

ESE. 1987. Update of the Initial Installation Assessment of Fort Ord and Subinstallations: Presidio at Monterey and Fort Hunter Liggett. Prepared for US Army Toxic and Hazardous Materials Agency. Environmental Science \& Engineering, Inc.

ESE. 1993. Environmental Evaluation and Assessment for the North Post 40 Complex, Camp Grayling Training Facility, Grayling, Michigan. ESE \#591-8218. Environmental Science \& Engineering, Inc. Williamston, MI.

ESE. 1994. Report of Findings for 1993 Hydrogeologic Investigation at North Post 40 Complex, Camp Grayling Training Facility, Grayling, Michigan. ESE \#591-8218. Environmental Science \& Engineering, Inc. Williamston, MI.

ESE. 1995. Camp Grayling North Post 40 Complex Surface Water Investigation Volume 1. ESE \# 47-94003. Environmental Science \& Engineering, Inc. Cadillac, MI.

ESE. 1996. Report of Findings for 1995 Remedial Action North Post 40 Complex Camp Grayling Training Facility Grayling, MI. ESE \# 47-95033. Environmental Science \& Engineering, Inc. Cadillac, MI.

ESE. 1997. 1995/1996 Hydrogeological Investigation/Monitoring Results North Post 40 Complex Camp Grayling Training Facility Grayling, MI. ESE \# 47-95076 \& 4795078. Environmental Science \& Engineering, Inc. Cadillac, MI.

Etnier, E. L. 1986. Water Quality Criteria for Hexahydro-1,3,5-trinitro-1,3,5-triazine (RDX). ORNL-6178. Oak Ridge National Laboratory. Oak Ridge, TN.

Etnier, E. L. 1987. Water Quality Criteria for 2,4-Dinitrotoluene and 2,6-Dinitrotoluene. ORNL-6312. Oak Ridge National Laboratory. Oak Ridge, TN.

Feenstra, S., D. M. Mackay, and J. A. Cherry. 1991. A Method for Assessing Residual NAPL Based on Organic Chemical Concentrations in Soil Samples. Groundwater Monitoring and Review 11:128-136. 
Fielder, H. 1998. Thermal formation of PCDD/PCDF: A survey. Environmental Engineering Science 15:49-58.

Fleming, E. C., R. M. Bricka, and S. R. Bailey. 1995. Ultraviolet/Chemical Oxidation Treatment of RDX-Contaminated Waters at Picatinny Arsenal. Technical Report EL-95-7. US Army Corps of Engineers, Waterways Experiment Station. Vicksburg, MS.

Fleming, E. C., R. Cerar, and K. Christenson. 1996. Removal of RDX, TNB, TNT, and HMX from Cornhusker Army Ammunition Plant Waters Using Adsorption Technologies. Technical Report EL-96-5. US Army Corps of Engineers, Waterways Experiment Station. Vicksburg, MS.

Fletcher, C. L., and W. A. McKay. 1993. Polychlorinated Dibenzo-p-dioxins (PCDDs) and Dibenzofurans (PCDFs) in the Aquatic Environment-A Literature Review. Chemosphere 26:1041-1069.

FOCIS Associates. 2004. State of Knowledge Regarding Military Range Contamination. Prepared for US Army Research and Development Center (ARDEC). FOCIS Associates. July 30, 2004. Newton, MA.

Freeman, D. J., and F. C. R. Cattell. 1990. Woodburning as a Source of Atmospheric Polycyclic Aromatic Hydrocarbons. Environmental Science and Technology 24:1581-1585.

Froese, K. L., D. A. Verbrugge, S. A. Snyder, F. Tilton, M. Tuchman. A. Ostaszewski, and J. P. Giesy. 1997. PCBs in the Detroit River Water Column. J ournal of Great Lakes Research 23:440-449.

Gevao, B., and K. C. Jones. 1998. Kinetics and Potential Significance of Polycyclic Aromatic Hydrocarbon Desorption from Creosote-Treated Wood. Environmental Science and Technology 32:640-646.

Glover, D. J., and J. C. Hoffsommer. 1979. Photolysis of RDX in Aqueous Solution with and without Ozone. NSWC/WOL-TR-78-175. Naval Surface Weapons Center. Silver Spring, MD.

Goodfellow, W. L., D. T. Burton, W. C. Graves, L. W. Hall, and K. R. Cooper. 1983. Acute Toxicity of Picric Acid and Picramic Acid to Rainbow Trout Salmo Gairdneri and American Oyster Crassostrea Virginica. Water Resource Bulletin 19:641-648.

Gorontzy, T., O. Drzyga, M. W. Kahl, C. Bruns-Nagel, J. Breitung, E. von Loew, and K. H. Blotevogel. 1994. Microbial degradation of explosives and related compounds. Critical reviews in Microbiology 20: 265-284.

Greene, B., D. L. Kaplan, and A. M. Kaplan. 1985. Degradation of Pink Water Compounds in Soil: TNT, RDX, and HMX. NATICK/85/046. US Army Natick Research and Development Center. Natick, MA.

Groom, C. A., A. Halasz, L. Paquet, N. Morris, L. Olivier, C. Dubois, and J. Hawari. 2002. Accumulation of HMX (Octahydro-1,3,5,7-tetranitro-1,3,5,7-tetrazocine) in Indigenous and Agricultural Plants Grown in HMX-Contaminated Anti-Tank Firing-Range Soil. Environmental Science and Technology 36:112-118. 
Haderlein, S. B., K. W. Weissmahr, and R. P. Schwarzenbach. 1996. Specific Adsorption of Nitroaromatic Explosives and Pesticides to Clay Minerals. Environmental Science and Technology 30:612-622.

Hale, V. Q., T. B. Stanford, and L. G. Taft. 1979. Evaluation of the Environmental Fate of Munition Compounds in Soil. Contract No. DAMD 17-76-C-6065. Battelle Columbus Laboratories. Columbus, $\mathrm{OH}$.

Haque, R., D. W. Schmedding, and V. H. Freed. 1974. Aqueous Solubility, Adsorption, and Vapor Behavior of Polychlorinated Biphenyl Aroclor 1254. Environmental Science and Technology 8:139-142.

Hargrave, B. T., G. C. Harding, W. P. Vass, P. E. Erickson, B. R. Fowler, and V. Scott. 1992. Organochlorine Pesticides and Polychlorinated Biphenyls in the Arctic Ocean Food Web. Archives of Environmental Contamination and Toxicology 22:41-54.

Harrad, S. J., A. P. Stewart, R. Alcock, R. Boumphrey, V. Burnett, R. Duarte-Davidson, C. Halsall, C. G. Sanders, K. Waterhouse, S. R. Wild, and K. C. Jones. 1994. Polychlorinated Biphenyls (PCBs) in the British Environment: Sinks, Sources and Temporal Trends. Environmental Pollution 85:131-146.

Harvey, S. D., R. J. Fellows, D. A. Cataldo, and R. M. Bean. 1990. Analysis of 2,4,6Trinitrotoluene and Its Transformation Products in Soils and Plant Tissues by High-Performance Liquid Chromatography. J ournal of Chromatography 518:361-374.

Harvey, S. D., R. J. Fellows, D. A. Cataldo, and R. M. Bean. 1991. Fate of the Explosive Hexahydro-1,3,5-trinitro-1,3,5-triazine (RDX) in Soil and Bioaccumulation in Bush Bean Hydroponic Plants. Environmental Toxicology and Chemistry 10:845-855.

Hawari, J. 2000. Microbial Degradation of RDX and HMX: From Basic Research to Field Application. Biotechnology Research Institute, NRC. Montreal (PQ) Canada.

Hawari, J., G. Sunahara, C. Greer, D. Rho, and S. Beaudet. 2000a. Characterization and Remediation of Soil Contaminated with Explosives: Development of Practical Technologies. National Research Council Canada. NRCC \# 43315.

Hawari, J., S. Beaudet, A. Halasz, S. Thiboutot, G. Ampleman. 20oob. Microbial Degradation of Explosives: Biotransformation Verses Mineralization. Applied Microbiology Biotechnology 54: 605-618.

Hawari, J., A. Halasz, S. Beaudet, L. Paquet, G. Ampleman, and S. Thiboutot. 2001a. Biotransformation Routes of Octahydro-1,3,5,7-tetranitro-1,3,5,7-tetrazocine by Municipal Anaerobic Sludge. Environmental Science and Technology 35:70-75.

Hawari, J., A. Halasz, T. Sheremata, S. Beaudet, C. Broom, L. Paquet, C. Rhofir, G. Ampleman, and S. Thiboutot. 2001b. Characterization of metabolites during biodegradation of Hexahydro-1,3,5-Trinitro-1,3,5-Triazine (RDX) with municipal anaerobic sludge. Applied and Environmental Microbiology 66:2652-2657. 
Haywood, W., D. McRae, J. Powell, and B. W. Harris. 1995. An Assessment of HighEnergy Explosives and Metal Contamination in Soil at TA-67 (12), L-Site, and TA-14, Q-Site. LA-12752-MS. Los Alamos National Laboratory. Los Alamos, NM.

Heit, M. 1979. Concentrations of Benzo(a)pyrene in the Sediments of Six Western United States Lakes. Water, Air and Soil Pollution 11:447-454.

Hering, S. V., A. H. Miguel, and R. L. Dod. 1984. Tunnel Measurements of the PAH Carbon Thermogram and Elemental Source Signature for Vehicular Exhaust. The Science of the Total Environment 36:39-45.

Herman, D. C., and W. T. Frankenberger, Jr. 1998. Microbial-Mediated Reduction of Perchlorate in Groundwater. J ournal of Environmental Quality 27: 750-754.

Hewitt, A. D. 2002. Analysis of Nitroglycerine in Soils and on Mortar Fins Using GC-TID. CRREL Report TR-02-03. US Army Corps of Engineers, Cold Regions Research and Engineering Laboratory. Hanover, NH.

Hewitt A. D., and S. R. Bigl. 2005. Elution of Energetic Compounds from Propellant and Composition B Residues. ERDC/CRREL TR-05-13. US Army Engineer Research and Development Center, Cold Regions Research and Engineering Laboratory. Hanover, NH.

Hewitt, A. D., and K. F. Myers. 1999. Sampling and On-Site Analytical Methods for Volatiles in Soil and Groundwater. Field Guidance Manual. CRREL Special Report 99-16. US Army Corps of Engineers, Cold Regions Research and Engineering Laboratory. Hanover, NH.

Hewitt, A. D., T. F. Jenkins, T. Ranney, J. Stark, M. E. Walsh, S. Taylor, M. R. Walsh, D. Lambert, N. Perron, and N. Collins. 2003. Estimates for Explosives Residue from the Detonation of Army Munitions. ERDC/CRREL TR-03-16. US Army Engineer Research and Development Center, Cold Regions Research and Engineering Laboratory. Hanover, $\mathrm{NH}$.

Hewitt, A. D., T. F. Jenkins, C. A. Ramsey, K. L. Bjella, T. A. Ranney, and N. M. Perron. 2005. Estimating Energetic Residue Loading on Military Artillery Ranges: Large Decision Units. ERDC/CRREL TR-05-7. US Army Engineer Research and Development Center, Cold Regions Research and Engineering Laboratory. Hanover, NH.

Hites, R. 1990. Environmental Behavior of Chlorinated Dioxins and Furans. Accounts of Chemical Research 23:194-201.

Hoffsommer, J. C., and J. M. Rosen. 1972. Analysis of Explosives in Sea Water. Bulletin of Environmental Contamination and Toxicology 7:177-181.

Hoffsommer, J. C., L. A. Kaplan, D. J. Glover, D. A. Kubose, C. Dickinson, H. Goya, E. G. Kayser, C. L. Groves, and M. E. Sitzmann. 1978, Biodegradability of TNT: A Three-Year Pilot Plant Study. NSWC/WOL TR 77-136. Naval Surface Weapons Center. Silver Spring, MD.

Hou, M., and G. L. Baughman. 1992. Predicting the Precipitation of Acid and Direct Dyes in Natural Waters. Dyes and Pigments 18:35-46. 
Hou, M., G. L. Baughman, and T. A. Perenich. 1991. Estimation of Water Solubility and Octanol/Water Partition Coefficient of Hydrophobic Dyes. Part II: Reverse-Phase High Performance Liquid Chromatography. Dyes and Pigments 16: 291-297.

Howard, P. H. 1989. Handbook of Physical Properties of Organic Compounds. Volume 1: Priority Pollutants. Chelsea, MI: Lewis Publishers.

Howard, P. H., and W. M. Meylan. 1997. Handbook of Physical Properties of Organic Chemicals. Boca Raton, LA: CRC Press.

Huang, C. P., C. R. O’Melia, and J. J. Morgan. 1992. Aquatic Chemistry: Interfacial and Interspecies Processes. American Chemical Society. Washington, D.C.

Hughes, J. B., C. Y. Wang, and C. Zhang. 1999. Anaerobic Biotransformation of 2,4Dinitrotoluene and 2,6-Dinitrotoluene by Clostridium Acetobutylicum: A Pathway Through Dihydroxylamino Intermediates. Environmental Science and Technology 33:1065-1070.

Hwang, P., T. Chow, and N. R. Adrian. 1999. Transformation of Trinitrotoluene to Triaminotoluene by Mixed Cultures Incubated Under Methanogenic Conditions. Environmental Toxicology and Chemistry 18:836-841.

James, B. R., J. C. Petura, R. J. Vitale, and G. R. Mussoline. 1997. Oxidation-Reduction Chemistry of Chromium: Relevance to the Regulation and Remediation of Chromate Contaminated Soils. J ournal of Soil Contamination 6:569-580.

Jenkins, T. F., M. E. Walsh, P. W. Schumacher, and P. H. Miyares. 1989. Liquid Chromatographic Method for Determination of Extractable Nitroaromatic and Nitramine Residues in Soil. J ournal of the Association of Official Analytical Chemists 72:890-899.

Jenkins, T. F., P. G. Thorne, K. F. Myers, E. F. McCormick, D. E. Parker, and B. L. Escalan. 1995. Evaluation of the New Clean Solid Phases for Extraction of Nitroaromatics and Nitramines from Water. CRREL Special Report 95-22. US Army Corps of Engineers, Cold Regions Research and Engineering Laboratory. Hanover, NH.

Jenkins, T. F., C. L. Grant, G. S. Brar, P. G. Thorne, T. A. Ranney, and P. W. Schumacher. 1996. Assessment of Sampling Error Associated with Collection and Analysis of Soil Samples at Explosives-Contaminated Sites. CRREL Special Report 96-15. US Army Corps of Engineers, Cold Regions Research and Engineering Laboratory. Hanover, NH.

Jenkins, T. F., M. E. Walsh, P. G. Thorne, S. Thiboutot, G. Ampleman, T. A. Ranney, and C. L. Grant. 1997a. Assessment of Sampling Error Associated with the Collection and Analysis of Soil Samples at a Firing Range Contaminated with HMX. CRREL Special Report 97-22. US Army Corps of Engineers, Cold Regions Research and Engineering Laboratory. Hanover, NH.

Jenkins, T. F., C. L. Grant, G. S. Brar, P. G. Thorne, P. W. Schumacher, and T. A. Ranney. 1997b. Sampling Error Associated with Collection and Analysis of Soil Samples at TNT-Contaminated Sites. Field Analytical Chemistry and Technology 1:151-163. 
Jenkins, T. F., M. E. Walsh, P. G. Thorne, P. H. Miyares, T. A. Ranney, C. L. Grant, and J. R. Esparza. 1998. Site Characterization for Explosives Contamination at a Military Firing Range Impact Area. CRREL Special Report 98-9. US Army Corps of Engineers, Cold Regions Research and Engineering Laboratory. Hanover, NH.

Jenkins, T. F., C. L. Grant, M. E. Walsh, P. G. Thorne, S. Thiboutot, G. Ampleman, and T. A. Ranney. 1999. Coping with Spatial Heterogeneity Effects on Sampling and Analysis at an HMX-Contaminated Antitank Firing Range. Field Analytical Chemistry and Technology 3:19-28.

Jenkins, T. F., T. A. Ranney, M. E. Walsh, P. H. Miyares, A. D. Hewitt, and N. H. Collins. 2000a. Evaluating the Use of Snow-Covered Ranges to Estimate the Explosives Residues That Result from Detonation of Army Munitions. ERDC/CRREL TR-00-15. US Army Corps of Engineers. Engineer Research and Development Center. Hanover, NH.

Jenkins, T. F., M. E. Walsh, P. H. Miyares, J. A. Kopczynski, T. A. Ranney, V. George, J. C. Pennington, and T. E. Berry, Jr. 200ob. Analysis of Explosives-Related Chemical Signatures in Soil Samples Collected Near Buried Land Mines. ERDC TR-00-5. US Army Corps of Engineers, Engineer Research and Development Center. Hanover, NH.

Jenkins, T. F., J. C. Pennington, T. A. Ranney, T. E. Berry, P. H. Miyares, M. E. Walsh, A. D. Hewitt, N. M. Perron, L. V. Parker, C. A. Hayes, and E. G. Wahlgren. 2001a. Characterization of Explosives Contamination at Military Firing Ranges. ERDC TR-01-5. US Army Corps of Engineers, Engineer Research and Development Center. Hanover, NH.

Jenkins, T. F., T. A. Ranney, A. D. Hewitt, M. E. Walsh, J. A. Stark, and J. C Pennington. 2001b. Use of Snow-Covered Ranges to Determine the Amount of Explosives Residues Deposited from High-Order Detonations of Army Munitions. Geological Society of America National Meeting. November 1-10. Boston, MA.

Jenkins, T. F., M. E. Walsh, P. H. Miyares, A. D. Hewitt, N. H. Collins, and T. A. Ranney. 2002. Evaluation of the Use of Snow-Covered Ranges to Estimate the Explosive Residues That Result from High Order Detonations of Army Munitions. Thermochimica Acta 384:173-185.

Jenkins, T. F., C. Bartolini, and T. A. Ranney. 2003. Stability of CL-20, TNAZ, HMX, RDX, NG, and PETN in Moist Unsaturated Soil. ERDC/CRREL TR-03-7. US Army Corps of Engineers, Engineer Research and Development Center. Hanover, $\mathrm{NH}$.

Jenkins, T. F., T. A. Ranney, A. D. Hewitt, M. E. Walsh, and K. L. Bjella. 2004a. Representative Sampling for Energetic Compounds at an Antitank Firing Range. ERDC/CRREL TR-04-7. US Army Corps of Engineers. Engineer Research and Development Center, Hanover, NH.

Jenkins, T. F, A. D. Hewitt, T. A. Ranney, C. A. Ramsey, D. J. Lambert, K. L. Bjella, and N. M. Perron. 2004b. Sampling Strategies Near a Low-Order Detonation and a Target at an Artillery Impact Area. ERDC/CRREL TR-04-14. US Army Corps of Engineers, Engineer Research and Development Center. Hanover, NH. 
Jenkins, T. F., A. D. Hewitt, M. E. Walsh, T. A. Ranney, C. A. Ramsey, C. L. Grant, and K. L. Bjella. 2005a. Representative Sampling for Energetic Compounds at Military Ranges. Environmental Forensics 6:45-55.

Jenkins, T. F., S. Thiboutot, G. Ampleman, A. D. Hewitt, M. E. Walsh, T. A. Ranney, C. A. Ramsey, C. L. Grant, C. M. Collins, S. Brochu, S. R. Bigl, and J. C. Pennington. 2005b. Identity and Distribution of Residues of Energetic Compounds at Military Live-Fire Training Ranges. ERDC TR-05-10. US Army Corps of Engineers, Engineer Research and Development Center. Hanover, NH.

Jenkins, T. F., A. D. Hewitt, C. L. Grant, S. Thiboutot, G. Ampleman, M. E. Walsh, T. A. Ranney, C. A. Ramsey, A. J. Palazzo, and J. C. Pennington. 2006. Identity and distribution of residues of energetic compounds at Army live-fire training ranges. Chemosphere 63:1280-1290.

Jones, K. C., J. A. Stratford, K. S. Waterhouse, E. T. Furlong, W. Giger, R. A. Hites, C. Schaffner, and A. E. Johnson. 1989. Increases in the Polynuclear Aromatic Hydrocarbon Content of an Agricultural Soil Over the Last Century. Environmental Science and Technology 23:95-101.

Kain, R. M. 1990. Crevice Corrosion Resistance of Stainless Steels in Waters Containing Chloride and Sulfate Ions. In Corrosion in Natural Waters, pp 37-53. Special Technical Publication 1086. Philadelphia, PA: American Society for Testing and Materials.

Kain, R. M., A. H. Tuthill, and E. C. Hoxie. 1984. The Resistance of Types 304 and 316 Stainless Steels to Crevice Corrosion in Natural Waters. J ournal of Materials for Energy Systems 5:205-211.

Kaplan, D. 1995. Biotechnology and Bioremediation for Organic Energetic Compounds. Research Paper 95-41407-0-3. US Army Natick Research, Development and Engineering Center. Natick, MA.

Kaplan, D. L., and A. M. Kaplan. 1982a. 2,4,6-Trinitrotoluene-Surfactant Complexes, Biodegradability, Mutagenicity, and Soil Leaching Studies. Technical Report NATICK/TR-82/o06. US Army Natick Research \& Development Laboratories. Natick, MA.

Kaplan, D. L., and A. M. Kaplan. 1982b. 2,4,6-Trinitrotoluene-Surfactant Complexes: Decomposition, Mutagenicity, and Soil Leaching Studies. Environmental Science and Technology 16:566-571.

Kaplan, D. L., and A. M. Kaplan. 1983. Reactivity of TNT and TNT-Microbial Reduction Products with Soil Components. Technical Report NATICK/TR-83/041. US Army Natick Research \& Development Laboratories. Natick, MA.

Kayser, E. G., and N. Burlinson. 1982. Migration of Explosives in Soil. NSWC TR 82-566. Naval Surface Weapons Center. Silver Springs, MD.

Kayser, E. G., N. E. Burlinson, and D. H. Rosenblatt. 1984. Kinetics of Hydrolysis and Products of Hydrolysis and Photolysis of Tetryl. Technical Report 84-68. Naval Surface Weapons Center. Silver Springs, MD.

Kim, K., B. Logan, and E. Bruce. 2001. . Water Resources 35: 3071-3076. 
Kitchens, J. F., W. E. Harward, D. M. Lauter, R. W. Wentsel, and R. S. Valentine. 1978. Preliminary Problem Definition Study of 48 Munitions-Related Chemicals, Volume I: Explosives Related Chemicals. Report 49-5730-01. Prepared for US Army Medical Research and Development Command. Atlantic Research Corporation. Alexandria, VA.

Kolpin, D. W., J. E. Barbash, R. J. Gilliom. 1998. Occurrence of Pesticides in Shallow Groundwater of the United States: Initial Results from the National WaterQuality Assessment Program. Environmental Science and Technology, 32:558566.

Kostka, J., and K. Nealson. 1995. Dissolution and reduction of magnetite by Bacteria. Environmental Science and Technology 29:2535-2540.

Kostka, J., J. Stucki, K. Nealson, and J. Wu. 1996. Reduction of Structural Fe(III) in Smectite by a Pure Culture of Shewanella Putrefaciens Strain MR-1. Clays and Clay Minerals 44:522-529.

Kubose, D. A., and J. C. Hoffsommer. 1977. Photolysis of RDX in Aqueous Solution, Initial Studies. NSWC/WOL/TR-77-20. Naval Weapons Surface Center. Silver Spring, MD.

Larson, S. L., C. A. Weiss, M. R. Martino, and J. W. Adams. 1998. Role of Expandable Clays in the Environmental Fate of Trinitrotoluene Contamination. Technical Report IRRP-98-6. US Army Corps of Engineers, Engineer Waterways Experiment Station. Vicksburg, MS.

Larson, S. L., R. P. Jones, L. Escalon, and D. Parker. 1999. Classification of Explosives Transformation Products in Plant Tissue. Environmental Toxicology and Chemistry 18:1270-1276.

Layton, D., B. Mallon, W. Mitchell, L. Hall, R. Fish, L. Perry, G. Snyder, K. Bogen, W. Malloch, C. Ham, and P. Dowd. 1987. Conventional Weapons Demilitarization: A Health and Environmental Effects Data Base Assessment. Explosives and Their Co-contaminants. Final Report, Phase II. Lawrence Livermore National Laboratory. Livermore, CA.

LeFaivre, M. H., and G. H. Peyton. 1994. Identification of Reaction By-Products from Oxidative and Photolytic Remediation of Groundwater Contaminated with TNT and RDX. TM-2028-ENV (CR). Naval Facilities Engineering Services Center. Port Hueneme, CA.

Leggett, D. C. 1985. Sorption of Military Explosive Contaminants on Bentonite Drilling Muds. CRREL Report 85-18. US Army Corps of Engineers, Cold Regions Research and Engineering Laboratory. Hanover, NH.

Leggett, D. C. 1991. Role of Donor-Acceptor Interactions in the Sorption of TNT and Other Nitroaromatics from Solution. CRREL Report 91-13. US Army Corps of Engineers, Cold Regions Research and Engineering Laboratory. Hanover, NH.

Leggett, D. C., T. F. Jenkins, and R. P. Murrmann. 1977. Composition of Vapors Evolved from Military TNT as Influenced by Temperature Solid Composition, Age, and Source. CRREL Report 77-16. US Army Corps of Engineers, Cold Regions Research and Engineering Laboratory. Hanover, NH. 
Li, Z. M., K. A. Marx, J. Walker, and D. L. Kaplan. 1997. Trinitrotoluene and Metabolites Binding to Humic Acid. Environmental Science and Technology 31:584-589.

Linhardt, P. 1997. Corrosion of Metals in Natural Waters Influenced by Manganese Oxidizing Microorganisms. Biodegradation 8:201-210.

Little, B., R. Ray, and R. Pope. 2000. Relationship Between Corrosion and the Biological Sulfur Cycle: A Review. Corrosion 56:433-443.

Liu, D. S., K. Thomson, and A. C. Anderson. 1984. Identification of Nitroso Compounds from Biotransformation of 2,4-Dinitrotoluene. Applied and Environmental Microbiology 47:1295-1298.

Logan, B.E., H. Zhang, P. Mulvaney, M. G. Milner, I. M. Head, and R. F. Unz. 2001. Kinetics of Perchlorate and Chlorate-Respiring Bacteria. Applied and Environmental Microbiology 67:2499-2506.

Lopez-Avila, V., J. Milanes, F. Constantine, and W. Becker. 1990. Typical Phthalate Ester Contamination Incurred Using EPA Method 8060. J ournal of the Association of Official Analytical Chemistry 73:709-720.

Lula, R. A. 1986. Stainless steel. In: An Introduction to Stainless Steel. pp 1-151. J. G. Parr and A. Hanson, Ed. Metals Park, Ohio: American Society for Metals.

Lyman, W. J., W. F. Reene, and D. H. Rosenblatt. 1982. Handbook of Chemical Property Estimation Methods, Environmental Behavior of Organic Compounds. New York, NY: McGraw-Hill.

Lynch, J. C. 2002. Dissolution Kinetics of High Explosive Compounds. (TNT, RDX, HMX). ERDC/EL TR-02-23. US Army Corps of Engineers, Engineer Research and Development Center, Environmental Laboratory. Vicksburg, MS.

Lynch, J. C., K. F. Myers, J.M. Brannon, and J. J. Delfino. 2001. Effects of pH and Temperature on the Aqueous Solubility and Dissolution Rate of 2, 4, 6Trinitrotoluene (TNT), Hexahydro-1,3,5-trinitro-1,3,5-triazine (RDX), and Octahydro-1,3,5,7-tetranitro-1,3,5,7-tetrazocine (HMX). J ournal of Chemical Engineering Data 46:1549-1555.

Lynch, J. C., J. M. Brannon, and J. J. Delfino. 2002a. Effects of Component Interactions on the Aqueous Solubilities and Dissolution Rates of the Explosive Formulations Octal, Composition B, and LX-14. J ournal of Chemical Engineering Data, 47: 542-549.

Lynch, J. C., J. M. Brannon, and J. J. Delfino. 2002b. Dissolution Rates of Three High Explosive Compounds: TNT, RDX, and HMX. Chemosphere 47:725-734.

Mabey, W. R., D. Tse, A. Baraze, and T. Mill. 1983. Photolysis of Nitroaromatics in Aquatic Systems. I. 2,4,6-Trinitrotoluene. Chemosphere 12:3-16.

Major, M. A. 1999. Biological Degradation of Explosives. American Society of Agronomy. Bioremediation of Contaminated Soils, Agronomy Monograph 37:112-131. Madison, Wisconsin. 
Major, M. A., M. S. Johnson, C. J. Salice. 2002. Bioconcentration, Bioaccumulation, and Biomagnification of Nitroaromatic and Nitramine Explosives and Their Metabolites and Environmental Breakdown Products. May 2000-March 2002. 87-MA-4677-01.

Manahan, S. 1994. Environmental Chemistry. Lewis Publishers.

Martel, R., R. Lefebvre, K. Martel, and N. Roy. 1996. Preliminary Soil and Groundwater Characterization Study at the CFAD Dundurn Explosives Facility (Saskatchewan). INRS-Georessources, Sainte-Foy, Quebec. Prepared for Defense Research Establishment Department of National Defense. Valcartier, Quebec, Canada.

Martel, R., A. Hebrt, and R. Lefebvre. 1998. Complementary Soil and Groundwater Characterization Study at the Open Burning/Open Detonation Site CFAD Dundurn (Saskatchewan). Universite du Quebec. Prepared for DREV.

McCormick, N. G., F. F. Feeherry, and H. Levinson. 1976. Microbial Transformation of 2,4,6-Trinitrotoluene and Other Nitroaromatic Hydrocarbons. Applied Environmental Microbiology 31:949-958.

McCormick, N. G., J. H. Cornell, and A. M. Kaplan. 1978. Identification of Biotransformation Products from 2,4-Dinitrotoluene. Applied and Environmental Microbiology 35:945-948.

McCormick, N. G., J. H. Cornell, and A. M. Kaplan. 1981. Biodegradation of Hexahydro1,3,5-trinitro-1,3,5-triazine. Applied and Environmental Microbiology 42:817823 .

McCormick, N. G., J. H. Cornell, and A. M. Kaplan. 1984a. The Anaerobic Biotransformation of RDX, HMX, and Their Acetylated Derivatives. NATICK/85/007. US Army Natick Research and Development Laboratory. Natick, MA.

McCormick, N. G., J. H. Cornell, and A. M. Kaplan. 1984b. The Fate of Hexahydro-1,3,5trinitro-1,3,5-triazine (RDX) and Related Compounds in Anaerobic Denitrifying Continuous Culture Systems Using Simulated Wastewater. NATICK/85/oo8. US Army Natick Research and Development Laboratory. Natick, MA.

McGrath, C. J. 1995. Review of Formulations for Processes Affecting Subsurface Transport of Explosives. Report IRRP-95-2. US Army Corps of Engineers, Waterways Experiment Station. Vicksburg, MS.

McGrath, C. J. 1996. Updated Version of Physical, Chemical, and Environmental Data for Common, Explosive-Associated Compounds (XACs) tables. US Army Corps of Engineers, Waterways Experiment Station. Vicksburg, MS.

Mendoza, A. R., and F. Corvo. 2000. Outdoor and Indoor Atmospheric Corrosion of NonFerrous Metals. Corrosion Science 42: 1123-1147.

Merck. 1989. The Merck Index: An Encyclopedia of Chemicals, Drugs, and Biologicals, 11th Edition. Merck and Company, Rahway, New Jersey. 
Miyares, P. H., and T. F. Jenkins. 2000. Estimating the Half-Lives of Key Components of the Chemical Vapor Signature of Land Mines. ERDC/CRREL TR-oo-17. US Army Corps of Engineers, Cold Regions Research and Engineering Laboratory, Hanover, New Hampshire,

Moore, W. J. 1962. Physical Chemistry. 3rd Edition. Englewood Cliffs, NJ: Prentice Hall.

Morrison, R., and R. Boyd. 1968. Organic Chemistry. 2nd Edition. Boston, MA: Allyn and Bacon, Inc.

Myers, T. E., J. M. Brannon, J. C. Pennington, W. M. Davis, K. F. Myers, D. M. Townsend, M. K. Ochman, and C. A. Hayes. 1998a. Laboratory Studies of Soil Sorption/ Transformation of TNT, RDX, and HMX. Technical Report IRRP 98-8. US Army Corps of Engineers, Waterways Experiment Station. Vicksburg, MS.

Myers, T. E., D. M. Townsend, and B. C. Hill. 1998b. Application of a Semianalytical Model to TNT Transport in Laboratory Soil Columns. Technical Report IRRP-987. US Army Corps of Engineers, Waterways Experiment Station. Vicksburg, MS.

NIOSH (National Institute for Occupational Safety and Health). 1985. NIOSH Pocket Guide to Chemical Hazards. Publication No. 85-114. National Institute for Occupational Safety and Health. Washington, DC.

Nishino, S. F., and J. C. Spain. 2001. Explosives Biodegradation: Novel Enzymatic Reactions, Mechanisms and Pathways for Nitroaromatic Compounds. Air Force Research Laboratory. Tyndall AFB, FL.

Nishino, S. F., J. C. Spain, H. Lenke, and H. Knackmuss. 1999. Mineralization of 2,4- and 2,6-Dinitrotoluene in Soil Slurries. Environmental Science and Technology 33: 1060-1064.

Nishino, S. F., G. C. Paolli, and J. C. Spain. 2000. Aerobic Degradation of Dinitrotoluenes and Pathway for Bacterial Degradation of 2,6-Dinitrotoluene. Applied and Environmental Microbiology 66: 2139-2147.

Nzengung, V., C. Wang, and G. Harvey. 1999. Plant-Mediated Transformation of Perchlorate into Chloride. Environmental Science and Technology 33:1470-1478.

Ogden. 1997. Draft Range Use History Report for the Camp Edwards Impact Area Groundwater Quality Study Massachusetts Military Reservation Cape Cod, Massachusetts (MMR-0029), July 1997. Ogden Environmental and Energy Services, Westford, MA.

Ogden. 1998a. Draft Completion of Work Report Volume 1-5: Camp Edwards Impact Area Groundwater Quality Study, Massachusetts Military Reservation Cape Cod, Massachusetts (MMR-0050), July 1998. Ogden Environmental and Energy Services. Westford, MA.

Ogden. 1998b. Interim Results Report for the Camp Edwards Impact Area Groundwater Quality Study, Massachusetts Military Reservation Cape Cod, Massachusetts (MMR-0027), February 1998. Ogden Environmental and Energy Services, Westford, MA. 
Ogden. 1998c. Reporting of Preliminary Results of Background Soil Sampling for the Camp Edwards Impact Area Groundwater Quality Study, Massachusetts Military Reservation Cape Cod, Massachusetts (MMR-5541), April 1998. Ogden Environmental and Energy Services, Westford, MA.

Ogden. 1999a. Draft Interim Results Report for the Camp Edwards Impact Area Groundwater Quality Study, Massachusetts Military Reservation Cape Cod, Massachusetts (MMR-0025), November 1999. Ogden Environmental and Energy Services. Westford, MA.

Ogden. 1999b. Draft Supplemental Soil Results Report for KD and U Ranges for the Camp Edwards Impact Area Groundwater Quality Study, Massachusetts Military Reservation Cape Cod, Massachusetts (MMR-0901), November 1999. Ogden Environmental and Energy Services. Westford, MA.

Ogden. 2000a. J-2 Range Final Workplan for the Camp Edwards Impact Area Groundwater Quality Study. Massachusetts Military Reservation, Cape Cod, Massachusetts (MMR-2117), August 1, 2000. Ogden Environmental and Energy Services. Westford, MA.

Ogden. 200ob. Final IAGS Technical Team Memorandum 99-1 KD \& U Ranges for the Camp Edwards Impact Area Groundwater Quality Study, Massachusetts Military Reservation Cape Cod, Massachusetts (MMR-2071), July, 2000. Ogden Environmental and Energy Services. Westford, MA.

Ogden. 200oc. Final Phase I Initial Site Investigation Report KD Range, RTN 4-15033 for the Camp Edwards Impact Area Groundwater Quality Study, Massachusetts Military Reservation Cape Cod, Massachusetts (MMR-2384). Ogden Environmental and Energy Services. Westford, MA.

Ogden. 2000d. Final Phase I Initial Site Investigation Report, Area 17, Gun Position 7, RTN 4-15032 for the Camp Edwards Impact Area Groundwater Quality Study, Massachusetts Military Reservation Cape Cod, Massachusetts (MMR-2382). Ogden Environmental and Energy Services. Westford, MA.

Oldfield, J. W., and W. H. Sutton. 1980. New Technique for Predicting the Performance of Stainless Steels in Sea Water and Other Chloride Containing Environments. British Corrosion J ournal 15: 31-34.

Olin, T. J., T. E. Myers, and D. M. Townsend. 1996. 2,4,6-Trinitrotoluene (TNT) Transformation/Sorption in Thin-Disk Soil Columns Under Anaerobic Conditions. Technical Report IRRP-96-6. US Army Corps of Engineers, Waterways Experiment Station. Vicksburg, MS.

Packer, B., K. Thomsen, and C. Adams. 2002. Preliminary UXO Corrosion Data from Massachusetts Military Reservation. US Army Environmental Center.

Pankow, J.F., and J.A. Cherry. 1996. Dense Chlorinated Solvents and Other DNAPLs in Groundwater. Waterloo Press, Waterloo, Ontario, Canada.

Papadopoulos, J. A. 2003. Munition Metal Parts Manufacturing Changes, 1920 to Present, for Unexploded Ordnance Corrosion Database. AD-E402 954. US Army Armament Research, Development and Engineering Center. Picatinny Arsenal, NJ. 
Pennington, J. C. 1988. Soil Sorption and Plant Uptake of 2,4,6-Trinitrotoluene. Technical Report EL-88-12. US Army Corps of Engineers, Waterways Experiment Station. Vicksburg, MS.

Pennington, J. C., and W. H. Patrick. 1990. Adsorption and Desorption of 2,4,6Trinitrotoluene by Soils. J ournal of Environmental Quality 19:559-567.

Pennington, J. C., K. F. Myers, W. M. Davis, T. J. Olin, T. A. McDonald, C. A. Hayes, and D. M. Townsend. 1995. Impacts of Sorption on In-Situ Bioremediation of Explosives-Contaminated Soils. Technical Report IRRP-95-1. US Army Corps of Engineers, Waterways Experiment Station. Vicksburg, MS.

Pennington, J. C., D. W. Harrelson, M. Zakikhani, D. Gunnison, J. U. Clarke, C. J. McGrath, H. Fredrickson, J. H. May, E. Perkins, C. A. Hayes, and D. Ringelberg. 1998a. Feasibility of Using Natural Attenuation as a Remedial Alternative for Explosives-Contaminated Groundwater at Site L1, Joliet Army Ammunition Plant, Joliet, Illinois. Technical Report IRRP-98-3. US Army Corps of Engineers, Waterways Experiment Station. Vicksburg, MS.

Pennington, J. C., D. Gunnison, V. A. McFarland, L. S. Inouye, H. Fredrickson, C. H. Lutz, A. S. Jarvis, J. U. Clarke, K. A. Thorn, P. G. Thorne, D. Ringelberg, D. R. Felt, C. A. Hayes, M. Richmond, B. O'Neal, and B. E. Porter. 1998b. Explosives Conjugation Products in Remediation Matrices: Interim Report 2, Technical Report. SERDP-98-12. US Army Engineer Waterways Experiment Station. Vicksburg, MS.

Pennington, J. C., D. Gunnison, D. W. Harrelson, J. M. Brannon, M. Zakikhani, T. F. Jenkins, J. U. Clarke, C. A. Hayes, T. Myers, E. Perkins, D. Ringelberg, D. M. Townsend, H. Fredrickson, and J. H. Mays. 1999. Natural Attenuation of Explosives in Soil and Water Systems at Department of Defense Sites: Interim Report. Technical Report IRRP-99-8. US Army Corps of Engineers, Waterways Experiment Station. Vicksburg, MS.

Pennington, J. C., T. F. Jenkins, J. M. Brannon, S. Thiboutot, J. E. Delaney, LTC J. Lynch, J. L. Clausen, and J. J. Delfino. 2001. Distribution and Fate of Energetics on DoD Test and Training Ranges. SERDP and ESTCP Symposium. November 27-29, 2001. Washington, DC.

Pennington, J., J. M. Brannon, J. E. Mirecki, T. F. Jenkins, T. A. Ranney, J. A. Stark, M. E. Walsh, A. D. Hewitt, N. Perron, G. Ampleman, S. Thiboutot, J. Lewis, LTC J. Lynch, J. J. Delfino, J. L. Clausen, and C. A. Hayes. 2002a. Distribution and Fate of Energetics on DoD Test and Training Ranges. Interim Report 1, TR-01-13. US Army Corps of Engineers, Engineer Research and Development Center. Vicksburg, MS. Annual Technical Report Prepared for Strategic Environmental Research and Development Program. Arlington, VA.

Pennington, J. C., J. M. Brannon, J. E. Mirecki, T. F. Jenkins, T. A. Ranney, J. A. Stark, M. E. Walsh, A. D. Hewitt, N. Perron, G. Ampleman, S. Thiboutot, J. Lewis, LTC J. Lynch, J. J. Delfino, J. L. Clausen, and C. A. Hayes. 2002b. Distribution and Fate of Energetics on DoD Test and Training Ranges: Interim Report 2. ERDC TR-02-8. US Army Corps of Engineers, Engineer Research and Development Center. Arlington, VA. 
Pennington, J. C., T. F. Jenkins, G. Ampleman, S. Thiboutot, J. M. Brannon, J. Lewis, J. E. DeLaney, J. Clausen, A. D. Hewitt, M. A. Hollander, C. A. Hayes, J. A. Stark, A. Marois, S. Brochu, H. Q. Dinh, D. Lambert, A. Gagnon, M. Bouchard, R. Martel, P. Brousseau, N. M. Perron, R. Lefebvre, W. Davis, T. A. Ranney, C. Gauthier, S. Taylor, and J. Ballard. 2003a. Distribution and Fate of Energetics on DoD Test and Training Ranges. ERDC TR-03-2. US Army Corps of Engineers, Engineer Research and Development Center. Arlington, VA.

Pennington, J. C., K. A. Thorn, C. A. Hayes, B. E. Porter, and K. R. Kennedy. 2003b. Immobilization of 2,4- and 2,6-Dinitrotoluenes in Soils and Compost. ERDC/EL TR-03-02. US Army Corps of Engineers, Engineer Research and Development Center. Vicksburg, MS.

Pennington, J. C., T. F. Jenkins, A. D. Hewitt, J. A. Stark, D. Lambert, N. M. Perron, S. Taylor, G. Ampleman, S. Thiboutot, J. Lewis, A. Marois, C. Gauthier, P. Brousseau, R. Martel, R. Lefebvre, J. Ballard, S. Brochu, J. Clausen, J. E. Delaney, M. A. Hollander, H. Q. Dinh, I. Davis, T. A. Ranney, and C. A. Hayes. 2004. Distribution and Fate of Energetics on DoD Test and Training Ranges: Interim Report 4. Annual Technical Report Prepared for Strategic Environmental Research and Development Program. ERDC TR-04-4. Arlington, VA.

Pennington, J. C., T. F. Jenkins, S. Thiboutot, G. Ampleman, J. Clausen, A. D. Hewitt, J. Lewis, M. R. Walsh, M. E. Walsh, T. A. Ranney, B. Silverblatt, A. Marois, A. Gagnon, P. Brousseau, J. E. Zufelt, K. Poe, M. Bouchard, R. Martel, D. D. Walker, C. A. Ramsey, C. A. Hayes, S. L. Yost, K. L. Bjella, L. Trepanier, T. E. Berry, D. J. Lambert, P. Dube, and N. M. Perron. 2005. Distribution and Fate of Energetics on DoD Test and Training Ranges. Report 5. ERDC TR-05-2. Vicksburg, MS: US Army Engineer Research and Development Center, Environmental Laboratory.

Phelan, J. M. 2001. Measurement and Modeling of Energetic Material Mass Transfer to Pore Water. Sandia National Laboratories. Albuquerque, NM.

Phelan, J., and J. L. Barnett. 2001. Solubility of 2,4-Dinitrotoluene and 2,4,6-Trinitrotoluene in Water. J ournal of Chemical Engineering Data 46:375-376.

Phelan, J. M., and S. W. Webb. 1997. Environmental Fate and Transport of Chemical Signatures from Buried Landmines-Screening Model Formulation and Initial Simulations. SAND97-1426. Sandia National Laboratory. Albuquerque, NM.

Pisigan, R., and J. E. Singley. 1985. Evaluation of Water Corrosivity Using the Langelier Index and Relative Corrosion Rate Models. Materials Performance. National Association of Corrosion Engineers. Houston, Texas.

Pisigan, R., and J. E. Singley. 1987. Influence of Buffer Capacity, Chlorine Residual, and Flow Rate on Corrosion of Mild Steel and Copper. J ournal of the American Water Works Association 79:62-70.

Popp, J. A., and T. B. Leonard. 1985. The Hepatocarcinogenicity of Dinitrotoluenes. In Toxicity of Nitroaromatic Compounds. D. E. Rickert, Ed. Washington, DC: Hemisphere Publishing Co. pp. 53-6o.

Price, C. B., J. M. Brannon, and C. A. Hayes. 1997a. Effect of Redox Potential and pH and TNT Transformation in Soil-Water Slurries. J ournal of Environmental Engineering 123:988-992. 
Price, C. B., J. M. Brannon, and C. A. Hayes. 1997b. TNT Transformations: An Exhaustible or Continuing Process. Technical Report. US Army Corps of Engineers, Waterways Experiment Station. Vicksburg, MS.

Price, C. B., J. M. Brannon, and S. L. Yost. 1998. Transformation of RDX and HMX Under Controlled Eh/pH Conditions. IRRP-98-2. US Army Corps of Engineers, Waterways Experiment Station. Vicksburg, MS.

Price, C. B., J. M. Brannon, S. L. Yost, and C. A. Hayes. 2000. Adsorption and Transformation of Explosives in Low-Carbon Aquifer Soils. ERDC/EL TR-o0-11. US Army Corps of Engineers, Engineer Research and Development Center, Environmental Laboratory. Vicksburg, MS.

Price, C. B., J. M. Brannon, and C. A. Hayes. 2001. Relationship Between Redox Potential and pH on RDX Transformation in Soil-Water Slurries. J ournal of Environmental Engineering 127: 26-31.

Qaisi, K. M., K. S. Ro, D. Reible, L. J. Thibodeaux, K. T. Valsaraj, and W. D. Constant. 1996. Transport Process of TNT from Flooded Highly Contaminated Surface Soil Bed. J ournal of Environmental Science Health 31:2515-2532.

Racine, C.H., M.E. Walsh, C.M. Collins, D.J. Calkins, and B.D. Roebuck. 1992. Waterfowl Mortality Rate in Eagle River Flats, Alaska: The Role of Munitions Residues. CRREL Report 92-5. US Army Corps of Engineers, Cold Regions Research and Engineering Laboratory. Hanover, NH.

Radian. 1999a. Sampling Results for AEC Phase I Training Ordnance Emission Characterization. Radian International. Prepared for US Army Dugway Proving Ground, Dugway, Utah. March 1999.

Radian. 1999b. Sampling Results for AEC Phase II Training Ordnance Emission Characterization. Radian International. Prepared for US Army Dugway Proving Ground, Dugway, Utah. July 1999.

Radian. 2001. Sampling results for AEC Phase III Training Ordnance Emission Characterization. Prepared for US Army Dugway Proving Ground, Dugway, Utah. May 2001.

Radtke, C. W., D. Gianotto, and F. F. Roberto. 2002. Effects of Particulate Explosives on Estimating Contamination at Historical Explosives Testing Area. Chemosphere 46:3-9.

Rodacy, P., and P. Leslie. 1992. Ion Mobility Spectroscopy as a Means of Detecting Explosives in Soil Samples. SAND92-13226. Sandia National Laboratories. Albuquerque, NM.

Rogge, W., L. Hildemann, M. Mazurek, G. Cass, and B. Simoneit. 1993. Sources of Fine Organic Aerosol III. Road Dust, Tire Debris, and Organometallic Brake Lining Dust: Roads as Sources and Sinks. Environmental Science and Technology 27:1892-1904.

Romanoff, M. 1957. Underground Corrosion. National Institute of Standards and Technology, National Bureau of Standards Circular 579. National Association of Corrosion Engineers (NACE), 227 pp. Washington, DC. 
Rosenblatt, D.H., E.P. Burrows, W.R. Mitchell, and D.L. Parmer. 1989. Organic Explosives and Related Compounds. The Handbook of Environmental Chemistry. O. Hutzinger, ed., 3, Part G, 195-234.

Rosser, S., A. Basran, E. Travis, C. French, and N. Bruce. 2001. Microbial Transformations of Explosives. Advances in Applied Microbiology 49:1-35.

Sarouhan, B., D. Tedaidi, B. Lindsey, and A. Piszkin. 1998. Microbiologically Induced Corrosion in Stainless Steel Groundwater Wells. Water Environment Federation Conference.

Schmelling, D. C., K. A. Gray, and P. V. Kamat. 1996. Role of Reduction in the Photocatalytic Degradation of TNT. Environmental Science and Technology 30:25472555 .

Sedlak, D. L., J. T. Phinney, and W. W. Bedsworth. 1997. Strongly Complexed Cu and Ni in Wastewater Effluents and Surface Runoff. Environmental Science and Technology 31:3010-3016.

Selim, H. M., and I. K. Iskandar. 1994. Sorption-Desorption and Transport of TNT and RDX in Soils. CRREL Report 94-7. US Army Corps of Engineers, Cold Regions Research and Engineering Laboratory. Hanover, $\mathrm{NH}$.

Sheu, H. L., W. J. Lee, S. J. Liu, G. C. Fang, H. C. Chang, and W. C. You. 1997. ParticleBound PAH Content in Ambient Air. Environmental Pollution 96:369-382.

Shoesmith, D. 1987. Effects of Metallurgical Variables on Aqueous Corrosion. Metals Handbook.

Sikka, H. C., S. Bannerjee, E. J. Pack, and H. T. Appleton. 1980. Environmental Fate of RDX and TNT. US Army Medical Research and Development Command. Report TR-81-538. Fort Detrick, MD.

Smith, P. N., C. W. Theodorakis, T. A. Anderson, and R. J. Kendall. 2001. Preliminary Assessment of Perchlorate in Ecological Receptors at the Longhorn Army Ammunition Plant (LHAAP), Karnack, Texas. Ecotoxicology 10:305-313.

Spain, J. C., G. C. Paoli, and S. F. Nishino. 2000. Aerobic Degradation of Dinitrotoluenes and Pathway for Bacterial Degradation of 2,6-Dinitrotoluene. Air Force Research Laboratory, Tyndall Air Force Base, FL.

Spalding, R. F., and J. W. Fulton. 1988. Groundwater Munition Residues and Nitrate Near Grand Island, Nebraska, U.S.A. J ournal of Contaminant Hydrology 2:139153 .

Spanggord, R. J., T. Mill, T. W. Chou, R. W. Mabey, J. H. Smith, and S. Lee. $1980 a$. Environmental Fate Studies on Certain Munition Wastewater Constituents, Final Report, Phase 2: Laboratory Study. LSU-7934. SRI International. Menlo Park, CA.

Spanggord, R. J., T. Mill, T. W. Chou, R. W. Mabey, J. H. Smith, and S. Lee. 1980 ob. Environmental Fate Studies on Certain Munition Wastewater Constituents, Final Report, Phase 1: Literature Review. LSU-7934. SRI International. Menlo Park, CA. 
Spanggord, R. J., R. W. Mabey, T. Mill, T. W. Chou, J. H. Smith, and S. Lee. 1981. Environmental Fate Studies on Certain Munition Wastewater Constituents, Phase 3, Part II: Laboratory Studies. LSU-7934. SRI International. Menlo Park, CA.

Spanggord, R. J., R. W. Mabey, T. W. Chou, D. L. Haynes, P. L. Alfernese, D. S. Tse, and T. Mill. 1983. Environmental Fate Studies of HMX, Screening Studies, Final Report, Phase 2: Laboratory Study. SRI International. Menlo Park, CA.

Speitel, G. E., H. Yamamoto, R. L. Autenrieth, T. McDonald. 2002. Laboratory Fate and Transport Studies of High Explosives at the Massachusetts Military Reservation. Final Report. January 2002. University of Texas at Austin and Texas A\&M University.

Stackelberg, P. E., J. A. Hopple, and L. J. Kaufman. 1997. Occurrence of Nitrate, Pesticides, and Volatile Organic Compounds in the Kirkwood-Cohansey Aquifer System, Southern New Jersey. USGS Water Resource Investigation Report 974241. US Geological Survey. Denver, CO.

Staples, C., D. Peterson, T. Parkerton, and W. J. Adams. 1997. The Environmental Fate of Phthalate Esters: A Literature Review. Chemosphere 35:667-749.

Stenhouse, I. A., and K. S. Badsha. 1990. PCB, PCDD, and PCDF Concentrations in Soils from the Kirk Sandall/Edenthorpe/Barnby Dun Area. Chemosphere 21:563-573.

Stumm, W., and J. J. Morgan. 1981. Aquatic Chemistry. $2^{\text {nd }}$ Ed. New York, NY: John Wiley \& Sons.

Sung, K., C. L. Munster, R. Rhykerd, M. C. Drew, and M. Y. Corapcioglu. 2002. The Use of Box Lysimeters with Freshly Contaminated Soils to Study the Phytoremediation of Recalcitrant Organic Contaminants. Environmental Science and Technology 36: 2249-2255.

Szklarska-Smialowska, Z. 1986. Pitting corrosion of metals. National Association of Corrosion Engineers. Houston, Texas.

Tatnall, R. E. 1981. Case Histories: Bacterial Induced Corrosion. Materials Performance August:41-48.

Taylor, S., J. Lever, L. Perovich, E. Campbell, and J. Pennington. 2004a. A Study of Composition B Particles from 81-mm Mortar Detonations. Columbus, Ohio: Battelle Press.

Taylor, S., A. Hewitt, J. Lever, C. Hayes, L. Perovich, P. Thorne, and C. Daghlian. 2004b. TNT Particle Size Distribution from Detonated 155-mm Howitzer Rounds. Chemosphere 55:357-367.

Thiboutot, S., G.Ampleman, P. Dube, J. Hawari, B. Spencer, and L. Paquet. 1998a. Protocol for the Characterization of Explosive-Contaminated Sites. DREV-R9721. Defence Research Establishment Valcartier, Quebec, Canada. 
Thiboutot, S., G. Ampleman, A. Gagnon, A. Marois, T. F. Jenkins, M. E. Walsh, P. G. Thorne, and T. A. Ranney. 1998b. Characterization of Antitank Firing Ranges at CFB Valcartier, WATC Wainwright and CFAD Dundrun. DREV Report DREV-R9809. Defence Research Establishment Department of National Defense, Canada.

Thiboutot, S., G. Ampleman, P. Dube, C. Dubois, R. Martel, R. Lefebvre, M. Mailloux, G. Sunahara, P. Y. Robidoux, and J. Hawari. 2000a. Characterization of DND Training Ranges Including Anti-Tank Firing Ranges and Ecotoxicological Assessment. Defence Research Establishment Valcartier, Quebec, Canada.

Thiboutot, S., G. Ampleman, A. Gagnon, and A. Marois. 200ob. Characterization of an Unexploded Ordnance Contaminated Range (Tracadie Range) for Potential Contamination by Energetic Materials. DREV TR-2000-102. Defence Research Establishment Valcartier, Quebec, Canada.

Thiboutot, S., G. Ampleman, and A. D. Hewitt. 2002. Guide for Characterization of Sites Contaminated with Energetic Materials. ERDC/CRREL Report TR-02-01. US Army Corps of Engineers, Cold Regions Research and Engineering Laboratory. Hanover, NH.

Thiboutot, S., G. Ampleman, J. Lewis, D. Faucher, A. Marois, R. Martel, J. M. Ballard, S. Downe, T.F. Jenkins, and A. Hewitt. 2003a. Environmental Conditions of Surface Soils and Biomass Prevailing in the Training Area at CFB Gagetown, New Brunswick. DREV-TR-2003-152. Defense Research Establishment Department of National Defense. Valcartier, Quebec, Canada.

Thiboutot, S., G. Ampleman, A. Hamel, J. M. Ballard, and R. Martel. 2003b. Research on the Environmental Conditions of Ground and Surface Water Prevailing in the Training Area of CFB Gagetown, New Brunswick. DREV TR-2003-016. Defence Research Establishment Valcartier, Quebec, Canada.

Thiboutot, S., G. Ampleman, A. Marois, A. Gagnon, M. Bouchard, A. Hewitt, T. Jenkins, M. Walsh, K. Bjella, C. Ramsey, and T. A. Ranney. 2004. Environmental Conditions of Surface Soils, CFB Gagetown Training Area: Delineation of the Presence of Munitions-Related Residues (Phase III, Final Report). DREV-TR-2004-205. Defence Research Establishment Department of National Defence. Valcartier, Quebec, Canada.

Thompson, P. L., L. A. Ramer, and J. L. Schnoor. 1998. Uptake and Transformation of TNT by Hybrid Poplar Trees. Environmental Science and Technology 32: 975980 .

Thompson, P. L., L. A. Ramer, and J. L. Schnoor. 1999. Hexahydro-1,3,5-trinitro-1,3,5triazine Translocation in Poplar Trees. Environmental Toxicology and Chemistry 18: 279-284.

Thorne, P.G. 1999. Fate of Explosives in Plant Tissues Contaminated During Phytoremediation. CRREL Special Report 99-19. US Army Corps of Engineers, Cold Regions Research and Engineering Laboratory. Hanover, NH. 
Thorne, P. G., and T. F. Jenkins. 1995. Development of a Field Method for Quantifying Ammonium Picrate and Picric Acid in Soil and Water. CRREL Special Report 95-20. US Army Corps of Engineers, Cold Regions Research and Engineering Laboratory. Hanover, NH.

Thorne, P.G., and D.C. Leggett. 1997. Hydrolytic Release of Bound Residues from Composted Soil Contaminated with 2,4,6-Trinitrotoluene. Environmental Toxicology and Chemistry 16:1132-1134.

Thorne, P. G., and D. C. Leggett. 1999. Investigations of Explosives and Their Conjugated Transformation Products in Biotreatment Matrices. CRREL Special Report 99-3. US Army Corps of Engineers, Cold Regions Research and Engineering Laboratory. Hanover, NH.

Tipton, D. K., D. E. Rolston, and K. M. Scow. 2003. Transport and Biodegradation of Perchlorate in Soils. J ournal of Environmental Quality 32:40-46.

TNRCC. 2002. Texas Natural Resource Conservation Commission. Chapter 350 Texas Risk Reduction Program. March 28, 2002.

Townsend, D. M., and T. E. Myers. 1996. Recent Developments in Formulating Model Descriptors for Subsurface Transformation and Sorption of TNT, RDX, and HMX. Technical Report IRRP-96-1. US Army Corps of Engineers, Waterways Experiment Station. Vicksburg, MS.

Townsend, D. M., T. E. Myers, and D. D. Adrian. 1995 2,4,6-Trinitrotoluene (TNT) Transformation/Sorption in Thin-Disk Soil Columns. Technical Report IRRP-954. US Army Corps of Engineers, Waterways Experiment Station. Vicksburg, MS.

Townsend, D. M., D. D. Adrian, and T. E. Myers. 1996. RDX and HMX Sorption in Thin Disk Soil Columns. Technical Report IRRP-96-8. US Army Corps of Engineers, Waterways Experiment Station. Vicksburg, MS.

TT. 2003. Draft Final High Use Target Area Investigation Report Phase I (HUTA I), Volume 1 Text, Figures, and Tables. Massachusetts Military Reservation,Camp Edwards, MA. (MMR-8005), October. Brookfield, WI: Tetra Tech Inc.

TT. 2002. Draft Final High Use Target Area Investigation Report Phase II (HUTA II). Massachusetts Military Reservation,Camp Edwards, MA. (MMR-690o), November. Brookfield, WI: Tetra Tech Inc.

Urbansky, E. T. 1998. Review and Discussion of Perchlorate Chemistry as Related to Analysis and Remediation. Bioremediation J ournal 2:81-95.

Urbansky, E. T. 2000. Quantitation of Perchlorate Ion: Practices and Advances Applied to the Analysis of Common Matrices. Critical Reviews in Analytical Chemistry 30:311-343.

USACE. 1999. Ordnance and Explosives Archives Search Report: Findings, Conclusions, and Recommendations and Appendices A-N for the Massachusetts Military Reservation, Falmouth, Massachusetts. US Army Corps of Engineers, Rock Island District. Rock Island, IL. 
USAMC. 1971. Engineering Design Handbook: Explosive Series, Properties of Explosives of Military Interest. AMC Pamphlet 706-177. US Army Materiel Command.

US Army. 1984. Military Explosives. TM9-1300-214. Department of the Army Technical Manual. Headquarters Department of the Army, Washington, DC.

US Army Defense Ammunition Center. 2000. Report of Findings for Study of Ammunition Dud and Low Order Detonation Rates. US Army Technical Center for Explosives Safety.

USCHPPM. 2003. Training Range Site Characterization and Risk Screening Regional Range Study, Jefferson Proving Ground, Madison, Indiana. Report No. 38-EH8220-03, US Army Center for Health Promotion and Preventive Medicine. Aberdeen Proving Ground, Maryland.

USEPA. 1975. Ambient Water Quality Criteria for Phthalate Esters. US Environmental Protection Agency. Washington, DC.

USEPA. 1993. Approaches for the Remediation of Federal Facility Sites Contaminated with Explosive or Radioactive Wastes. EPA/625/R-93/013. US Environmental Protection Agency, Office of Research and Development. Cincinnati, OH.

USEPA. 1997. Innovative Uses of Compost. Composting of Soils Contaminated by Explosives. EPA530-F-97-045. US Environmental Protection Agency, Solid Waste and Emergency Response. Washington, DC.

Valsaraj, K. T., K. M. Qaisi, W. D. Constant, L. J. Thibodeauz, and K. S. Ro. 1998. Diffusive Transport of 2,4,6,-Trinitrotoluene (TNT) from Contaminated Soil to Overlying Water. J ournal of Hazardous Materials 59:1-12.

Van Aken, B., and J. L. Schnoor. 2002. Evidence of Perchlorate $\left(\mathrm{CIO}_{4}^{-}\right)$Reduction in Plant Tissue (Poplar Tree) Using Radio-Labeled ${ }^{36} \mathrm{CIO}_{4}{ }^{-}$. Environmental Science and Technology 36:2783-2788.

Van Beelen, P., and D. R. Burris. 1995. Reduction of the Explosive 2,4,6-Trinitrotoluene by Enzymes from Aquatic Sediments. Environmental Toxicology and Chemistry 14:2115-2123.

Van den Berg, M., L. Birnbaum, A. Bosveld, B. Brunstrom, P. Cook, M. Feeley, J. P. Giesy, A. Hanberg, R. Hasegawa, S. Kennedy, T. Kubiak, J. C. Larsen, F. X. van Leeuwen, A. K. Djien Liem, C. Nolt, R. Peterson, L. Poellinger, S. Safe, D. Schrenk, D. Tillitt, M. Tysklind, M. Younes, F. Waern, and T. Zacharewski. 1998. Toxic Equivalency Factors (TEFs) for PCBs, PCDDs, and PCDFs, for humans and wildlife. Environmental Health Perspectives 106:775-792.

Verschueren, K. 1983. Handbook of Environmental Data on Organic Chemicals, Second Edition. New York, NY: Van Nostrand Reinhold Company. pp. 575-578.

Waid, J. S., Ed. 1986. PCBs and the Environment, Volumes 1 and 2. Boca Raton, Florida: CRC Press. 
Walsh, M. E. 1990. Environmental Transformation Products of Nitroaromatics and Nitramines. Literature Review and Recommendations for Analytical Method Development. CRREL Special Report 90-2. US Army Corps of Engineers, Cold Regions Research and Engineering Laboratory. Hanover, NH.

Walsh, M. E., and T. F. Jenkins. 1992. Identification of TNT transformation products in soils. CRREL Special Report 92-16. US Army Corps of Engineers, Cold Regions Research and Engineering Laboratory. Hanover, NH.

Walsh, M. E., T. F. Jenkins, P. S. Schnitker, J. E. Elwell, and M. H. Stutz. 1993. Evaluation of SW846 Method 8330 for Characterization of Sites Contaminated with Residues of High Explosives. CRREL Special Report 93-5. US Army Corps of Engineers, Cold Regions Research and Engineering Laboratory. Hanover, NH.

Walsh, M. E., C. Racine, and C. M. Collins 1995. Factors that Determine the Persistence of White Phosphorus Particles in Sediment. CRREL Report 95-23. US Army Corps of Engineers, Cold Regions Research and Engineering Laboratory. Hanover, NH.

Walsh, M. E., C. M. Collins, and C. H. Racine. 1996. Persistence of White Phosphorus $\left(\mathrm{P}_{4}\right)$ particles in salt marsh sediments. Environmental Toxicology and Chemistry 15: $846-855$.

Walsh, M. E., C. M. Collins, C. H. Racine, T. F. Jenkins, A. B. Gelvin, and T. A. Ranney. 2001. Sampling for Explosives Residues at Fort Greely, Alaska. ERDC-CRRELTR-01-15. US Army Corps of Engineers, Cold Regions Research and Engineering Laboratory. Hanover, $\mathrm{NH}$.

Walsh, M. E., C. A. Ramsey, and T. F. Jenkins. 2002. The Effect of Particle Size Reduction by Grinding on Subsampling Variance for Explosive Residues in Soil. Chemosphere 49:1267-1273.

Walsh, M. E., C. M. Collins, A. D. Hewitt, M. R. Walsh, T. F. Jenkins, J. Stark, A. B. Gelvin, T. A. Douglas, N. Perron, D. Lambert, R. Bailey, and K. Myers. 2004a. Range Characterization Studies at Donnelly Training Area, Alaska: 2001 and 2002. ERDC/CRREL-TR-04-3. US Army Corps of Engineers, Engineer Research and Development Center, Cold Regions Research and Engineering Laboratory. Hanover, NH.

Walsh, M. E., M. R. Walsh, C. M. Collins, C. H. Racine, and W. Gossweiler. 2004b. White Phosphorus Contamination at an Active Army Impact Area: In Sustainable Range Management-2004, Proceedings of the Conference on Sustainable Range Management. B. Alleman and S. Downes, Ed. Columbus, OH: Battelle Press.

Walsh, M. E., C. A. Ramsey, C. M. Collins, A. D. Hewitt, M. R. Walsh, K. Bjella, D. Lambert, and N. Perron. 2005. Collection Methods and Laboratory Processing of Samples from Donnelly Training Area Firing Points Alaska 2003. ERDC/CRREL TR-05-6. US Army Corps of Engineers, Engineer Research and Development Center, Cold Regions Research and Engineering Laboratory. Hanover, NH.

Walsh, M. R., M. E. Walsh, C. M. Collins, S. P. Saari, J. Zufelt, A. Gelvin, and J. Hug. 2005. Energetic residues from live-fire detonations of $120-\mathrm{mm}$ mortar rounds. ERDC/CRREL TR-05-15. Hanover, NH: Engineer Research and Development Center. 
Wang, C. J., S. Thiele, and J. M. Bollag. 2002. Interaction of TNT and 4-Amino2,6, dinitrotoluene with Humic Monomers in the Presence of Oxidative Enzymes. Archives of Environmental Contaminant Toxicology 42(1):1-8.

Washington, J. W. 1995. Hydrolysis Rates of Dissolved Organic Compounds: Principles, Temperature Effects and Literature Review. Ground Water May-June:415-424.

Weissmahr, K. W., M. Hildenbrand, S. B. Haderlein, and R. P. Schwarzenbach. 1999. Laboratory and Field Scale Evaluation of Geochemical Controls on Groundwater Transport of Nitroaromatic Ammunition Residues. Environmental Science and Technology 33:2,596-2,600.

Wild, S. R., and K. C. Jones. 1995. Polynuclear Aromatic Hydrocarbons in the United Kingdom Environment: A Preliminary Source Inventory and Budget. Environmental Pollution. 88:91-108.

Willis, R. C. 2002. The E-Scent of Danger. Today's Chemist at Work. October p. 43-48.

Wyman, J. F., H. E. Guard, W. D. Eon, and J. H. Quay. 1979. Conversion of 2,4,6Trinitrophenol to a Mutagen by Pseudomonas Aeruginosa. Applied and Environmental Microbiology 37: 222-226.

Xue, S. K. 1995. Adsorption-Desorption of 2,4,6-Trinitrotoluene and Hexahydro-1,3,5Trinito-1,3,5-Triazine in Soils. Soil Science 160:317-327.

Xue, S. K., I. K. Iskandar, and H. M. Selim. 1995. Transport of 2,4,6-Trinitrotoluene and Hexahydro-1,3,5-trinitiro-1,3,5-triazine in Soils. Soil Science 160:328-339.

Yalkowsky, S., and R. Dannenfelser. 1992. Aquasol Database of Aqueous Solutions v.5. College of Pharmacy, University of Arizona. 1992.

Yang, Y., X. Wang, and P. Yin. 1983. Three Strains of Corynebacterium Degrading Cyclotrimethylenetrinitroamine. Acta Microbiologica Sinica 23: 251-256.

Yen, C. C., and T. A. Perenich. 1991. Fate of Commercial Disperse Dyes in Sediments. Environmental Toxicology and Chemistry 10:1009-1017.

Yen, C. C., T. A. Perenich, and G. L. Baughman. 1989. Fate of Dyes in Aquatic Systems II. Solubility and Octanol/Water Partition Coefficients of Disperse Dyes. Environmental Toxicology and Chemistry 8: 981-986.

Zakikhani, M., M. S. Dortch, S. Coakley, and M. Hawkins. 2004. Risk Characterization for Future Training Scenarios at the Massachusetts Military Reservation (MMR). ERDC/EL TR-04-2. US Army Corps of Engineers, Engineer Research and Development Center, Environmental Laboratory. Vicksburg, MS.

Zakikhani, M., M. S. Dortch, J. A. Gerald, and M. S. Hawkins. 2005. Risk Characterization for Future Training Scenarios at the Massachusetts Military Reservation (MMR), Final Results. ERDC/EL TR-05-11. US Army Corps of Engineers, Engineer Research and Development Center. Environmental Laboratory. Vicksburg, MS. 


\section{Appendix A: Physical and Chemical Properties of Explosives and Other Compounds.}

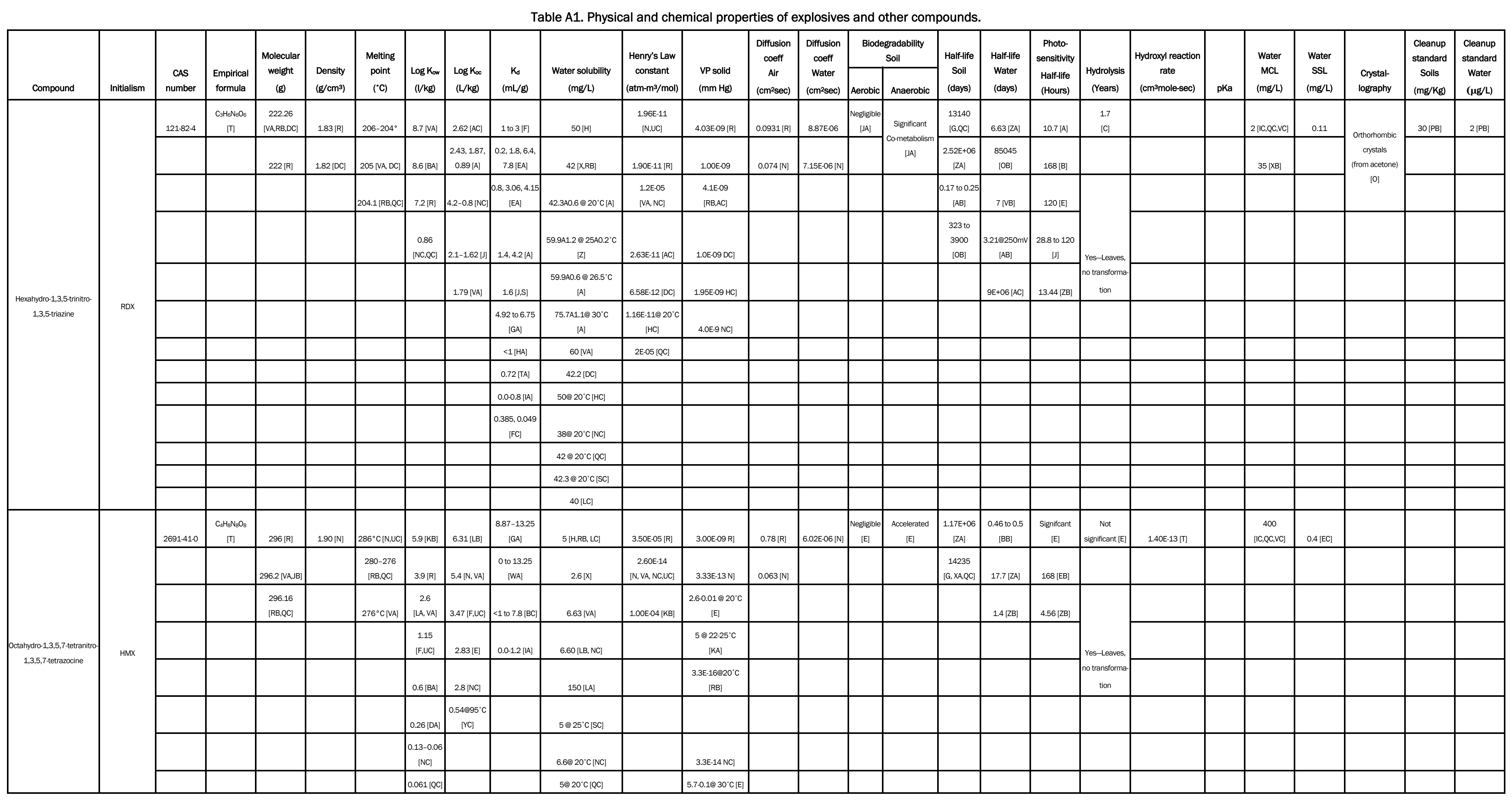


Table A1 (cont'd).

\begin{tabular}{|c|c|c|c|c|c|c|c|c|c|c|c|c|c|c|c|c|c|c|c|c|c|c|c|c|c|c|c|}
\hline \multirow{11}{*}{ 2,4,6-Trinitrotolluene } & \multirow{11}{*}{ TNT } & 118967 & 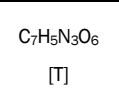 & $227[\mathrm{R}]$ & $1.46[\mathrm{R}]$ & $80.1^{\circ} \mathrm{C}[\mathrm{DC}]$ & $100+[\mathrm{F}]$ & $525[\mathrm{~F}, \mathrm{UCC}]$ & 2 to $256[\mathrm{~F}]$ & $130[\mathrm{H}, \mathrm{OC}]$ & $4.57=-07[\mathrm{R}, \mathrm{NC}]$ & 1.49E-06 R] & $0.083[\mathrm{R}]$ & 6.71E-06 (W] & $\begin{array}{c}\text { Siginfir } \\
\text { cant }\end{array}$ & Significant & $\begin{array}{c}53 \mathrm{~A} 20 \\
{[\mathrm{J]}}\end{array}$ & $\begin{array}{c}28103655 \\
\text { [UA] }\end{array}$ & & \multirow{3}{*}{\begin{tabular}{|c|} 
Yes-Roots, \\
transformation \\
to $2 \mathrm{~A}, 4 \mathrm{~A}-\mathrm{DNT}$
\end{tabular}} & 1.46E-13 (T) & & $44[\mathrm{XB}]$ & \multirow{2}{*}{0.21} & \multirow{3}{*}{ 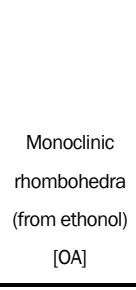 } & \multirow{2}{*}{$30[\mathrm{~PB}]$} & \multirow{2}{*}{\begin{tabular}{|l|l|}
$2[\mathrm{~PB}, \mathrm{SB}]$ \\
\end{tabular}} \\
\hline & & & & $\begin{array}{r}227.13 \\
{[\mathrm{RB}, \mathrm{DC}, \mathrm{CC}]}\end{array}$ & $1.654[\mathrm{MA}]$ & $\begin{array}{l}8181.6 \\
{[8 B, C, C]}\end{array}$ & $40[\mathrm{R}]$ & $27.2[\mathrm{DA}]$ & $1.90016 .2[$ [L] & $100 \mathrm{M}$ & $1.8[\mathrm{]}]$ & $\begin{array}{c}12.8 @ 20 E E^{\circ} \mathrm{C} \\
{[\mathrm{RAA]}} \\
\end{array}$ & $0.064[\mathbb{N}]$ & $6.711-06[\mathbb{N}]$ & & & $\begin{array}{r}320 \text { to } \\
3200[08]] \\
\end{array}$ & $\begin{array}{l}0.125 \text { to } \\
0.916[\mathrm{J]} \\
\end{array}$ & & & & & $2[\mathrm{Cl}]$ & & & & \\
\hline & & & & & $1.65[\mathrm{DC}]$ & $80.9[0 \mathrm{Cc}]$ & $20.6[\mathrm{~N}]$ & $3.2[\mathrm{NCl}$ & $53[\mathrm{[J}$ & $200 @ 15^{5} \mathrm{C}[\mathrm{OA]}]$ & & $\begin{array}{c}55.1 E-06 \text { ब } 25^{\circ} \mathrm{C} \\
{[\mathrm{N}]}\end{array}$ & & & & & $\begin{array}{c}365 \\
{\left[G, X_{A}, C_{C}\right]} \\
\end{array}$ & $\begin{array}{c}28 \text { to } 3600 \\
\text { [WA] }\end{array}$ & & & & & 1.0[oc,vc] & & & & \\
\hline & & & & & & & $18.6[\mathrm{BA}]$ & $61.57[00]$ & $4.0[\mathrm{SA}]$ & $130 @ 30^{\circ} \mathrm{C}[\mathrm{ZC}]$ & 1.1. [N] & 1.1. $-08[R B]$ & & & & & & 69350 [0B] & & & & & & & & & \\
\hline & & & & & & & $1.84[\mathrm{NCl}$ & & $\begin{array}{c}1.6 \text { to } 16.6 \\
{[H A]}\end{array}$ & $-1002_{25^{\circ} \text { CPA] }}$ & 2.632E-09 [DC] & 1.1.E-06 [DC] & & & & & & & & & & & & & & & \\
\hline & & & & & & & \begin{tabular}{|c|}
$1.6-1.99$ \\
{$[00]$}
\end{tabular} & & & $\begin{array}{c}150 @ 22^{\circ} \mathrm{C} \\
{[\mathrm{DA}, \mathrm{CC}]}\end{array}$ & $1.44 \mathrm{E} 08$ [HC] & $\begin{array}{c}7.21 E-06 @ 25^{\circ} \mathrm{C} \\
{[\mathrm{HC}]}\end{array}$ & & & & & & & & & & & & & & & \\
\hline & & & & & & & $1.86[\mathrm{lOC}]$ & & $52[\mathrm{TA}]$ & $\begin{array}{l}130 @ 22^{\circ} \mathrm{C} \\
{[\mathrm{RB}, \mathrm{NC}, \mathrm{CC}]} \\
\end{array}$ & & & & & & & & & & & & & & & & & \\
\hline & & & & & & & & & $6.16[\mathrm{DD}]$ & $123[\mathrm{DC}]$ & $2.02 E-5[0 \mathrm{CC}]$ & $1.99 E-4[\mathrm{NC}]$ & & & & & & & & & & & & & & & \\
\hline & & & & & & & & & 0056 (WA] & $140 \otimes 25^{\circ} \mathrm{C}[S C]$ & 1.1.E $[\mathrm{UCC}]$ & $0.05[0 \mathrm{CO}]$ & & & & & & & & & & & & & & & \\
\hline & & & & & & & & & $21500[\mathrm{Ccc}]$ & & & $\begin{array}{c}8.25 E-8 @ 23^{\circ} \mathrm{C} \\
\text { [C] }\end{array}$ & & & & & & & & & & & & & & & \\
\hline & & & & & & & & & $\begin{array}{c}2.65,0.095 \\
{[\mathrm{FF}]} \\
\end{array}$ & & & & & & & & & & & & & & & & & & \\
\hline 2Amino-4,6-Dinitrotolluene & 2ADNT & 35572.782 & $\mathrm{C}_{\mathrm{H}} \mathrm{H}_{\mathrm{N}} \mathrm{O}_{3} \mathrm{O}_{4}$ & $197[R, S B]$ & & $176[0 T, Y C]$ & $79[\mathrm{R}]$ & & $2900[\mathrm{CC}]$ & $2800 @ 20^{\circ} \mathrm{C}[$ [QT] & & & & & $\begin{array}{c}\text { signifir } \\
\text { cant }\end{array}$ & Significant & & & & & & $0.36 \mathrm{M}$ & & 0.39 & & & \\
\hline & & & & $197.17[([0])$ & & & $1.94[\mathrm{loc}]$ & & & & & & & & & & & & & & & & & & & & \\
\hline 4Amino-2,6-Dinitrotolluene & 4A.DNT & $19406.51-0$ & $\mathrm{C}_{\mathrm{H}} \mathrm{H}_{2} \mathrm{~N}_{3} \mathrm{O}_{4}$ & $197[$ [R,SB] & & $171[0, \mathrm{QCC}]$ & $79[R]$ & & $125[\mathrm{ccc}]$ & $2800 @ 20^{\circ} \mathrm{C}$ (1T) & & & & & $\begin{array}{c}\text { signifi. } \\
\text { cant }\end{array}$ & Significant & & & & & & & & 0.39 & & & \\
\hline & & & & $197.17 \mathrm{NCl}$ & & & $1.91[\mathrm{loc}]$ & & & & & & & & & & & & & & & & & & & & \\
\hline & & $121-142^{28}$ & $\begin{array}{c}\mathrm{C}_{\mathrm{C}} \mathrm{H}_{\mathrm{H}} \mathrm{N}_{2} \mathrm{O}_{4} \\
{[\mathrm{~T}}\end{array}$ & $182[R, Q B]$ & $1.52[\mathrm{R}]$ & $70[\mathrm{RB}, \mathrm{QC}]$ & $100[\mathrm{R}]$ & $87[\mathrm{AC}]$ & $1.206 .4[\lfloor]$ & $270[R, R B]$ & $1.30 E-07[\mathrm{R}]$ & $1.10 E-06[R]$ & $0.098[\mathrm{R}]$ & $8.955-06[\mathrm{R}]$ & $\begin{array}{c}\text { Sienifif } \\
\text { cant }\end{array}$ & Significant & $\begin{array}{c}0.112550 \\
1.7[\mathrm{MM}]\end{array}$ & $47[\mathrm{AC}]$ & $<10[]$ & & $2.255-13 \mathrm{~m}$ & & 5 & 19.64 & & & \\
\hline 24.Dinitrotoluene & 2400T & & & $\begin{array}{l}182.15 \\
{[\mathrm{RB}, \mathrm{QC}]}\end{array}$ & & $72[$ [U] & $1.98[\mathrm{loc}]$ & & $7400[\mathrm{CC}]$ & $270 @ 22^{\circ} \mathrm{C}[\mathrm{COC}]$ & 7.5E-06 [QB] & $22 E-06[\mathrm{RB}]$ & $0.067[08]$ & & & & $53[\mathrm{CB}]$ & & 120 & & & & & & & & \\
\hline the & $x^{2}$ & & & & & & & & $3.22,0.36 \mathrm{FFC} \mid$ & $250 @ 25^{\circ} \mathrm{C}[\mathrm{SC}]$ & 4.47飞=06 [AC] & 5.1E-03 $[\mathrm{AC}]$ & & & & & $\begin{array}{c}1.6 \text { to } 17 \\
{[D B]} \\
\end{array}$ & & & & & & & & & & \\
\hline & & & & & & & & & & $280 \Theta 25^{\circ} \mathrm{C} \mathrm{NCl}$ & 1.86E-7 ( UC] & $\begin{array}{c}1.42 E-9 @ 22^{2} \mathrm{C} \\
\pi \mathrm{TC} \\
\end{array}$ & & & & & & & & & & & & & & & \\
\hline & & $606-20-2$ & $\begin{array}{c}\mathrm{C}_{\mathrm{H}} \mathrm{H}_{6} \mathrm{~N}_{2} \mathrm{O}_{4} \\
\text { [T] }\end{array}$ & $182[R, Q B]$ & $1.54[\mathrm{R}]$ & 64-66[lec] & $100+[F$ & $251 \mathrm{VCl}$ & $125[\mathrm{cCl}]$ & $182[\mathrm{R}]$ & 7.74E-07[R] & $4.25 E-06[\mathrm{R}]$ & $0.096[\mathrm{~F}]$ & $9.01 E_{06}[\mathrm{R}]$ & $\begin{array}{c}\text { signifin- } \\
\text { cant }\end{array}$ & significant & & $9[A C]$ & 24 & & $2.25 E-13[\mathrm{~T}$ & $1.8 \mathrm{~T}$ & 5 & 8.76 & & & \\
\hline 2,6-Dinitrotolluene & 2,6-DNT & & & $182.15[\mathrm{loc}]$ & & $66[\mathrm{ICC}]$ & $110[\mathrm{RJ}]$ & & & 206 @ $25^{\circ} \mathrm{C}[\mathrm{lOC}]$ & $7.5 E-06[[\mathrm{BB}]$ & $0.018 \mathrm{ACl}$ & $0.067[1[8]$ & & & & & & & & & & & & & & \\
\hline & & & & & & & $2.02[\mathrm{COC}]$ & & & $180 @ 25^{\circ} \mathrm{C}[\mathrm{SC}]$ & $2.36 E-05[\mathrm{AC}]$ & $\begin{array}{c}3.69 E-9 @ 22^{\circ} \mathrm{C} \\
\text { TCC] }\end{array}$ & & & & & & & & & & & & & & & \\
\hline 2,4 diamino- nitrototluene & 2,4DANT & & $\mathrm{C}_{\mathrm{H} H \mathrm{H} \mathrm{O}_{3} \mathrm{O}_{2}}$ & 172 & & & $\begin{array}{c}4.6 E-01 \\
\text { [U] } \\
\end{array}$ & & $3.5[\mathrm{ccl}]$ & $2800 \mathrm{NC]}$ & & & & & $\begin{array}{c}\text { Siginif- } \\
\text { cant }\end{array}$ & Significant & & & & & & $3.13 \mathrm{~m}$ & & & & & \\
\hline & & & & 167 [ Гв] & & & & & & & & & & & & & & & & & & & & & & & \\
\hline 2,6-diamino-4nitrotoluene & 2.6.DANT & & $\mathrm{C}_{\mathrm{H} \mathrm{H}_{9} \mathrm{~N}_{3} \mathrm{O}_{2}}$ & 172 & & & $\begin{array}{c}4.6 E-01 \\
\text { [U] }\end{array}$ & & $11[\mathrm{CC}]$ & $2800 \mathrm{NCl}$ & & & & & $\begin{array}{c}\text { signifi- } \\
\text { cant }\end{array}$ & Significant & & & & & & $2.54 \mathrm{M}$ & & & & & \\
\hline & & & & 67 [TB] & & & & & & & & & & & & & & & & & & & & & & & \\
\hline
\end{tabular}


Table A1. Physical and chemical properties of explosives and other compounds.

\begin{tabular}{|c|c|c|c|c|c|c|c|c|c|c|c|c|c|c|c|c|c|c|c|c|c|c|c|c|c|}
\hline \multirow{2}{*}{ Nitrogycerin } & \multirow{2}{*}{ NG } & 55.630 & $\begin{array}{c}\mathrm{C}_{3} \mathrm{H}_{\mathrm{N}} \mathrm{N}_{3} \mathrm{O}_{9} \\
\text { T] }\end{array}$ & $227[R, R B]$ & $1.6[\mathrm{R}]$ & $13.2[\mathrm{RB}]$ & $\begin{array}{l}100 \\
{[\mathrm{R}]}\end{array}$ & $588[\mathrm{~N}]$ & $2.02,0.64[\mathrm{FF}]$ & $\left.\begin{array}{c}1380 \\
{[R, 19500 n]}\end{array}\right]$ & $4.30 \mathrm{E}-08[\mathrm{R}]$ & $1.50 \mathrm{E}-06[\mathrm{R}]$ & $0.0865[\mathrm{RP}]$ & $8.10 \mathrm{E}-06[\mathrm{RP}]$ & \begin{tabular}{|c|} 
signifif \\
cant
\end{tabular} & & & & Unknown & & & 5 & 1.02 & & \\
\hline & & & & & & & \begin{tabular}{|c|}
$\begin{array}{c}416.6,58.9 \\
{[\mathrm{~N}]}\end{array}$ \\
\end{tabular} & $46[\mathrm{~N}]$ & & $1500022^{\circ} \mathrm{C}[\mathrm{RB}]$ & $2.71 \mathrm{E} 6 \mathrm{NC \textrm {C }}$ & 2.6E-06 [RB] & & & & & & & & & & & & & \\
\hline \multirow{2}{*}{ 1,3,5-5Trinitrobenzene } & \multirow{2}{*}{${ }^{\mathrm{NNB}}$} & $99: 354$ & 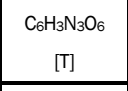 & $213[\mathrm{R}]$ & $1.63[\mathrm{R}]$ & 1222 [UC] & $15[\mathrm{R}]$ & & & $350[H, R]$ & $1.60 E-08[\mathrm{R}]$ & 1.49E-07 [R] & $0.091[\mathrm{R}]$ & 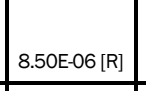 & & & & & Unknown & $1.30 \mathrm{E}-15[\mathrm{~T}]$ & & & & & \\
\hline & & & & & & $122.5 \mathrm{NCl}$ & & & & 385 ه $25^{\circ} \mathrm{C}[\mathrm{SC}]$ & $\begin{array}{c}2.21 \mathrm{E} \cdot 9 \\
{[\mathrm{SC}]}\end{array}$ & 2.21E-9 [UC] & & & & & & & & & & & & & \\
\hline Ammonium picrate & $A P$ & $7790 \cdot 989$. & $\mathrm{NH}_{4} \mathrm{CO}_{4}$ & $118 \mathrm{rcl}$ & $1.95 \mathrm{rCl}]$ & $>220 \mathrm{NCl}$ & & & & $200,000 @ 25^{\circ}$ (TTC] & & & & & & & & & & & & & & & \\
\hline Picicic acid & PA & 131-748 & $\begin{array}{c}\mathrm{C}_{0} \mathrm{H}_{\mathrm{B}} \mathrm{N}_{\mathrm{O}} \mathrm{O}_{\mathrm{T}} \\
\mathrm{T}]\end{array}$ & $246[\mathrm{~F}]$ & $1.72[\mathrm{R}]$ & 123 [UC] & $\begin{array}{c}4.0 E=02 \\
\pi\end{array}$ & & & $10000[\mathrm{R}]$ & $2.94 E-22[\mathrm{R}]$ & $3.37 E-11 \mathrm{~T}$ & $0.0846[[\mathrm{R}]$ & & & & & & & 1.13E-15[T] & & & & & \\
\hline \multirow{2}{*}{$\begin{array}{c}\text { Pentaenthritol } \\
\text { tetranitrate }\end{array}$} & \multirow{2}{*}{ PETN } & 78.11 .5 & 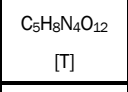 & $316[\mathrm{fl}]$ & 1.76 & 141.3 [WB] & $4.0[\mathrm{R}]$ & & & $0.99[\mathrm{R}]$ & $3.16 \mathrm{E}-05[\mathrm{R}]$ & $8.40 E-04[\mathrm{R}]$ & $0.77[\mathrm{R}]$ & & & & $69[\mathrm{ll}$ & & Unknown & $1.62 \mathrm{E}-12 \mathrm{~T}$ & & & & & \\
\hline & & & & & & & & & & $2.1 @ 25^{\circ} \mathrm{C}[\mathrm{SC}]$ & $1.07 \mathrm{E}-9 \mathrm{sC}]$ & & & & & & $\begin{array}{l}33580 \\
[\times A, Q]]\end{array}$ & & & & & & & & \\
\hline Tetryl & Tetryl & 479458 & 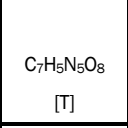 & $287[\mathrm{RJ}]$ & $1.57[\mathrm{R}]$ & 129.5 [uc] & $45[\mathrm{R}]$ & & & $80[\mathrm{~F}]$ & $2.69 E-11[\mathrm{R}]$ & $5.10 E-09[R]$ & $0.0732[\mathrm{Fe}]$ & $6.94 E-06$ & $\begin{array}{c}\text { Siginifi } \\
\text { cant }\end{array}$ & & $\begin{array}{c}302+76 \\
\text { [UB] }\end{array}$ & $7.2 \mathrm{E}+03[\mathrm{FB}]$ & $\begin{array}{l}0.17 \text { [FB] } \\
\text { Yes, rots } \\
\text { transform }\end{array}$ & $1.27 \mathrm{E}-12 \mathrm{~T}]$ & & & 63.66 & & $10[X B]$ \\
\hline \multirow[t]{2}{*}{ 2-Nitrotoluene } & \multirow[t]{2}{*}{ 2NT } & 88.72 .2 & 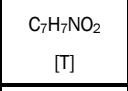 & $137 \pi$ & & & 200 [] & & $4.6[\mathrm{CCC}]$ & 650 [1] & $2.35 E-05[\mathrm{~T}]$ & 0.188 历 & $0.085[\mathrm{R}]$ & & & & & & & $7.00 E-13^{\top}$ & & & 2.18 & & \\
\hline & & & & & & & & & & 650 @ $30^{\circ} \mathrm{C}[\mathrm{SC}]$ & & & & & & & & & & & & & & & \\
\hline 3-Nitrotoluene & 3NT & & & & & & & & & $500 @ 30^{\circ} \mathrm{C}[\mathrm{SC}]$ & & & & & & & & & & & & & & & \\
\hline \multirow[t]{2}{*}{ 4Nitrotoluene } & \multirow[t]{2}{*}{$4 \mathrm{NT}$} & $99 \cdot 990$ & $\begin{array}{c}\mathrm{CHH}_{\mathrm{N} N \mathrm{NO}_{2}} \\
\text { (1) }\end{array}$ & $137 \pi$ & & & 200 [] & & $45[\mathrm{CC}]$ & 650 [ & $2.35 E-05[\pi]$ & 0.188 历 & & & & & & & & $7.72 E-13 \mathrm{~m}$ & & & & & \\
\hline & & & & & & & & & & 500 @ $30^{\circ} \mathrm{C}[\mathrm{SC}]$ & & & & & & & & & & & & & & & \\
\hline $\begin{array}{l}\text { Perchlorate } \\
\text { Pat }\end{array}$ & & & $\mathrm{ClO}_{4}$ & $99.5[\mathrm{HB}]$ & & & & & $0.83[\mathrm{MB}]$ & $2.50 €+05$ & & & & & None & significant & & & & & & & 3.14 & & $18[\mathrm{YA}]$ \\
\hline Dir-buty phthalate & & & & & & & & & & & & & & & & & & & & & & & \begin{tabular}{|l|l|}
$150,832,25$ \\
\end{tabular} & & \\
\hline N-nitrosodoliphenylamine & & & & $198.23[\mathrm{JB]}]$ & & & $31.6[\mathrm{~KB}]$ & $\begin{array}{c}1.200 E+03 \\
{[\mathrm{~B}]}\end{array}$ & & $3.51 E+01[\mathrm{JB}]$ & $5.00 E-06[K B]$ & & & & & & & & & & & & 7.77 & & \\
\hline Aluminium & $\mathrm{Al}$ & $7429 \cdot 90.5$ & & & & & & & & & & & & & \begin{tabular}{|l|l|} 
None \\
\end{tabular} & None & & & & & & & $54,006.28$ & & \\
\hline \multicolumn{2}{|c|}{ 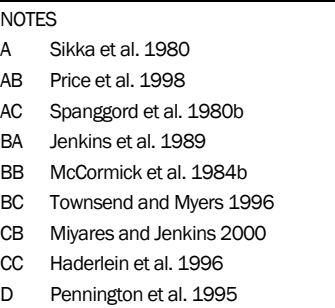 } & $\mid \begin{array}{ll}\mathrm{D} \\
\mathrm{D} \\
\mathrm{D} \\
\mathrm{D} \\
\mathrm{D} \\
\mathrm{E} \\
\mathrm{E} \\
\mathrm{E} \\
\mathrm{E} \\
\mathrm{E} \\
\mathrm{E} \\
\mathrm{EC} \\
\mathrm{EC} \\
\mathrm{F} \\
\mathrm{FE} \\
\mathrm{FE}\end{array}$ & \multicolumn{3}{|c|}{ 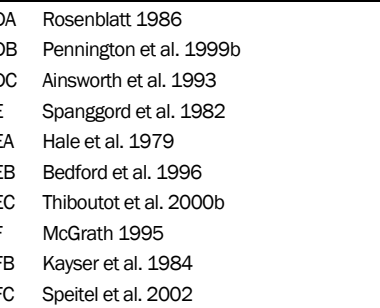 } & \multicolumn{4}{|c|}{ 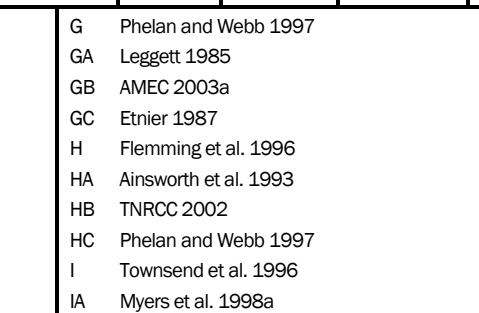 } & \multicolumn{3}{|c|}{ 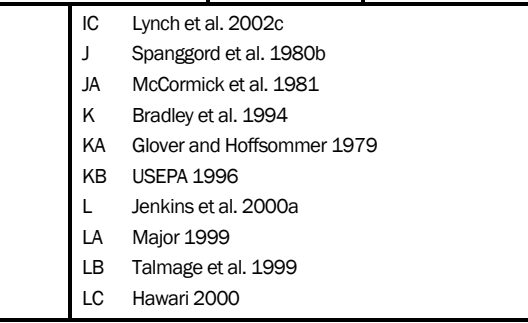 } & \multicolumn{4}{|c|}{ 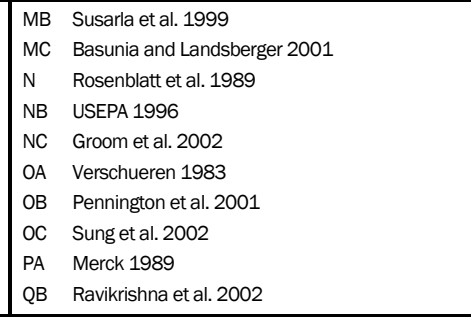 } & \multicolumn{3}{|c|}{ 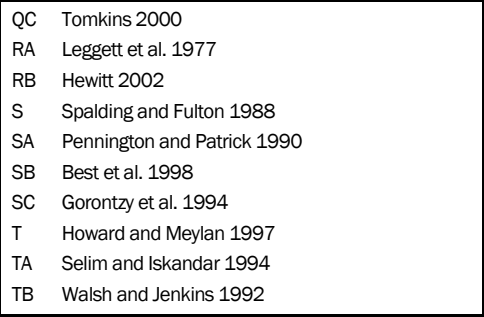 } & \multicolumn{3}{|c|}{ 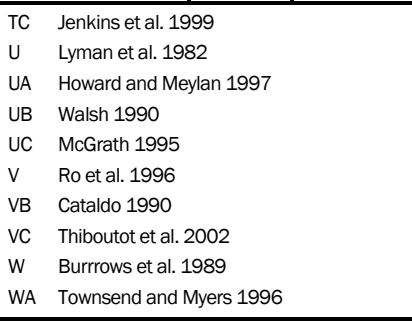 } & \begin{tabular}{|l|l} 
WB \\
$x$ \\
$x A$ \\
$x B$ \\
$x$ \\
$y$ \\
$r A$ \\
$r C$ \\
$z A$ \\
$z B$ \\
$z C$ \\
$z C$
\end{tabular} & \multicolumn{2}{|l|}{ 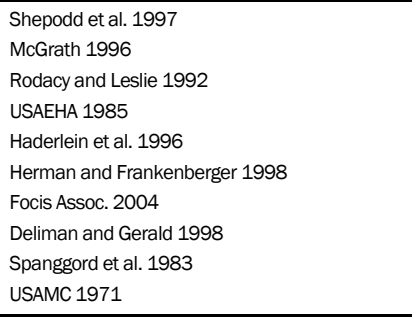 } \\
\hline
\end{tabular}




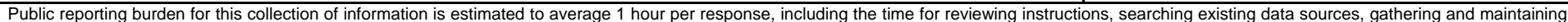

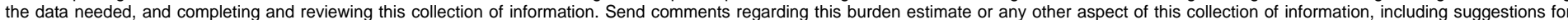

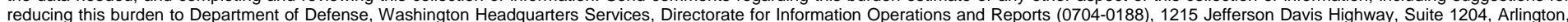

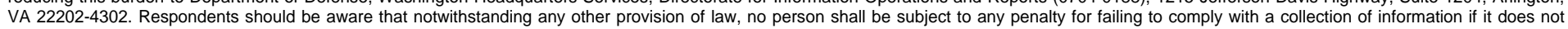
display a currently valid OMB control number. PLEASE DO NOT RETURN YOUR FORM TO THE ABOVE ADDRESS.
1. REPORT DATE (DD-MM-YYYY)
November 2006

4. TITLE AND SUBTITLE

Conceptual Model for the Transport of Energetic Residues

from Surface Soil to Groundwater by Range Activities
3. DATES COVERED (From - To)

5a. CONTRACT NUMBER

5b. GRANT NUMBER

5c. PROGRAM ELEMENT NUMBER

5d. PROJECT NUMBER

5e. TASK NUMBER

5f. WORK UNIT NUMBER

8. PERFORMING ORGANIZATION REPORT NUMBER

ERDC/CRREL TR-06-18

U.S. Army Engineer Research and Development Center

Cold Regions Research and Engineering Laboratory

72 Lyme Road

Hanover, New Hampshire 03755-1290

9. SPONSORING I MONITORING AGENCY NAME(S) AND ADDRESS(ES)
10. SPONSOR/MONITOR'S ACRONYM(S)

11. SPONSOR/MONITOR'S REPORT NUMBER(S)

\section{DISTRIBUTION / AVAILABILITY STATEMENT}

Approved for public release; distribution is unlimited.

Available from NTIS, Springfield, Virginia 22161.

13. SUPPLEMENTARY NOTES

\section{ABSTRACT}

This report integrates and summarizes research on the fate-and-transport properties of munition energetic compounds potentially migrating to groundwater. The goals of the report are to 1) review and summarize previous work; 2) identify data gaps; 3) provide research recommendations; and integrate conclusions from peer-reviewed research, results from investigations at military ranges, and consultations with explosives experts in the United States and Canada (Waterways Experiment Station, Army Environmental Center, Defence Research Establishment-Valcartier, and various universities) into a conceptual model for the transport of energetic compounds from the land surface to groundwater.

\section{SUBJECT TERMS}

Energetics, Fate and transport, Ranges, Residues

16. SECURITY CLASSIFICATION OF:

\section{a. REPORT}

U

\section{b. ABSTRACT}

U c. THIS PAGE
17. LIMITATION OF ABSTRACT

U
18. NUMBER OF PAGES

U
172 19a. NAME OF RESPONSIBLE PERSON

19b. TELEPHONE NUMBER (include area code) 